UNITED STATES DEPARTMENT OF COMMERCE ELIMINATION OF WASTE SERIES

\title{
RECOMMENDED MINIMUM REQUIREMENTS FOR PLUMBING IN DWELLINGS AND SIMILAR BUILDINGS
}

FINAL REPORT OF SUBCOMMITTEE ON PLUMBING OF THE BUILDING CODE COMMITTEE

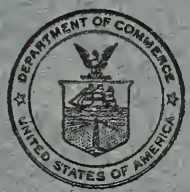

BUREAU OF STANDARDS 


\section{$x^{3} x=18$}

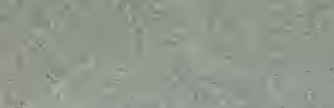

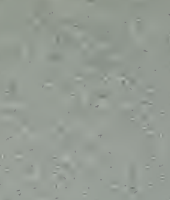

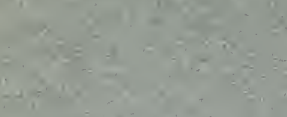

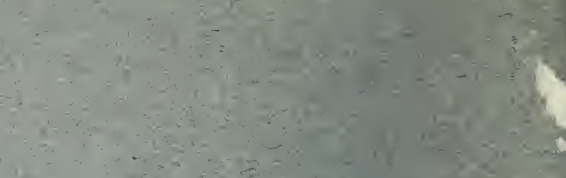

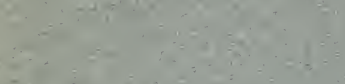

5

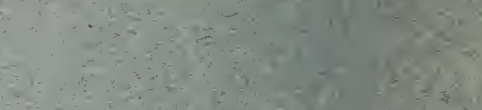

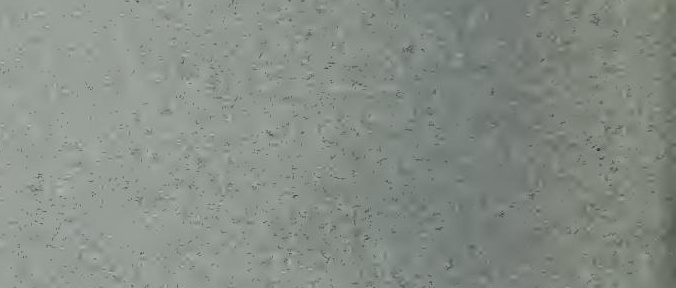

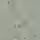

$=-2=$

$+2$

$+4$

se

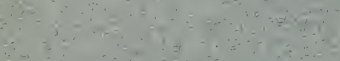

$3 \div$

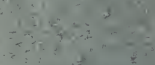

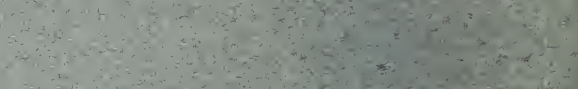

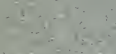

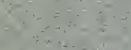

$\therefore, 15$

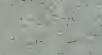

$(1+2)$

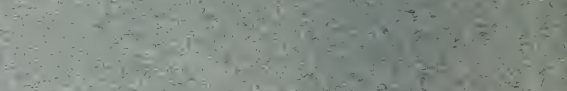

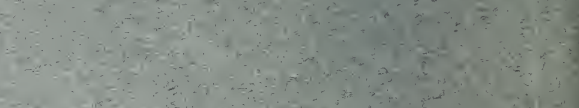
the $x=18$

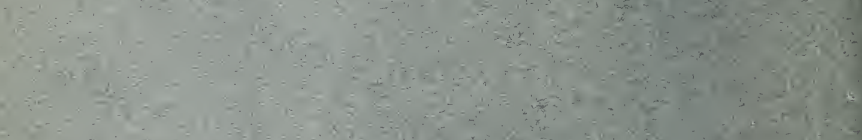

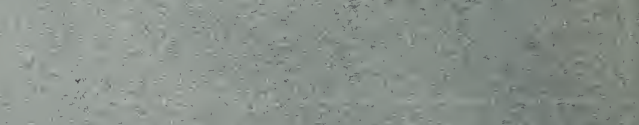

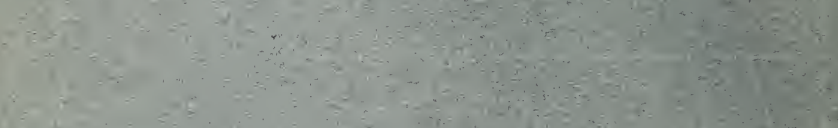

$x=0, k=1$<smiles>[C]1[C]C1</smiles>

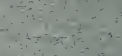

$\frac{1}{4}$

有

$\left(\frac{1}{6}\right)$

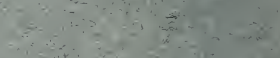
$-8=8+2=$

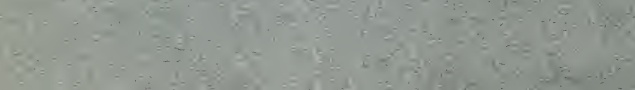

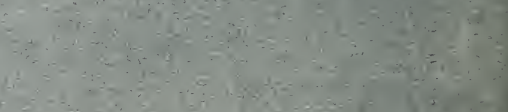


UNITED STATES DEPARTMENT OF COMMERCE

HERBERT HOOVER, SECRETARY

ELIMINATION OF WASTE SERIES

\title{
RECOMMENDED MINIMUM REQUIREMENTS FOR PLUMBING IN DWELLINGS AND SIMILAR BUILDINGS
}

\author{
FINAL REPORT OF \\ SUBCOMMITTEE ON PLUMBING OF THE \\ BUILDING CODE COMMITTEE \\ JULY 3, 1923
}

\author{
GEORGE C. WHIPPLE, Chairman \\ HARRY Y. CARSON \\ THOMAS F. HANLEY \\ WILLIAM C. GROENIGER \\ ALBERT E. HANSEN
}

\section{JOHN M. GRIES, Chief Division of Building and Housing \\ FRANK P. CARTWRIGHT, Technical Secretary \\ R. B. HUNTER, In Charge of Tests}

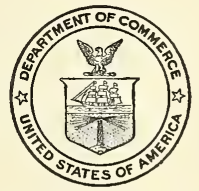

BUREAU OF STANDARDS

PRICE, 35 CENTS

Sold only by the Superintendent of Documents, Government Printing Office Washington, D. C.

WASHINGTON

GOVERNMENT PRINTING OFFICE 



\section{CONTENTS}

\section{PART I-_INTRODUCTION-GENERAL CONSIDERATIONS}

Mode of procedure

Tentative report

Local conditions

Acknowledgment

Chapter 1.-Regulation of plumbing

Definition of plumbing

Relation of plumbing to health

Public control of plumbing justifiable

Legal principles

Chapter 2.-Present status of plumbing regulations

Supervision of plumbing inspection

Conclusions based on scientific procedure

Chapter 3.-Basic plumbing principles

\section{PART II.-CHAPTER 4-RECOMMENDED PLUMBING CODE FOR DWELL-} INGS AND SIMILAR BUILDINGS

Article I.-Definition of terms

Sec. 1. Plumbing

Sec. 2. Plumbing system 18

Sec. 3. Water-service pipe

Sec. 4. Water-distribution pipes

Sec. 5. Plumbing fixtures

See. 6. Trap

Sec. 7. Trap seal

Sec. 8. Vent pipe 18

Sec. 9. Local ventilating pipe__. 18

Sec. 10. Soil pipe

Sec. 11. Waste pipe and special waste 18

Sec. 12. Main

Sec. 13. Branch 19

Sec. 14. Stack 19

Sec. 15. House drain 19

Sec. 16. House sewer 19

Sec. 17. Size and length._. 19

Sec. 18. Dead end

Article II.-General regulations

Sec. 19. Grades of horizontal piping _._. 20

Sec. 20. Change in direction 20

Sec. 21. Prohibited fittings

Sec. 22. Dead ends___._._._._. 20

Sec. 23. Protection of material

Sec. 24. Workmanship_._._._. 20

Sec. 25. Installation of plumbing by owner 20 
Article III.-Quality and weights of materials__._. 21

Sec. 26. Materials, quality of _..._............. 21

Sec. 27. Label, east or stamped_..._. 21

Sec. 28. Vitrified clay pipe._._. 21

Sec. 29. Cast-iron pipe_._.

Sec. 30. Wrought-iron pipe _._._._. 21

Sec. 31. Mild-steel pipe___. 21

Sec. 32. Brass and copper pipe

Sec. 33. Lead pipe, diameter, weights _._. 21

Sec. 34. Sheet lead

Sec. 35. Sheet copper or brass.

Sec. 36. Galvanized sheet iron_._._.

Sec. 37. Threaded fittings

Sec. 38. Calking ferrules....... 22

Sec. 39. Soldering nipples and bushings____._. 23

Sec. 40. Floor flanges for water-closets____..... 23

Article IV.-Joints and connections__._._._.

Sec. 41. Water and air tight joints_... 24

Sec. 42. Vitrified pipe.

Sec. 43. Calked joints

Sec. 44. Screw joints

Sec. 45. Cast iron

Sec. 46. Wrought iron, steel, or brass to cast iron

Sec. 47. Lead pipe

Sec. 48. Lead to cast iron, steel, or wrought iron $\ldots \ldots 24$

Sec. 49. Slip joints and unions._._._.

Sec. 50. Roof joints.

Sec. 51. Closet, pedestal urinal and trap, standard slop sink, floor connections

Sec. 52. Increasers and reducers

Sec. 53. Prohibited joints and connections... 25

Sec. 54. Expansion bolts____._. 25

Sec. 55. New materials___._. 25

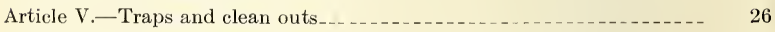

Sec. 56. Traps, kind

Sec. 57. Traps, prohibited__._. 26

Sec. 58. Traps, where required 26

Sec. 59. Water seal

Sec. 60. Trap clean outs___ 26

Sec. 61. Trap levels and protection

Sec. 62. Pipe clean outs_._._. 26

Sec. 63. Pipe clean outs, where required 26

Sec. 64. Manholes____._........ 27

Sec. 65. Clean outs; equivalents

Sec. 66. Grease traps___. 27

Sec. 67. Sand traps

Sec. 68. Basement floor drains

Sec. 69. Back-water valves_._. 27

Article VI. - Water supply and distribution

Sec. 70. Quality of water.... 28

Sec. 71. Distribution

Sec. 72. Water service

Sec. 73. Water supply to fixtures 
Article VI.-Water supply and distribution-Continued

Sec 74. Size of water-supply pipes -

Sec. 75. Water-supply control

Sec. 76. Water-supply pipes and fittings-material

Sec. 77. Water-supply protection 29

Sec. 78. Relief valves

Sec. 79. Pumps and hydrants _._._._. 29

Article VII.-Plumbing fixtures

Sec. 80. Materials_._. 30

Sec. 81. How installed ....... 30

Sec. 82. Water-closet bowls___________ 30

Sec. 83. Frost-proof closets-where permitted _._. 30

Sec. 84. Fixtures prohibited _._._. 30

See. 85. Floor drains and shower drains__._. 30

Sec. 86. Fixture strainers

Sec. 87. Fixture overflow

Article VIII. - Ventilation of rooms and fixtures _...

Sec. 88. Location of fixtures...

Sec. 89. Ventilating pipe, how connected 31

Article IX.-Soil, waste, and vent pipes _._. 32

Sec. 90. Material

Sec. 91. Fixture unit

Sec. 92. Soil and waste stacks

Sec. 93. Soil and waste stacks, fixture connections

Sec. 94. Changing soil and vent pipes._. 33

Sec. 95. Prohibited connections

Sec. 96. Soil and waste pipe protected... 33

Sec. 97. Roof extensions _._. 33

Sec. 98. Terminals___. 33

Sec. 99. Terminals adjoining high buildings _... 33

Sec. 100. Traps protected, vents

Sec. 101. Distance of vent from trap seal _. . . 34

Sec. 102. Main vents, to connect at base

Sec. 103. Vents, required sizes _._. 34

Sec. 104. Branch and individual vents____._. 35

Sec. 105. Vent-pipe grades and connections ____ 35

Sec. 106. Circuit and loop vents _... 36

Sec. 107. Vents not required......... 36

Article X.-House drains and sewers.

Sec. 108. Independent system.

Sec. 109. Old house sewers and drains_._. 37

Sec. 110. Connections with cesspools _._. 37

Sec. 111. Excavations _._._. 37

Sec. 112. House drains underground

Sec. 113. Material_._._. 38

Sec. 114. Depth of drains and sewers

Sec. 115. Size of drains and sewers _._._._._. 38

Sec. 116. Combined storm and sanitary sewer systems _____ 39

Sec. 117. House sewer in made ground 39

Sec. 118. Drainage below sewer level _._. 39

Sec. 119. Sumps and receiving tanks_._._. 39

Sec. 120. Ejectors, vented.- 39

Sec. 121. Motors, compressors, etc

Sec. 122. Ejectors for subsoil drainage 
Article XI - Storm-water drains _-

Sec. 123. Drainage of yards, areas, and roofs $\ldots 40$

Sec. 124. Size of gutters and leaders _....... 40

Sec. 125. Inside conductors _ _

Sec. 126. Outside conductors _._.

Sec. 127. Defective conductor pipes_.... 41

Sec. 128. Vent connections with conductors prohibited _._.

Sec. 129. Overflows _._. 41

Sec. 130. Subsoil, foundation, clear water, and absorption tile drains_- $\quad 41$

Sec. 131. Subsoil drains below sewer level _. _ _ _ _ _ _ . _ 41

Article XII.-Refrigerator, safe, and special wastes_._.

Sec. 132. Fixtures permitted to connect____

Sec. 133. Refrigerator wastes_....._.

Sec. 134. Overflow pipes and motor exhausts _ _

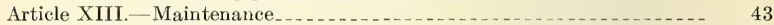

Sec. 135. Defective fixtures____._._.

Sec. 136. Temporary toilet facilities _._.

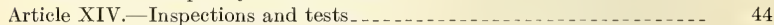

Sec, 137. Inspections _...

Sec. 138. Notification___._._._.

Sec. 139. Material and labor for tests_._.

Sec. 140. System tests._..._.

Sec. 141. Methods of testing _...... 44

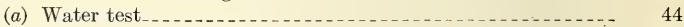

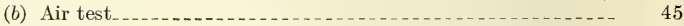

(c) Final air test......... 45

Sec. 142. Order of tests_._.

Sec. 143. Covering of work _._. 45

Sec. 144. Uncovering of work _._.

Sec. 145. Defective work

Sec. 146. House sewer and house drain tests _._.

Sec. 147. Conductor pipes_._. 46

Sec. 148. Stable and stable-yard drain test_ _

Sec. 149. Garage and drainage system_ _._. 46

Sec. 150. Test of water distribution system _._. 46

Sec. 151. Certificate of approval_____

Sec. 152. Air test of defective plumbing

See. 153. Inspections and tests not required _._.

\section{PART III.-EXPERIMENTAL INVESTIGATIONS, STANDARDIZATION, ADMINISTRATION, AND COMMENTS}

Chapter 5.-Experimental investigations._.

Unit of fixture discharge.

Water-closets_...... 48

Peak loads in house drainage systems

Capacities of house drains_... 50

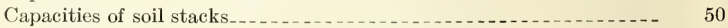

Characteristics of fall of water in partially filled stacks_..._..... 51

Vent requirements_._.

Admission of storm water.

Running trap

Effect of wind blowing over stack tops 
Chapter 5.-Experimental investigations-Continued

Frost closure of the stack tops

Siphonage of fixture traps.

Resealing or antisiphon traps.

Unvented horizontal branch waste pipes

Venting of branch wastes

Separate trap venting not necessary

Concrete examples of vent requirements _...

Factors of safety

Planning for simplicity _...

Chapter 6.-Physies of plumbing systems. Report of experimental and theoretical investigations.

Purpose and method of investigations . . . .

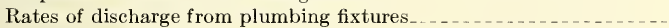

Apparatus employed . . .

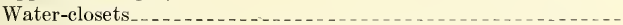

Interpretation and discussion of results . . . .

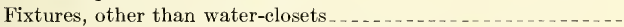

Determination of the peak load in any plumbing system ........

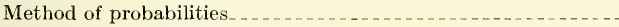

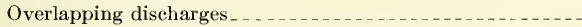

Mixed systems

Time factors $\ldots \ldots \ldots \ldots$

Capacities of stacks and drains

Drains_._._.

Stacks_...

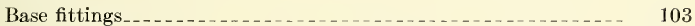

Characteristies of flow of water in partially filled vertical pipes_... 104

Spiral flow _... 105

Velocity of flow

Vent requirements _. 109

Pressure effects_._._._._._. 110

Pressure effects in a stack-vented system

Partial vacuums and vent requirements______._._._. 115

Back pressures and vent requirements_._._._._._._. 120

Self-siphonage and vent requirements______._._. 122

Modifying conditions_..._. 124

Heavy rains_....... 124

Submerged drains

House traps

Offsets in stacks.

Winds _._.

Frost closure

Floor drains $\ldots$

Siphonage of fixture traps . _ _ 129

Self-siphonage _... 130

Permissible length of unvented horizontal branch waste pipes _........ 138

Resealing traps................. 141

Back venting

Recommendations 
Chapter 6.-Physies of plumbing systems-Continued

The factor of safety in a plumbing system and determination of the upper limit of service for a 3-inch soil stack Establishment of a factor of safety Limits of service for a 3 -inch soil stack Inereased by methods of construction Simplification of plumbing construction Separate floor layouts tested.....

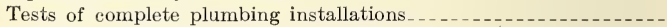

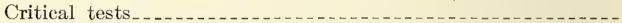

Test conditions

Notation_-_.

Test installation No. 1._._.

Conclusions

Test installation No. 2.

Test i stallation No. 3

General conclusions

Recommended construction details_._._._._._. 176

Chapter 7.-Standardization of plumbing materials_... 188

Chapter 8.-Administration.

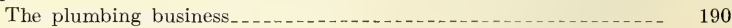

Enforcement of plumbing regulations_._.

The owner and his agents

The plumber

Proper administrative authority

State plumbing laws_._-_. 192

Licenses $v$. certificates of eompetency

Chapter 9.-Explanatory notes and comments____._._. 194

Note 1. Data obtained by questionnaire _._._._. 194

Note 2. Purity of water supply

Note 3. Dual sources of water supply

Note 4. Adequacy of water supply

Note 5. Pressure relief for water-heating apparatus________._ 196

Note 6. Desirability of sewer connections _._._. 196

Note 7. Provision of water-closets

Note 8. Fixture design _._._._._._._._._._._. 196

Note 9. Velocity of waste water in drainage systems _...... 198

Note 10. Useful life of system_._._._._. 198

Note 11. Limitations to the use of clean outs____._. 199

Note 12. Trapping of fixtures_._________ 199

Note 13. Grease-trap requirements__________________._. 199

Note 14. Air circulation in plumbing 200

Note 15. Simultaneous discharges_._. 200

Note 16. Admission of destructive substances_._._._._._._. 201

Note 17. Lighting and ventilation of water-closet compartments...- 201

Note 18. Sewage disposal _._._. 201

Note 19. Omission of the main house trap __________... 202

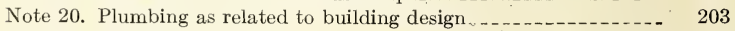

Note 21. Three-inch soil stacks_._. 203

Note 22. Vitrified clay pipe _ _ 204

Note 23. Sizes of distribution pipe

Note 24. Cast-iron pipe

Note 25. Simplification and cost reduction 
Appendix A.- Minority report

Reply to minority report

Appendix B.-Corrosion of metals in plumbing systems _. _...

1. The rusting of pure iron in pure water. . _ _ 210

2. The effect of nonferrous constituents in the iron

3. The effect of substances dissolved in water ................ 213

4. Various conditions affecting the corrosion of iron _. 215

5. The corrosion of nonferrous metals in water.

6. The corrosion of different metals in contact _._. 218

7. The corrosion of iron in air. . . 219

Practical considerations. _. _..._.

Bibliography of corrosion. . _..._. 221

Appendix C._-A study of air currents in a horizontal waste pipe _...... 222

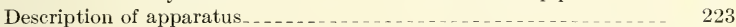

Eddy currents...... 224

Diffusion

Carbon dioxide experiments _.......

Evaporation of water._._. 230

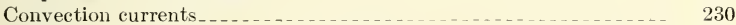

Diffusion of gases through water-seal traps _._. 230

Appendix D.-Standard specifications of the American Society for Testing Materials_................... 234

Clay sewer pipe

Cast-iron soil pipe and fittings .

Welded wrought-iron pipe_._._.

Welded and seamless steel pipe . . .

Brass pipe, standard sizes. _... _...

Copper pipe, standard sizes

TABLES

1. Rates of discharge from plumbing fixtures.

2. Probabilities of overlapping, etc., 1, 2, and 3 hour periods__..... 97

3. Probabilities of overlapping, ete., 2, 3, and 10 hour periods _... 98

4. Capacities of cast-iron drains, etc 100

5. Capacities of stacks, with fixtures connected direct_._. 103

6. Volume of air transmitted, etc _._.

7. Equivalent lengths of pipe in venting eapacity, etc _._. 120

8. Length of straight pipe equivalent in resistance to one elbow or tce of equal diameter.

9. Lengths of nominally horizontal unvented waste pipes believed safe, etc

10. Assumed simultaneous discharges compared with possible maximum discharges in typical installations illustrated, etc

11. Possible combinations of natural conditions affecting cach plumbing installation, etc

\section{FIGURES}

1. Photograph of fixture-rating apparatus. facing 62

2. Detailed section of fixture-rating apparatus

3. Typical record of discharge-time curve from fixture-rating apparatus.

4. Plotted reproduction of discharge-time curve

5. Typical derivative curve for fixture discharge (rate of discharge against time) 
6. Experimental system for rating water-closet discharges

19. Experimental supply and discharge systems for rating water-closets_ $\quad 74$

20-25. Discharge curves for typical water-closet installations________ _ 7.5-77

26. Supply line used for flush valves in rating water-closet discharges_._._. $\quad 77$

27-38. Discharge curves for typical water-closet installations_______ _ 78-88

39. Supply tanks at top of stack for determining the capacity of fittings

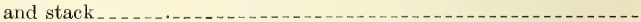

40. Pitot tube for measuring velocity of water at base of stack

41. Curve showing velocity of fall in a 3 -inch stack

42. Pressure curves near base of a 3 -inch stack with house drain, volume rate of water 66 gallons per minute

43. Pressure curves near base of a 3 -inch stack, volume rate of water 108 gallons per minute.

44. Recording pressure gauge

46. Experimental stack and vent system for determining air movements in a plumbing system.

47. Pressure curve for a 3 -inch stack, water introduced at rate of 200 gallons per minute.

48. Pressure curve for a 2-inch stack, water introduced at rate of 90 gallons per minute

49. Pressure curve for a 2 -inch stack, water introduced at rate of 45 gallons per minute

50. Chart for determining permissible length of main vent for a 3 -inch soil or waste stacks of known capacity.......

51. Experimental rain leader system

52. Submerged outfall of house sewer

53. Vented running trap

54. Apparatus for producing air current over stack top

55. Illustration of trail discharge from a flat bottom fixture

56. Arrangement of waste pipe to produce self-siphonage of a fixture trap.

57. Fixture and waste pipe to study effect of length of horizontal pipe on self-siphonage

58. Fixture and waste pipe to study effect of inclined waste pipe on selfsiphonage

59. Fixture and waste pipe to study effect of combined horizontal and inclined waste pipes

60. Diagram to illustrate the effect of horizontal waste pipe on velocity and scour

61. Diagram to illustrate the effect of a vertical section of waste pipe on velocity and scour.

62. Diagram to illustrate type of venting liable to clog

64. Diagram to illustrate type of venting liable to clog

65. Diagram to illustrate type of group venting in which vent is protected from clogging -

66. Diagram to illustrate type of group venting in which the vent is protected.

67. Diagram to illustrate type of yoke venting tending to increase the capacity of a system. 
68. Diagram to illustrate type of yoke venting applied to larger toilet rooms

69. Arrangement of bathroom group of fixtures tested

70. Illustration, erowfoot fittings

71. Arrangement of bathroom and kitchen-sink group tested

72. Arrangement of stack-vented bathroom group tested.

73. Alternate arrangement of bathroom and kitchen-sink group tested -.-

74. Arrangement of stack vented bathroom and kitchen-sink group tested.

75. Experimental plumbing system showing arrangement of pipes and location of fixtures.

6. Return bend used in house sewer

164

165

77. Trap fitted with window and scale as used in tests

78. Experimental plumbing system showing arrangement of pipes and location of fixtures.

79. Change in arrangement of basement fixtures of Figure 78

80. Experimental plumbing system erected for demonstration purposes - -

81. Approved design for a stack-vented bathroom group of fixtures (the highest group of fixtures on the stack)

82. Approved design for stack and group vented fixtures

83. Approved design showing one alternative arrangement of waste pipes for Figure 82

84. Approved design for stack-vented and group-vented fixtures_._._._.

85. Approved design for lower floor

86. Approved design for lower floor bathroom group

87. Approved design for duplex bathroom group

88. Approved venting for lavatory and water-closet

89. Approved forms of venting single fixtures_.

90. Types of one-story one-family houses showing required venting -....-

91. Types of two-story one-family houses showing required venting - . - -

92. Types of two-story two-family houses showing required venting -..-

93. Arrangement of piping for the study of air currents in horizontal

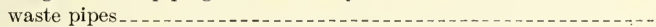

94. Experiment A. Diffusion of carbon dioxide in a $1 \frac{1}{2}$-inch horizontal branch connected with a vertical stack. (Time, $20 \frac{1}{2}$ hours; no forced draft.)

95. Experiment B. Diffusion of carbon dioxide in a $1 \frac{1}{2}$-inch horizontal branch connected with a vertical stack. (Time, 48 hours; draft in stack, $180 \mathrm{ft} . / \mathrm{min}$.)

96. Experiment C. Diffusion of carbon dioxide in a $1 \frac{1}{2}$-inch horizontal branch connected with a vertical stack. (Time, 44 hours; no forced draft.)

97. Experiments D and E. Diffusion of carbon dioxide in a 2-inch horizontal branch connected with a vertical stack. (Time, 48 hours; no forced draft.)

98. Experiment F. Evaporation of water in a $1 \frac{1}{2}$-inch horizontal branch connected with a vertical stack. (Time, 46 hours; no forced draft.)

99. Experiment G. Evaporation of water in a $1 \frac{1}{2}$-inch horizontal branch connected with a vertical stack. (Time, 48 hours; foreed draft, $100 \mathrm{ft} . / \mathrm{min}$.)

100. Experiment $H$. Diffusion of earbon dioxide in $1 \frac{1}{4}, 1 \frac{1}{2}$, and 2 inch horizontal branches connected with vertical stacks.......... 


\section{LETTERS OF SUBMITTAL}

Mr. IrA H. Woolson,

Washington, October 10, 1923.

Chairman, Building Code Committee,

Department of Commerce, Washington, D. C.

Dear Sir: We, the undersigned, members of the subcommittee on plumbing, submit the following final report covering our investigations of plumbing in dwelling houses.

Certain important matters not within the scope of our instructions were considered by the committee but were not brought to a conclusion, namely, tests of materials, standardization of dimensions, and plumbing administration.

It is our opinion that simplified practice and standardization of plumbing should be brought about by mutual agreement of interested parties rather than by detailed legislation, but without uniform basic regulation standardization of plumbing is impossible. We have, therefore, given our chief attention to this part of the problem and have embodied the results of our studies in a recommended Code of Plumbing Rules.

It is our opinion that important changes in present methods of governmental control of plumbing are needed but that these should not be attempted until the parties most interested have had an opportunity to discuss thoroughly not only the legal but the business and labor problems which are involved.

In our investigations we have necessarily been obliged to consider the subject from the point of view of sanitarian, manufacturer, plumber, and inspector, but in formulating the code we have endeavored to keep first in our minds the interests of the people whose health may be endangered by faulty plumbing and whose comfort will be increased by living in houses well supplied with means for using water and for disposing of liquid wastes.

Respectfully yours,

George C. Whipple, Chairman.

H. Y. Carson,

William C. Groeniger,

Thomas F. Hanley,

A. E. Hansen. 
Mr. George C. Whipple,

Washington, December 15, 1923.

Chairman of the Subcommittce on Plumbing of the

Department of Commerce.

Dear Sir: The report of your committee transmitted with your letter of July 3, 1923, has been received and has been given careful consideration by the individual members of the Building Code Committee, and it is my pleasure to inform you that we are a unit in expressing our admiration of the exhaustive treatment your committee has given to the subject assigned.

There is abundant evidence of the thorough study given to each phase of the subject and the earnest effort made to base your recommendations upon demonstrated physical facts, unbiased by personal opinion or the rules of existing practice. It is recognized that the judgment and experience of your committce members has been freely exercised in analyzing the evidence produced in order to interpret its full significance and determine its value.

My committee was particularly impressed with the thorough and comprehensive character of the original research conducted by the Bureau of Standords under your committee's direction. Such investigations are of great value not only for the information developed for your report, but also for the accumulation of data useful for comparison with subsequent similar studies.

The Building Code Committee has instructed me to express to your committee its sincere appreciation of the excellent service rendered.

The report more than fulfills our expectations, and we believe it will prove a very valuable public document, helpful alike to individuals and municipalities in simplifying the operations and reducing the cost of plumbing installations, particularly in dwelling-house construction.

The report will be duly transmitted to Secretary Hoover, with an expression of my committee's approval, and recommendation that it be printed for distribution.

Yours very truly,

Ira H. Woolson, Chairman, Building Code Committee, Department of Commerce.

Hon. Herbert Hoover,

Washington, December 15, 1923.

Secretary of Commerce, Washington, D.C.

My Dear Mr. Secretary: I have the honor to transmit herewith the report of the subcommittee on plumbing appointed by you to cooperate with the Building Code Committee. The report bears evidence of its thorough and conscientious preparation. 
It is a valuable document. The views of my committee upon the merits of the report are briefly expressed in our letter of acknowledgment to the chairman of the subcommittee, copy of which is attached hereto and hence need not be repeated.

The Building Code Committee respectfully recommends that this report be approved and printed for public distribution as a document of the Department of Commerce.

Yours very truly,

Ira H. Woolson, Chairman, Building Code Committee, Department of Commerce. 


\title{
LETTER OF ACCEPTANCE
}

Mr. Ira H. Woolson,

\author{
Department of Commerce, \\ Office of the Secretary, \\ Washington, February 11, 1924.
}

Chairman, Building Code Committee, Department of Commerce, Washington, D. C.

Dear Mr. Woolson: I am indeed well pleased with the completion of the Recommended Minimum Requirements for Plumbing in Dwellings and Similar Buildings. The members of the subcommittee and of the Bureau of Standards staff deserve the greatest credit for their unselfish and public-spirited devotion to the work.

Economical and sanitary plumbing systems are a vital necessity for health in all settled communities and are hardly less essential in rural households. Although the American people have expended hundreds of millions of dollars for plumbing installations, the principles of their general layout have never been thoroughly understood. Actual practice has been governed by opinions and guesswork, often involving needless costly precautions which many families could ill afford. The lack of generally recognized principles is responsible to a certain extent for the contradictory plumbing regulations in different localities.

Thanks to the work of the subcommittee and of the Bureau of Standards, the whole situation is altered, and there is now a scientific basis upon which State and local codes and small-dwelling installations may be based.

The way is opened for effective standardization of plumbing supplies, with reduced costs to the industry and savings to the consumer.

The subcommittee achieved these fine results by enlisting the aid of the voluntary professional and commercial associations to which its members are attached and of public officials, engineers, manufacturers, and representatives of workers, who willingly gave their time and services in helping to arrive at conclusions in accordance with the most varied experience. The experimental work necessary was performed with the utmost economy on account of the ability of the Bureau of Standards staff, the contributions of materials by manufacturers and the assistance given by members of the subcommittee.

The report stands as a credit to leading men in the industry and in public regulation. Prompt recognition of its principles by local authorities and by the plumbing industry generally is forecast by advices that have reached this department, and such action will mean cheaper and better sanitation for the American people.

Yours faithfully,

Herbert Hoover. 



\title{
RECOMMENDED MINIMUM REQUIREMENTS FOR PLUMBING IN DWELLINGS AND SIMILAR BUILDINGS
}

\author{
$\infty$
}

Final Report of Subcommittee on Plumbing of the Building Code Committee

\section{PART 1.-INTRODUCTION - GENERAL CONSIDERATIONS}

In May, 1921, there was organized in the Department of Commerce a group of architects and engineers experienced in matters of building regulation, to be known as the Department of Commerce Building Code Committee. Investigations by several agencies, and particularly by the Senate Committee on Reconstruction and Production, had disclosed that prevailing inactivity in the building industries was due in part to unnecessarily restrictive building code requirements, and that under normal conditions great economic loss resulted from lack of uniformity and justice in such regulations.

The Building Code Committee proceeded to gather information upon which minimum code requirements governing the various phases of building construction might be based. These are being issued in the form of ordinances recommended for adoption by those writing or revising building codes.

Early in its work the committee undertook as a part of its program the formulation of rules for the plumbing of small dwelling houses. Data regarding present practice were secured, and, in response to a questionnaire, the opinions of plumbers, sanitary engineers, and others in regard to some of the mooted questions were obtained. It soon became evident that the problem could not be solved satisfactorily by the questionnaire method, and that instead of mere opinions there should be conclusions deduced logically from scientific evidence obtained by experiment and experience. The committee therefore decided to have the Bureau of Standards investigate the underlying principles of house drainage under the general supervision of a subcommittee of experienced sanitary engineers and plumbers. This subcommittee was appointed by Secretary Hoover in September, 1921, as follows:

George C. Whipple, chairman, professor of sanitary engineering in Harvard

University, Cambridge, Mass.

American Society of Civil Engineers.

American Public Health Association (fellow).

American Water Works Association.

New England Water Works Association.

American Academy of Arts and Sciences.

American Chemical Society.

Royal Sanitary Institute (honorary fellow).

$94877^{\circ}-24-2$ 
Harry Y. Carson, research engineer, American Cast Iron Pipe Co., Birningham, Ala.

American Society of Civil Engineers.

Iron and Steel Institute.

American Society for Testing Materials.

American Foundrymen's Association.

National Research Council.

William C. Groeniger, consulting engineer, Columbus, Ohio.

American Public Health Association.

American Society of Sanitary Engineering.

American Water Works Association.

Thomas F. Hanley, Hanley \& Co., mechanical engineers and contractors, Chicago, Ill.

American Society of Sanitary Engineering.

National Association of Master Plumbers (chairman of standardization committee).

Western Society of Engineers.

A. E. Hansen, hydraulic and sanitary engineer, New York, N. Y.

American Society of Sanitary Engineering.

American Public Health Association.

American Water Works Association.

James A. Messer, ${ }^{1}$ president of the James A. Messer Co., Washington, D. C.

William J. Spencer, ${ }^{1}$ secretary-treasurer of building trades department, American Federation of Labor, Washington, D. C.

United Association of Journeymen Plumbers.

Albert L. Webster, ${ }^{1}$ consulting engineer, New York, N. Y.

American Society of Civil Engineers.

American Public Health Association.

New England Water Works Association.

Franklin Institute.

\section{MODE OF PROCEDURE}

Several meetings were held for planning and discussion of the tests which were carried on at the Bureau of Standards. At the first meeting Secretary Hoover received the members of the subcommittee and explained in a general way his hopes in regard to the solution of the problem, emphasizing especially the benefits which should result from simplified practice in plumbing as well as in other branches of industry. John M. Gries, chief of the division of building and housing; Ira H. Woolson, chairman of the Building Code Committee; and Frank P. Cartwright, technical secretary of the Building Code Committee, have all met the subcommittee from time to time and discussed methods of procedure. Conferences have been held with Dr. S. W. Stratton, then director of the Bureau of Standards; Dr. L. J. Briggs, chief of the engineering physics division, and Dr. R. B. Hunter, associate physicist of the Bureau of Standards, to whom was delegated the task of conducting the experimental work.

\footnotetext{
LCircumstances not related to the work of the subcommittee compelled the resignation of Mr. Messer on Jan. 5, 1922, and of Mr. Spencer and Mr. Webster during October, 1922. Their colleagues wish to express sincere appreciation of their valued services during their connection with the work.
} 


\section{TENTATIVE REPORT}

On June 17, 1922, a preliminary report was submitted to the chairman of the Building Code Committee, stating the tentative conclusions of the committee at that time, and briefly describing the experimental work at the Bureau of Standards. This tentative report was signed by all of the members of the committee except William J. Spencer, who presented a minority report favoring individual venting for traps, but concurred in the rest of the tentative report. (See p. 207.)

One thousand copies of the tentative report were distributed in all parts of the country among sanitary engineers, plumbers, architects, manufacturers, plumbing inspectors, and others whose experience qualified them to discuss plumbing matters with authority, with a request for critical discussion of the proposed requirements. In response nearly 200 communications were received, discussing the subject from all points of view and bringing to bear a vast amount of practical experience and operating data. The discussions and criticisms thus obtained were found much more valuable than usually result from the ordinary questionnaire method of obtaining information. The tentative report afforded a focus for criticisms and suggestions, and the recommendations of the committee have been revised in the light of the information thus received. It is worthy of note that approval of the majority report on the part of those who discussed its provisions was quite general. More than half of the respondents approved the tentative findings unconditionally, and many more had only minor criticisms or suggestions to make. Very few of the correspondents supported the contention of the minority report.

The letters received indicated that some matters had not been made sufficiently clear, and the committee has taken pains in preparing the final report to clarify these doubtful points. Where the treatment of any particular question evoked considerable criticism, the reasons for the final conclusions of the committee are stated in a series of notes to be found in chapter 9 . This final report also has been influenced by the results of much additional experimental work at the United States Bureau of Standards, completed since the tentative report was distributed.

\section{LOCAL CONDITIONS}

Although the findings of this report are believed to be based on sound general principles, nevertheless the committee recognizes that in a large country like the United States, which includes wide differences of climate and living conditions, situations will occasionally be found which will justify modification of the practices recommended. No attempt has been made to outline these special situations. 


\section{ACKNOWLEDGMENT}

The committee wishes to express its sincere appreciation of the cooperation extended by the Bureau of Standards under direction of Dr. S. W. Stratton and Dr. George K. Burgess. Measures for the furtherance of its investigations have been prompt and adequate. Especial commendation should be given to Dr. R. B. Hunter for his ingenious and accurate physical investigations of the hydraulics and pneumatics of drainage systems under various conditions of use. Acknowledgment is made of the valuable cooperation extended by the great number of engineers, plumbing inspectors and plumbers, architects, and others who have furnished data, reviewed the tentative recommendations, and have otherwise exhibited interest in the work. 


\section{CHAPTER 1.-REGULATION OF PLUMBING}

\section{DEFINITION OF PLUMBING}

The "plumbing" of a building, as the term is commonly used, includes the pipes for distributing the water supply', the fixtures for using water, and drainage pipes for removing waste water and sewage, together with fittings and appurtenances of various kinds, all within or adjacent to the building. The "service pipe," which forms the connection between the water main and the building, and the "house sewer," which conveys the waste water and sewage from the building to the street sewer or other point of disposal, are included in the "plumbing system" of a building, using the term in a broader sense. Connections for rain water are also included if the water is discharged through a house sewer or a house drain. The water supply and drainage system are mutually dependent. Drains are needed to carry away the used water; water is needed to cleanse the fixtures and transport solid wastes.

The work of the committee has emphasized the necessity of considering the plumbing systems of buildings as intimately releted to and forming an integral part of public water-supply and sewerage systems. The number and character of plumbing fixtures in a building are largely matters of individual choice, and owners have not sufficiently considered their relation to features of public service. Plumbing fixtures are the terminals of water-supply systems, and, to a large extent, control the quantity of water used. At the same time they are the beginnings of the sewerage system. The aggregate discharges from plumbing fixtures determine the flow in sewers and the volume of sewage reaching the outfall, this volume materially affecting the cost of any pumping or treatment of the sewage. It is evident, therefore, that the public interest may well justify a certain degree of governmental control over plumbing fixtures as affecting both the quantity of water available for public use and the economical operation of the sewerage system.

\section{RELATION OF PLUMBING TO HEALTH}

An important function of the house-drainage system is to carry away from plumbing fixtures human excreta and wastes which may contain disease-producing bacteria. Because of the possible presence of such organisms sewage may be dangerous and must be disposed of in such a manner that there will be no chance of disease transmission. Sanitarians to-day place great emphasis on the importance of sewage treatment and safe methods of ultimate sewage disposal. 
The leakage of polluted water from the house-drainage system is insanitary and dangerous. Leakage within the house may pollute the habitation and permit food infection through the medium of insects. Leakage in the ground outside the house may pollute water supplies taken from neighboring wells or find its way into or under the building. The maintenance of water seals between fixtures and drains and the permanent tightness of plumbing systems are important not only because they prevent the passage of air, but because they prevent the access of insects to the interior of the drains and sewers. If cockroaches, water bugs, and other vermin can pass from drains to food, they may transport disease germs, and thus be a bacteriological menace to health. It is therefore important that the drainage system be tight and without danger of leakage.

L. O. Howard, chief of the Bureau of Entomology of the United States Department of Agriculture, and C. W. Stiles, United States Public Health Service, in personal conversation with the chairman of the committee, are authority for the statement that insects can and do pass from the interior of leaking drainage systems to living quarters. Several other observers also report such occurrences.

Another danger to be guarded against is the use of fixtures in which the water supply and waste connections are so arranged that polluted waste water from the fixtures may, under certain circumstances, return into the water-supply pipes.

The line where the safe water supply ends and sewage begins is sometimes very finely drawn. If faucets with open spouts discharge over plumbing fixtures and if there is a break between the water supply and the waste pipe, self-protection exists against possible pollution of the water-supply distributing system by the back flow of waste water into it. Plumbing fixtures such as water-closets, urinals, bidets, bathtubs, and lavatories with direct connections, secret wastes and overflows, and combination cocks offer possible sources of pollution.

The air in sewers and drains often contains gases resulting from the decomposition of excreta, soap, fats, and other wastes, together with gases from mineral oils which may come from garages, streets, and industrial establishments. Illuminating gas may also find its way into sewers through leakage. Among these gases may be found methane, sulphuretted hydrogen, and carbonic oxide. In large amounts those gases are poisonous to the human system, and there are physiological objections to breathing them even in small quantities. Hence, the air of sewers or drains should be kept from entering buildings intended for human habitation or occupancy by the use of proper plumbing installations and by suitable ventilation of the rooms or compartments in which the plumbing fixtures are located. The smell of these gases and other emanations from decomposing organic matter is naturally repugnant to human beings. It not only 
offends the sensibilities, but may produce shallow breathing, headache, and even nausea.

In addition to the above facts, it is important to consider the bacteriological aspects of sewer and drain air, a subject upon which there has been some misunderstanding. In recent years bacteriologists have made studies which have thrown light upon this subject. They have shown by experiment that while sewage often contains disease-producing bacteria derived from human excreta and body wastes these bacteria are rarely found in the air which escapes from sewers and drains. Hence, it has been argued by some that escaping sewer air has no influence on health. The committee does not agree with this conclusion. Health may be influenced by factors which do not cause specific diseases, for there are chemical and physiological as well as bacteriological factors involved. The investigations thus far made by bacteriologists should be considered to be merely a beginning of larger and more complete investigations which will doubtless be made as the science of bacteriology advances. The committee is of the opinion, therefore, that until further light on this somewhat obscure subject has been obtained the escape of sewer air from the house-drainage system, at frequent intervals or in considerable quantities, threatens the health of the building's occupants.

This whole matter has a quantitative as well as a qualitative aspect. The temporary losses of water seal in traps, which rarely occur and which are immediately replaced, do not involve any great danger to the health of the occupants, for in many cases the final drainage from the fixture will renew the seal within a short time, but where a loss of seal is likely to be of frequent occurrence and not readily replaced, or where breaks in the system admit sewer air continually to a building, the health of the occupants is subject to the dangers heretofore described.

\section{PUBLIC CONTROL OF PLUMBING JUSTIFIABLE}

For the above-mentioned reasons regulations governing the installation of plumbing have been established by law in many places. These regulations have been potent in improving living conditions throughout the country; in fact, they have even set the standards for those places where plumbing is not under public control. The knowledge now in possession of sanitarians in regard to the lessened bacteriological dangers of sewer air leads logically to some simplification in plumbing design, but it should not lead to an abandonment of practices necessary to protect buildings against the air of drains, which, in addition to its possible danger, is offensive to the smell.

The committee believes that good plumbing is a matter which concerns health. Government has the right to protect the people's 
health, but people also have rights, and plumbing regulations carried too far are unjust. Regulations which will not be supported by the courts fully and without question under a liberal interpretation of the police power may be regarded as unjust. Sanitary science, however, must be the guide to justice in this matter. The principles of science change as knowledge advances, and it is proper, therefore, that plumbing regulations be reviewed from time to time and, if necessary, revised.

\section{LEGAL PRINCIPLES}

It is impossible to study the subject of plumbing regulation without having a proper conception of the common-law principle known as "police power," for, though a part of the common law and without absolutely definite limits, it can and must control court decisions, without which plumbing regulations would be futile. Attention should be called to the fact that this legal term "police power" does not mean the power of a policeman. It is true that the policeman, with his uniform and his stick, is one agency for enforcing the "police power," but plumbing inspectors, building inspectors, fire marshals, and health officers also act under the same "police power." Police power is that inherent power of government which protects the people against harmful acts of individuals, in so far as matters of safety, health, morals, or the like are concerned. "Police power" is "community power." Injuries against health come within the proper scope of the police power; but acts of government to enhance or promote health above normal, while laudable and often justifiable, do not fall within the scope of the police power.

There is a difference between conferring a benefit and preventing an injury, which, though difficult to define, is nevertheless real. Some of the requirements now generally included in plumbing codes represent a failure to make this distinction properly and can not be justified as essential to the protection of the public health from injury. When there is difficulty in enforcing such regulations and the cases are brought into court, it often happens that the code requirements are not supported. In this way well-meaning citizens comply with regulations which can not be enforced upon the unwilling citizen, and injustice results. Unfortunately, this situation exists to-day. Plumbing regulations, therefore, should be carefully examined in the light of modern sanitary science and accepted legal principles to determine their legality, keeping in mind that in so far as they protect the human health against injury they are justifiable, but no farther. It should be observed also that legally the police power has to do with "health," not merely the "public health." This is a distinction which even a health officer of ten fails to make.

The following principles may be considered as safe guides in the matter of governmental control: 
1. The control of plumbing by government is distinctly an act done under the police power, beeause it has to do with proteetion of the health of the people against injury, using this term in its broad and popular sense.

2. This use of the police power resides fundamentally in the State governments, but may be and often is delegated to cities, towns, or other subdivisions of States.

3. The police power has not been delegated to the Federal Government, except so far as needed to carry out certain delegated powers (as, for example, quarantine); hence, the Federal Government has only advisory powers regarding its employment by States.

4. The use of the police power in plumbing regulations is justified on the theory, supported by seientifie evidenee, that the passage of rats, cockroaches, water bugs, and other vermin in and out of drains, or the escape of sewage or of air from drains or sewers into occupied human dwellings, are menaces to health, using this term in its broad and popular sense.

5. Plumbing regulations can not legally eontain requirements which do not, either directly or indirectly, prevent injury to health, safety, morals, or the like. No requirements can legally be made which have to do merely with economies of eonstruction, with benefits to the house owner or occupants, or with benefits to manufacturers, traders, or laborers, for the right and only legal use of the police power is to protect against injury.

6. The design of plumbing systems is properly within the scope of legal regulation in so far as it has to do with the escape of solids, liquids, or gases from, or the access of vermin and insects to drains and sewers, in such a way as to endanger health, and in so far as a safe and adequate supply of water to the fixtures is concerned.

7. Plumbing materials are properly subject to legal regulation in so far as their reliability in preventing dangers to health is eoneerned, looking ahead to a reasonable life of the building.

8. Methods of plumbing construction are properly subject to legal regulation in so far as they may be necessary to guard against danger to health through faulty workmanship.

9. The control of plumbing by the system of permit and inspection and test is a logieal and apparently a satisfactory way of guarding against injury to health through faulty plumbing; but in view of different conditions existing in large and small communities the States should delegate to local communities the manner of administrating this control.

10. The system of examining plumbers is for the public benefit and should be continued, but it might be better for the examining authorities to issue certificates of competeney rather than "licenses."

11. The requirement that plumbing work, subjeet to permit and inspection, be done by licensed plumbers is justifiable under the poliee power. 
12. Uniformity in methods of plumbing control is desirable, as it makes for convenience and economy. Uniformity can be secured by following models set up by Federal or State governments.

13. Standardization of plumbing designs, so far as dimensioning is concerned, standardization of plumbing materials, and even standardization of code requirements are for the public benefit, rather than for protection against injury, and should be brought about by agreement and concerted action. They can not be required legally under the police power.

14. As the police power resides in State governments and as uniformity in plumbing regulation is for the public benefit, it is well for all States to have simple, uniform, State-wide plumbing regulations alike in essential respects, limited to matters which properly come within the scope of the police power under a wide range of conditions, with provision for permitting local communities to regulate installation and inspection by such methods as they see fit to adopt. These may be appropriately called "basic plumbing principles."

15. The residence or dwelling is the basis for plumbing codes, because the majority of all buildings are of this type. A code applicable to dwellings is also applicable, although not necessarily sufficient, for other classes of buildings. Buildings differ as to plumbing conditions, so that different regulations for different classes of buildings are fully justified under the police power. In fact, to apply the same regulations to different conditions; that is, to require practices necessary in one case for another case where they are not necessary, is an improper use of the police power. The fourteenth amendment to the Constitution of the United States provides for "equal protection of the law," but equal protection means under like circumstances.

16. In addition to the basic plumbing principles, it is well for each State to adopt a code of plumbing rules conforming substantially to that hereinafter recommended, which has been so drawn that compliance therewith will practically assure compliance with the basic plumbing principles.

17. It is a well-established principle in drawing specifications for works which involve operation that guaranteed results and detailed methods of construction should not both be specified at the same time. If certain guaranteed results are demanded, the contractor should be allowed some latitude in construction, and if detailed methods of construction are specified, it should be expected that the desired results will follow as a matter of course. Similarly, if reliance is placed on a general code of basic plumbing principles, there should obviously be freedom of choice as to many details; whereas if cities or towns choose to adopt a more rigid and detailed set of requirements compliance with them should be regarded as prima facie evidence that the desired results will be obtained. 


\section{CHAPTER 2.-PRESENT STATUS OF PLUMBING REGULATIONS}

The committee has collected a large number of plumbing codes, State laws, and local ordinances and given them careful study. The situation may be described as chaotic.

Some States have no laws which regulate plumbing other than local enactments. A few States have mandatory plumbing laws state-wide in scope. Some have laws mandatory for cities of a certain size or for cities and towns having public water supplies. Others require cities to adopt ordinances regulating plumbing. Still others have permissive acts. There is an utter lack of uniformity in legal procedure governing these matters.

In the matter of administration some cities and some States require master plumbers and journeymen to be licensed, but some cities do not require licenses even though there are plumbing ordinances. The method of permit and inspection is almost universal, where there is any regulation at all, but sometimes the inspection is under a board of health, sometimes under a building department, occasionally under a special plumbing inspector, and, in a few instances, under a water department.

In the matter of codes the lack of uniformity is even greater. Some State codes are simple in their provisions; others set forth rules of plumbing practice in great detail. In many States the different cities have different codes. In one State there is a permissive State code, as well as many city codes resulting from local enactments.

Going further into detail, it is found that there are unaccountable differences in the regulations. Thus, in one State, where the whole subject of plumbing has recently been under investigation, some cities require the use of the running trap, other near-by cities prohibit its use, and some allow its use to be optional with the owner. Minor differences in regulations in different parts of the country may sometimes be justified on account of different climatic or local conditions, but the many radical differences found in the cities of a single State are unjustifiable.

Nearly all of the present plumbing codes are applied in their entirety to all of the buildings within the limits of their jurisdiction. Compiled originally for dwellings, they have been extended to other types of buildings, but proper discrimination has not always been made between high and low buildings, single or multiple, public or private, or between buildings used for different purposes. It is 
natural, perhaps, that codes should have developed in a rigid way, because the first code drawn was based on the requirements of a single city. Subsequent codes have been influenced by precedent, local pride, and selfish prejudice. Many codes have been established by copying other codes. Prejudice in favor of this or that method of construction has brought about unnecessary differences.

\section{SUPERVISION OF PLUMBING INSPECTION}

There is frequently a lack of coordination between the different municipal departments which, in one way or another, are concerned with plumbing, namely, the departments of health, fire, water, sewers, buildings, and streets. Under prevailing arrangements the owner or plumbing contractor must of ten obtain several permits from different city authorities and arrange for inspection by several men in order to comply fully with the regulations. For example, he may be obliged to go to the department of public works for permission to cut the pavement and for an inspector to see that the fill is property made, to the city engineer for line and grade of the sewer, to the city engineer and health officer for permission to make connections with the sewer, to the division of water supply for permission to make water connection, and to the plumbing inspector for approval of his plumbing installation.

\section{CONCLUSIONS BASED ON SCIENTIFIC PROCEDURE}

Because of the irregularities and incongruities in plumbing codes the committee has not attempted to formulate minimum plumbing requirements by any method of selection or by any averaging process based on existing codes. Instead, the committee has studied the entire problem anew and has based its conclusions for small buildings on legal principles and the applications of modern science, but has kept in mind existing conditions in order that suggested changes may not be great enough to cause serious inconvenience. 


\section{CHAPTER 3.-BASIC PLUMBING PRINCIPLES}

The committee has given consideration to the formulation of a set of basic plumbing principles so general in scope and so fundamental in character as to be worthy of adoption by State, city, or town as a basis for its sanitary law. These have been drawn on the principle of specifying the results desired, making provision for testing the plumbing work to ascertain if the results are likely to be secured, but not attempting to specify details of construction.

These requirements are not regarded as sufficient for all cities, but the committee is of the opinion that States should adopt them on a state-wide mandatory basis or should give to eities, towns, or other subdivisions the power to choose between them and the more detailed plumbing code hereinafter recommended.

These principles were adopted by the committee early in its work as embodying the fundamental sanitary considerations which successful plumbing systems must satisfy. They have been utilized as a guide, both in directing the investigational work and in formulating recommendations.

In adopting these basic plumbing principles the committee has endeavored to keep in mind differences in climate in different parts of the country, differences in buildings, in methods of sewerage and sewage disposal, in disposal of rain water, and other differences. Some of the details of plumbing construction must vary with these conditions, but the basic sanitary principles are the same and the results desired and necessary to protect the health of the people are the same everywhere.

These principles are stated in the following pages. Explanations of the reasons for their adoption and of their application to conditions met with in practice are given in the notes in chapter 9 . In making these explanatory notes the committee has given careful consideration to the questions raised by those who have reviewed the tentative report and has attempted to deal with the considerations naturally arising when the adoption of such basic principles is under discussion.

1. All premises intended for human habitation or occupancy shall be provided with a supply of pure and wholesome water.

2. Buildings in which water-closets and other plumbing fixtures exist shall be provided with a supply of water adequate in volume and pressure for flushing purposes.

3. The pipes conveying water to water-closets shall be of sufficient size to supply the water at a rate required for adequate flushing without unduly reducing the pressure at other fixtures. 
4. Devices for heating water and storing it in "boilers," or hotwater tanks, shall be so designed and installed as to prevent all dangers from explosion and also prevent a back flow of hot water through a meter connected with a public water supply.

5. Every building intended for human habitation or occupancy on premises abutting on a street in which there is a public sewer shall have a connection with the sewer, and, if possible, a separate connection.

6. In multiple dwellings provided with a house drainage system there shall be for each family at least one private water-closet.

7. Plumbing fixtures shall be made of smooth nonabsorbent material, shall be free from concealed fouling surfaces, and shall be set free of inclosures.

8. The entire house drainage system shall be so designed, constructed, and maintained as to conduct the waste water or sewage quickly from the fixture to the place of disposal with velocities which will guard against fouling and the deposit of solids and will prevent clogging.

9. The drainage pipes shall be so designed and constructed as to be proof for a reasonable life of the building, against leakage of water or drain air due to defective materials, imperfect connections, corrosion, settlements or vibrations of the ground or building, temperature changes, freezing, or other causes.

10. The drainage system shall be provided with an adequate number of cleanouts so arranged that in case of stoppage the pipes may be readily accessible.

11. Each fixture or combination fixture shall be provided with a separate, accessible, self-scouring, reliable water-seal trap placed as near to the fixture as possible.

12. The house-drainage system shall be so designed that there will be an adequate circulation of air in all pipes and no danger of siphonage, aspiration, or forcing of trap seals under conditions of ordinary use.

13. The soil stack shall extend full size upward through the roof and have a free opening, the roof terminal being so located that there will be no danger of air passing from it to any window and no danger of clogging of the pipe by frost or by articles being thrown into it or of roof water draining into it.

14. The plumbing system shall be subjected to a water or air pressure test and to a final air-pressure test in such a manner as to disclose all leaks and imperfections in the work.

15. No substances which will clog the pipes, produce explosive mixtures, or destroy the pipes or their joints shall be allowed to enter the house-drainage system. 
16. Refrigerators, ice boxes, or receptacles for storing food shall not be connected directly with the drainage system.

17. No water-closet shall be located in a room or compartment which is not properly lighted and ventilated to the outer air.

18. If water-closets or other plumbing fixtures exist in buildings where there is no sewer within reasonable distance, suitable provision shall be made for disposing of the house sewage by some method of sewage treatment and disposal satisfactory to the health authority having jurisdiction.

19. Where a house-drainage system may be subjected to back flow of sewage, suitable provision shall be made to prevent its overflow in the building.

20. Plumbing systems shall be maintained in a sanitary condition. 



\section{PART II.-CHAPTER 4-RECOMMENDED PLUMBING CODE FOR DWELLINGS AND SIMILAR BUILDINGS}

As a result of its investigations the committee has drafted the following code of minimum requirements for the plumbing of dwellings and similar buildings.

Starting with the fundamental principle that plumbing regulations are applications of the police power in the interest of health, two ideas have been kept steadily in mind - simplification and standardization. Early studies showed the futility of attempting to bring about complete standardization by law. Apart from questionable legality was the insuperable difficulty of including in a code the innumerable items that would be necessary. The committee's attitude in regard to the subject of standardization is set forth in chapter 7 . On the other hand, an attempt to simplify plumbing regulations by eliminating all items which are in the nature of specifications would reduce them practically to the list of basic principles given in chapter 3 . The code recommended is a compromise between the two extreme ideas. It is shorter than some of the codes now being used, curtailments having been made in the interest of simplicity; it is longer than some, details having been included with a view to bringing to pass a certain amount of standardization. It is hoped that its requirements of design, coupled with its detailed structural requirements, will result not only in cheaper and better plumbing, but in a fairer and more uniform administration. A study of the recommended code will show that its length is due quite as much to its detailed classification as to its subject matter, brevity being sacrificed for the sake of clearness.

Attention should be called to the fact that the code, as presented, has been drawn primarily for dwelling houses, although most of its provisions apply to any sort of building. With slight modifications required to adapt it to local administrative conditions and with the addition, where necessary, of items applicable to buildings other than dwellings, the committee believes that its adoption by States and municipalities will tend to bring order out of the present chaos.

In Article III, which covers the subject of quality and weight of plumbing materials, references are made to standard specifications adopted by the American Society for Testing Materials, instead of writing these detailed requirements into the code, but for the information of persons studying this report the specifications referred to are given in Appendix D. In the case of lead pipe, no specifications have yet been adopted by the American Society for Testing Materials, and, therefore, detailed weights are inserted in the code. The idea of the committee is that codes adopted throughout the country shall require that plumbing materials conform to prevailing standards of good practice, and that an association of technical experts is better qualified to establish such standards and revise them as manufacturing arts progress than the State or municipal legislative authorities responsible for the plumbing code. 


\section{PLUMBING CODE FOR DWELLINGS AND SIMILAR BUILDINGS}

\section{Recommended by the Subcommittee on Plumbing of the De- partment of Commerce Building Code Committee}

\section{ARTICLE I.-DEFINITIONS OF TERMS}

[These recommendations apply only to dwellings and similar small buildings. The experimental work at the Bureau of Standards developed some additional information on installations for larger buildings, and this has been made available wherever possible throughout the report]

Section 1. Plumbing.-Plumbing is the art of installing in buildings the pipes, fixtures, and other apparatus for bringing in the water supply and removing liquid and water-carried wastes.

Sec. 2. Plumbing System.-The plumbing system of a building includes the water supply distributing pipes; the fixtures and fixture traps; the soil, waste, and rent pipes; the house drain and house sewer; the storm-water drainage: with their devices, appurtenances, and connections all within or adjacent to the building.

Sec. 3. Water-Service Pipe.- The water-service pipe is the pipe from the water main to the building served.

Sec. 4. Water-Distribution Pipes.-The water-distribution pipes are those which convey water from the service pipe to the plumbing fixtures.

Sec. 5. Plumbing Fixtures.-Plumbing fixtures are receptacles intended to receive and discharge water, liquid, or water-carried wastes into a drainage system with which they are connected.

Sec. 6. Trap. - $\Lambda$ trap is a fitting or device so constructed as to prevent the passage of air or gas through a pipe without materially affecting the flow of sewage or waste water through it.

Sec. 7. Trap Seal.- The trap seal is the vertical distance between the crown weir and the dip of the trap.

Sec. 8. Vent PIPE.-A vent pipe is any pipe provided to ventilate a house-drainage system and to prevent trap siphonage and back pressure.

Sec. 9. Local Ventilating Pipe.-A local ventilating pipe is a pipe through which foul air is removed from a room or fixture.

Sec. 10. Soll PIPE.-A soil pipe is any pipe which conveys the discharge of water-closets, with or without the discharges from other fixtures, to the house drain.

Sec. 11. Waste Pipe and Special Waste.-A waste pipe is any pipe which receives the discharge of any fixture, except water- 
closets, and conveys the same to the house drain, soil, or waste stacks. When such pipe does not connect directly with a house drain or soil stack, it is termed a special waste.

SEc. 12. Marn.- The main of any system of horizontal, vertical, or continuous piping is that part of such system which receives the wastes, vent or back vents, from fixture outlets or traps, direct or through branch pipes.

SEc. 13. Branch.-The branch of any system of piping is that part of the system which extends horizontally at a slight grade, with or without lateral or vertical extensions or vertical arms, from the main to receive fixture outlets not directly connected to the main.

SEc. 14. STACk.-Stack is a general term for any vertical line of soil, waste, or vent piping.

Sec. 15. House Drain.-The house drain is that part of the lowest horizontal piping of a house drainage system which receives the discharge from soil, waste, and other drainage pipes inside the walls of any building and conveys the same to the house sewer.

Sec. 16. House Sewer.-The house sewer is that part of the horizontal piping of a house drainage system extending from the house drain to its connection with the main sewer or cesspool and conveying the drainage of but one building site.

Sec. 17. Size and Length.-The given caliber or size of pipe is for a nominal internal diameter, except that other than iron pipe size, brass pipe is measured by its outside diameter. The developed length of a pipe is its length along the center line of pipe and fittings.

Sec. 18. Dead End.-A dead end is a branch leading from a soil, waste, vent, house drain, or house sewer, which is terminated at a developed distance of 2 feet or more by means of a cap, plug, or other fitting not used for admitting water to the pipe. 


\section{ARTICLE II.-GENERAL REGULATIONS}

[These recommendations apply only to dwellings and similar small buildings. The experimental work at the Bureau of Standards developed some additional information on installations for larger buildings, and this has been made available wherever possible throughout the report.]

Sec. 19. Grades of Horizontal Piping.-All horizontal piping shall be run in practical alignment and at a uniform grade of not less than one-eighth of an inch per foot, and shall be supported or anchored at intervals not to exceed 10 feet. All stacks shall be supported at their bases, and all pipes shall be rigidly secured.

Sec. 20. Change is Direction.-All changes in direction shall be made by the appropriate use of $45^{\circ}$ "wyes, half wyes, long sweep quarter bends, sixth, eighth, or sixteenth bends, except that single sanitary tees may be used on vertical stacks, and short quarter bends may be used in soil and waste lines where the change in direction of flow is from the horizontal to the vertical. Tees and crosses may be used in vent pipes.

Sec. 21. Prohibited Fittings.-No double hub, double $T$, or double sanitary $T$ branch shall be used on soil or waste lines. The drilling and tapping of house drains, soil, waste, or vent pipes, and the use of saddle hubs and bands are prohibited.

Sec. 22. Dead Exds.-In the installation of any drainage system dead ends shall be avoided.

Sec. 23. Protection of Materlal.-All pipes passing under or through walls shall be protected from breakage. All pipes passing through or under cinder concrete or other corrosive material shall be protected against external corrosion.

Sec. 24. Wовкмамsimp.-Workmanship shall be of such character as fully to secure the results sought to be obtained in all of the sections of this code.

Sec. 25. Installation of Plumbing by Owner.-All plumbing installed by the owner shall comply with the requirements of this code and in such erent the word "owner" shall be substituted for the word "plumber" throughout this code. 


\section{ARTICLE III. - QUALITY AND WEIGHTS OF MATERIALS}

[These recommendations apply only to dwellings and similar small huildings. The experimental work at the Bureau of Standards developed some additional information on installations for larger buildings, and this has been made available wherever possihle throughout the report]

Sec. 26. Materials, Quality of.-All materials used in any drainage or plumbing system, or part thereof, shall be free from defects.

Sec. 27. Label, Cast or Stamped.-Each length of pipe, fitting, trap, fixture, and device used in a plumbing or drainage system shall be stamped or indelibly marked with the weight or quality thereof and the maker's mark or name.

Sec. 28. Vitrified Clay Pipe.-All vitrified clay pipe shall conform to the A. S. T. M. "Standard Specifications for Clay Sewer "Pipe" (serial designation, C 13-20).

Sec. 29. Cast-Iron PIPe.-(a) Quality.-All cast-iron pipe and fittings shall conform to the A. S. T. M. "Standard Specifications for Cast-Iron Soil Pipe and Fittings" (serial designation, A 74-18). (See note 24, p. 205.)

(b) Coating. - All cast-iron pipe and fittings for underground use shall be coated with asphaltum or coal tar pitch.

Sec. 30. Wrought-Iron Pipe.-All wrought-iron pipe shall conform to the A. S. T. M. "Standard Specifications for Welded WroughtIron Pipe" (serial designation, A 72-21), and shall be galvanized.

Sec. 31. Mild-Steel Pipe.-All steel pipe shall conform to the A. S. T. M. "Standard Specifications for Welded and Seamless Steel Pipe" (serial designation, A 53-21), and shall be galvanized.

Sec. 32. Brass and Copper Pipe.-Brass and copper pipe shall conform, respectively, to the standard specifications of the A. S. T. M. for "Brass Pipe, Standard Sizes," and for " Copper Pipe, Standard Sizes," (serial numbers B 43-23 and B 42-23, respectively).

Sec. 33. Lead Pipe, Dinameter, Weights.-All lead pipe shall be of best quality of drawn pipe, of not less weight per linear foot than shown below.

(a) Lead soil, waste, vent, or flush pipes, including bends and traps (extra light):

\begin{tabular}{|c|c|c|c|c|c|c|c|}
\hline & \multirow[t]{2}{*}{ Internal diameter } & \multicolumn{2}{|c|}{ Weights per foot } & & \multirow[t]{2}{*}{ Internal diameter } & \multicolumn{2}{|c|}{ Weights per foot } \\
\hline & & & Ozs. & Inches & & Lbs. & Ozs. \\
\hline & & $\ldots 2$ & .. & & & 4 & -- \\
\hline & & --2 & 8 & & & 4 & 12 \\
\hline & $\ldots$ & --3 & 8 & $4 \ldots$ & & 6 & - \\
\hline
\end{tabular}

1 A merican Society for Testing Materials. These specifications are given in full in Appendix D, beginning on page 234 of this report. 
(b) Lead water-supply pipe above ground (strong):

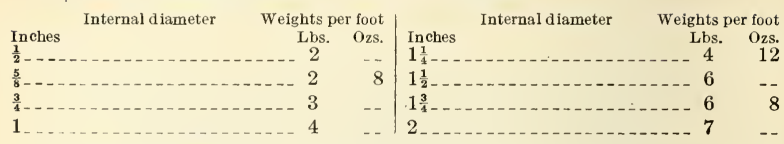

(c) Lead water-supply pipe under ground (extra strong):

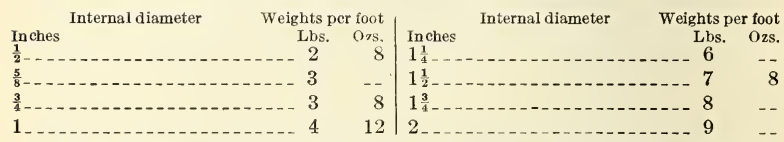

Sec. 34. Sheet Lead.- Sheet lead shall weigh not less than 4 pounds per square foot.

Sec. 35. Sheet Copper or Brass.-Sheet copper or brass shall be not lighter than No. 18 B. and S. gauge, except that for local and interior ventilating pipe it shall be not lighter than No. 26 B. and $\mathrm{S}$. gauge.

Sec. 36. Galvanized Sheet Iron.-Galvanized sheet iron shall be not lighter than the following $\mathrm{B}$. and $\mathrm{S}$. gauge:

No. 26 for 2 to 12 inch pipe.

No. 24 for 13 to 20 inch pipe.

No. 22 for 21 to 26 inch pipe.

Sec. 37. Threaded Fitrings.- (a) Plain screwed fittings shall be of cast iron, malleable iron, or brass of standard weight and dimensions. (b) Drainage fittings shall be of cast iron, malleable iron, or brass, with smooth interior waterway, with threads tapped out of solid metal. (c) All cast-iron fittings used for water-supply distribution shall be galvanized. (d) All malleable iron fittings shall be galvanized.

Sec. 38. Calking Ferrules.-Brass calking ferrules shall be of the best quality red cast brass, with weights and dimensions in accordance with the following table:

\begin{tabular}{|c|c|c|c|c|}
\hline \multirow[t]{2}{*}{ Pipe size (inches) } & $\begin{array}{l}\text { Actual } \\
\text { inside } \\
\text { diameter }\end{array}$ & Length & \multicolumn{2}{|c|}{ Weight } \\
\hline & $\begin{array}{r}\text { Inches } \\
{ }_{2} \frac{1}{4} \\
3 \frac{1}{4} \\
4 \frac{1}{4}\end{array}$ & $\begin{array}{l}\text { Inches } \\
\begin{aligned} 4 \frac{1}{2} \\
4 \frac{1}{2} \\
4 \frac{1}{2}\end{aligned}\end{array}$ & $\begin{array}{r}\text { Lbs. } \\
1 \\
1 \\
2\end{array}$ & $\begin{array}{r}\text { Ozs. } \\
12 \\
8\end{array}$ \\
\hline
\end{tabular}


Sec. 39. Soldering Nipples and Busmings.-- (a) Soldering nipples shall be of brass pipe, iron-pipe size, or of heavy, cast red brass not less than the following weights:

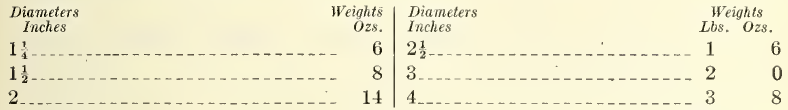

(b) Soldering bushings shall be of brass pipe, iron-pipe size, or of heavy, cast red brass.

Sec. 40. Floor Flanges for Water-Closets.-Floor flanges for water-closets shall be not less than three-sixteenths of an inch thick, and of brass or cast iron. 


\section{ARTICLE IV.-JOINTS AND CONNECTIONS}

IThese recommendations apply only to dwellings and similar small buildings. The experimental work at the Bureau of Standards developed some additional information on installations for larger buildings, and this has been made avaliable wherever possible throughout the report]

Sec. 41. Water and Air Tight Joints.-All joints and connections mentioned under this article shall be made permanently gas and water tight.

Sec. 42. Vitrified Pipe.-All joints in vitrified clay pipes, or between vitrified clay pipe and metals, shall be poured joints.

Sec. 43. Calked Jornts. All calked joints shall be firmly packed with oakum or hemp, and shail be secured only with pure lead, not less than 1 inch deep, well calked, and no paint, varnish, or putty will be permitted until after the joint is tested.

Sec. 44. Screw JoInTs.-All screw joints shall be American standard screw joints, and all burrs or cuttings shall be removed.

Sec. 45. Cast Iron.-Cast-iron joints may be either calked or screw joints made in the approved manner.

Sec. 46. Wrovght Iron; Steel, or Brass to Cast Iron.The joints may be either screwed or calked joints made in the approved manner.

Sec. 47. Lead PIPE.- Joints in lead pipe or between lead pipe and brass or copper pipes, ferrules, soldering nipples, bushings, or traps, in all cases on the sewer side of the trap and in concealed joints on the inlet side of the trap, shall be full-wiped joints, with an exposed surface of the solder to each side of the joint of not less than three-quarters of an inch and a minimum thickness at the thickest part of the joint of not less than three-eighths of an inch.

Sec. 48. Lead to Cast Iron, Steel, or Wrought Iron.-The joints shall be made by means of a calking ferrule, soldering nipple, or bushing.

SEC. 49. SLIP JoINTS AND UnIons.-Slip joints will be permitted only in trap seals or on the inlet side of the trap. Unions on the sewer side of the trap shall be ground faced, and shall not be concealed or inclosed.

SEC. 50. Roof JoIvTs.-The joint at the roof shall be made watertight by use of copper, lead, or iron plates or flashings.

Sec. 51. Closet, Pedestal Urinal and Trap, Standard Slop Sink, Floor Connections.-A brass floor connection shall be wiped or soldered to lead pipe, an iron floor connection shall be calked to cast-iron pipe, or an iron floor connection calked or screwed to 
wrought-iron pipe, and the floor connection bolted to an earthenware trap flange. A metal to earthenware, a metal to metal union, or a lead or asbestos gasket or washer shall be used to make a tight joint.

Sec. 52. Increasers and Reducers. - Where different sizes of pipes or pipes and fittings are to be connected, proper size increasers or reducers, pitched at an angle of $45^{\circ}$ between the two sizes, shall be used.

Sec. 53. Prohibited Joints and Connections. - Any fitting or connection which has an enlargement, chamber, or recess with a ledge shoulder or reduction of the pipe area in the direction of the flow on the outlet or drain side of any trap is prohibited.

Sec. 54. Expansiox Bolts.-Connections of wall hangers, pipe supports, or fixture settings with the masonry, stone, or concrete backing shall be made with expansion bolts without the use of wooden plugs.

Sec. 55. New Materials.-Any other material than that specified in this code, which the proper administrative authority approves as being equally efficient, may be permitted. 


\section{ARTICLE V. - TRAPS AND CLEAN OUTS}

[These recommendations apply only to dwellings and similar small buildings. The experimental work at the Bureau of Standards developed some additional information on installations for larger buildings, and this has been made available wherever possible throughout the report.]

Sec. 56. Traps, Kind.--Every trap shall be self-cleaning. Traps for bathtubs, lavatories, sinks, and other similar fixtures shall be of lead, brass, cast iron, or of malleable iron, galvanized or porcelain enameled inside. Galvanized or porcelain enameled traps shall be extra heavy, and shall have a full bore smooth interior waterway, with threads tapped out of solid metal:

Sec. 57. Traps, Pronibited.-No form of trap which depends for its seal upon the action of movable parts or concealed interior partitions shall be used for fixtures.

Sec. 58. Traps, Where Requtred.-Each fixture shall be separately trapped by a water-seal trap placed as near to the fixture as possible, except that a set of not more than 3 laundry trays or lavatories or a set of 2 laundry trays and 1 sink may connect with a single trap, provided the trap is placed centrally and the branches connect into the trap seal at an angle of not more than $60^{\circ}$ to the vertical arm. In no case shall the waste from a bathtub or other fixture discharge into a water-closet trap. No fixture shall be double trapped.

SEc. 59. Water Seal.-Each fixture trap shall have a water seal of not less than 2 inches and not more than 4 inches.

Sec. 60. Trap Clean Outs,--Each trap, except those in combination with fixtures in which the trap seal is plainly visible and accessible, shall be provided with an accessible brass trap screw of ample size, protected by the water seal.

Sec. 61. Trap Levels and Protection.-All traps shall be set true with respect to their water seals and protected from frost and evaporation.

Sec. 62. Pipe Clean Outs.-The bodies of clean-out ferrules shall be made of standard pipe sizes, conform in thickness to that required for pipe and fittings of the same metal, and extend not less than onequarter inch above the hub. The clean-out cap or plug shall be of heavy red brass not less than one-eighth inch thick and be provided with raised nut or recessed socket for removal.

Sec. 63. Pipe Clean Outs-Where Required.-A clean out easily accessible shall be provided at the foot of each vertical waste or soil stack. There shall be at least two clean outs in the house drain-one at or near the base of the stack and the other, with full-size $Y$ branch, 
inside the wall near the connection between the house drain and house sewer. Except for the latter, clean outs shall be of the same nominal size as the pipes up to 4 inches and not less than 4 inches for larger pipes. The distance between clean outs in horizontal soil lines shall not exceed 50 feet.

Sec. 64. Manholes.-All underground traps and clean outs of a building, except where clean outs are flush with the floor, and all exterior underground traps shall be made accessible by manholes with proper covers.

Sec. 65. Clean Outs-Equivalents.-Any floor or wall connection of fixture traps when bolted or screwed to the floor or wall shall be regarded as a clean out.

Sec. 66. Grease Traps.-When a grease trap is installed, it shall be placed as near as possible to the fixture from which it receives the discharge and should have twice the capacity of the discharge.

SEc. 67. SAnd Traps. - Sand traps when installed should be so designed and placed as to be readily accessible for cleaning.

Sec. 68. Basement Floor Drains.-Cellar or basement floor drains shall connect into a trap so constructed that it can be readily cleaned and of a size to serve efficiently the purpose for which it is intended. The drain inlet shall be so located that it is at all times in full view. When subject to back flow or back pressure, such drains shall be equipped with an adequate back-water valve.

Sec. 69. ВACK-WAter VAlves.-Back-water valves shall have all bearing parts or balls of noncorrodible metal and so constructed as to insure a positive mechanical seal and remain closed except when discharging wastes. 


\section{ARTICLE VI.-WATER SUPPLY AND DISTRIBUTION}

[These recommendations apply only to dwellings and similar small buildings. The experimental work at the Bureau of Standards developed some additional information on installations for larger buildings, and this has been made available wherever possible throughout the report]

Sec. 70. Quality of Water.-The quality of the water supply shall meet accepted standards of purity

Sec. 71. Distribution.-The water supply shall be distributed through a piping system entirely independent of any piping system conveying another water supply.

Sec. 72. Water Service.- The water-service pipe of any building shall be of sufficient size to permit a continuous ample flow of water on all floors at a given time.

Sec. 73. Water Supply to Fixtures.-All plumbing fixtures shall be provided with a sufficient supply of water for flushing to keep them in a sanitary condition. Every water-closet or pedestal urinal shall be flushed by means of an approved tank or flush valve of at least 4 gallons flushing capacity for water-closets and at least 2 gallons for urinals, and shall be adjusted to prevent the waste of water. The flush pipe for water-closet flush tanks shall be not less than $1 \frac{1}{4}$ inches in diameter, and the water from flush tanks shall be used for no other purpose.

No water-closet or urinal bowl shall be supplied directly from a water-supply system through a flushometer or other valve unless such valve is set above the water-closet or urinal in a manner such as to prevent any possibility of polluting the water supply.

Sec. 74. Size of Water-Supply Pipes.-The minimum size of water-service pipes from the curb to the dwelling shall be one-half inch, and to fixtures as follows:

\begin{tabular}{|c|c|}
\hline Inc & \\
\hline & Lavatories_- \\
\hline$-\frac{1}{2}_{2}$ & Bathtubs _... \\
\hline $\begin{array}{l}\text { undry trays........ } \\
\text { aks }\end{array}$ & Water-closet tanks \\
\hline
\end{tabular}

Sec. 75. Water-Supply Control.-A main shut-off on the watersupply line shall be provided near the curb. Accessible shut-offs shall be provided on the main supply line just inside the foundation wall for each flat or apartment of a building, for each lawn sprinkler, for supply to each hot water tank, and for each water-closet.

Sec. 76. Water-Supply Pipes and Fittings-Material.-All water-supply pipes for a plumbing system shall be of lead, galva- 
nized wrought-iron, or steel, brass, or cast iron, with brass or galvanized cast iron or galvanized malleable iron fittings. No pipe or fittings that have been used for other purposes shall be used for distributing water.

Sec. 77. Water Supply, Protection.-All concealed water pipes, storage tanks, flushing cisterns, and all exposed pipes or tanks subject to freezing temperatures shall be efficiently protected against freezing.

Sec. 78. Relief Valves.-Wherever a check valve is installed on the cold-water supply pipe between the street main and the hotwater tank there shall be installed on the hot-water distributing system a suitable relief valve.

SEc. 79. Pumps And Hydrants.-All pumps and hydrants shall be protected from surface water and contamination. 


\section{ARTICLE VII.--PLUMBING FIXTURES}

[These recommendations apply only to dwellings and similar small buildings. The experimental work at the Bureau of Standards developed some additional information on installations for larger buildings, and this has been made available wherever possible throughout the report]

Sec. 80. Materials.-All receptacles used as water-closets, urinals, or otherwise for the disposal of human excreta, shall be vitrified earthenware, hard natural stone, or cast iron, white enameled on the inside.

SEc. 81. How Installed.-All plumbing fixtures shall be installed free and open in a manner to aftord access for cleaning. Where practical all pipes from fixtures shall be run to the wall, and no lead trap or pipe shall extend nearer to the floor than 12 inches unless protected by casing.

Sec. 82. Water-Closet Bowls.-Water-closet bowls and traps shall be made in one piece and of such form as to hold sufficient quantity of water, when filled to the trap overflow, to prevent fouling of surfaces, and shall be provided with integral flushing rims constructed so as to flush the entire interior of the bowl.

Sec. 83. Frost-Proof Closets-Where Permitted.-Frostproof closets may be installed only in compartments which have no direct connection with a building used for human habitation or occupancy. The soil pipe between the hopper and the trap shall be 3 inches in diameter and shall be of lead, or cast iron enameled on the inside.

Sec. 84. Fixtures Prohibited.-Fixed wooden wash trays or sinks shall not be installed in any building designed or used for human habitation. No new copper lined wooden bathtubs shall be installed, and an old fixture of this class taken out shall not be reconnected. Pan and valve plunger, offset washout and other water-closets having invisible seals or unventilated space, or walls not thoroughly washed at each flush shall not be used. Long hopper closets or similar appliances shall not hereafter be installed. No dry closet or chemical closet shall be installed in a dwelling.

Sec. 85. Floor Drains and Shower Drains.-A floor drain or a shower drain shall be considered a fixture and provided with a strainer.

Sec. 86. Fixture Strainers.-All fixtures other than waterclosets and pedestal urinals shall be provided with fixed strong metallic strainers with outlet areas not less than that of the interior of the trap and waste pipe.

Sec. 87. Fixture Overflow.-The overflow pipe from a fixture shall be connected on the house or inlet side of the trap and be so arranged that it may be readily and effectively cleaned. 


\section{ARTICLE VIII.-VENTILATION OF ROOMS AND FIXTURES}

[These recommendations apply only to dwellings and similar small buildings. The experimental work at the Bureau of Standards developed some additional information on installations for larger buildings, and this has been made available wherever possible throughout the report.]

Sec. 88. Location of Fixtures.- No trapped plumbing fixtures shall be located in any room or apartment which does not contain a window placed in an external wall or is not otherwise provided with proper ventilation.

Sec. 89. Ventilating Pipe, How Connected.-Ventilation pipes from fixtures and toilet rooms shall be separate and distinct and have no connection whatever with the other ventilating ducts or pipes in the building. 


\section{ARTICLE IX.-SOIL, WASTE, AND VENT PIPES}

[These recommendations apply only to dwellings and similar small buildings. The experimental work at the Bureau of Standards developed some additional information on installations for larger buildings, and this has been made available wherever possible throughout the report.]

Sec. 90. Material. - All main or branch soil, waste, and vent pipes within the building shall be of cast iron, galvanized steel or wrought iron, lead, brass, or copper, except that no galvanized steel or wrought iron pipe shall be used for underground soil or waste pipes.

Sec. 91. Fixture Unit.-The following table based on the rate of discharge from a lavatory as the unit shall be employed to determine fixture equivalents:

units,

One lavatory or wash basin . . .

One kitchen sink

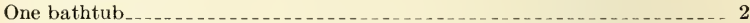

One laundry tray

One combination fixture

One urinal _....................... 3

One shower bath _...

One floor drain _...

One slop sink _. _...

One water-closet _....... 6

One hundred and eighty square feet of roof or drained area in horizontal projection shall count as one fixture unit.

Sec. 92. SoIL AND Waste Stacks.-Every building in which plumbing fixtures are installed shall have a soil or waste stack, or stacks, extending full size through the roof. Soil and waste stacks shall be as direct as possible and free from sharp angles and turns. The required size of a soil or waste stack shall be independently determined by the total fixture units of all fixtures connected to the stack in accordance with the following tables:

Waste stacks

\begin{tabular}{|c|c|c|}
\hline Number fixture units & $\begin{array}{l}\text { Diameter } \\
\text { of stack }\end{array}$ & $\begin{array}{l}\text { Permitted } \\
\text { length }\end{array}$ \\
\hline $\begin{array}{l}1 \\
9 \text { to } 8 \\
19 \text { to } 36\end{array}$ & $\begin{array}{r}\text { Inches } \\
1 \frac{1}{4} \\
1 \frac{1}{2} \\
2 \\
2 \frac{1}{2}\end{array}$ & Feet $\begin{array}{r}45 \\
60 \\
75 \\
105\end{array}$ \\
\hline
\end{tabular}


Soil and waste stacks

\begin{tabular}{|c|c|c|c|}
\hline Number fixture units & $\begin{array}{l}\text { Number of } \\
\text { water- } \\
\text { closets or } \\
\text { equivalent }\end{array}$ & $\begin{array}{l}\text { Diameter } \\
\text { of stack }\end{array}$ & $\begin{array}{l}\text { Maximum } \\
\text { permitted } \\
\text { length }\end{array}$ \\
\hline $\begin{array}{l}37 \text { to } 72 \\
301 \text { to } 720 \\
721 \text { to } 1,080 \\
1,081 \text { to } 1,920\end{array}$ & $\begin{array}{l}1 \text { to } 12 \\
13 \text { to } 50 \\
51 \text { to } 120 \\
121 \text { to } 180 \\
181 \text { to } 320\end{array}$ & $\begin{array}{r}\text { Inches } \\
3 \\
4 \\
5 \\
6 \\
8\end{array}$ & $\begin{array}{ll}\text { Feet } & \\
& 150 \\
225 \\
300 \\
400 \\
600\end{array}$ \\
\hline
\end{tabular}

Restrictions.-No water-closet shall discharge into a stack less than 3 inches in diameter. Not more than three water-closets or their equivalent in fixture units shall discharge into a 3 -inch stack from one 3-inch branch, and not more than two such branches may connect to a 3-inch stack at the same point or level.

Sec. 93 Soll and Waste Stacks, Fixture Connections.-All soil and waste stacks and branches shall be provided with correctly faced inlets for fixture connections.

Sec. 94. Changing Soll and Vent Pipes.-In existing buildings where the soil or waste vent pipe is not extended undiminished through or above the roof, or where there is a sheet metal soil or waste vent pipe, and the fixture is changed in style or location or is replaced, a soil or waste vent pipe of the size and material prescribed for new work shall be installed.

Sec. 95. Prohibited Connections.-No fixture connection shall be made to a lead bend or branch of a water closet or similar fixture. No soil or waste vent, circuit or loop vent above the highest installed fixture on the branch or main shall thereafter be used as a soil or waste pipe.

Sec. 96. Soll and Waste Pipe Protected.-No soil or waste stack shall be installed or permitted outside a building unless adequate provision is made to protect it from frost.

Sec. 97. Roof Extexsions.-All roof extensions of soil and waste stacks shall be run full size at least 1 foot above the roof, and when the roof is used for other purposes than weather protection such extension shall not be less than 5 feet above the roof.

When there is danger of frost closure, no roof extension shall be less than 4 inches in diameter. Change in diameter shall be made by use of a long increaser at least 1 foot below the roof, and where access to the roof is difficult a test opening shall be provided at this point.

Sec. 98. Terminals.-The roof terminal of any stack or vent, if within 12 feet of any door, window, scuttle, or air shaft, shall extend at least 3 feet above the same.

Sec. 99. Terminals Adjoining High Bulldings.-No soil, waste or vent pipe extension of any new or existing building shall be run or $94877^{\circ}-24-4$ 
placed on the outside of a wall, but shall be carried up in the inside of the roof.

In the event that a new building is built higher than an existing building, the owner of the new building shall not locate windows within 12 feet of any existing vent stack on the lower building unless the owncr of such new building shall defray the expenses or shall himself make such alteration to conform with section 98 of this article.

It shall be the duty of the owner of the lower or existing building to make such alteration therein upon the receipt in advance of money or security therefor, sufficient for the purpose, from the owner of the new or higher building or to permit, at the election of the owner of the new or higher building, the making of such alteration by the owner of said new or higher building.

Sec. 100. Traps Protected, Vents.-Every fixture trap shall be protected against siphonagc and back pressure, and air circulation assured by means of a soil or waste stack vent, a continuous waste or soil vent, or a loop or circuit vent. No crown vent shall be installed.

Sec. 101. Distance of Vent from Trap Seal.-No trap shall be placed more than 5 feet, horizontal developed length, from its vent. The distance shall be measured along the central line of the waste or soil pipe from the vertical inlet of the trap to the vent opening. The vent opening from the soil or waste pipe, except for water-closets and similar fixtures, shall not be below the dip of the trap.

Sec. 102. Main Vents to Connect at base.-All main vents or vent stacks shall connect full size at their base to the main soil or waste pipe at or below the lowest fixture branch and shall extend undiminished in size above the roof or shall be reconnected with the main soil or waste vent at least 3 feet above the highest fixture branch.

Sec. 103. Vents, Required Sizes.- The required size of main vents or vent stacks shall be determined on the basis of the size of the soil or waste stack, the number of fixtures or fixture units connected to the soil or waste stack, and the developed length of the main vent or vent stack in accordance with the following tables:

Waste stack

\begin{tabular}{|c|c|c|c|}
\hline \multirow[b]{2}{*}{ Diameter of stack (inches) } & \multirow{2}{*}{$\begin{array}{c}\text { Fixture } \\
\text { units on } \\
\text { stack }\end{array}$} & \multicolumn{2}{|c|}{ Dimensions of vent } \\
\hline & & Diameter & $\begin{array}{c}\text { Maximum } \\
\text { length. }\end{array}$ \\
\hline $\begin{array}{l}1 \\
1 \\
11 \\
1 \\
12 \\
2 \\
2 \\
2\end{array}$ & $\begin{array}{l}1 \\
2-8 \\
2-8 \\
9-18 \\
9-18\end{array}$ & $\begin{aligned} & \text { Inches } \\
& 11 \\
& 1 \frac{1}{4} \\
& 1 \frac{1}{2} \\
& 1 \frac{1}{4} \\
& 1 \frac{1}{2}\end{aligned}$ & Feet $\begin{array}{l} \\
4.5 \\
35 \\
50 \\
30 \\
60\end{array}$ \\
\hline 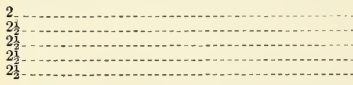 & $\begin{array}{r}9-18 \\
19-36 \\
19-36 \\
19-36 \\
19-36\end{array}$ & $\begin{array}{l}2 \\
1 \frac{1}{2} \\
1 \frac{1}{2} \\
2 \\
2 \frac{1}{2}\end{array}$ & $\begin{array}{r}75 \\
25 \\
45 \\
60 \\
105\end{array}$ \\
\hline
\end{tabular}


Soil or waste stack

\begin{tabular}{|c|c|c|c|c|}
\hline \multirow{2}{*}{ Diameter of stack (inches) } & \multirow{2}{*}{$\begin{array}{c}\text { Fixture units } \\
\text { on stack }\end{array}$} & \multirow{2}{*}{$\begin{array}{l}\text { Water- } \\
\text { closets } \\
\text { only }\end{array}$} & \multicolumn{2}{|c|}{ Dimensions of vent } \\
\hline & & & Diameter & $\underset{\text { length }}{\text { Maximum }}$ \\
\hline 3 & $\begin{array}{cc}6- & 18 \\
6- & 18 \\
19- & 42 \\
19- & 42 \\
43- & 72\end{array}$ & $\begin{array}{l}1-3 \\
1-\quad 3 \\
4-7 \\
4-7 \\
8-12\end{array}$ & $\begin{array}{c}\text { Inches } \\
1 \frac{1}{2} \\
2 \\
2 \\
23 \\
2\end{array}$ & $\begin{array}{rr}\text { Feet } \\
20 \\
60 \\
45 \\
1150 \\
30\end{array}$ \\
\hline $\begin{array}{l}3 \\
3 \\
4 \\
4 \\
4\end{array}$ & $\begin{array}{ll}43- & 72 \\
43- & 72 \\
24- & 42 \\
24- & 42 \\
24- & 42\end{array}$ & $\begin{array}{l}8-12 \\
8-12 \\
4-7 \\
4-7 \\
4-7\end{array}$ & $\begin{array}{l}2 \frac{1}{2} \\
3 \\
2 \\
2 \frac{1}{2} \\
3\end{array}$ & $\begin{array}{r}90 \\
150 \\
20 \\
45 \\
100\end{array}$ \\
\hline $\begin{array}{l}4 \\
4 \\
4 \\
4\end{array}$ & $\begin{array}{lr}43- & 72 \\
43- & 72 \\
43- & 72 \\
43- & 72 \\
73- & 150\end{array}$ & $\begin{array}{r}8-12 \\
8-12 \\
8-12 \\
8-12 \\
13-25\end{array}$ & $\begin{array}{l}2 \frac{1}{2} \\
3 \\
3 \frac{1}{2} \\
4 \\
3\end{array}$ & $\begin{array}{r}30 \\
75 \\
150 \\
300 \\
60\end{array}$ \\
\hline $\begin{array}{l}4 \\
4 \\
4 \\
4 \\
4\end{array}$ & $\begin{array}{rr}73- & 150 \\
73- & 150 \\
151- & 300 \\
151- & 300 \\
151- & 300\end{array}$ & $\begin{array}{l}13-25 \\
13-25 \\
26-50 \\
26-50 \\
26-50\end{array}$ & $\begin{array}{l}3 \frac{1}{2} \\
4 \\
3 \\
3 \frac{1}{2} \\
4\end{array}$ & $\begin{array}{r}120 \\
225 \\
20 \\
50 \\
100\end{array}$ \\
\hline $\begin{array}{l}4 \\
5 \\
5 \\
5 \\
5\end{array}$ & $\begin{array}{ll}151- & 300 \\
301- & 480 \\
301- & 480 \\
301- & 480 \\
301- & 480\end{array}$ & $\begin{array}{l}26-50 \\
51-80 \\
51-80 \\
51-80 \\
51-80\end{array}$ & $\begin{array}{l}5 \\
2 \frac{1}{2} \\
3 \\
3 \frac{1}{2} \\
4\end{array}$ & $\begin{array}{r}1225 \\
20 \\
50 \\
100 \\
175\end{array}$ \\
\hline $\begin{array}{l}5 \\
5 \\
5 \\
5 \\
5\end{array}$ & $\begin{array}{l}301-\quad 480 \\
481-720 \\
481-720 \\
481-720 \\
481-720\end{array}$ & $\begin{array}{l}51-80 \\
81-120 \\
81-120 \\
81-120 \\
81-120\end{array}$ & $\begin{array}{l}5 \\
3 \frac{1}{2} \\
4 \\
5 \\
6\end{array}$ & $\begin{array}{r}1300 \\
25 \\
50 \\
125 \\
1 \quad 300\end{array}$ \\
\hline $\begin{array}{l}6 \\
6 \\
6 \\
6 \\
6 \\
6\end{array}$ & $\begin{array}{ll}721- & 840 \\
721- & 840 \\
721- & 840 \\
721- & 840 \\
721- & 840\end{array}$ & $\begin{array}{l}121-140 \\
121-140 \\
121-140 \\
121-140 \\
121-140\end{array}$ & $\begin{array}{l}3 \\
3 \frac{1}{2} \\
4 \\
5 \\
6\end{array}$ & $\begin{array}{r}20 \\
40 \\
75 \\
225 \\
1400\end{array}$ \\
\hline 6 & $\begin{array}{l}841-1,080 \\
841-1,080 \\
841-1,080 \\
841-1,080\end{array}$ & $\begin{array}{l}141-180 \\
141-180 \\
141-180 \\
141-180\end{array}$ & $\begin{array}{l}4 \\
5 \\
6 \\
8\end{array}$ & $\begin{array}{r}50 \\
125 \\
300 \\
+400\end{array}$ \\
\hline $\begin{array}{l}8 \\
8 \\
8 \\
8 \\
8\end{array}$ & $\begin{array}{l}1,081-1,920 \\
1,081-1,920 \\
1,081-1,920 \\
1,081-1,920\end{array}$ & $\begin{array}{l}181-320 \\
181-320 \\
181-320 \\
181-320\end{array}$ & $\begin{array}{l}4 \\
5 \\
6 \\
8\end{array}$ & $\begin{array}{r}20 \\
60 \\
150 \\
1600\end{array}$ \\
\hline
\end{tabular}

${ }^{1}$ Limit in height of soil stack but not in length of vent if greater is required.

NoTE.-The capacities and vent stack requirements for 4, 5, 6, and 8 inch soil stacks are extrapolated from data obtained for 2 and 3 inch stacks with liberal added factors of safety to provide for all necessary elbows or changes in direction in the vent stack. They are believed to represent safe installations and closer approximations to actual requirements than any tables now available.

Sec. 104. Branch and Individual Vents.--No vents shall be less than $1 \frac{1}{4}$ inches in diameter. For $1 \frac{1}{4}$ and $1 \frac{1}{2}$ inch wastes the vent shall be of the same diameter as the waste pipe, and in no case shall a branch or main vent have a diameter less than one-half that of the soil or waste pipe served, and in no case shall the length of a branch vent of given diameter exceed the maximum length permitted for the main vent serving the same size soil or vent stack.

Sec. 105. Vent-Pipe Grades and Connections.-All vent and branch vent pipes shall be free from drops or sags and be so graded 
and connected as to drip back to the soil or waste pipe by gravity. Where vent pipes connect to a horizontal soil or waste pipe the vent branch shall be taken off above the center line of the pipe, and the vent pipe must rise vertically or at an angle of $45^{\circ}$ to the vertical to a point 6 inches above the fixture it is venting before offsetting horizontally or connecting to the branch, main waste, or soil vent.

Sec. 106. Circuit and Loop Vents.--A circuit or loop vent will be permitted as follows: A branch soil or waste pipe to which two and not more than cight water-closets, pedestal urinals, trap standard slop sinks, or shower stalls are connected in the series may be vented by a circuit or loop vent, which shall be taken off in front of the last fixture connection. Where fixtures discharge above such branch, each branch shall be provided with a relief vent one-half the diameter of the soil or waste stack, taken off in front of the first fixture connection.

Sec: 107. Vents not Required.--No vents will be required on a down spout or rain leader, trap, a back-water trap, a subsoil catch basin trap, or on a cellar floor drain, provided the cellar floor drain branches into the house drain on the sewer side at a distance of 5 feet or more from the base of the stack.

Where bathrooms or water-closets or other fixtures are located on opposite sides of a wall or partition or directly adjacent to each other within the prescribed distance, such fixtures may have a common soil or waste pipe and common vent. 


\section{ARTICLE X.-HOUSE DRAINS AND SEWERS}

[These recommendations apply only to dwellings and similar small buildings. The experimental work at the Bureau of Standards developed some additional information on installations for larger buildings, and this has been made available wherever possible throughout the report.]

Sec. 108. Independent System.-The drainage and plumbing system of each new building and of new work installed in an existing building shall be separate from and independent of that of any other building, except as provided below, and every building shall have an independent connection with a public or private sewer when available.

Exception.-Where one building stands in the rear of another building on an interior lot and no private sewer is available or can be constructed to the rear building through adjoining alley, court, yard, or driveway, the house drain from the front building may be extended to the rear building and the whole will be considered as one house drain.

Sec. 109. Old House Sewers and Drains.-Old house sewers and drains may be used in connection with new buildings or new plumbing only when they are found, on examination and test, to conform in all respects to the requirements governing new sewers or drains, as prescribed in this code. If the old work is found defective, the proper administrative authority shall notify the owner to make the necessary changes to conform with this code.

Sec. 110. Connections with Cesspools.-When a sewer is not available, drain pipes from buildings shall be connected with approved private sewage disposal works.

Sec. 111. Excavations.--Each system of piping shall be laid in a separate trench, provided that drainage trenches may be benched not less than 18 inches for lighter piping, if not in violation of any city regulation preseribed for their installation. Where a double system of drainage is installed, the sanitary and surface house sewers or drains may be laid side by side in one trench.

Tunneling for distances not greater than 6 feet is permissible in yards, courts, or driveways of any building site. When pipes are driven, the drive pipe shall be at least one size larger than pipe to be laid.

All excavations required to be made for the installation of a housedrainage system, or any part there of within the walls of a building, shall be open trench work. All such trenches and tunnels shall be kept open until the piping has been inspected, tested, and approved.

Sec. 112. House Drains Underground.- Whenever possible all house drains shall be brought into the building below the basement or cellar floor. 
Sec. 113. Material. - (a) The house sewer beginning 5 feet outside the building shall be of cast iron or of vitrified clay pipe; (b) the house drain when underground shall be of lead, brass, or cast iron; (c) the house drain when above ground shall be of cast iron, galvanized wrought iron or steel, lead or brass, approved standards. (See Art. III, secs. 26 to 33 , inclusive.)

Sec. 114. Depth of Drains and Sewers.-No house sewer or underground house drain shall be laid parallel to or within 3 feet of any bearing wall, which might be thereby weakened. The house sewer and drains shall be laid at sufficient depth to protect them from frost.

Sec. 115. Size of Drains and Sewers. - The required size of sanitary house drains and sanitary house sewers shall be determined on the basis of the total number of fixture units drained by them in accordance with the following table:

Sanitary system only

\begin{tabular}{|c|c|c|c|c|}
\hline \multirow{2}{*}{ Fixture units } & \multicolumn{3}{|c|}{ Slope } & \multirow{2}{*}{$\begin{array}{l}\text { Number } \\
\text { water- } \\
\text { elosets or } \\
\text { equiva- } \\
\text { lent }\end{array}$} \\
\hline & $\begin{array}{l}\frac{1}{8} \text { inch } \\
\text { to } 1 \text { foot }\end{array}$ & $\begin{array}{l}\frac{1}{4} \text { inch } \\
\text { to } 1 \text { foot }\end{array}$ & $\begin{array}{l}\frac{1}{2} \text { inch } \\
\text { to } 1 \text { foot }\end{array}$ & \\
\hline $\begin{array}{l}6 \text { to } 12 \\
13 \text { to } 24 \\
25 \text { to } 72 \\
73 \text { to } 300 \\
721 \text { to } 720 \\
1,081 \text { to } 1,920 \text {. }\end{array}$ & $\begin{array}{r}4 \\
4 \\
6 \\
8 \\
8 \\
10 \\
12\end{array}$ & $\begin{array}{r}3 \\
4 \\
5 \\
6 \\
8 \\
10 \\
12\end{array}$ & $\begin{array}{r}3 \\
4 \\
5 \\
6 \\
8 \\
10\end{array}$ & $\begin{array}{c}1-2 \\
3-4 \\
5-12 \\
13-50 \\
51-120 \\
121-180 \\
181-320\end{array}$ \\
\hline
\end{tabular}

The required sizes of storm-water house drains and house sewers and other lateral storm drains shall be determined on the basis of the total drained area in horizontal projection in accordance with the following table:

Size of house drain and sewer for storm water only

\begin{tabular}{|c|c|c|c|}
\hline \multirow{2}{*}{ Number of square feet drained area } & \multicolumn{3}{|c|}{ Slope } \\
\hline & $\begin{array}{l}\frac{1}{8} \text { inch to } \\
1 \text { foot }\end{array}$ & $\begin{array}{l}\frac{1}{4} \text { inch to } \\
1 \text { foot }\end{array}$ & $\begin{array}{l}\frac{1}{2} \text { ineh to } \\
1 \text { foot }\end{array}$ \\
\hline $\begin{array}{l}\text { Up to } 90 \\
91 \text { to } 400 \\
401 \text { to } 660 \\
661 \text { to } 1,200 \\
1,201 \text { to } 1,800\end{array}$ & $\begin{array}{l}1 \frac{1}{2} \\
3 \\
3 \\
4 \\
4\end{array}$ & $\begin{array}{l}1 \frac{1}{2} \\
2 \\
3 \\
3 \\
4\end{array}$ & $\begin{array}{l}1 \frac{1}{2} \\
2 \\
2 \\
3 \\
3\end{array}$ \\
\hline $\begin{array}{l}1,801 \text { to } 2,500 \\
2,501 \text { to } 4,100 \\
4,101 \text { to } 4,600 \\
4,601 \text { to } 5,300\end{array}$ & $\begin{array}{l}5 \\
5 \\
6 \\
6\end{array}$ & $\begin{array}{l}4 \\
5 \\
5 \\
6\end{array}$ & $\begin{array}{l}4 \\
4 \\
5 \\
5\end{array}$ \\
\hline $\begin{array}{l}5,301 \text { to } 7,500 \ldots \\
7,501 \text { to } 11,100 \\
11,101 \text { to } 15,700 \ldots \\
15,701 \text { to } 19,500 \ldots\end{array}$ & $\begin{array}{r}8 \\
8 \\
10 \\
10\end{array}$ & $\begin{array}{r}6 \\
8 \\
8 \\
10\end{array}$ & $\begin{array}{l}6 \\
6 \\
8 \\
8\end{array}$ \\
\hline $\begin{array}{l}19,501 \text { to } 24,800 \ldots \\
24,801 \text { to } 31,000 \ldots \\
31,001 \text { to } 44,000 \ldots \\
44,001 \text { to } 60,000 \ldots\end{array}$ & $\begin{array}{l}12 \\
12 \\
14 \\
14\end{array}$ & $\begin{array}{l}10 \\
12 \\
12 \\
14\end{array}$ & $\begin{array}{r}8 \\
10 \\
10 \\
12\end{array}$ \\
\hline
\end{tabular}


Sec. 116. Combined Storm and Sanitary Sewer Systems.Whenever a combined sewer system is employed, the required size of the house sewer shall be determined by adding to the drained area in square feet 180 square feet for each "fixture unit" on the sanitary system (see table, sec. 91) and then applying the total to the preceding table for storm sewers, except that no combined sanitary and storm sewer shall be less than 4 inches in diameter. The required sizes of the sanitary house drain and the storm house drain up to their point of junction may be independently determined from the table.

Sec. 117. House Sewer in Made Ground.-The house sewer when laid in made or filled-in ground shall be of vitrified clay pipe, laid on bed of approved grillage or concrete, or of cast iron pipe, A. S. T. M. approved standards.

Sec. 118. Drainage Below Sewer Level.-In all buildings in which the whole or part of the house drainage and plumbing system thereof lies below the crown level of the main sewer, sewage or house wastes shall be lifted by approved artificial means and discharged into the house sewer.

Sec. 119. Sumps and Receiving Tanks.-All subhouse drains shall discharge into an air-tight sump or receiving tank so located as to receive the sewage by gravity, from which sump or receiving tank the sewage shall be lifted and discharged into the house sewer by pumps, ejectors, or any equally efficient method. Such sumps shall be either automatically discharged or be of sufficient capacity to receive the house sewage and wastes for not less than 24 hours.

Sec. 120. E.jectors, Vented.-The soil or vent pipe leading to an ejector or other appliance for raising sewage or other waste matter to the street sewer shall, where a water-closet or closets are installed, be provided with a vent pipe not less than 4 inches in diameter, and where fixtures other than water-closets are installed the waste vent pipe shall be the same diameter as the waste pipe.

Sec. 121. Motors, Compressors, Etc.-All motors, air compressors, and air tanks shall be located where they are open for inspection and repair at all times. The air tanks shall be so proportioned as to be of equal cubical capacity to the ejectors connected therewith, in which there shall be maintained an air pressure of not less than 2 pounds for each foot of height the sewage is to be raised.

Sec. 122. Ejectors for Subsoil Drainage.- When subsoil catch basins are installed below the sewer level, automatic water ejectors provided with a ball float attached to the main water supply shall be used. Such ejectors or any device raising subsoil water shall discharge into a properly trapped fixture or into a storm-water drain. 


\section{ARTICLE XI.-STORM-WATER DRAINS}

[These recommendations apply only to dwellings and similar small buildings. The experimental work at the Bureau of Standards developed some additional information on installations for larger huildings, and this has heen made availahle wherever possihle throughout the report]

Sec. 123. Drainage of Yards, Areas, and Roofs.-All roofs and paved areas, yards, courts, and courtyards shall be drained into the storm-water sewerage system or the combined sewerage systems, but not into sewers intended for sewage only. When drains used for this purpose are connected with the combined sewerage systems, they shall be effectually trapped, except roof leaders and conductors, where the roof or gutter opening is located not less than 12 feet from a door, window scuttle, or air shaft. One trap may serve for all such connections, but traps must be set below the frost line or on the inside of the building. Where there is no sewer accessible, such connections shall be discharged into the public gutter, unless otherwise permitted by the proper authorities, and in such case need not be trapped.

Sec. 124. Size of Gutters and Leaders.-No gatter or inside leader shall be of less size than the following:

\begin{tabular}{|c|c|c|}
\hline Area of roof (in square feet) & Gutter & Leader \\
\hline $\begin{array}{l}\text { Up to } 90 \\
91 \text { to } 270 \\
271 \text { to } 810 \\
811 \text { to } 1,800001 \text { to } 3,600 \\
1,801\end{array}$ & $\begin{array}{r}\text { Inches } \\
3 \\
4 \\
4 \\
5 \\
6 \\
8 \\
10\end{array}$ & 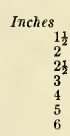 \\
\hline
\end{tabular}

Outside leaders to the frost line shall be one size larger than required in the above table.

Gutters 8 inches or over in width on new buildings shall be hung with wrought-iron hangers of approved type.

The above sizes of rain leaders are based on diameter of circular rain leaders, and gutters based on semicircular sheet-metal gutters with the top dimension given and other shapes shall have the same sectional area.

Sec. 125. Inside Conductors.-When placed within the walls of any building or run in an inner or interior court or ventilating pipe shaft, all conductors or roof leaders shall be constructed of cast iron or of galvanized wrought iron or steel pipe.

Sec. 126. Outside Conductors.-When outside conductors or down spouts of sheet metal are connected with the house drain, they 
shall be so connected by means of not less than one length of castiron pipe extending vertically at least 1 foot above the grade line.

Along public driveways without sidewalks they shall be placed in niches in the walls, protected by wheel guards, or enter the building through the wall at a $45^{\circ}$ slope at least 12 feet above the grade.

Sec. 127. Defective Conductor Pipes.-When an existing sheet-metal conductor pipe within the walls of any building becomes defective, such conductor shall be replaced by one which conforms to this code.

Sec. 128. Vent Connections with Conductors Prombited.Conductor pipes shall not be used as soil, waste, or vent pipes, nor shall any soil, waste, or vent pipes be used as conductors.

Sec. 129. Overflows. - Overflow pipes from eisterns, supply tanks, expansion tanks, and drip pans shall connect only indirectly with any house sewer, house drain, soil, waste, or vent pipe.

Sec. 130. Subsoll, Foundation, Clear Water, and Absorption Tile Drains.- Where subsoil drains are placed under the cellar floor or used to encircle the outer walls of a building, the same shall be made of open-jointed drain tile or earthenware pipe, not less than 4 inches in diameter, and shall be properly trapped and protected against back pressure by an automatic back-pressure valve accessibly. located before entering the house sewer or drain. They may discharge through a cellar drain.

Sec. 131. Subsoil Drains Below Sewer Level.-Subsoil drains below the main sewer level shall discharge into a sump or receiving tank, the contents of which shall be automatically lifted and discharged into the drainage system above the cellar through some properly trapped fixture or drain. 


\section{ARTICLE XII.-REFRIGERATOR, SAFE, AND SPECIAL WASTES}

[These recommendations apply only to dwellings and similar small buildings. The experimental work at the Bureau of Standards developed some additional information on installations for larger buildings, and this has been made available wherever possible throughout the report]

Sec. 132. Fixtures Permitted to Connect.-No waste pipe from a refrigerator or ice box floor drain, or any other receptacle where food is stored shall connect directly with any house drain, soil, or waste pipe. Such waste pipes shall in all cases empty into an open sink that is properly supplied with water, connected, trapped, and vented, the same as other fixtures, or they may discharge into a down spout or rain leader trap located inside the building or into a cellar floor drain, but their ends must be left open. Such waste connections shall not be located in inaccessible or unventilated cellars.

Sec. 133. Refrigerator WAstes.--Refrigerator-waste pipes shall be not less than $1 \frac{1}{4}$ inches for 1 opening, $1 \frac{1}{2}$ inches for 3 openings, and for 4 to 12 openings must be not less than 2 inches, and shall have at each opening a trap, and clean-out at angles, so arranged as properly to flush and clean pipe. Such waste pipes shall be continued not less than full size through the roof, except where such fixtures are located in the basement or first floor.

Sec. 134. Overflow Pipes and Motor Exhausts.-Pipes from a water-supply tank or exhaust from a water lift shall not be directly connected with any house drain, soil, or waste pipe. Such pipe shall discharge upon the roof or be trapped into an open fixture or discharge as for refrigerator wastes. 


\section{ARTICLE XIII.-MAINTENANCE}

[These recommendations apply only to dwellings and similar small buildings. The experimental work at the Bureau of Standards developed some additional information on installations for larger buildings, and this has been made available wherever possible throughout the report]

Sec. 135. Defective Fixtures.-All installed fixtures found defective or in an insanitary condition shall be repaired, renovated, replaced, or removed within 30 days upon written notice from the proper administrative authorities.

Sec. 136. Temporary Toilet Facilities.-Suitable toilet facilities shall be provided for the use of workmen during the construction of any building. These toilet facilities shall be maintained in a sanitary condition. 


\section{ARTICLE XIV.--INSPECTIONS AND TESTS}

[These recommendations apply only to dwellings and similar small buildings. The experimental work at the Bureau of Standards developed some additional information on installations for larger buildings, and this has been made available wherever possible throughout the report]

Sec. 137. Inspections.-All piping, traps, and fixtures of a plumbing system shall be inspected by the proper administrative authority to insure compliance with all the requirements of this code and the installation and construction of the system in accordance with the approved plans and the permit.

Sec. 138. Notification.- (a) It shall be the duty of the plumber to notify the proper administrative authority and the owner, or his authorized agent orally, by telephone, or in writing, not less than eight working hours between the hours of 8 a. m. and 4 p. m. before the work is to be inspected or tested.

(b) It shall be the duty of the plumber to make sure that the work will stand the test prescribed before giving the above notification.

(c) If the proper administrative authority finds that the work will not stand the test, the plumber shall be required to renotify as above and to pay the sum of - dollars for each renotification.

(d) If the proper administrative authority fails to appear within 24 hours of the time set for each inspection or test, the inspection or test shall be deemed to have been made, and the plumber required to file an affidavit with the proper administrative authority that the work was installed in accordance with the code, the approved plans and permit, and that it was free from defects and that the required tests had been made and the system found free from leaks; also whether the owner or his authorized agent was present when such inspection or test was made, or was duly notified.

(e) At the time the permit is taken out a written waiver by the owner of notification may be filed with the proper administrative authority.

Sec. 139. Material and Labor for Tests.-The equipment, material, power, and labor necessary for the inspection and test shall be furnished by the plumber.

Sec. 140. System Tests.-All the piping of a plumbing system shall be tested with water or air. After the plumbing fixtures have been set and their traps filled with water the entire drainage system shall be submitted to a final air-pressure test. The proper administrative authority may require the removal of any clean-outs to ascertain if the pressure has reached all parts of the system.

Sec. 141. Methods of Testing.-(a) Water test.-The water test may be applied to the drainage system in its entirety or in sections. If applied to the entire system, all openings in the piping 
shall be tightly closed, except the highest opening above the roof and the system filled with water to the point of overflow above the roof.

If the system is tested in sections, each opening shall be tightly plugged, except the highest opening of the section under test, and each section shall be filled with water; but no section shall be tested with less than a 10 -foot head of water or a 5 -pound pressure of air. In testing successive sections at least the upper 10 feet of the next preceding section shall be retested, so that no joint or pipe in the building shall have been submitted to a test of less than a 10-foot head of water or a 5-pound pressure of air.

Under any test the water or air pressure shall remain constant for not less than 15 minutes without any further addition of water or air.

(b) Air test.-The air test shall be made by attaching the air compressor or test apparatus to any suitable opening and closing all other inlets and outlets to the system, then foreing air into the system until there is a uniform pressure sufficient to balance a column of mercury 10 inches in height or 5 pounds per square inch on the entire system. This pressure shall be maintained for 15 minutes.

(c) Final air test.-The air machine shall be connected to any suitable opening or outlet and an air pressure equivalent to 1 inch water column shall be applied and left standing at least 15 minutes. If there is no leakage or forcing of trap seals indicated by the fluctuation of the drum, float, or water column, the system shall be deemed air-tight.

Sec. 142. Order of Tests.- The tests may be made separately, as follows:

(a) The house sewer and all its branches from the property line to the house drain.

(b) The house drain and yard drains, including all piping to the height of 10 feet above the highest point on the house drain, except the exposed connections to fixtures.

(c) The soil, waste, vent, inside conductor, and drainage pipes which would be covered up before the building is inclosed or ready for completion. The tests required for $(b)$ and $(c)$ may be combined.

(d) The final test of the whole system.

(e) After each of the above tests has been made and proved acceptable the proper administrative authority shall issue a written approval.

Sec. 143. Covering of Work.-No drainage or plumbing system or part thereof shall be covered until it has been inspected, tested, and approved as herein prescribed.

Sec. 144. Uncovering of Work.-If any house drainage or plumbing system or part thereof is covered before being regularly inspected, tested, and approved, as herein prescribed, it shall be uncovered upon the direction of the proper administrative authority. 
Sec. 145. Defective Work.--If inspection or test shows defects, such defective work or material shall be replaced within three days and inspection and test repeated.

Sec. 146. House Sewer and House Drain Tests.-The house sewer and house drain shall be tested with water or air. The water test shall have not less than a 10 -foot head of water and the air test not less than a 5-pound pressure. All alterations, repairs, or extensions, which shall include more than 10 feet, shall be inspected and tested.

Sec. 147. Conductor Pipes.-Conductor pipes and their roof connections within the walls of buildings, or conductor branches on the outside system where such branches connect with the house drain or are less than 3 feet from the wall of the building, shall be tested by the water or air test. Conductor branches on the outside system may be tested in connection with the house drain.

Sec. 148. Stable and Stable-Yard Drain Test.-If a stable or any part of a stable be used for human habitation, the same inspections and tests of plumbing and drainage systems thereof shall be made as in the case of an ordinary dwelling. Otherwise, all stable and stable-yard drains shall be inspected, but need not be tested.

Sec. 149. Garage and Drainage System.-For a garage or any part of a garage the same tests and inspection of the plumbing and drainage system thereof shall be made as in the case of an ordinary dwelling.

Sec. 150. Test of Water-Distribution System.-Upon the completion of the entire water-distribution system it shall be tested and proved tight under a water pressure not less than the maximum working pressure under which it is to be used.

Sec. 151. Certificate of Approval.-- Cpon the satisfactory completion and final test of the plumbing system a certificate of approval shall be issued by the proper administrative authority to the plumber to be delivered to the owner.

Sec. 152. Air Test of Defective Plumbing.- The air test shall be used in testing the sanitary condition of the drainage or plumbing system of all buildings where there is reason to believe that it has become defective. In buildings condemned by the proper administrative authority because of insanitary conditions of the plumbing system the alterations in such system shall not be considered as repairs, but as new plumbing.

Sec. 153. Inspections and Tests not Required.-No tests or inspections shall be required where a plumbing system or part thereof is set up for exhibition purposes and is not used for toilet purposes and not directly connected to a sewerage system; nor after the repairing or replacing of an old fixture, faucet, or valve by a new one (to be used for the same purpose); nor after forcing out stoppages and repairing leaks. 


\section{PART III.-EXPERIMENTAL INVESTIGATIONS, STANDARD- IZATION, ADMINISTRATION, AND COMMENTS}

\section{CHAPTER 5.-EXPERIMENTAL INVESTIGATIONS}

One of the chicf reasons for appointing the committee on plumbing was the manifest need of a carefully planned investigation of the scientific principles of plumbing systems. In spite of many experimental investigations which have been made in England, Germany, and the United States, some of the latter being of recent date, there is a widespread feeling that the subject is still imperfectly understood, and that some of the present-day plumbing regulations are without an adequate scientific foundation. The committee, therefore, welcomed the-opportunity of having a scientific study of housedrainage systems made under its direction by the Bureau of Standards. The results have thoroughly justified this course.

Through the courtesy of Dr. S. W. Stratton, then Director of the Bureau of Standards, and Dr. L. J. Briggs, chief of the engineering physics division, accommodations were provided at the laboratories of the Bureau of Standards in Washington, and Dr. R. B. Hunter and L. W. Snyder were assigned to the work. The investigations were begun in November, 1921, and were pursued continuously until January, 1923.

The original intention of the committee was to begin with vertical stacks and the simple elements of plumbing, combine these in an orderly and progressive way, and study the hydraulic and pneumatic principles, proceeding from simple low systems to higher and more complex layouts. Necessity for haste in the solution of certain problems applicable to the types of small dwellings under consideration by the Building Codc Committee caused this plan to be deferred and led to tests of certain concrete examples of plumbing installation suitable for one-story one-family dwellings, and for two-story onefamily and two-family dwellings. Wherever possible the work was extended so that the results could be applied to plumbing in larger buildings.

In view of the extensive nature of the series of experiments described, the systematic manner in which the subject was approached, the extreme care with which the mcasurements and observations were made and recorded, the generous facilities afforded and the disinterested attitude of the investigators, the conmittee is of the opinion that the results of the experimental work performed at the Bureau of Standards are by far the most important of any yet obtained. 
In view of the importance of corrosion as an element in the longevity of plumbing systems, one of the members of the committee has prepared a memorandum on this subject, which will be found in the appendix. Another experimental study bearing on the subject of corrosion was made in the Sanitary Engineering Laboratory of Harvard University, under the direction of the chairman of the committee, by Dana E. Kepner and Warren E. Howland. It concerned the movements of air and gases in horizontal branch waste-pipes, especially long branches. Mr. Howland's memorandum, to be found in the appendix, describes only a few of the many experiments conducted during a period of about six months.

Doctor Hunter's report (see ch. 6) will speak for itself, but because of its length and its technical character the committee wishes to call attention to some of its salient features and to express its own views on certain matters pertinent to the investigation.

\section{UNIT OF FIXTURE DISCHARGE}

In order to study the capacity of house drainage systems, it was found desirable to establish a unit of fixture discharge - a unit involving both volume and time; that is, rate. The rate of discharge of an ordinary washbasin having a nominal 11-inch outlet, trap, and waste was found to be about 7.5 gallons per minute, a figure so near to 1 cubic foot per minute that the latter was taken as the definition of one fixture unit. The maximum rate of discharge of other fixtures may be expressed in terms of this unit. For example, it will be seen from Table 1 that a sink with a $1 \frac{1}{2}$-inch outlet is equivalent to $1 \frac{1}{2}$ units; a bathtub with a $1 \frac{1}{2}$-inch outlet, to 2 units; and a watercloset, to 6 units. Fixtures differ a great deal, however, and minor details of design may considerably affect the rate of discharge. It would be useful in designing plumbing systems to know the unit value of each of the common fixtures on the market. No attempt was made to collect this information, although a dozen or more fixtures were studied with reference to their rates of discharge.

\section{WATER-CLOSETS}

Doctor Hunter devised an ingenious apparatus for determining the rates of discharge of water-closets by means of an autographic record. This showed the advantage of siphonic action in flushing. While no attempt was made to set definite limits for the rate of flush or for the volume of water required, it may be said that for "washdown closets" efficient flushing was obtained by using rates of 27 to 33 gallons per minute, or 3.6 to 4.4 units; for siphon-jet closets, 3.2 to 4.8 units, the average value being about 30 gallons per minute, or 4 fixture units. If the rate of discharge is too low, the closet may not be properly cleansed; if it is too high, flushing will be less efficient 
and there will be a waste of water. There seems to be good reason for limiting the volume of water to 5 gallons per flush and the rate of discharge to 5 units. The maximum rate of discharge of a closet may for an instant be as high as 45 gallons per minute; hence in Table 1 the water-closet was rated as 6 units.

The committee is of the opinion that it is possible to design waterclosets which, while preserving the necessary rate of discharge, will give a satisfactory flush with less than 5 gallons of water, perhaps with half this amount. It must not be forgotten, however, that the flow must be large enough to carry the solid matter into the street sewer. If this change were brought about, savings of water consumption of 5 to 10 gallons per capita daily might be effected. Future conservation of water resources will demand this saving.

A few studies of pressure flushing as compared with tank flushing were made, but were not followed up. From the standpoint of discharge, the two systems are not materially different. Flush valves make a more severe draft on the house water supply and demand supply pipes of larger diameter than do the water-closet tanks, which fill slowly after the closet has been used. A tank may be used in connection with a flush valve, and the necessity for using water pipes of a larger size somewhat obviated. Flush valves on a small house service interfere with the proper operation of the ordinary five-eighths inch water meter. A larger meter is undesirable not only because of added cost, but because larger volumes of water might pass without registration. The committee is of the opinion that the use of flush valves without tanks in small dwelling houses is undesirable, although they should not be debarred.

\section{PEAK LOADS IN HOUSE DRAINAGE SYSTEMS}

Most house drainage systems are designed to carry away the water from more than one fixture, and obviously the pipes must be large enough to carry the total volume of simultaneous or overlapping discharges. In a small dwelling, where the fixtures are so installed that all might be used and discharged at the same time, the house drain must have a capacity equal to the total number of fixture units. In larger buildings, where there are many fixtures of the same kind, the capacity of the house drain need not be equal to the total number of fixture units but must take into account the probable frequency of coincident discharges. Up to the present time this has been estimated by a rule-of-thumb procedure, which in the case of many fixtures has given too large a total and in the case of few fixtures too small a total. Doctor Hunter has submitted this problem to a mathematical analysis, applying the principles of probability to certain facts and observations secured by members of the committee in regard to the use of water-closets in public places. His computa-

$94877^{\circ}-24-5$ 
tions, set forth in pages 91 to 98 of his report (see ch. 6), give some interesting results, of which the following is a typical instance.

If, in a group of four water-closets, it be assumed that each flush lasts 10 seconds, and that the interval between flushes is 5 minutes during a rush period of 2 hours, the frequency of occurrence of 3 closets being discharged so that the flushes would overlap is once in 52 days, and the frequency of occurrence of all 4 overlapping is once in 28 years. In such a case it is sufficient to provide for a peak load of 3 times 6 fixture units, that is, 18 units, and not 4 times 6 units, or 24 units. Thus, even in such a commonplace subject as plumbing the so-called higher mathematics may be used to show what capacities are necessary and sufficient. In the case of small dwellings less dependence has been placed on mathematics, and required capacities have been established by the common judgment of the committee.

\section{CAPACITIES OF HOUSE DRAINS}

In designing a drainage system the house drain should be considered first and its capacity determined on the basis of the greatest number of fixture units likely to be frequently discharged together or so as to overlap, including rain water if discharged into it. The house drain should be able to take away the water as fast as received without backing up into the soil or waste stacks and at a velocity sufficient to prevent the deposit of solids; that is, a velocity of about 2 feet or more per second. A table (Table 4) based upon Darcy's formula has been prepared which shows for different sizes and slopes the volume of water in gallons per minute and the number of fixture units which can be safely delivered to the house drain. For example, a 4-inch pipe with a grade of one-fourth inch per foot will accommodate 14 fixture units, or practically one watercloset (6), one washbasin (1), one bathtub (2), one kitchen sink ( $\left.1 \frac{1}{2}\right)$, and two combined laundry trays (3), all discharged at once, which would seldom be the case. The figures in this table have been checked with Williams and Hazen's hydraulic tables. For small dwelling houses the common sizes and grades for house drains appear to be reasonable.

At this point attention is called to the fact that street sewers not infrequently become overloaded because of the growth of the city, the substitution of apartment houses for single-family dwellings, and skyscrapers for low buildings. This may cause sewage to back up in the house drain.

\section{CAPACITIES OF SOIL STACKS}

There has been a tendency to use soil stacks and waste stacks which are too large. Starting with the assumption that no static head should be developed in the stack and considering that the place 
where the stack would be first likely to run full would be immediately below the fitting through which the water entered, it was reasoned that the capacity of the stack should be determined by the capacity of the inlet fitting. Experiments were, therefore, made to determine the capacity of inlet fittings and, with these as a basis, the capacities of stacks of different sizes were found by experiments and computations. Doctor Hunter deduced a mathematical formula for stack capacities. The following figures will show the capacities of certain commonly used stacks and inlet fittings:

\begin{tabular}{|c|c|c|}
\hline \multirow[b]{2}{*}{ Diameter of stack in inches } & \multicolumn{2}{|c|}{$\begin{array}{l}\text { Capacity of stack in } \\
\text { fixture units }\end{array}$} \\
\hline & $\begin{array}{l}\text { Single or } \\
\text { double } \\
\text { sanitary T } \\
\text { fittings }\end{array}$ & $\begin{array}{l}\text { Single or } \\
\text { double Y, } \\
\text { combina- } \\
\text { tion Y, and } \\
\text { one-eighth } \\
\text { bend } \\
\text { fittings }\end{array}$ \\
\hline $\begin{array}{l}2 \\
3 \\
4 \\
4\end{array}$ & $\begin{array}{l}6 \\
13.5 \\
24\end{array}$ & $\begin{array}{l}12 \\
27 \\
48\end{array}$ \\
\hline
\end{tabular}

It will be observed that the sanitary $T$ is much less satisfactory than a $Y$ or a combination $Y$ and one-eighth bend as an inlet fitting, as it limits the stack capacity. Or, to put the matter in another way, a 3-inch stack with proper inlet fittings has almost as large a capacity as a 4 -inch stack with sanitary $T$ inlet fittings.

Another critical point in the design is the turn where the vertical stack enters the horizontal house drain. In systems where the stack and house drain have the same diameter no special provision need be made beyond providing a turn of sufficient radius to make an easy bend. In systems where the house drain is one or more sizes larger than the stack the bend should have a diameter at least one size larger than that of the stack.

\section{CHARACTE RISTICS OF FALL OF WATER IN PARTIALLY FILLED STACKS}

Small flows of water down a stack tend to adhere to the sides and to follow a spiral course. In the case of larger flows frictional resistance of the air causes the water to form diaphragms across the pipe which persist temporarily and then break through. With still larger flows the diaphragms become slugs and do not break through. Solids tend to encourage the formation of slugs.

The studies of velocities in partially filled pipes were interesting and instructive. The acceleration of falling water under the influence of gravity and the friction of the water on the sides of the pipe, which increases approximately as the square of the velocity, unite to produce a velocity which, after it attains a certain maximum, remains practically constant. This maximum is reached in a com- 
paratively short fall and increases as the volume of flow increases. This whole subject of vertical velocity is a matter of importance in the design of tall stacks, and the studies indicate that the height of stacks need not be limited because of the fear of excessive downward velocities. For example, in a 3 -inch stack open at both ends the velocity attained after a fall of 20 feet is 29 feet per second and after 100 feet 34.2 feet per second, a relatively small increase. Doctor Hunter's experiments and computations are a valuable contribution to hydraulic science in this field.

\section{VENT REQUIREMENTS}

The subject of venting is complicated and can not be discussed in a few words. The committee has given attention to the necessity of relieving back pressure, partial vacuum, and self-siphonage of traps in order that a plumbing system may function efficiently. It has also made studies of air circulation and diffusion. The experiments have been very numerous, and the results can be understood only by giving careful study to the particular arrangement of pipes in each case. The committee suggested as a criterion of satisfactory trappage that the 2-inch seal of a trap should not be reduced to less than 1 inch. Stacks of 3 and 2 inches were chiefly used.

Speaking in general terms, it may be said that the size of the vent stack depends upon three principal factors - the diameter of the soil pipe, the maximum volume of water discharged, and the length of the soil and vent stacks. Specifically, it was found that for a 3 -inch stack carrying its capacity load of 26 fixture units a 2 -inch vent 36 feet long or a $1 \frac{1}{2}$-inch vent 15 feet long gave satisfactory results.

The flow of air in pipes is the controlling factor in vent requirements. Use was made of well-known pneumatic laws for air flow, and these laws, together with the experiments themselves, gave the basis for some important generalizations in regard to the design of vent stacks. Given the discharge and the developed length of vent stack, the diameter required for a given soil stack can be determined. Increasing the diameter of a soil stack requires greater proportional increase in the diameter of the vent stack because of the increased volume of air to be moved. On the other hand, decreasing the diameter of a soil stack permits a greater proportional decrease in the diameter of the vent stack, but there are objections to using a vent stack less than $1 \frac{1}{4}$ inches in diameter.

\section{ADMISSION OF STORM WATER}

There are advantages in not admitting roof water to an interior house drainage system. If the city has a "separate" system of sewers-that is, domestic sewage and rain water kept apart-the admission of roof water to the house sanitary sewer would not be 
allowed. If the city has the "combined" system, the storm water should be carried separately to the house sewer. There is a tendency to change from the combined to the separate system, and if this were done the cost of alterations in the plumbing required to bring about the separation would be much greater if the roof water entered the house drain than if it entered the house sewer outside the building.

The admission of roof water to a house drain increases the danger of back pressure near the base of the stack, this danger increasing rapidly with the rainfall. In its computations the committee considered that a rainfall of 4 inches per hour was a reasonable allowance, and hence it was decided that 180 square feet of drained area in horizontal projection should be considered as equivalent to one fixture unit. The method of applying this figure to the table given in the code (see ch. 4, sec. 116) allows a large factor of safety.

This figure was reached after a careful study of the frequency of occurrence of different rates of rainfall in different parts of the United States as published by the Weather Bureau of the United States Department of Agriculture. At New York a 4-inch rain lasting one hour occurs once in about two years; at New Orleans, every year; and at St. Paul, Minn., once in three years. Where large systems are being designed the committee's reasonable allowance should not be used, but some other figure based on a careful study of local rainfall intensity should be substituted for it.

In computing the capacity of a house drain this rain allowance should be added to the other requirements, for, although the chance of such a rainfall as that assumed occurring at the time of the peak load from the fixtures is small, the factor of safety thus provided is none too large.

Storm water, a high tide, or sewer stoppage may cause the house sewer or even the house drain to be submerged, giving back-pressure effects similar to those produced by admitting roof water to the system. Where such complications as this are likely to occur the committee favors a distance of at least 3 feet between the lowest fixture inlet to the stack and the house drain.

\section{RUNNING TRAP}

Whatever be the supposed advantages of the house trap, or running trap, as a protection of the house drainage system against the air of street sewers, the experiments made by Doctor Hunter indicate that this device produces an effect similar to a partially submerged drain. Whether vented or not, it decreases the capacity of the house drain. Other reasons against using the house trap are given in note 19 , chapter 9 . 


\section{EFFECT OF WIND BLOWING OVER STACK TOPS}

Studies of the effect of winds blowing over the tops of stacks were included in the experiments. These effects were measurable, but too small to be of practical importance in the case of small dwellings.

\section{FROST CLOSURE OF THE STACK TOPS}

The closure of the top of the stack by frost or other cause was studied. Complete closure caused some of the traps to be siphoned by the discharge of a single water-closet, and this occurred whether or not the traps were individually vented. Incomplete closures gave less noticeable effects. It is a matter to be guarded against as well as possible, but can not be controlled by modifications of the venting system.

\section{SIPHONAGE OF FIXTURE TRAPS}

Careful study has been made of the action of plain traps; that is, the ordinary $\mathrm{S},{ }_{4}^{3} \mathrm{~S}$, and $\frac{1}{2} \mathrm{~S}$ (or P) traps, under different conditions. The efficiency of a trap is sometimes thought to mean its resistance to loss of seal, but the real efficiency is resistance to alternate suction and back pressure. Loss of seal does not concern the trap alone. The fixture itself is an element when self-siphonage is being considered. A trailing discharge, such as occurs in a bathtub, kitchen sink, or laundry tray, is almost invariably sufficient to refill an ordinary trap; but with an oval basin, where the discharge ends suddenly, greater care must be taken to prevent self-siphonage. The diameter of the tailpiece relative to that of the trap is an element. There are advantages in having the tailpiece one nominal size smaller than the trap. The length of the waste pipe and its inclination to the horizontal are also elements, as well as the presence of elbows in the wastepipes. Hence, it is more logical to consider the efficiency of the trap and waste pipes as a whole than that of the trap alone using the changes in trap seal as a measure of the efficiency of the system.

With this idea in mind extensive studies were made to ascertain the effects of pressure, aspiration, and self-siphonage on the seal of traps and the best arrangement of designing waste pipes to secure an efficient system in the simplest way. The possible situations are so numerous that the reader is referred to the detailed statements and diagrams in Dr. Hunter's report. The committee reached the conclusion that the minimum seal for a plain trap should be 2 inches, and that a loss of seal greater than 1 inch in such a trap should be regarded as unsatisfactory. While it is true that a seal is not actually broken unless the water in the trap falls below the "dip," some factor of safety must be allowed to provide for unexpected shocks, for evaporation, capillary loss, and for oscillations due to wind pressure, while a lowering of the seal exposes a foul surface on the house side of the trap. 
A fixture trap is almost sure to foul to some extent; sediment may collect at the bottom, grease may adhere to the sides, and growth of fungi may develop. The deeper the trap seal the greater the extent of the fouling. While deep seal traps can withstand siphonage better than traps of shallow seal, these other practical considerations combine to make it advisable to place a maximum limit upon trap seals, and the committee has placed this at 4 inches. Experiments and computations made by Mr. Howland (Appendix C) have shown that the danger of gases in the drainage system diffusing through the trap seal is negligible for water seals between 2 and 4 inches; that the liability of odors from deposits in the trap is also negligible; but that the possibility of odors from deposits on the pipe between the fixture and the trap in the overflow waste pipe, and in the trap itself when its seal is lowered below normal, is more important. While it is true that many traps which have seals as deep as 6 or 7 inches are in use, and while such deep-seal traps can not be said to be injurious to health the committee is of the opinion that the establishment of a minimum limit of 2 inches and a maximum limit of 4 inches for plain traps is desirable, and gives a basis for standardization.

\section{RESEALING OR ANTISIPHON TRAPS}

The committee has given attention to the subject of antisiphon, nonsiphon, or resealing traps, as they are called. Practically all traps, except the plain traps already mentioned, may be included in this class. There are many different kinds, many of them patented and more expensive than plain traps. They are supposed to resist siphonage better than plain traps by reason of having a deep seal, a greater area or volume, tortuous passages for the water, projecting lips, partitions, or, in some cases, moving parts. The best of the resealing traps when clean resist siphonage more than a plain trap of 2 to 4 inch seal, and this may be the case even when slightly fouled. When more completely fouled, this resistance to siphonage rapidly lessens. Properly designed resealing traps unvented and clean resist back pressure somewhat more than unvented plain traps of the same depth of seal, but the difference is not sufficient to justify their general use without vents. Their greater complexity causes them to clog more quickly than plain traps, and, if clogged, they are less easily cleaned by the householder and can not be thoroughly cleaned by the usual method of using a force pump or plunger. Lack of standardization of these traps makes replacement more troublesome and expensive. The supposed advantages of a resealing trap lie in the fact that greater resistance to siphonage makes it possible to omit some of the vent pipes commonly installed and to use longer horizontal unvented waste-pipes and thus secure greater freedom in the location of fixtures. Long unvented horizontal runs, however, are in themselves objectionable. 
As before stated, the efficiency of traps should not be considered alone; plain traps should not be compared with "resealing traps"; the true comparison is between a drainage system including plain traps and a drainage system including resealing traps. The experiments made by the Bureau of Standards have indicated that simplifications in venting are possible even when plain traps are used. Plain traps have the advantages of economy, simplicity, greater freedom from fouling, and greater ease of cleaning. For these reasons the committee favors having drainage systems designed on the basis of plain traps rather than on the basis of resealing traps and is of the opinion that the plain-trap system, with simplified venting, affords ample range in the location of fixtures. Resealing traps should not be accorded any special privilege with respect to venting over plain traps, but their use can not be prevented by regulation. In short, plain trapping with vents should be the prescribed rule, with resealing traps without vents permitted only under very restricted conditions.

\section{UNVENTED HORIZONTAL BRANCH WASTE PIPES}

Directly involved with the question of resealing traps is that of the allowable length of unvented horizontal branch waste pipes, because it is chiefly in connection with long branches that resealing traps have an advantage over plain traps.

Long branches have a number of practical disadvantages. There is a tendency to give them too little slope. Long straight runs are likely to interfere with framing timbers and encourage unnecessary cutting. If the fixture discharge is small and only partially fills the pipe, deposits may occur, and if the discharge is so large as to completely fill the pipe, self-siphonage of the trap may occur. It is this last danger that the resealing trap is supposed to prevent. If a long branch becomes stopped, it is more difficult to clean than a short branch.

If long branches are unvented, there is danger of corrosion. While this is well known by experience, especially where wrought iron or steel is the metal used, the committee thought it worth while to have this subject studied. The results of the experiments show that in unvented horizontal branches connected to a stack the movements of air in the stack produce eddy currents in the branch to a distance of only 1 or 2 feet; that temperature changes may cause slight air movements in the branch; that diffusion of gases throughout the length of the branch occurs; that if such a gas as carbon dioxide is produced from deposits of organic matter uniformly along the branch the maximum concentration of this gas will increase as the square of the length of the branch; that deposits of moisture occur on the inner walls of a pipe, especially along the top; that iron rust absorbs moisture; that moisture thus collected absorbs carbonic acid, which 
tends to stimulate the corrosion of iron. In other words, the danger of corrosion in an unvented branch 10 feet long is about four times as great as in a branch 5 feet long. In the case of exposed horizontal pipes leakage from corrosion might be detected and the pipe could be readily replaced, but waste pipes are usually concealed, where leakage might go undetected and replacement would be costly.

From the standpoint of self-siphonage the slope should lie between one-eighth and one-half inch per foot and the outlet should not be below the dip of the trap. Doctor Hunter's experiments show that in the case of wash basins plain traps of 2 to 4 inch seal, connected to horizontal wastes of 4 to 8 feet, would be safe against siphonage, and in the case of wide bottom fixtures the lengths might be about twice as long, with one $90^{\circ}$ elbow not more than 18 inches from the trap. But on the basis of all the evidence at hand the committee decided that 5 feet should be established as a reasonable limit for the length of an unvented horizontal waste, measured horizontally from the vertical inlet of the trap to the vent opening.

\section{VENTING OF BRANCH WASTES}

A clogged vent pipe is useless, just as useless as if no vent pipe had been installed. If waste pipes are so arranged that the waste water may rise into the vent pipe at times of discharge, the latter is very liable to become clogged. If the connection of the vent pipe and waste pipe lies below the hydraulic grade - that is, below a line which connects the high-water line of the fixture and the point where the waste pipe enters the stack - water is likely to rise into the vent pipe. The crown vent is an example of this condition, and the frequent clogging of this vent has caused this arrangement to be looked upon with disfavor and even to be prohibited by regulation, but almost any vent which rises from a horizontal branch may act in the same way if the discharge fills the waste pipe. If the vent forms a continuation of the vertical leg of the waste pipe and if this connection is above the hydraulic grade, there will be no danger of the vent becoming clogged. This is a reason for limiting the length of all horizontal waste pipes, whether vented or not. Doctor Hunter's explanations of this subject are clear and illuminating.

\section{SEPARATE TRAP VENTING NOT NECESSARY}

Every trap seal of a plumbing system should be adequately protected against failure, but to accomplish this it is not necessary that each particular trap have an individual vent pipe. For example, stack venting appropriate for the highest fixtures is the most efficient and certain of all forms of venting. Venting requirements rclate to the drainage system as a whole. Wet vents--that is, portions of the waste pipe which are used alternatcly for the discharge of water and for venting purposes-are unobjectionable if installed with regard to the principles already set forth. 
The committee is strongly of the opinion that if due thought is given to the design of the drainage system vent pipes may be reduced in size and number, plain traps may be used, and the whole system made simpler and cheaper than is often the case to-day. To do this, however, generally requires that fixtures be located relatively near a stack, and architects are urged to design buildings so that this can be done.

\section{THE 3-INCH SOIL STACK}

An important conclusion reached by the committee after a thorough discussion of the experimental data was that a 3-inch soil stack has a greater capacity than has often been thought, provided that the house drain is of adequate size, that the points of inlet are well chosen, and the inlet fittings of proper type. While admitting that a larger size has a greater capacity and may under some conditions be desirable, a 3-inch soil stack is deemed sufficient for any ordinary dwelling. The economies resulting from using a 3 -inch instead of a 4 -inch size are material. Less metal is required, transportation and construction costs are less. The 3 -inch pipe can be placed in an ordinary wall without furring, thus saving cost and room space. A 3-inch soil pipe can be placed in a partition having 4-inch studding, and a 3 -inch bend can be housed in the flooring better than a 4 -inch bend. A 3 -inch soil stack may be satisfactorily used for a high building, if the necessary conditions are complied with, but, as the committee's report is confined to small dwellings the reader is referred to Doctor Hunter's report for information on this point.

\section{CONCRETE EXAMPLES OF VENT REQUIREMENTS}

It is quite difficult to set forth vent requirements in words, and for that reason it is difficult to frame regulations which will be adequate and never unreasonable. Even Doctor Hunter's conclusions, set forth on page 176 of his report, are difficult to visualize. The committee, therefore, asked him to arrange a series of plumbing layouts, which should set forth in a concrete way the venting which the experiments indicated to be desirable, assuming that plain traps are used and that the simultaneous discharges of fixtures are those reasonably to be expected. These are shown in Figures 90, 91, and 92. It will be seen that in houses of the single, low bungalow type very little individual venting is required; that with fixtures on two stories an additional vent stack is needed, but few if any vents for waste branches; that with fixtures on three stories venting of branch waste pipes becomes necessary, but that even here group vents rather than individual vents for each fixture suffice.

These figures do not, of course, represent all possible layouts, but they may be taken as types and deserve careful study. Attention is 
called also to some of the more detailed layouts shown on Figures 81 to 89 , which will give a better idea of the situation than can be told in words.

\section{FACTORS OF SAFETY}

The committee has given much attention to the factors of safety needed in plumbing systems. That some margin should exist is obvious, for unforeseen conditions may arise, partial or complete stoppages of portions of a drainage system may occur, fixtures may remain out of use for long periods, workmanship is never perfect. On the other hand, the occasional failure of a trap seal does not injure the structure of the plumbing system, and in this instance the committee has decided that in the case of a trap having a water seal of 2 inches, two is a sufficient factor; that is, a 2 -inch seal should never be reduced to less than 1 inch. In structural work factors of safety of four or five are properly required.

With the best of intentions, factors of safety have sometimes been multiplied, one upon another, until the system was overburdened with precautions and expense. Yet even where this has occurred there have been examples of unimportant matters being stressed while vital requirements were neglected. The committee is of the opinion that a careful study of Doctor Hunter's report will clarify many ideas in regard to plumbing design.

\section{PLANNING FOR SIMPLICITY}

The committee has less faith in plumbing regulations than in the education of plumbers and the cooperation between sanitary engineers, plumbers, and architects. The plumbing system is an integral part of a modern dwelling. Structurally it must interlock with other parts of the building. It should be given serious thought when the building is planned. Simple plumbing can be obtained if it is planned for, but if the plumbing is made the last element of the design complications are sure to arise.

The committee is of the opinion that the principles of plumbing and house drainage are not being given sufficient attention in schools of engineering and architecture; that present-day textbooks of plumbing give too much attention to fixture details and not enough to the governing hydraulic and pneumatic principles of house drainage, and that in many ways the whole matter of plumbing has been put on a commercial rather than on an engineering plane. The committee hopes that the report of the experiments made under its direction by the Bureau of Standards will mark a turning point in the popular attitude toward plumbing and the plumber. Simplifying regulations should not be a matter of "letting down the bars" to encourage simpler designs; but better and simpler designs, resulting from scientific work, should make simple regulations sufficient. 


\title{
CHAPTER 6.-PHYSICS OF PLUMBING SYSTEMS. REPORT OF EXPERIMENTAL AND THEORETICAL INVESTIGATIONS
}

\author{
By R. B. Hunter and L. W. Snyder \\ Bureau of Standards
}

\section{PURPOSE AND METHOD OF INVESTIGATIONS}

The purpose of these investigations was to supply data to aid the subcommittee on plumbing in the formulation of essential regulations and sound rules of practice applicable to small dwelling-house construction with the view of securing simplification of plumbing design and uniformity of requirements and practice through the general adoption of these rules.

This report is a consolidation of the oral and written reports made to the committee at various times during the progress of the work. These partial or progress reports have been rearranged and abridged, retaining only the more essential data and applications.

The series of experiments outlined by the committee, including tests of several concrete examples of plumbing installation, covering one story, one story and basement, and two story and basement, onefamily houses; one story and basement duplex, and two story and basement, two-family houses, has not been completed in all parts. However, the investigations have advanced to the point where conclusions and generalizations, in so far as they affect small dwelling construction, are justified.

Certain phases of the investigation, the results of which may be applied to the general problem of house drainage, have been carried beyond the requirements for the small dwelling and are reported. It seems impractical to attempt to divorce entirely the requirements for dwellings from those of other types of buildings, since many of the principles involved are applicable, without modification or with only slight modification, to all classes of plumbing construction. This led to a number of independent experimental and theoretical investigations related to the general problem of house drainage.

The nature of the problem as presented and the manner in which the experimental work developed make it impractical to report the investigations in the order in which they were conducted. Therefore, the separate fields of investigation have been arranged in as logical an order as possible leading to final conclusions.

The fact that a plumbing system consists of many parts-the sewer, the house drain, the vertical stacks, the connections between the stacks and the house drain, lateral branch drains of various sizes, lengths and forms, the vent system, and the water-supply system- 
each of which may be varied independently and which are certain to be varied in practice, coupled with the fact that, in general, the pipes are only partially filled and that both water and air movements must be accounted for, make it impractical, if not impossible, to develop any single mathematical expression for general application. The problem of developing even a series of formulas is rendered more difficult by the failure of certain types of results to duplicate when the experiment is repeated. For example, with the simplest system, consisting of a washbasin fitted with a plain $\mathrm{P}$ trap and short waste open at the end there is a wide difference in results produced on the final seal of the trap when the basin is repeatedly discharged with the same quantity of water and as nearly as possible in the same manner. Some other types of experiments duplicate results with unfailing accuracy. For the most part conclusions have been drawn from the latter type of experiments and results of the former type have been applied with extreme caution. Therefore, because of these complications the different parts of the problem have been taken up separately for experimentation and discussion, and the results combined for application to the complete system and finally tested in a number of complete test installations. The results as applied are approximations, though based whenever possible on experimental values.

Many simple experiments in which the general result could have been foretold from theoretical considerations or experience have been performed merely to obtain numerical values to aid in tying the different parts together, and for the same reason some simple principles are treated at some length.

Experimental work and tables on hydraulics and flow of gases have been freely consulted and used whenever possible in checking our own experimental results and in extending them to a wider application. Many of the tables represent such a combination of existing tables and the results of these investigations.

The growing belief that the 3-inch stack is adaptable to a much wider use than found in present practice has given it a prominent place in these investigations from the beginning. The modifying effects of external conditions, frost closure, strong winds, heavy rainfall in case of combined sewer systems, house trap in main house drain, and submerged outfall of house drain have been considered in connection with the proportioning of soil, waste, and vent pipes, and have been made the subjects of special experimentation.

In passing we wish to state that a vailable reports of other experimental work on plumbing have been examined with considerable care, and that we have observed, as have others, contradictory conclusions reached from experiments apparently conducted with similar apparatus and under similar conditions. Some of these 
stand out from the others as conducted by men of high standing in their professions, and we venture the opinion that at least in these instances the work was honestly conducted and honestly reported, and that the charges of self-interest found in some of the later reviews of such experiments were unwarranted. Further, it is our opinion that the disagreements were due rather to what we may call small differences in the apparatus employed, to limited facilities, and to the viewpoint that experiments on a single system are conclusive.

Certain criticism of the committee's tentative report that has appeared, arising in part at least from misinterpretation due to lax reading, leads us to caution the reader against what seems to have been one of the most common forms of misinterpretation-namely, the extension of specific statements and conclusions to a general application-and to caution against drawing general conclusions from a single phase of the experimental work unless the results are clearly of such character as will not be modified when the part is included in a complete system or will be modified in such a manner as to increase the efficiency of the system. A superficial reading can be of little value, and a careful reading of the report as a whole, with a clear understanding of the application of the principles involved, will be found necessary to afford an intelligent, independent interpretation.

There is also a tendency on the part of some to discount experimental evidence supporting established physical principles on the grounds that it is not in accord with experience. In most cases such criticism is founded on impressions or prejudices rather than on a knowledge of the facts of the case. The fact that we get opposite opinions relative to the same point, both based on the so-called experience, indicates that little weight should be attached to them unless the opinions are backed by very specific data, gathered under accurately known conditions. It is true that the solution of certain points in the problem is offered only through experience, and that the final test of the whole problem is its working under service conditions. For that reason we have drawn freely on the knowledge of experienced engineers and plumbers and have kept in close touch with the plumbing committee and opinions obtained through their correspondence.

No claim is made that these investigations have been exhaustive in every detail or that the conclusions may not be modified or extended by improvement in materials or design. It is fully recognized that in the matter of venting it would be possible in some cases to omit some of the vents recommended for general application were it possible to have each system designed by a man familiar with all the principles involved and with all the conditions to be encountered where the system is to be installed. The judicious use of special fittings and traps would further modify the general con- 


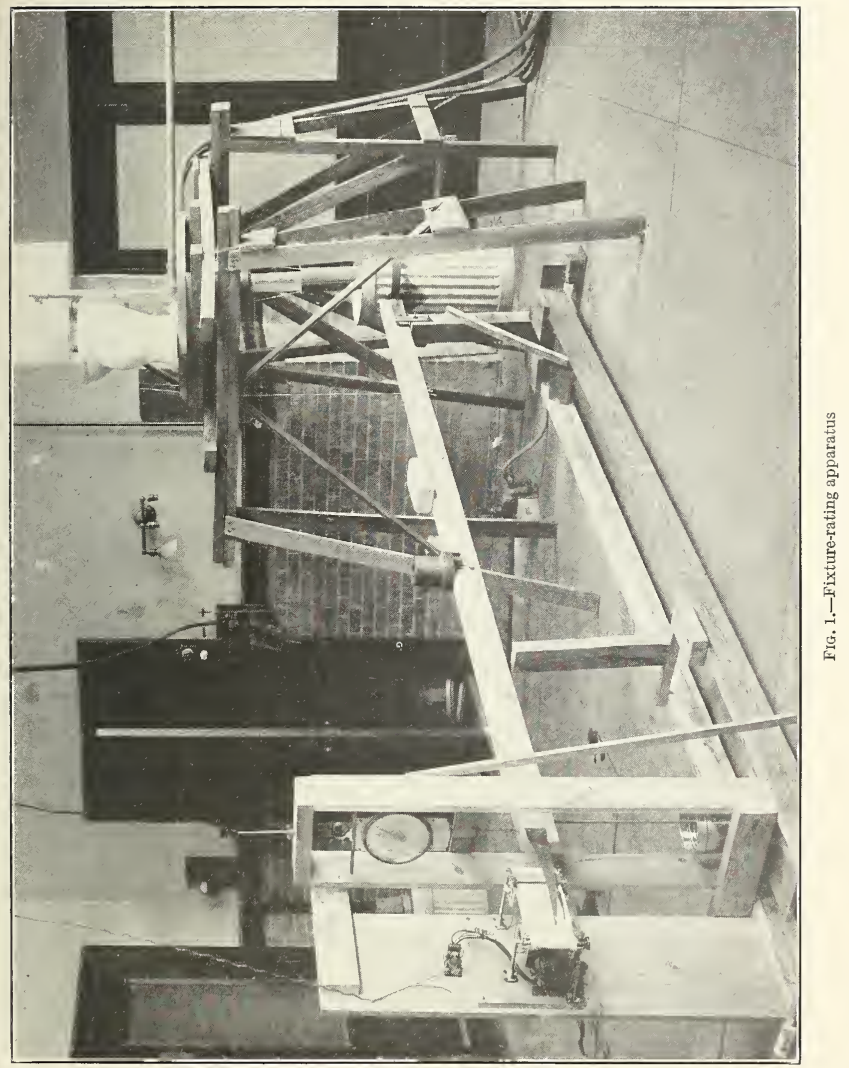




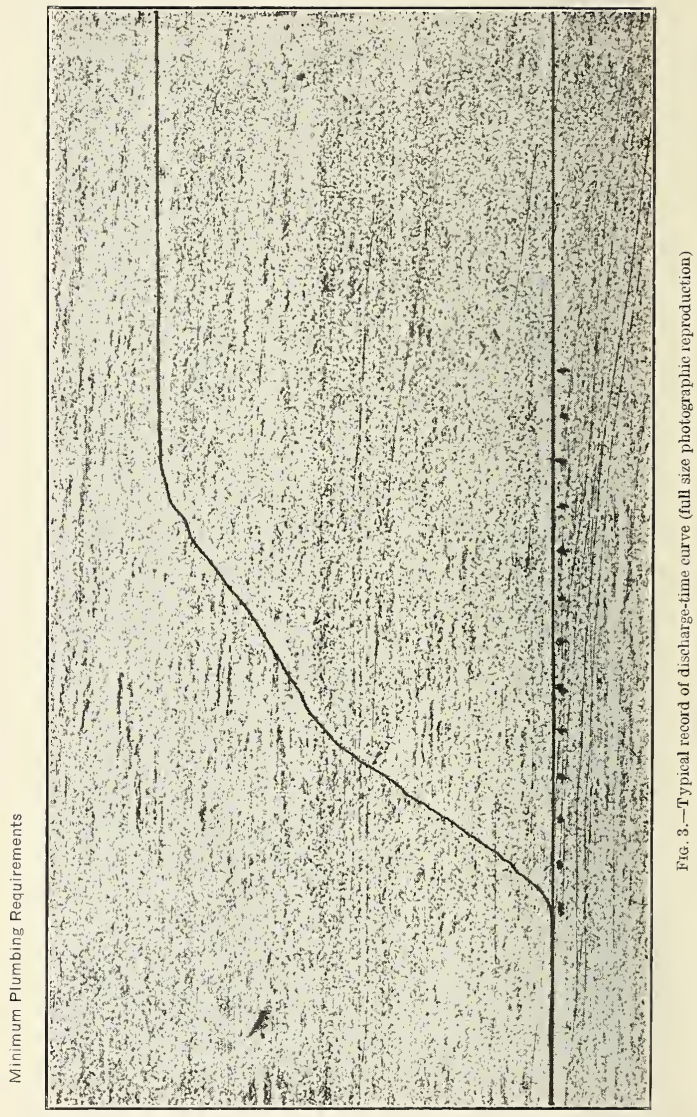


clusions for special cases. Stock materials not covered by patents have been used almost entirely.

We believe that our conclusions as far as they go are sound, offering a common ground on which all interests may safely unite, and a foundation on which the work may be extended to cover buildings other than the small house.

The Bureau of Standards desires to acknowledge and express its appreciation of the valuable material assistance rendered by the committee as individuals and as a body and by various private parties and firms in presenting problems, in offering suggestions, and in supplying equipment without which assistance the accomplishment of the results obtained within the time allotted would have been impossible.

\section{RATES OF DISCHARGE FROM PLUMBING FIXTURES}

In order to obtain data for the determination of the strain on any plumbing installation and for establishing a serviceable unit of measure for such strain, the rates of discharge from the various types of plumbing fixtures ordinarily installed in dwellings were determined as a preliminary to other experiments. To this end fixtures, flush tanks, flush valves, traps, and fittings, believed to be representative in kind and number, were secured.

APPARATUS EMPLOYED

The apparatus employed is shown in Figure 1 and in detailed section in Figure 2. It consists of a beam balance 10 feet 6 inches

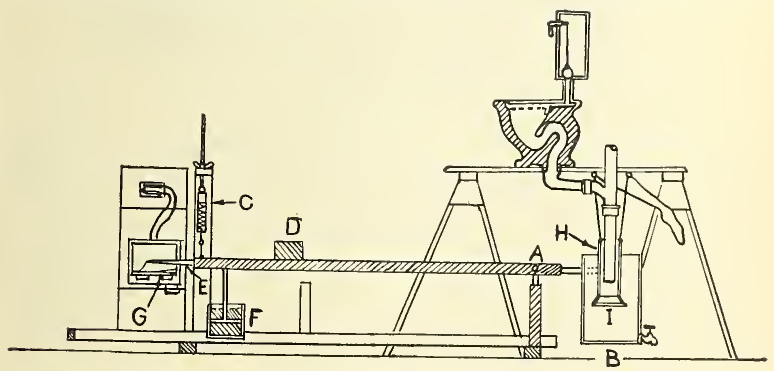

Fig. 2.-Detailed section of fixture-rating apparatus. $A$, ball-bearing fulcrum; $B$, weighing tank; $C$, spring balance; $D$, counterweight; $E$, tracing stylus; $F$, dash pot; $G$, fixed stylus tracing X-axis; $H$, sheet-iron pipe carrying baffle plate; $I$, baffle plate to take impaet

long supported on a ball-bearing fulcrum, $A$, a suspended tank, $B$, for catching the discharge, a spring or spring balance, $C$, attached to the end of the beam to bring the recording stylus, $E$, to the zero 
on the recording device, and a dash pot, $F$, for damping out vibrations of the beam. The recording device consists of a small motor geared to draw a specially prepared wax paper from a drum across a smooth plane at a uniform rate. A fixed stylus, $G$, traces the zero line, or $X$ axis, and the recording stylus, $E$, rising with the beam under the weight of the discharge, traces a smooth curve on the waxed paper. The discharge pipes from the fixture to the weighing tank were varied to meet the demands of each purpose. The sketch (fig. 2) represents a water-closet operating on a low tank supply and discharging through a 3 -inch cast iron closet bend into a section of vertical 3-inch stack. The part below the fitting is a glass section 3 inches by 2 feet. Around this is a moveable pipe,

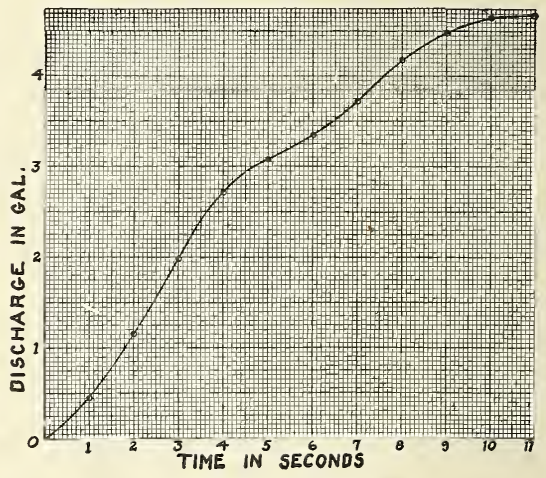

FIG. 4.-Plotted reproduction of Figure 3

$H$, carrying a baffle plate, $I$, to take the impact of the discharge. During the operation the baffle plate, suspended with a moveable section of pipe from the platform above, is kept level with the surface of water in the tank and the discharge thrown horizontally to the walls of the tank. The impact of the discharge is thus taken by the platform and resultant vibrations reduced to a minimum. A baffle plate serving the same purpose was arranged for each fixture rated. Any lag produced either by the baffle plate or dash pot is imperceptible in the general form of the record curve.

The apparatus was accurately calibrated, so that the discharge in gallons at one second intervals may be obtained from an accurate measurement of the record curve. Figure 3 is a full-size photographic reproduction of a typical record and Figure 4 the same curve plotted to a convenient scale. 
Data determined from Figure 3 , and plotted in Figures 4 and 5

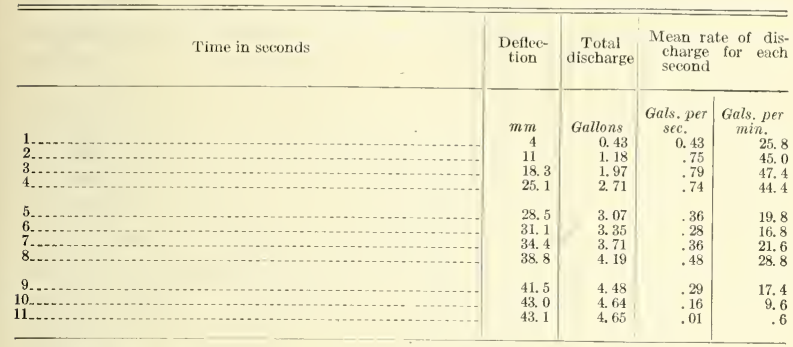

The slight waves observed in the record curve do not materially affect the accuracy and are entirely eliminated in the plotted curve. Figure 5 is the derivative curve of the same discharge plotted with

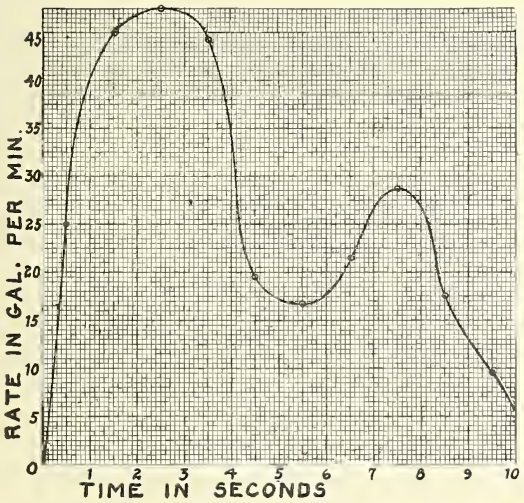

FIg. 5.-Derivative curve (rate of discharge against time) plotted from Figure 3 . Total discharge 4.7 gallons, peak discharge 45.8 gallons per minute, mean rate of discharge 30.0 gallons por minute

rates of discharge in gallons per minute as ordinates and time in seconds as abscissa. The data for this last form of curve are obtained by reducing the mean rate of discharge for each second of the total time of discharge to rate of discharge in gallons per minute. The exact maximum at a point is in some cases slightly higher than the maximum obtained in the above mamer. This difference is partially corrected by the method of drawing a smooth curve through the plotted points of the derivative curve, thus giving in many cases

$94877^{\circ}-24-6$ 
a slightly higher maximum than any plotted point on the curve and one corresponding to the maximum slope of the original curve. The difference, however, is unimportant, since a maximum that does not last for more than one second can have little effect on the combined maximum rate of discharge from two or more water-closets. In this connection we have considered a mean maximum rate of discharge over a two-second interval, which we refer to as the peak discharge. This is believed to be a more representative value than the simple maximum for two reasons, first in all efficient flushes the approximate maximum was sustained for periods of from two to three seconds, and, second, any swell in the discharge of shorter duration has but slight bearing on the problem. It will be noticed that for all high rates of supply the "peak discharge" and maximum rate of discharge approach the same value. The mean rate of discharge recorded is the mean for the whole time neglecting the trail discharge at the end. This is approximately the same as the mean rate of supply to the water-closet. The reader is cautioned against confusing the rate of supply and rate of discharge in later discussions.

A number of derivative curves plotted as in Figure 5, with descriptive details of the conditions under which each was determined, follow. These are believed to be sufficiently representative of the characteristics and rates of discharge from water-closets under different conditions for our purpose. It should be kept in mind that the detailed results herein recorded represent a small part of the total work done on the subject. Duplicate records of most determinations were made. The method is sufficiently accurate that, in general, duplicates superimposed show no difference to the eye. The slight differences that do appear are evidently due to variations in the operation of the supply devices rather than to inaccuracies in the weighing and recording apparatus. No attempt has been made to average duplicate records, since such averages tend to obscure the true characteristics of the discharge.

In order to give the reader a conception of the extent of the work and the quantity of data obtained the following table is added:

\begin{tabular}{|c|c|c|c|c|}
\hline Fixture & $\begin{array}{l}\text { Number } \\
\text { of differ- } \\
\text { ent types } \\
\text { em- } \\
\text { ployed }\end{array}$ & $\begin{array}{c}\text { Number } \\
\text { of varia- } \\
\text { tions in } \\
\text { discharge } \\
\text { pipes }\end{array}$ & $\begin{array}{l}\text { Number } \\
\text { of varia- } \\
\text { tions in } \\
\text { supply }{ }^{2}\end{array}$ & $\begin{array}{l}\text { Approx- } \\
\text { imate } \\
\text { total } \\
\text { number } \\
\text { of } \\
\text { records }\end{array}$ \\
\hline $\begin{array}{l}\text { Water-closet } \\
\text { Bathtub } \\
\text { Washbasin } \\
\text { Kitchen sink } \\
\text { Laundry tray }\end{array}$ & $\begin{array}{l}6 \\
2 \\
2 \\
2 \\
2 \\
2\end{array}$ & $\begin{array}{l}3 \\
4 \\
6 \\
4 \\
6\end{array}$ & $\begin{array}{l}3 \text { to } 5 .-.- \\
\text { None-.- } \\
\text { None--.- } \\
\text { None--.- } \\
\text { None.-.- }\end{array}$ & $\begin{array}{r}150 \\
16 \\
24 \\
16 \\
24\end{array}$ \\
\hline Grand total & & & & 230 \\
\hline
\end{tabular}

1"Standing fixtures," bathtubs, washbasins, kitchen sinks, and laundry trays were rated with vessels filled to the overflow or to fixed depths and were discharged by lifting the plug. 


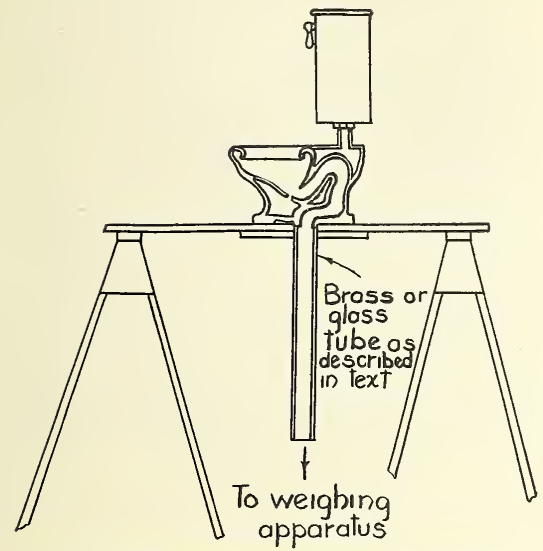

Fig. 6.-Experimental system for rating water-closet discharges

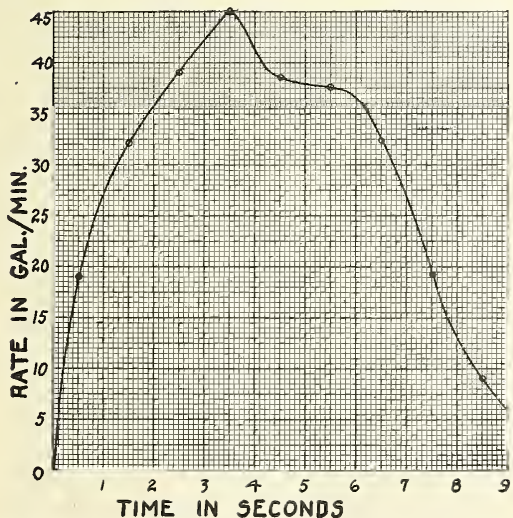

Fig. 7.-Rate of discharge curve for a Maddox wash-down bowl, 6-gallon low tank with 2-inch elbow flush pipe, discharged through a straight unvented glass tube $2 \frac{7}{4}$ inches diameter by 2 feet 8 inches long. (See fig. 6.) Total discharge 4.6 gallons, peak discharge 40.5 gallons per minute, mean rate of discharge 34.2 gallons per minute 


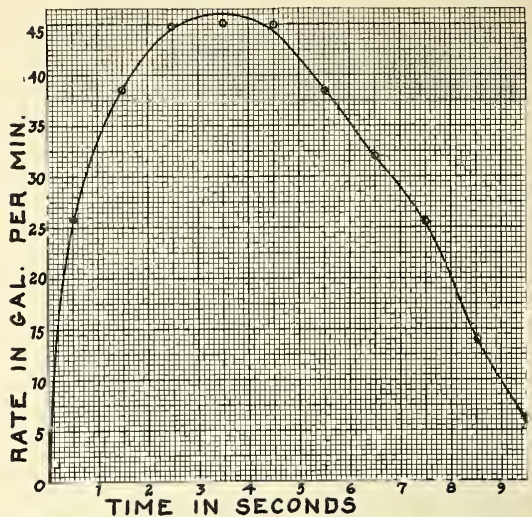

Fig. 8.-Rate of discharge curve for the Maddox wash-down bowl, 8-gallon low tank with 2-inch elbow flush pipe, discharged through the straight glass tube. Total discharge 5.3 gallons, peak discharge 45.0 gallons per minute, mean rate of discharge 37.6 gallons per minute

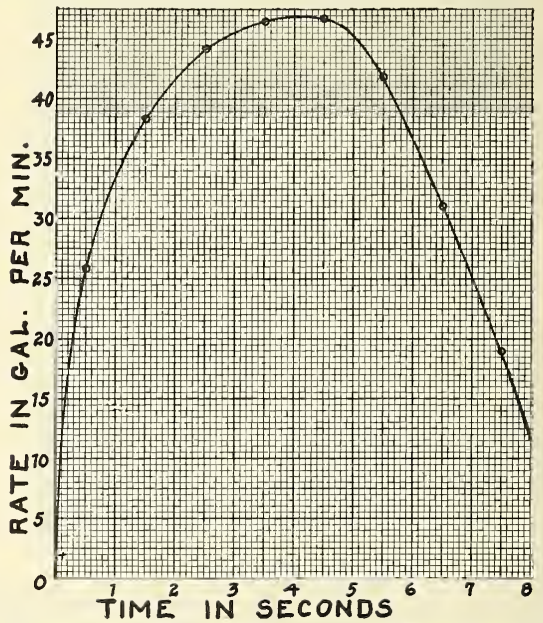

Fig. 9, Rate of diseharge curve for the Maddox wash-down bowl, 8-gallon low tank with 2-inch elbow flush pipe, discharged through a straight unvented brass tube 4 inches diameter by 2 feet 5 inches long, Total discharge 5.1 gallons, peak discharge 46.1 gallons per minute, mean rate of discharge 40.2 gallons per minute 


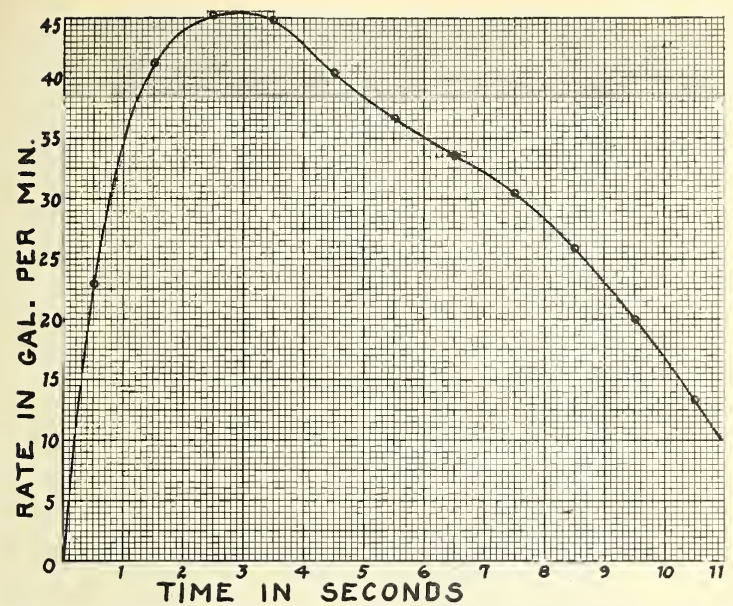

FIG. 10.-Rate of discharge curve for the same set-up as Figure 9, with the tank valve held open until the tank was nearly empty, then allowed to close automatically. Total discharge 6.0 gallons, peak discharge 44.3 gallons per minute, mean rate of discharge 36.6 gallons per minute

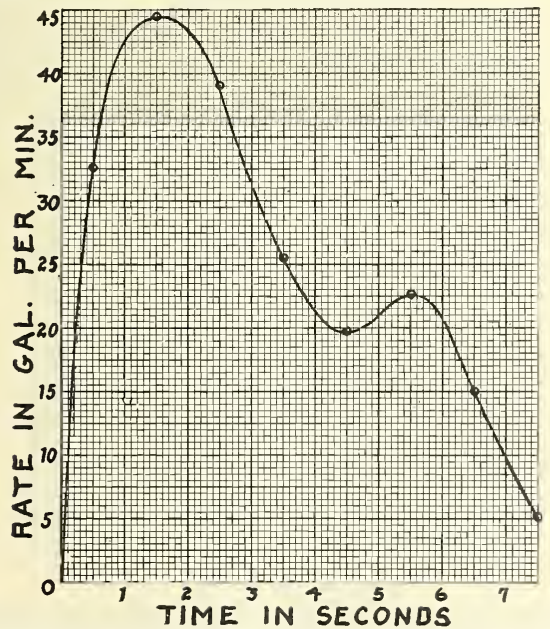

FIG. 11.-Rate of discharge curve for a Maddox siphon jet bowl, 6-gallon high tank with straight flush pipe $1 \frac{1}{2}$ inches diameter by 4 feet 6 inches long, discharged through the straight 4 -inch brass tube. Total discharge 3.8 gallons, peak discharge 40.2 gallons per minute, mean rate of discharge 34.0 gallons per minute 


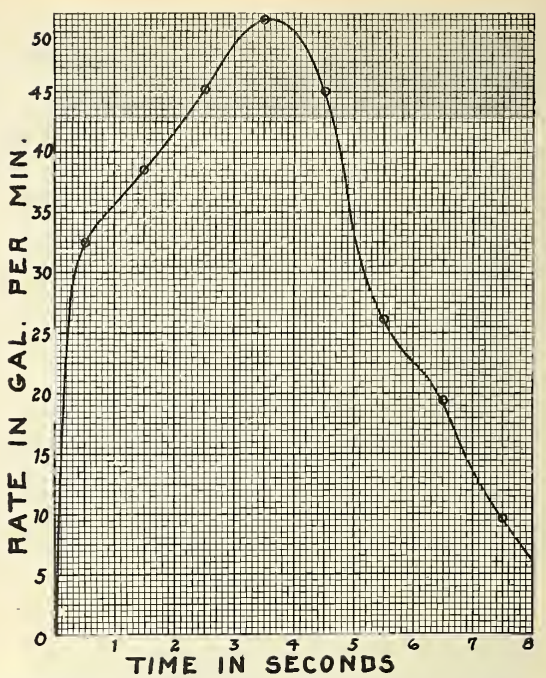

FIG. 12.-Rate of discharge curve for the same set-up as Figure 11, with the tank valve held open 5 seconds, then allowed to close automatically. Total discharge 4.5 gallons, peak discharge 48.0 gallons per minutc, mean.rate o discharge 40.5 gallons per minute

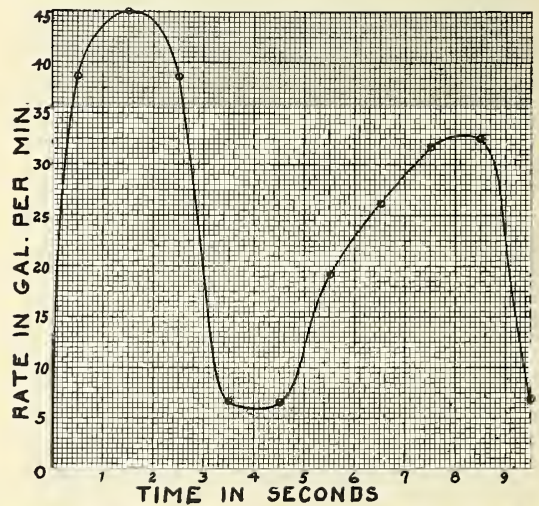

FIG. 13.-Rate of discharge curve for the Maddox siphon jet bowl, 6-gallon high tank, with straight 1x-inch flush pipe, discharged through the 27 -inch glass tube. Total discharge 4.2 gallons, peak discharge 41.7 gallons per minute, mean rate of discharge 27.6 gallons per minute 


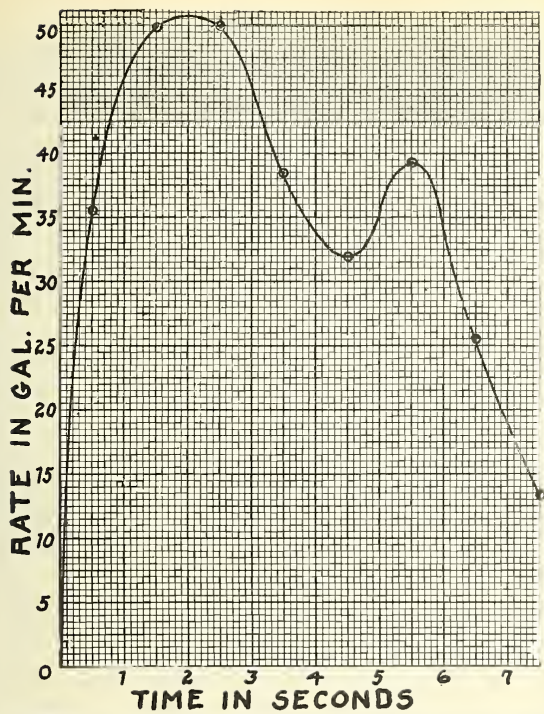

FIG. 14,-Rate of discharge curve for the same set-up as Figure 13, with the tank valve held open for 5 seconds, then allowed to close automatically. Total discharge 4.7 gallons, peak discharge 47.7 gallons per minute, mean rate of discharge 38.1 gallons per minute

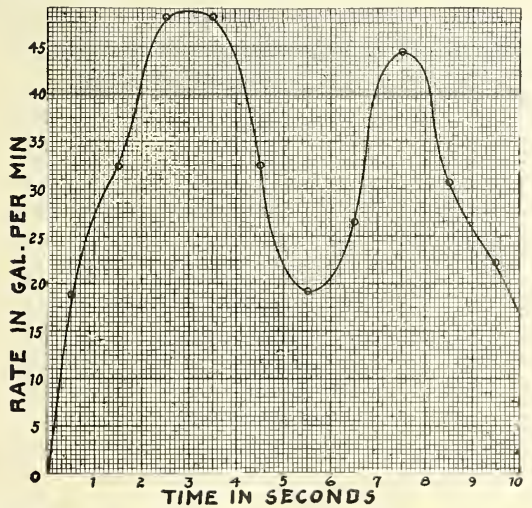

Fig. 15.-Rate of discharge curve for the Maddox siphon jet bowl, 8-gallon low tank with straight 2-inch flush pipe, discharged through the $2 \frac{7}{5}$-inch glass tube. Total discharge 55 gallons, peak discharge 45.2 gallons per minute, mean rate of discharge 33.6 gallons per minute 


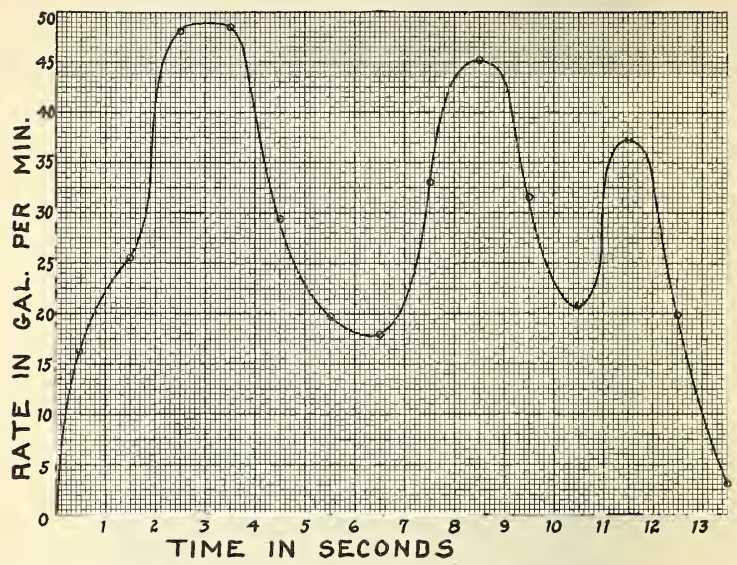

Fig. 16.-Rate of discharge curve for the same set-up as Figure 15, with the tank valve held open until the tank was nearly empty, then allowed to close automatically. Total discharge 6.6 gallons, peak discharge 44.2 gallons per minute, mean rate of discharge 31.2 gallons per minute

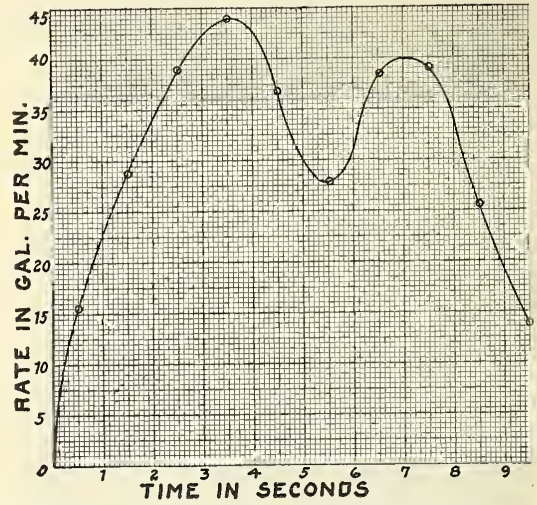

Fig. 17,-Rate of discharge curve for the Maddox siphon jet bowl, 8-gallon low tank with straight 2-inch flush pipe, discharged through the 4 -inch brass tube. Total discharge 5.2 gallons, peak discharge 41.0 gallons per minute, mean rate of discharge 33.4 gallons per minute 


\section{WATER-CLOSETS}

The water-closet supply tanks used in the plotted determinations were filled automatically through the supply valve furnished with the tank, operating on a supply with pressure varying from 50 to 60 pounds per square inch. The floats were adjusted to allow the tanks to fill approximately to the overflow, thus giving a greater total volume and slightly greater rate of supply than the same tanks would give in service where they are usually adjusted to give a margin of safety in the overflow. The water-closets were flushed by fully opening the tank valve, then allowing it to close automatically under

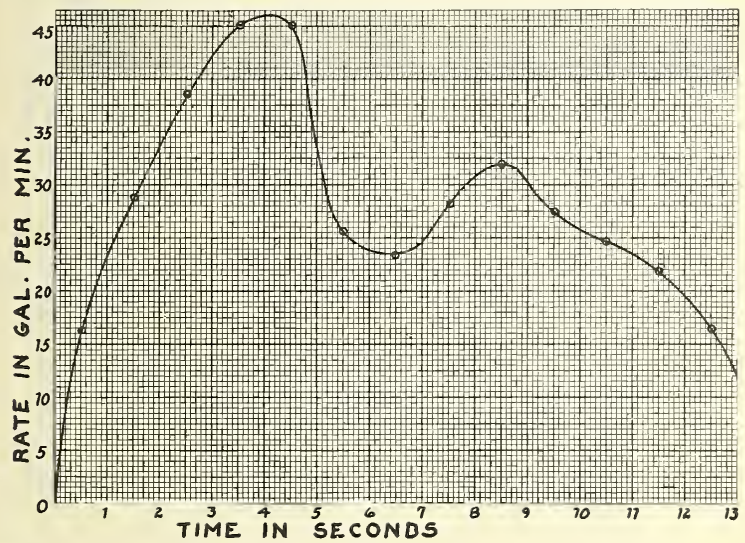

Fig. 18.-Rate of discharge curve for the same set-up as Figure 17, with the tank valve held open until the tank was nearly empty, then allowed to close automatically. Total discharge 6.3 gallons, peak discharge 42.7 gallons per minute, mean rate of discharge 30.0 gallons per minute

the tank refill, except in a few instances specifically noted in the legend of the figure when the valve was held open for a period.

The maximum rate of discharge may be read from the graph. The total discharge, "peak discharge," and mean rate of discharge (mean rate of supply) are recorded with each graph.

The curves shown in Figures 20 to 38 were obtained by discharging the water-closets through a 3 -inch cast-iron closet bend "sanitary $\mathrm{T}$ " and short section of glass pipe, more nearly representing service conditions than the preceding determinations. The upper end of the "sanitary T" was left open, venting the discharge system at this point. The glass section extended 20 inches below the "sanitary $T "$ fitting (fig. 19). 
Figure 19 also shows a water-supply line, not drawn to scale, which was used for flush valves in a few experiments. The supply line consisted of a three-fourth-inch section about 30 feet long leading from a 2 -inch main in which the static pressure varied between 50 and 60 pounds per square inch, and a 1-inch section connecting from the three-fourth-inch section to the flush valve, with gate valves and one-fourth bends as indicated. The three-fourth-inch supply line was old and gave inadequate supply, so was discarded for the new supply line run later. Two curves (figs. 24 and 25) are shown to illustrate the characteristics with low rates of supply yet

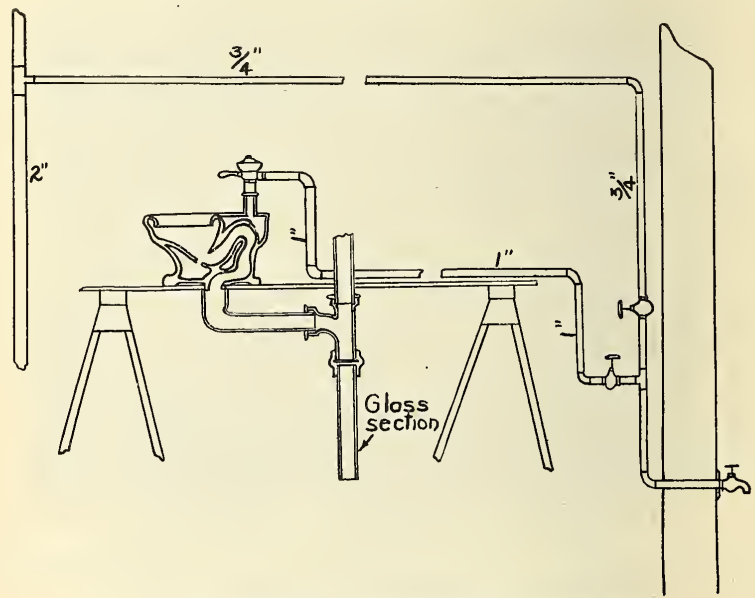

FIG. 19.-Experimental supply and discharge systems for rating water-closets

sufficient to induce siphon action in the closet bowl. It should be noted that the rate of supply for these two curves is limited by the supply line, and only slight change was produced by adjustments in the flush valve.

To give adequate supply and allow adjustment in the rate of supply, a new supply line, not drawn to scale (fig. 26), was installed. It consisted of a $1 \frac{1}{2}$-inch section about 16 feet long leading from the 2 -inch main and a section of 1 inch about $9 \frac{1}{4}$ feet long from the $1 \frac{1}{2}-$ inch section to the flush valve, with gate valve, pressure gauge, and elbows in positions shown in the figures. The gate valve was installed to throttle the line and control the maximum rate of supply and in a measure controlled the operating pressure in the 1-inch section 


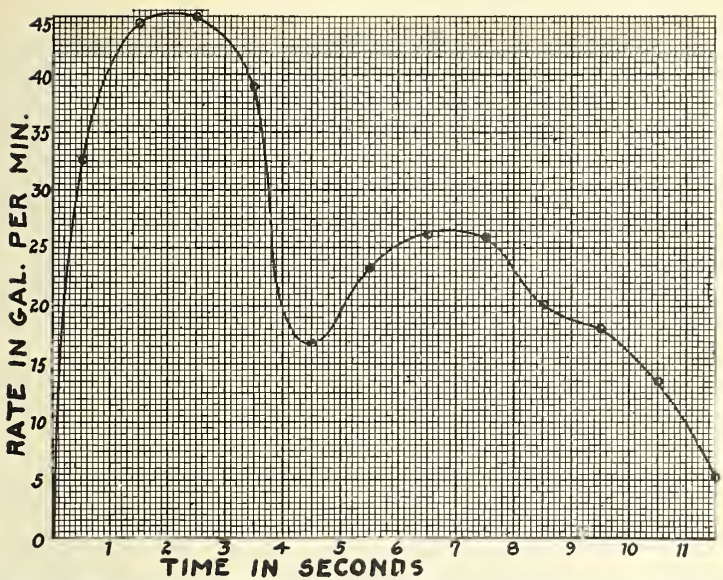

FIG. 20.-Rate of discharge curve for the Maddox siphon jet bowl, 6-gallon high tank with straight $1 \frac{1}{2}$-inch flush pipe, discharged through 3-inch cast-iron closet bend. (See fig. 19.) Total discharge 5.1 gallons, peak discharge 43.6 gallons per minute, mean rate of discharge 28.8 gallons per minute

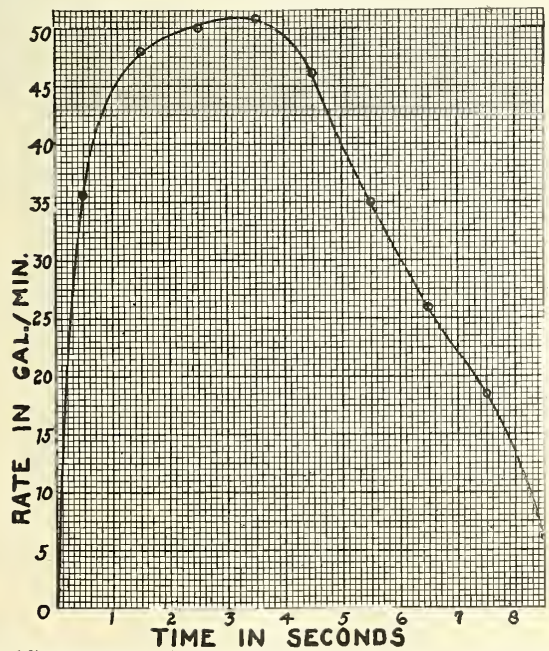

Fro. 21.-Rate of discharge curve for the same set-up as Figure 20, with the tank valve held open 5 seconds, then allowed to close automatically. "Total discharge 5.2 gallons, peak discharge 49.7 gallons per minute, mean rate of discharge 40.8 gallons per minute 


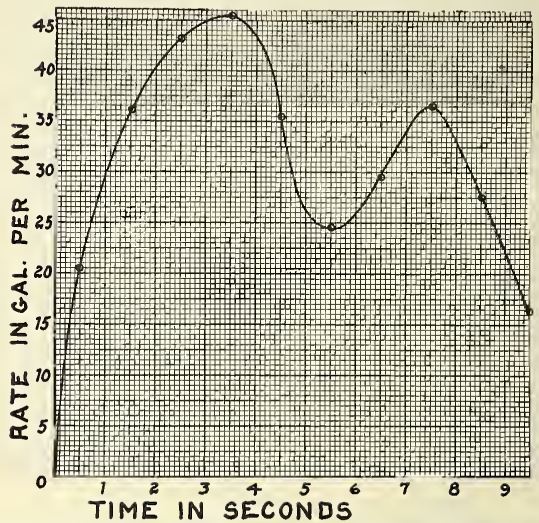

FIG. 22,-Rate of discharge curve for the Maddox siphon jet bowl, 8-gallon low tank with straight 2-inch flush pife, discharged through the 3 -inch closet bend. Total discharge 5.2 gallons, peak discharge 43.5 gallons per minute, mean rate of discharge 35.5 gallons per minute

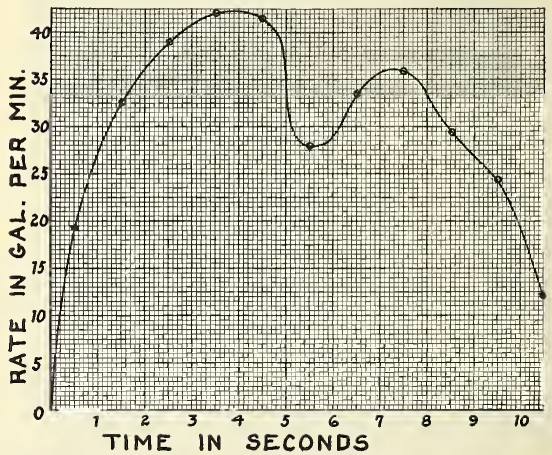

FIG. 23.-Rate of discharge curve for the same set-up as Figure 22 with toilet paper and semisolid matter added to represent soil. Total discharge 5.6 gallons, peak discharge 41.0 gallons per minute, mean rate of discharge 31.8 gallons per minute 


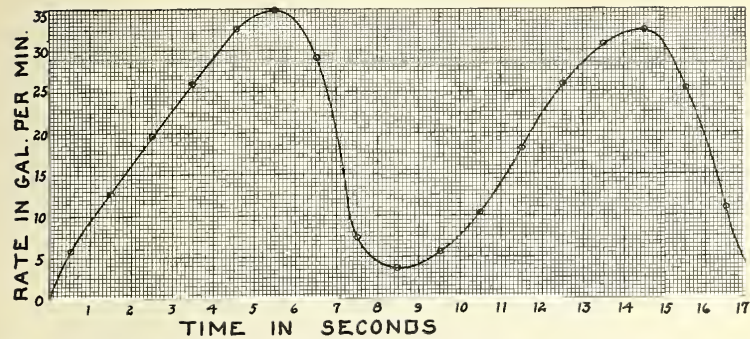

FIG. 24.- Rate of discharge curve for the Maddox siphon jet bowl, supplied by a Sloan flush valve operating on a ${ }_{4}^{3}$-inch supply line (see fig. 19) discharged through the 3-inch closet bend. Total discharge 5.5 gallons, peak discharge 33.1 gallons per minute, mean rate of discharge 19.8 gallons per minute

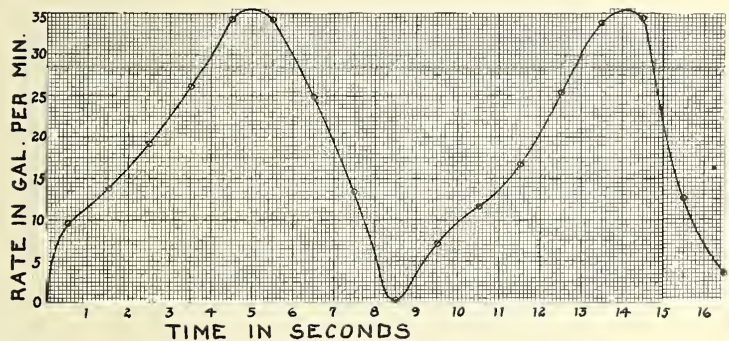

FIG. 25.- Rate of discharge curve for the same set-up as Figure 24 except a special high-rate guide was used on the valve seat. Total discharge 5.2 gallons, peak discharge 32.5 gallons per minute, mean rate of discharge 20.4 gallons per minute

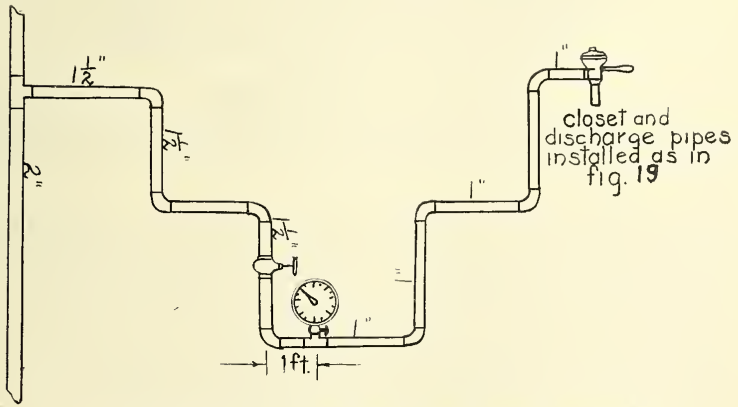

Fig. 26.--Supply line used for flush valves in rating water-ctoset discharges 
of the supply line. The pressure gauge enabled us to read the static pressure in the supply line and the minimum pressure to which the pressure dropped in the 1-inch section of the line during operation. The static pressure in the line at the time is recorded as the maximum pressure and varied between 44 and 60 pounds per square inch. The minimum pressure is also recorded for each figure given and represents the lowest operating pressure for the 1-inch section in that particular experiment. The valves opened and closed under the maximum

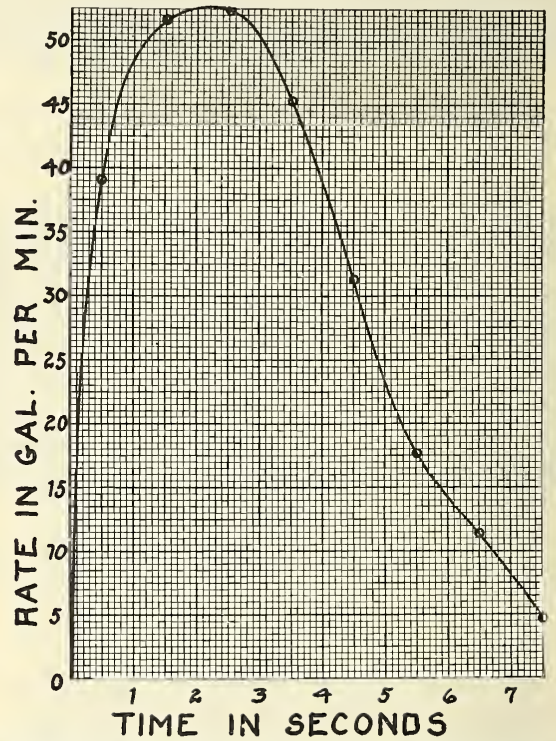

FIG. 27.-Rate of discharge curve for the Maddox siphon jet bowl supplied by Sloan flush valve operating on 1-inch supply line (fig. 26) under 57 pounds maximum and 26 pounds minimum pressure. Total discharge 4.2 gallons, peak discharge 50.7 gallons per minute, mean rate of discharge 39.6 gallons per minute

pressure. The operating pressure quickly dropped to the minimum when the flush valve was opened, and gradually approached the maximum as the valve closed. This variation in operating pressure is similar to the variation that occurs in service lines during use. When supply lines give unnecessarily high rates under the service pressure, the rate of supply may be reduced to the desired value by partially closing the shut-off valve usually installed with flush valves. The general effect is similar to that produced by partially closing the gate valve in the experimental supply line used. 
It is recognized that had the testing of flush valves been our purpose the work would be incomplete without a more accurate control of the operating pressure by means of pressure regulators or other devices. The variations secured were sufficient for our immediate purpose, namely, the determination of rates and characteristies of the discharge from water-closets relative to the rate of supply.

In this connection we wish to state that we have made no tests on flush valves, and that their use has been incidental to the other experiments. It is true we have gained some information on the relative merits of the flush valves used, which we withhold from this report.

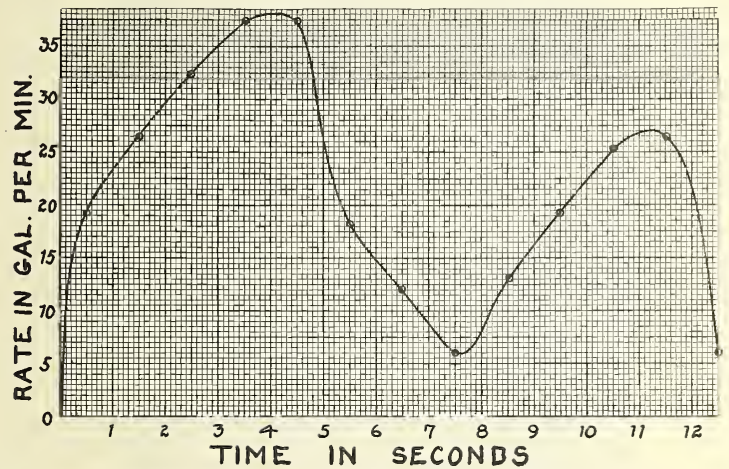

FIG. 28.-Rate of discharge curve for the same set-up as Figure 27, flush valve operating under 55 pounds maximum and 5 pounds minimum pressure. Total discharge 4.6 gallons, peak discharge 35.9 gallons per minute, mean rate of discharge 22.8 gallons per minute

It would be unfair to the manufacturers to publish incomplete data on the subject.

Interpretation and Discussion of Results.-In the interpretation of the preceding rate-of-discharge curves it is essential that the characteristics of the discharge producing the best results be kept in mind. The most certain and efficient cleansing of the water-closet bowl occurs when there is a strong siphon action in the first two or three seconds, followed by a period of weak or broken siphon action, during which the bowl is practically empty, and this in turn followed by a second siphon action. These characteristics appear in the rate curves as a maximum point on from the second to the fourth second, followed by a minimum or decided tendency toward a minimum point, in turn followed by a second maximum point lower than the first. The curves showing these maxima and minima points as described are indicative of strong efficient flushes. 
If the rate of supply is too low, a complete break in the siphon action occurs, and in extreme cases the minimum point approaches zero while the bowl is refilling following the first siphon action. (See figs. 24 and 25.) The result is a sluggish and uncertain flush. If the rate of supply is too high, the siphon action becomes continuous with the bowl partially filled until the end of the flush. This may result in paper and fecal matter being floated in the bowl to settle to the bottom,

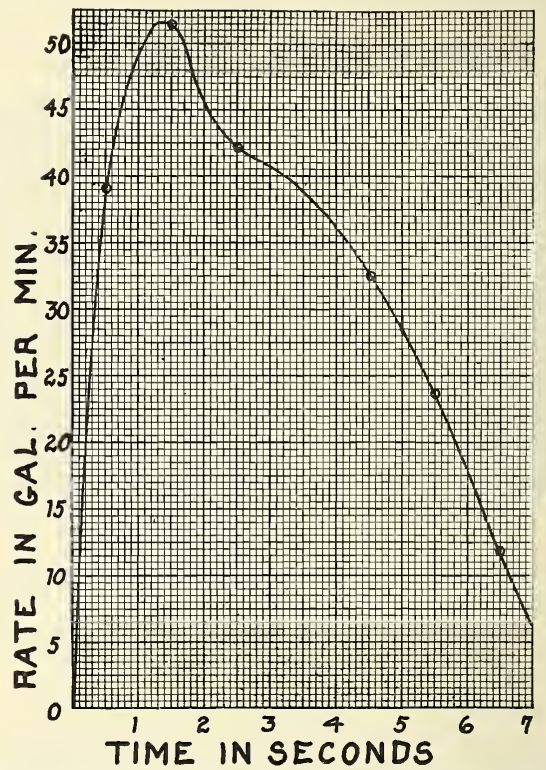

Fig, 29,--Rate of discharge curve for a Mott siphon jet bowl supplied by Sloan flush valve operating under 50 pounds maximum and 25 pounds minimum pressure. Total discharge 4.0 gallons, peak discharge 46.6 gallons per minute, mean rate of discharge 37.2 gallons per minute

or at best to be drawn into the trap at the end of the flush, and in an incomplete refill, due to the flush ending with a strong siphon action. The curves showing a single maximum with no tendency toward a minimum point are indicative of rates of supply too high for the best results. The dividing line appears to be that which permits the discharge to drop from a maximum to an approximately constant rate of flow. (See figs. 10, 31, and 36.) A rate lower than this permits the formation of a minimum (figs. 11, 14, and 17). A rate higher than 
this gives a continuous rate of discharge approximately equal to the maximum, which drops abruptly at the end of the discharge (figs. 9, 12 , and 21). The conclusion, therefore, is that a rate of supply that does not permit the formation of a minimum is unnecessarily high. The siphon jet bowl, due to the jet action, has a somewhat wider range of serviceable supply than the wash-down bowl, and for the same reason the upper limit of the most serviceable rates is not as sharply marked as for the wash-down bowl.

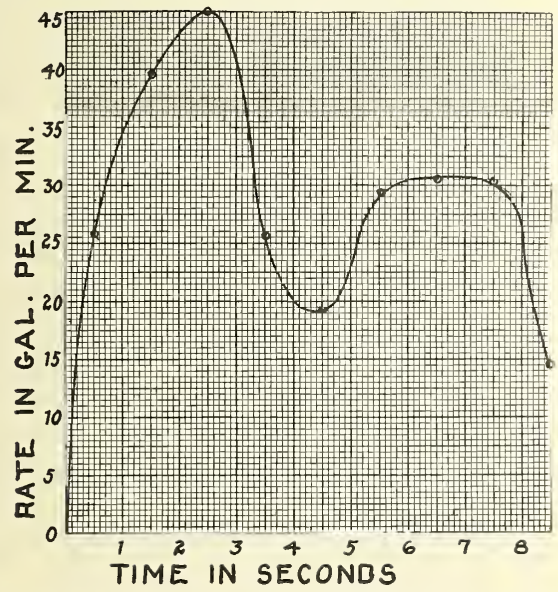

Fig. 30.- Rate of discharge curve for the same set-up as Figure 29, the flush valve operating under 44 pounds maximum and 14 pounds minimum pressure. Total discharge 4.3 gallons, peak discharge 40.8 gallons per minute, mean rate of discharge 30.4 gallons per minute

It is impossible to fix a definite value for either the rate of supply or the total quantity of water required which will give the best results for all water-closets. These will vary with different bowls and conditions. There are, however, pretty definite limits within which the serviceable rates for all water-closets employed in these tests, and we believe all water-closets that should be approved for general use, fall. A study of the curves of discharge given will show that for wash-down closets the curves indicating a strong efficient flush were obtained when the mean rate of discharge and approximately the mean rate of supply was between 27 and 33 gallons per minute. For siphon-jet closets the range is between 24 and 36 gallons per minute. This gives a mean value of approximately 30 
gallons per minute as a rate of supply that, in general, will prove satisfactory for either type of closet bowl. The quantity of water required depends on the duration of the flush. The time varies from 6 to 10 seconds, the lower rate of supply, in general, requiring the longer time. Considering this in connection with the curves of discharge indicates a range of from 3 to 5 gallons as a serviceable quantity. No doubt there are many closets on the market which a

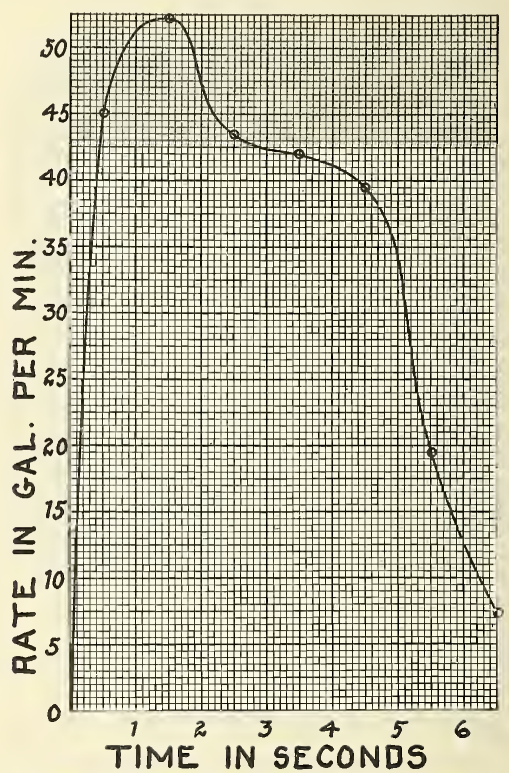

Fig. 31.-Rate of discharge curve for a Trenton Potteries "Speedway" siphon jet bowl supplied by Sloan valve operating under 55 pounds maximum and 28 pounds minimum pressure. Total discharge 4.1 gallons, peak discharge 48.2 gallons per minute, mean rate of discharge 40.2 gallons per minute

smaller quantity would serve satisfactorily under certain conditions. The approximate mean values are, therefore, 4 gallons supplied at the average rate of 30 gallons per minute for eight seconds.

If the mean rate of supply exceeds 36 gallons per minute, in general, not only does a less efficient flush result, but there is an unnecessary waste of water and an unnecessary strain placed on the drainage and sewage-disposal systems. It is believed these are sufficient reasons for prohibiting for general use any flushing device that deliv- 
ers more than 5 gallons or at a mean rate greater than 36 gallons per minute and for prohibiting for general use any water-closet that requires a greater quantity or greater rate than this. This leads to slight, if any, change in existing materials or practice, since practically all flushing devices, with minor adjustments possible and desirable at the time of installation, as well as the requirements of most water-closets, fall within these limits. The details of these restrictions apply more particularly to the water-supply system than to the drainage system, which is the particular field of this investigation and which is concerned only with the limits.

If the above restriction, which is believed justifiable, is granted, we may proceed at once to determine the maximum rate of discharge

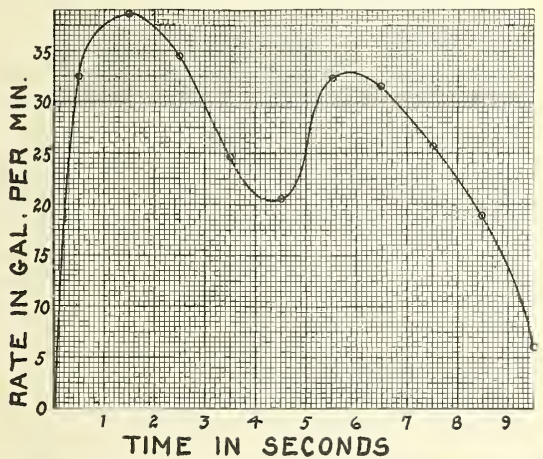

FIG. 32.-Rate of discharge curve for the same set-up as Figure 31, the flush valve operating under 50 pounds maximum and 15 pounds minimum pressure. Total discharge 4.3 gallons, peak discharge 36.0 gallons per minute, mean rate of discharge 28.2 gallons per minute

from water-closets. A further reference to the curves will show that in one case only, in which the mean rate of supply does not axceed 36 gallons per minute, does the "peak discharge" rise above 45 gallons per minute.

There are several reasons for selecting and applying the "peak discharge" (see p. 66) as determined rather than the maximum discharge at a point or for periods as low as 1 second. First, the application will have a particular bearing on the subject only when the peak load is approaching the limiting capacity of the stack or drain. This will be the combined discharge of four or more waterclosets for stacks and possibly three or more water-closets for lateral branch drains. Second, the combined discharge from several waterclosets in coincidence or overlapping will, in general, be more uniform than the discharge from any single one of the group. This 
combined discharge will become more uniform as the number of water-closets is increased. Third, in general, not more than two water-closets will discharge at the same point in a system and the effect, barring stoppage or overcharging, will tend to make combined discharges when overlapping occurs more uniform and tend toward a mean value. And, finally, there is ordinarily but slight difference

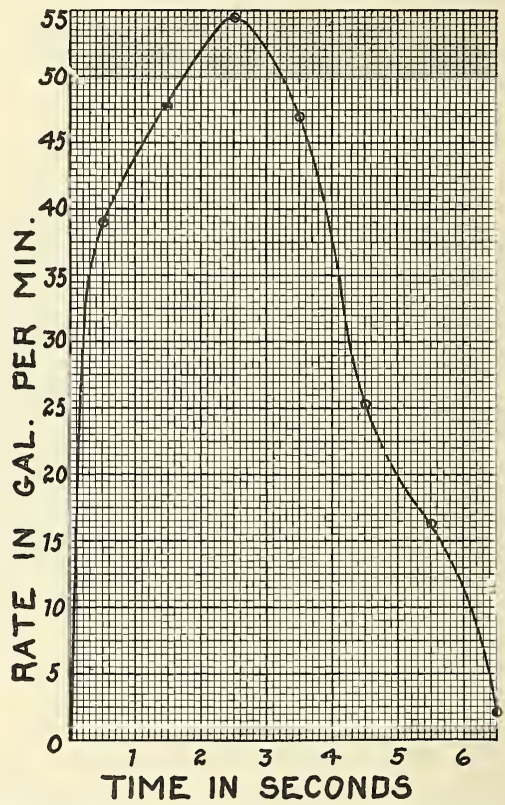

FIG. 33,-Rate of discharge curve for a Trenton Potteries siphon jet bowl supplied by Sloan valve operating under 55 pounds maximum and 33 pounds minimum pressure. Total discharge 3.9 gallons, peak discharge 50.8 gallons per minute, mean rate of discharge 43.2 gallons per minute

between the "peak discharge" and maximum when the rates are high enough to produce a "peak discharge" of 45 gallons per minute.

It therefore seems reasonable to assume a maximum rate of discharge from water-closets to be allowed for of 45 gallons per minute. This is a value that, in general, will not be exceeded and seldom reached if the former reasonable restriction in the rate of supply is adhered to. The rate may be criticized by some as too high, but it should be kept in mind that it is our purpose to fix minimum re- 
quirements on the basis of maximum effects; that the employment of this rate will be relative to the rate of discharge of other plumbing fixtures; and that due to the nature of the material and more thorough scouring the rate will decrease less than that of other fixtures.

FIXTURES OTHER THAN WATER-CLOSETS

The curves of discharge obtained from plumbing fixtures other than water-closets show no characteristic that may not readily be predicted from the conditions involved.

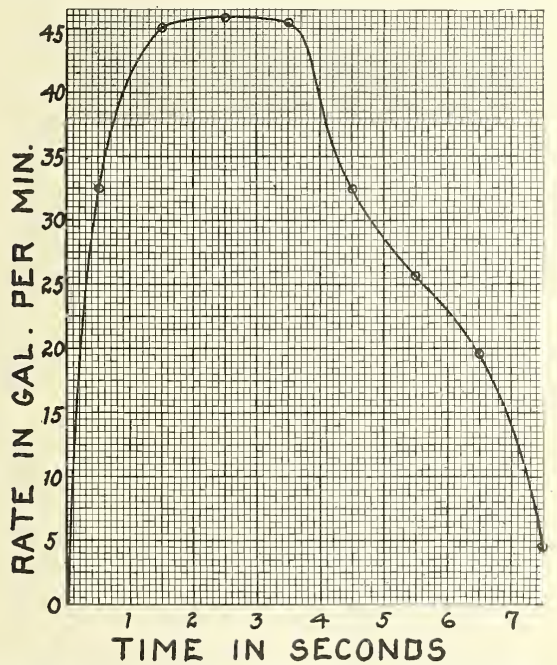

Fig. 34,-Rate of discharge curve for the same set-up as Figure 33 , the flush valve operating under 55 pounds maximum and 21 pounds minimum pressure. Total discharge 4.2 gallons, peak discharge 45.5 gallons per minute, mean rate of discharge 36.6 gallons per minute

The rate of discharge from these fixtures, which we hereafter refer to collectively as "standing fixtures," is evidently dependent on the head of water in the fixture itself, on the developed head in the unvented portion of the waste, on the area of the cross sections of the outlet orifices, tailpiece, trap, and waste, with modifying effects produced by strainer, bends, etc.

The curves of discharge for "standing fixtures" are smooth curves showing a uniformly decreasing rate of discharge with decrease in head in the fixture, the rate of decrease being dependent on the area of horizontal cross section of the fixture. The rate for a given 


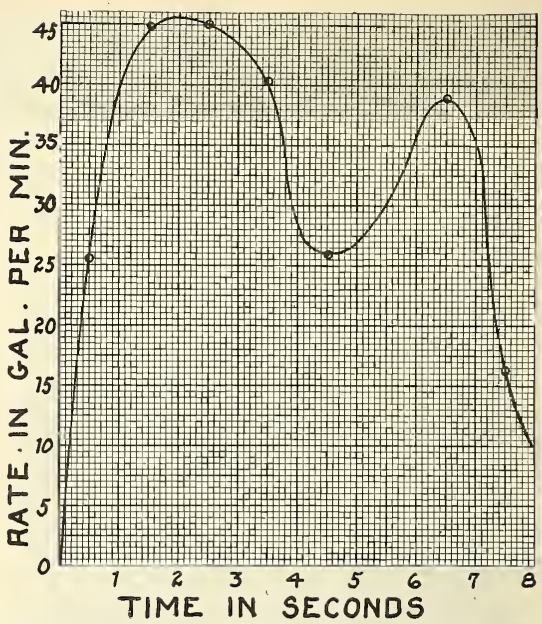

FIG. 35.-Rate of discharge curve for the same set-up as Figures 33 and 34, the flush valve operating under 59 pounds maximum and 12 pounds minimum pressure. Total discharge 4.6 gallons, peak dis. charge 44.1 gallons per minute, mean rate of discharge 33.6 gallons per minute

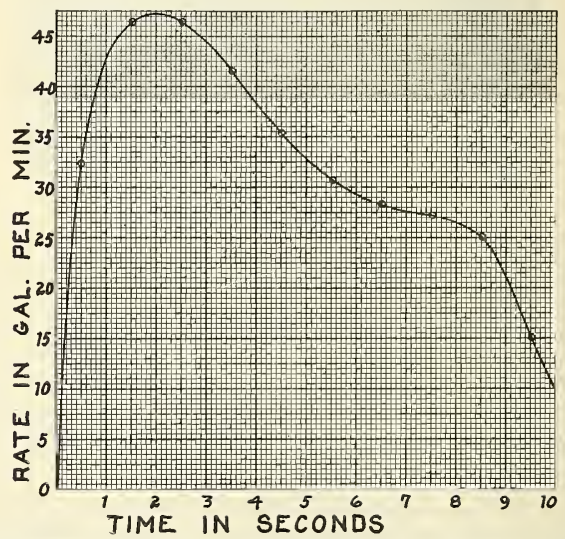

FIG, 36.-Rate of discharge curve for a Trenton Potteries siphon jet bowl supplied by Kenney flush valve operating under 60 pounds maximum and 29 pounds minimum pressure. Total discharge 5.5 gallons, peak discharge 44.6 gallons per minute, mean rate of discharge 34.8 gallons per minute 
head is independent of the area of the cross section and the shape of the fixture.

These points are not of sufficient importance to justify the use of the space necessary for a detailed description and illustration. We therefore omit these curves and data and confine the discussion to results based more on data obtained from fixtures set in place on the stacks of the test installations. After a few determinations

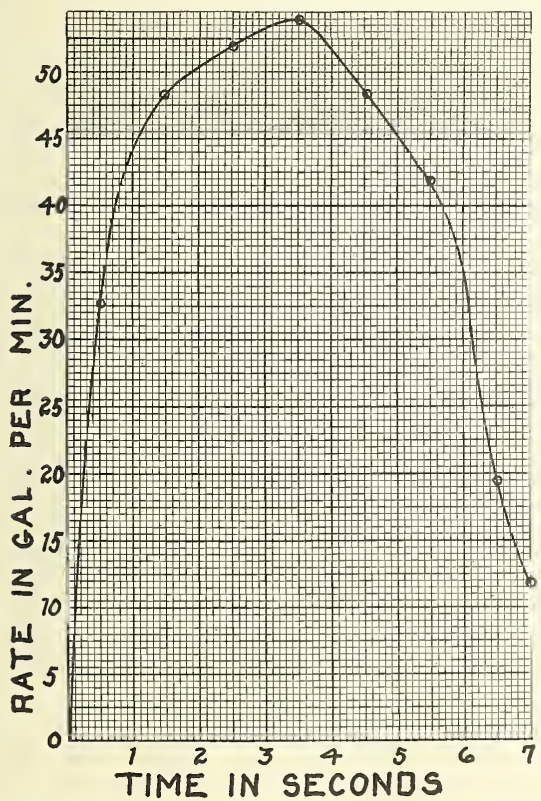

FiG. 37,-Rate of discharge curve for a Trenton Potteries siphon jet bowl supplied by Mott flush valve operating under 60 pounds maximum and 21 pounds minimum pressure. Total discharge 5.0 gallons, peak discharge 52.2 gallons per minute, mean rate of discharge 46.2 gallons per minute

which verify certain of these points it became evident that data for "standing fixtures" more applicable to our purpose could readily be obtained from time and volume measurements with the fixtures set in place on the stacks of the test installations.

It is impossible with the great variety of fittings now in use to establish a single common unit of measure applicable to all. Even by restricting the application to one size of outlet orifice, trap, and 
waste, a unit that will serve to express relative rates of diseharge must at best be a rough approximation. Evidently such a unit should represent highest mean rates of discharge.

The fixtures were fitted with plain $P$ traps and wastes running from the traps to the stacks or vented wastes with one-fourth inch fall to the foot; hence, the rates of diseharge are strictly applieable only when this eondition is approximated. Any ehange in the form of installation, such as the use of an unvented $S$ trap and waste to the floor, that tends to develop a greater head, increases the rate of

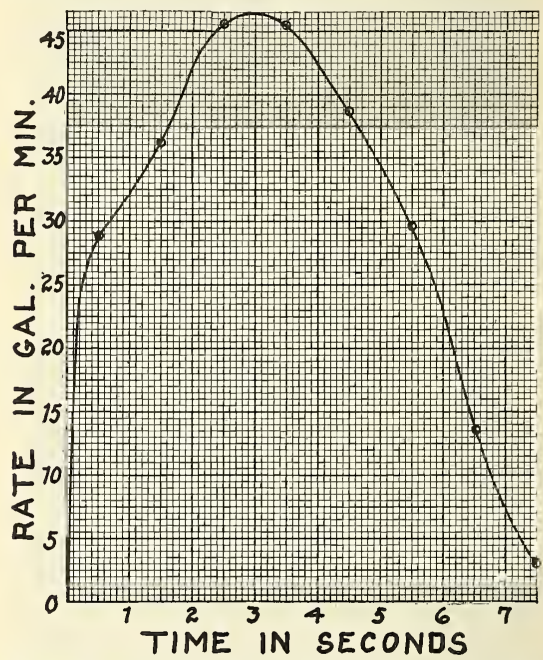

FIG. 38.--Rate of discharge curve for a Trenton Potteries wash-down bowl supplied by Sloan flush valve operating under 55 pounds maximum and 30 pounds minimum pressure. Total discharge 4.0 gallons, peak discharge 44.1 gallons per minute, mean rate of discharge 37.2 gallons per minute

diseharge from that fixture. Ordinarily the application of the same value for either eondition in the case of a small fixture would lead to no diffieulties and would avoid eomplicated tables.

Based on all the data at hand from both sources, we propose the following rates of discharge for "standing fixtures" applicable when the specifications are approximately adhered to:

For washbasins fitted with $1 \frac{1}{4}$-ineh $P$ traps and wastes, with nominal $1 \frac{1}{4}$-inch tailpieces and strainers giving equal eross-seetional areas of orifices, the highest mean rate of discharge is approximately 7.5 gallons ( 1 eubic foot) per minute. 
For bathtubs fitted with $1 \frac{1}{2}$-inch outlet and wastes, and nominal $1 \frac{1}{2}$-inch outlet connections with strainer giving equal cross-sectional areas of orifices, the highest mean rate is approximately 15 gallons per minute.

For kitchen sinks fitted with $1 \frac{1}{2}$-inch $P$ traps and wastes, and nominal $1 \frac{1}{2}$-inch tailpieces with strainers giving equal cross-sectional areas of orifices, the highest mean rate is approximately 11.3 gallons per minute. This refers to the normal use of sinks with the outlet orifice continually open. If the sink is used with a plug and discharged by filling and lifting the plug, the rate of discharge approaches that given for laundry trays.

For laundry trays fitted with $1 \frac{1}{2}$-inch tailpieces, with strainers giving equal cross-sectional areas of orifices, the highest mean rate is approximately 22.5 gallons per minute.

For a combination fixture of one kitchen sink and one or two laundry trays, or of two or three laundry trays, fitted with one $1 \frac{1}{2}$-inch $P$ trap and waste and nominal $1 \frac{1}{2}$-inch tailpieces, the maximum rate of discharge when two or more are discharging simultaneously is not greater, and, in general, is less, than the maximum rate of the one of the group giving the highest rate when discharging alone. This conclusion has been questioned, and in its support we offer the following data obtained from two combinations of laundry trays of two each.

Two single laundry trays practically identical, and without strainers were set end to end on the same level and fitted with a $1 \frac{1}{2}$-inch lead $\mathrm{P}$ trap with nominal 2-inch seal depth and short $1 \frac{1}{2}$-inch wrought-iron waste and nominal $1 \frac{1}{2}$-inch tailpieces and connection. The tailpiece of one tray, $A$, was connected vertically into the $\mathrm{P}$ trap, the tailpiece of the other tray, $B$, was connected vertically into the short arm of a $1 \frac{1}{2}$-inch lead one-fourth bend, and the long arm of the lead bend was wiped into the side of the trap inlet above the water seal, forming a $T$ union. (See fig. 80.) They were filled with the same volume each time and were discharged separately and also together by lifting the plugs simultaneously. The time was taken from lifting the plugs to the beginning of the swirl and trail discharge at the end. The experiment was also repeated using trays $A^{\prime}$ and $B^{\prime}$ of smaller capacity, with strainers.

Combination 1, without strainers

\begin{tabular}{|c|c|c|c|c|}
\hline Volume discharged & $\begin{array}{l}\text { Depth } \\
\text { in } \\
\text { fixture }\end{array}$ & $\begin{array}{l}\text { Time to } \\
\text { empty } \\
\text { single } \\
\text { fixture }\end{array}$ & $\begin{array}{c}\text { Rate per } \\
\text { minute }\end{array}$ & $\begin{array}{l}\text { Time to } \\
\text { empty } \\
\text { each tray } \\
\text { both } \\
\text { flowing }\end{array}$ \\
\hline $\begin{array}{l}\text { A, } 9 \text { gallons. } \\
\text { B,9 gallons }\end{array}$ & $\begin{array}{r}\text { Inches } \\
8 \\
8\end{array}$ & $\begin{array}{r}\text { Seconds } \\
21.4 \\
24.0\end{array}$ & $\begin{array}{r}\text { Gallons } \\
25.2 \\
22.4\end{array}$ & $\begin{array}{r}\text { Seconds } \\
41.9 \\
48.3\end{array}$ \\
\hline
\end{tabular}

Mean rate of discharge with both laundry trays flowing, 22.3 gallons per minute. 
Combination 2, with strainers .

\begin{tabular}{|c|c|c|c|c|}
\hline Volume discharged & $\begin{array}{l}\text { Depth } \\
\text { in } \\
\text { fixture }\end{array}$ & $\begin{array}{l}\text { Time to } \\
\text { empty } \\
\text { single } \\
\text { fisture }\end{array}$ & $\begin{array}{c}\text { Rate per } \\
\text { minute }\end{array}$ & $\begin{array}{l}\text { Time to } \\
\text { empty } \\
\text { each tray } \\
\text { both } \\
\text { flowing }\end{array}$ \\
\hline $\begin{array}{l}\mathrm{A}^{\prime}, 9 \text { gallons } . . . \\
\mathrm{B}^{\prime}, 9 \text { gallons } . . .\end{array}$ & $\begin{array}{r}\text { Inches } \\
8 \frac{1}{2} \\
8 \frac{1}{2}\end{array}$ & $\begin{array}{r}\text { Seconds } \\
22.4 \\
23.6\end{array}$ & $\begin{array}{r}\text { Gallons } \\
24.3 \\
22.8\end{array}$ & $\begin{array}{r}\text { Seconds } \\
38.1 \\
46.8\end{array}$ \\
\hline
\end{tabular}

Mean rate of discharge with both laundry trays flowing, 22.9 gallons per minute.

These results are as were anticipated and are fully explained by the fact that the resistance at the point of junction of two streams from different directions more than balances the decreases in resistance, due to the two outlets to the point of junction, the head being the same in both cases. The above is true in case there is no material change in sizes of waste. If the trap and waste were increased in size at and beyond the point of junction over that of the waste pipes to the point of junction, the combined rate of discharge would be greater than the rate of a single fixture of the combination, but in no case would it be double that of the one giving the highest rate of discharge. It may be anything between these values, depending on the relative lengths and cross-sectional areas of the portions of the combination waste pipes. The combination rate in most cases is nearer that of a single fixture than double the rate and frequently falls below the rate of a single fixture. It therefore seems reasonable to treat combination fixtures as one fixture and groups of fixtures with separate traps as separate fixtures. The normal use of combination fixtures would be separate discharging, so that generally the single-fixture rating would apply directly. The variation in combination rate of discharge from the single-fixture rate of discharge is, in general, so small that no material error would be introduced by treating the combination as one fixture and the discharge rate the same as for a single fixture of the same kind. Any attempt to allow for possible variation in combination fixtures leads to complications that destroy any value attached to a table of relative rates of discharge. Such a table to be of service must necessarily be as simple as possible.

The following table, based on all determinations and observations made, is offered as approximately representing the rates of discharge of the common plumbing fixtures under conditions specified with relative values expressed in fixture units as well as rates of discharge. 
TABLE 1.-Rates of discharge from plumbing fixtures

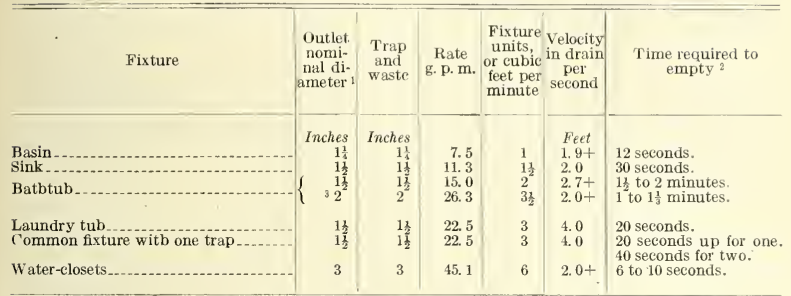

1 Outiets from fixtures are commonly made one nominal size smaller than tbe trap for convenience in making slip-union joints, a practice that offers otber advantages; hence tbe actual diameter is less than stated nominal values, varying from one-eighth to one-fourtb inch.

${ }_{2}^{2}$ Time for emptying the basin and sink are given for the full fixture $1 \frac{1}{2}$ and 6 gallons capacity, respectively. Tbe time given for other fixtures gives a range that will vary witb tbe capacity of the fixture and extent of filling.

${ }^{3}$ No determinations were made with 2-inch batbtub outlets, and the values given represent an estimate to the nearest one-balf fixture unit.

It will be observed that the fixture unit adopted, 7.5 gallons per minute, is approximately 1 cubic foot per minute. It may be found more convenient to express rates of flow in cubic feet per unit time than in gallons per minute as has been done in later tables.

\section{DETERMINATION OF THE PEAK LOAD IN ANY PLUMBING SYSTEM}

In fixing the limits of use of soil stacks and drains it seems to have been the custom to establish arbitrarily a given fraction of the combined discharge of all the fixtures on a plumbing system as representing the probable peak load to be provided for. It is generally recognized that it is unnecessary to provide for the total simultaneous discharge of all the fixtures. While the arbitrary fixing of the peak load is supported to some extent by experience, this only shows that the estimates have been liberal on the side of safety.

\section{METHOD OF PROBABILITIES}

From the standpoint of economy in the installation of plumbing systems it is obviously desirable to secure a closer approximation of the peak load and the frequency of its occurrence based logically upon data representing the conditions involved. This can be done by determining the probability of coincident discharge of the various fixtures based upon the observed frequency of use, the duration of the individual discharge, and the predetermined rates of discharge of the various fixtures.

The application of the method of probabilities to such a problem is not precise, since it is based upon variable and somewhat indeterminate time factors. The results are, therefore, to be regarded as approximations and applicable to large systems more closely than 
to small ones. The method will, however, be found helpful in the analysis of small systems.

To illustrate the method, let us suppose a system composed of five water-closets and assume (1) that each water-closet requires 10 seconds to flush, and (2) that each water-closet is flushed at random once during a 10-minute, or 600-second, interval. Let us assume also that the flushing of two water-closets is coincident if the flush periods overlap nine seconds or more.

Probability may be defined as the ratio of the favorable ways in which an event may occur to the total number of ways, favorable and unfavorable, in which the same event may occur. On the assumption of random flushing, any one of the 5 water-closets may begin its flush during any of the 600 seconds in the 10-minute interval. Therefore, the total number of ways in which the event may occur is $660^{5}$. Suppose we wish to determine the probability of 3 of the 5 water-closets being flushed together. The number of different combinations of 5 objects taken 3 at a time $C_{3}^{5}$ is $\frac{5 \times 4 \times 3}{3 \times 2 \times 1}=10$. The 3 water-closets of any of these combinations may begin their flushes during any one of the 600 seconds, and either of the 2 remaining water-closets may begin its flush during any of the remaining 599 seconds. The number of ways in which the event may occur favorable to the coincidence of 3 water-closets only, is, therefore, $C_{3}^{5} \times 600 \times 599 \times 599=10 \times 600 \times 599^{2}$. Therefore, the probability of 3 only of the 5 water-closets flushing in coincidence is $\frac{10 \times 600 \times 599^{2}}{600^{5}}=\frac{1}{36,115}$, approximately, or once in 36,115 times or cycles.

A close approximation simplifying the computation may be made as follows: In general, if $n$ is the number of water-closets on the system and $r$ the number flushing in coincidence, and $C_{r}^{n}$ the combination of $n$ things $r$ at a time, the probability of coincidence of $r$ only out of $n$ water-closets, provided $r$ is equal to or greater than $\frac{n}{2}$ is $\frac{C_{r}^{n} \times 600 \times 599^{n-r}}{600^{n}}$, which is less than $\frac{C_{r}^{n} 600^{n-r+1}}{600^{n}}=\frac{C_{r}^{n}}{600^{r-1}}$. If $r$ is less than $\frac{n}{2}$, the probability of coincidence of $r$ only is also less than $\frac{C_{r}^{n}}{600^{r-1}}$. The approximation in both cases is close and in reality includes all coincidences from $r$ to $n$ water-closets.

Overlapping Discharges.- It is evident that the chance of actual coincidence is so remote as not to require serious consideration. There is, however, a greater chance for overlapping discharges which may produce effects in a plumbing system quite as great as actual coincidence. It is necessary, therefore, to extend the method to 
include overlapping. The process of transforming the equation to include overlapping is tedious and somewhat complicated. The final form, however, is fully as simple as the original approximation for probability of actual coincidence.

In overlapping both the duration of flush and period of overlap come into the full equation. If we take into account all overlapping of 4 seconds or more in flushes of 10 seconds duration, we shall have included all except trail discharges at the beginning and end of the flush.

If the results determined on the basis of 10 seconds duration of flush and an overlap of 4 seconds or more are applied to a system in which the duration of flush is only 6 seconds, all overlapping will be included. A study of the discharge curves of water-closets in this connection shows that if we allow for an overlap of 4 seconds or more, few, if any, of the overlapping coincidences will give a combined maximum rate of discharge equal to the sum of the maximum rates of the individual water-closets.

Briefly, the inclusion of all overlapping of from 4 to 10 seconds is equivalent to reducing the interval between flushes by the ratio $\frac{10-4}{10-9}=6$. The probability of overlapping flushes then becomes $C_{\mathrm{r}}^{\mathrm{a}} / 100^{r_{-}}{ }^{1}$, and also includes the probability of from $r$ to $n$ waterclosets overlapping. This is evidently fixing sufficiently wide ranges to include all variations that might produce detrimental effects. The probability of 3 or more out of 5 water-closets overlapping 4 seconds or more, then, is $C_{3}^{5} / 100^{2}=\frac{10}{10,000}=\frac{1}{1,000}$. To put the results into a more tangible form and allow for rush periods and periods of infrequent use, they have been reduced to occurrence of once in a period of days or years as follows: If we assume a rush period of two hours daily during which all fixtures on the system are in constant use, and assume that at other times only a small part of the fixtures are in use, then, there will be 12 flushes of each closet, or 12 complete cycles within the two hours rush period in which coincidences may occur, $\frac{60}{10} \times 2=12$. Then the probability of once in 1,000 times or cycles becomes once in $\frac{1,000}{12}=83$ days, or once in $\frac{83}{365}$ years.

If it were possible to deal with accurately determined time intervals throughout, the results by this method might be directly applied with perfect safety. In practice all the factors will vary according to conditions, the duration of the flush with the kind and condition of supply apparatus, the interval between flushes with the number of people using the system and their habits, and the length of the rush period with the type of installation and its location. The effect of 
each of these time factors on the results should be considered in connection with any data on which it is based before passing judgment on the selection of the factor.

The longer the duration of the flush the greater is the probability of overlapping discharges. In selecting this factor we have chosen 10 seconds as the maximum duration of flush which we believe should be permitted for general use and a value that represents an approximate maximum as water-closets are installed at present. The same value would apply in all types of installation.

Mrxed Systems.- -Up to this point we have considered systems composed of water-closets alone. While it is possible by a similar method to calculate probabilities for mixed systems of water-closets and other smaller fixtures, all the time factors vary with the kind of fixture and are more indeterminate for the small fixtures than for water-closets. It may be shown, however, that for two systems both having the same total combined rate of discharge, one composed entirely of water-closets and the other a mixed system of waterclosets and smaller fixtures, the probability of a given volume discharge is greater for the system composed of water-closets than for the mixed system. We therefore propose the extension of the tables for water-closets to include water-closets or equivalents, translating in terms of fixture units. Any error thus introduced will be on the safe side and simplifies the application by reducing the number of tables necessary.

Time Factors.--Before considering the other two time factors, the interval between flushes and the length of the rush period, we would divide installations into at least two classes-private and public. The first class includes homes, private baths in hotels, and such installations, in which a number of fixtures are inclosed in the same room or compartment and are ordinarily not accessible to more than one person at a time. The second class includes publiccomfort stations, railway toilets, factory and office building toilets, schools, etc., in which each fixture is inclosed in a separate compartment or is open and accessible for use at all times. Other classifications might be made if found desirable.

We have prepared Table 2 to apply to the private class of installation and Table 3 to apply to public installations. Table 2 is based on the average interval of 10 minutes between flushes and rush periods of one, two and three hours daily. Table 3 is based on the average interval of five minutes between flushes and rush periods of 2,3 , and 10 hours daily. These two time factors are the most difficult to determine with any degree of accuracy and are the most variable. Both the interval between flushes during the rush period and the length of the rush period should be taken as the averages over the whole period of years considered. It will be observed that the shorter the interval between flushes the greater the probability 
of coincidence or overlapping and the longer the rush period the greater the probability.

We have based the interval between flushes for Table 3 on the data following, supported by our own observations, and by physical limitations as to possible frequency of use. It is physically impossible for a number of people normally to use water-closets at a much higher average rate except as urinals. Table 3 is merely a suggestion of possible application to larger structures and has no application to our immediate problem, the small dwelling house plumbing.

Data furnished to the plumbing committee by C. T. Coley from observation on the Equitable Building, New York, N. Y.

Male population.

Number of toilets in group

Time of observation, 8.30 a. m. to $5 \mathrm{p} . \mathrm{m} \ldots \ldots$ hours $\quad 8 \frac{1}{2}$

Total number of uses

Average time in toilet per person_._._._._._._._._.

Maximum time in toilet per person _._. 37

Minimum time in toilet per person

Apparently, though not stated, there were separate urinals in the toilet room in this instance.

Data furnished to the plumbing committee by Charles F. Horan from observations made at the factory of the Hood Rubber Co., Watertown, Mass.

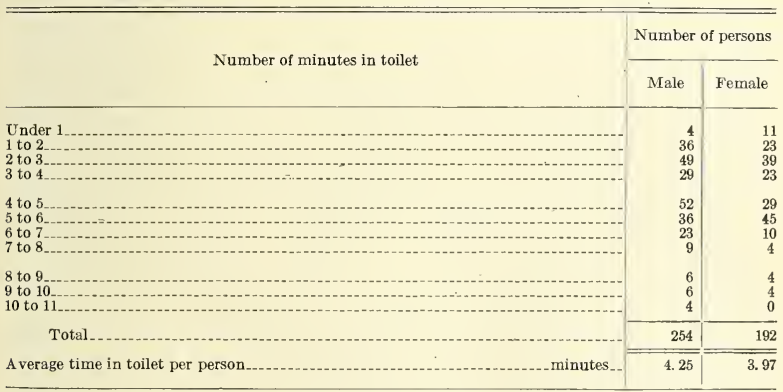

Evidently, though not stated, these observations included use as urinals. Both the very short periods of use and the manner in which the number of persons for different periods vary indicate this. The highest number of uses by males was for between 4 and 5 minutes and the highest number of females between 5 and 6 minutes, indicating an average of approximately 5 minutes when not used as urinals. However, taking the mean of the two sets of data regardless of the kind of use, it is 5.11 minutes per person. The mean, weighted according to number of users, is 5.4 minutes per person. 
The five-minute interval made the basis of Table 3 is close enough to indicate the possibilities of the method as a means of approximation. It would be desirable and perhaps necessary, to secure more data on the subject before making an extended application. The method might also be applied with some modification to the proportioning of water-supply pipes for large buildings.

Table 2 applicable to private systems, though carried beyond the requirements of separate dwelling houses, has some application in this field. The basic difference between the two classes is the inclosure of several fixtures in one room or compartment in the private system. This at once restricts the possible use if privacy is maintained. The time intervals for Table 2 are not based on any specific data, but rather on the extent of use they allow. It is to be kept in mind that the rush period is not only an average over a long period of time, but is independent of the number or duration of the short rush periods into which the assumed daily rush period may be broken. The real consideration is the number of cycles that occur at the rush rate in the entire period of years considered. A rush period of two hours on alternate with none on intervening days will have exactly the same effect in the long run as a rush period of one hour daily.

On this basis consider the extent of service a flushing interval or frequency of use of 10 minutes and a daily rush period of one hour will permit in the case of a mixed system. It will allow an average of six persons to the bath for an average time of 10 minutes each, each person flushing the water-closet, the bathtub, and the basin, or it will allow half the number of persons for double the time each flushing the fixtures twice. If the same number of persons use the bath to the same extent in a two-hour period instead of one hour, the probability of overlapping is decreased. Again, it should be remembered that the method will apply, in general, to systems composed of several bathrooms and that six persons per bath is a high, and 10 minutes per person to use all three fixtures a low, average for these conditions. The liberal allowance here will amply take care of cases of the same person flushing one or more of the fixtures twice in one use of the bathroom. In addition to the use of the bath as described, the assumptions would allow kitchen sinks, laundry trays, and any other separate fixture on the system each to flush 6 times within the one-hour rush period. This is a very liberal allowance for these fixtures. Not only will any rush period for these, in general, be at a different time in the day, but weekly rather than daily for laundry trays. Laundry trays and even kitchen sinks might well be neglected so far as their presence affects the required sizes for main stack and house drain. They have not been disregarded but have been rated at full value throughout. We 
have discussed this subject at length merely to show that any conceivable normal variation in service from the conditions assumed tends to decrease the probability of coincident or of overlapping discharges.

TABLE 2.-Probabilities of overlapping coincidence assuming 10 seconds' duration of flush and 10 minutes interval between flushes with rush periods of 1, 2, and 3 hours daily

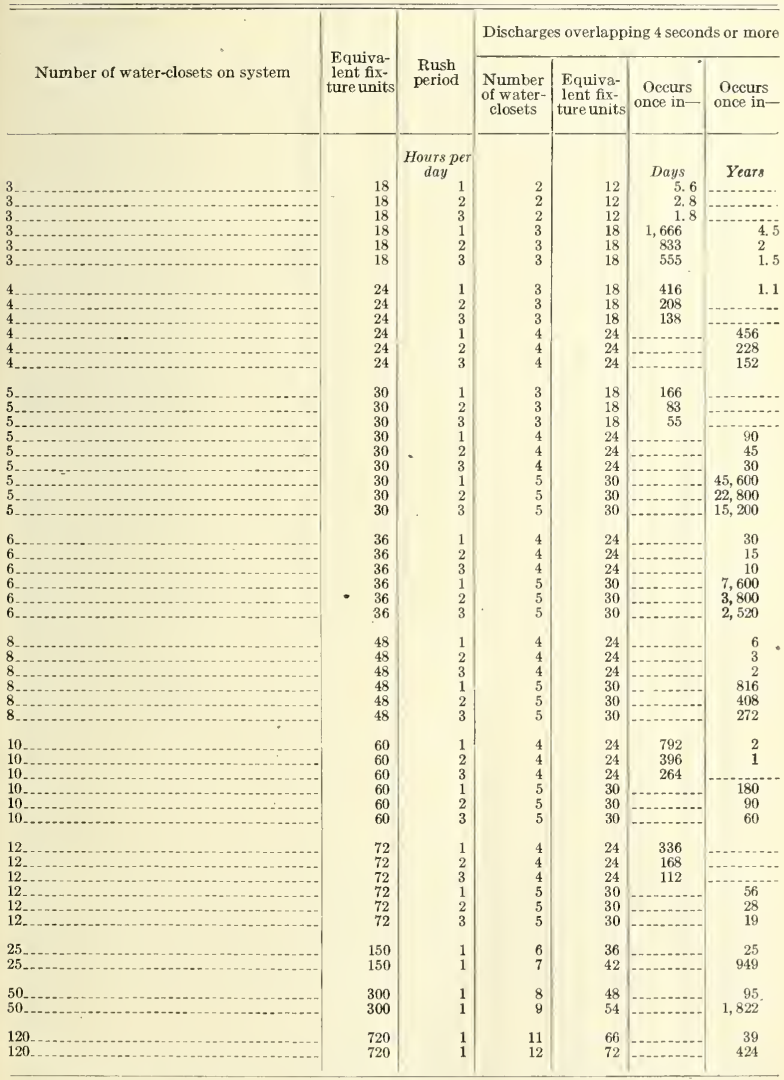


TABLE 3.-Probabilities of overlapping coincidence, assuming 10 seconds duration of flushes and a 5-minute interval between flushes, with rush periods of 2, 3, and 10 hours daily

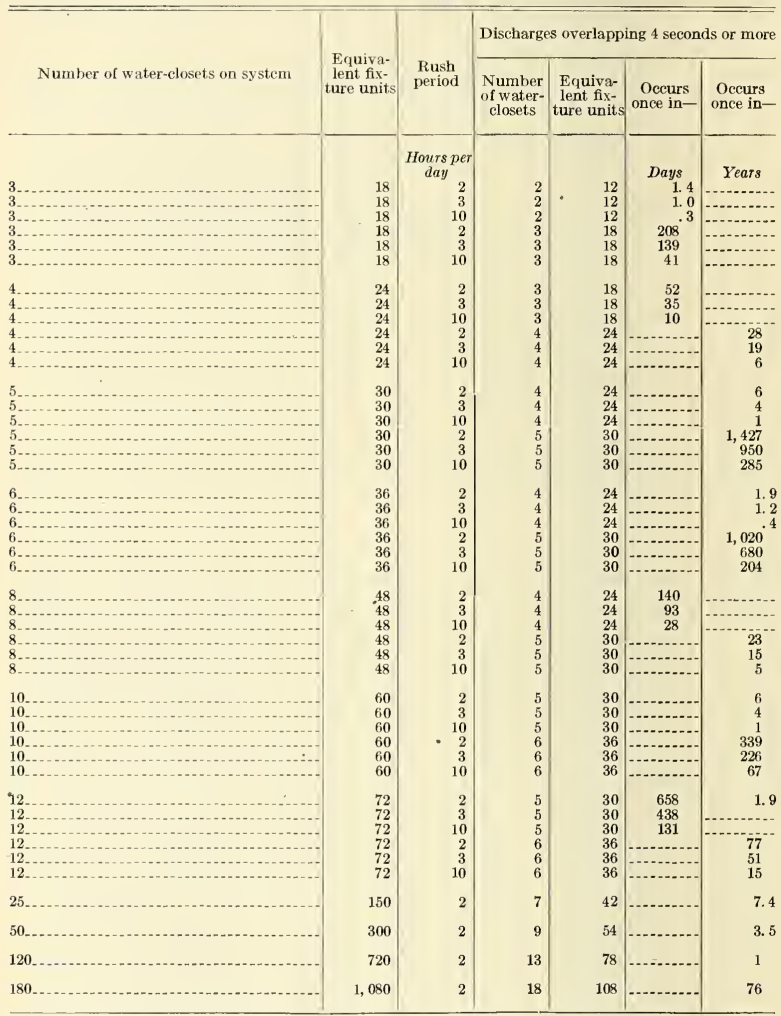

These tables have been placed early in the report for the purposes of reference in later chapters. The question of what frequency of occurrence should be provided for in an installation is one closely connected with establishing a reasonable factor of safety, and the dividing line should vary with the size and character of the installation. We, therefore, leave this question and the details of application for amplification in the chapter dealing with factors of safety in plumbing systems. 


\section{CAPACITIES OF STACKS AND DRAINS}

The problem of accurately determining the carrying capacity of a system of drainage pipes composed of vertical and horizontal sections of varying diameters in which, in general, the vertical sections are only partially filled is difficult in comparison with the determination of the carrying capacity of the same system flowing full under a known head. The problem is further complicated in the plumbing system by the fact that both water and air movements must be taken into account.

Apparently, in view of the varying degrees to which the system or parts of the system may be filled, a very rough approximation of the maximum carrying capacity is all that may be hoped for. The fact that an appreciable head of water developed in any portion of a plumbing system into which branches are discharging tends to impair the efficiency of the drainage indicates a limiting condition on which to base determinations of capacities. While the development of a head of water in certain portions of a given system-namely, in unvented small waste branches-may produce no detrimental effects, the assumption of a condition under which no head can develop in any portion of the stacks or house drain is certainly a safe procedure and apparently the only one that will permit a general application of results. The determinations following have, therefore, been based on this assumption.

With a system composed of vertical and horizontal sections of the same diameter throughout it is evident that on the assumption that no static head may develop the limit of carrying capacity will first be reached in the horizontal sections of the systems. This at once suggests the separate consideration of vertical and horizontal sections. The economical use of material would be that gradation of diameters which gave the same carrying capacities in all sections. The limitations in number of pipe sizes available and the nature of demands from certain fixtures both render such close approximation impractical and again lead to rough approximation by selection of the nearest size above actual requirements.

The plumbing system naturally divides into distinct sectionsthe house drain, the vertical stack or stacks, the lateral horizontal branch drains, and the bends or turns connecting the stacks and vertical branches to horizontal sections. The house drain and large lateral branch drains, which we have referred to as horizontal sections, in reality sections of low hydraulic gradient, may be considered together since either may run full without head. By the expression. "without head" we mean flowing under its own head, that is, without developing a static head above the highest point in the horizontal section.

DRAINS

Existing hydraulic formulas offer means for fairly close approximations under these conditions. Kutter's formula is generally 
accepted as the most applicable to large sizes (14 inches in diameter and over). Darcy's formula is generally considered more accurate for smaller sizes (under 14 inches in diameter), being based on data obtained from pipes in this region while Kutter's formula was based on data obtained from large pipes and open conduits.

Results calculated by Kutter's formula with $n=0.015$ and by Darcy's formula agree for a pipe of 14 inches diameter and show increasing divergence on either side of this diameter, Darcy's formula giving higher values for smaller sized pipes and lower values for large sized pipes than Kutter's formula.

We therefore submit the following table of capacities for pipes flowing full under their own head, based on Darcy's formula for old cast-iron pipes lined with deposit, which is offered for approximating required sizes of lateral drains in which a static head is undesirable or detrimental.

TABLE 4.-Capacities of cast-iron drains, in gallons per minute and fixture units or cubic feet per minute

\begin{tabular}{|c|c|c|c|c|}
\hline \multirow[b]{2}{*}{ Diameter in inches } & \multirow[b]{2}{*}{ Fall } & \multicolumn{2}{|c|}{ Capacities } & \multirow{2}{*}{$\begin{array}{l}\text { Velocity } \\
\text { full or } \\
\text { one-half } \\
\text { full }\end{array}$} \\
\hline & & $\begin{array}{c}\text { Gallons } \\
\text { per } \\
\text { minute }\end{array}$ & $\begin{array}{c}\text { Fixture } \\
\text { units }\end{array}$ & \\
\hline 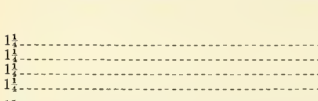 & $\begin{array}{c}\text { Inch per } \\
\text { foot } \\
\frac{\pi}{\frac{\pi}{6}} \\
\frac{1}{\frac{1}{2}} \\
1^{\frac{1}{2}}\end{array}$ & $\begin{array}{r}3.6 \\
5.1 \\
8.0 \\
11.2\end{array}$ & $\begin{array}{l}0.48 \\
.63 \\
1.07 \\
1.50\end{array}$ & 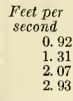 \\
\hline $\begin{array}{l}1 \frac{1}{1}-\cdots \\
1 \frac{1}{2} \\
1 \frac{1}{12} \\
1 \frac{1}{2}-\cdots\end{array}$ & $\begin{array}{r}\frac{1}{6} \\
\frac{1}{3} \\
\frac{3}{2} \\
1^{\frac{1}{2}}\end{array}$ & $\begin{array}{r}5.8 \\
8.2 \\
13.0 \\
18.4\end{array}$ & $\begin{array}{l}.78 \\
1.10 \\
1.70 \\
2.40\end{array}$ & $\begin{array}{l}1.05 \\
1.48 \\
2.34 \\
3.31\end{array}$ \\
\hline $\begin{array}{l}2 \\
2 \\
2 \\
2 \\
2\end{array}$ & \begin{tabular}{r|}
$\frac{1}{1}$ \\
$\frac{1}{3}$ \\
$\frac{1}{2}$ \\
$1^{2}$
\end{tabular} & $\begin{array}{l}12.6 \\
17.6 \\
27.8 \\
40.0\end{array}$ & $\begin{array}{l}1.68 \\
2.25 \\
2.70 \\
5.20\end{array}$ & $\begin{array}{l}1.28 \\
1.80 \\
2.85 \\
4.00\end{array}$ \\
\hline $\begin{array}{l}3 \ldots \ldots \ldots \\
3 \ldots \ldots \\
3 \ldots \ldots \\
3 \\
3\end{array}$ & $\begin{array}{r}\frac{1}{1} \\
\frac{1}{1} \\
\frac{1}{2} \\
1^{2}\end{array}$ & \begin{tabular}{r|r|}
36.2 \\
51.3 \\
80.3 \\
113.8
\end{tabular} & $\begin{array}{r}4.86 \\
6.80 \\
10.07 \\
15.20\end{array}$ & $\begin{array}{l}1.65 \\
2.34 \\
3.70 \\
5.24\end{array}$ \\
\hline $\begin{array}{l}4 \\
4-\ldots \\
4 \\
4\end{array}$ & $\begin{aligned} \frac{1}{3} \\
\frac{1}{4} \\
\frac{1}{2} \\
1^{2}\end{aligned}$ & $\begin{array}{r}77.4 \\
109.6 \\
173.6 \\
245.4\end{array}$ & $\begin{array}{l}10.3 \\
14.6 \\
23.1 \\
32.7\end{array}$ & $\begin{array}{l}\text { 1. } 97 \\
\text { 2. } 79 \\
4.42 \\
6.25\end{array}$ \\
\hline $\begin{array}{l}5 \\
5 \ldots \ldots \\
5 \ldots \ldots \ldots \\
5 \ldots \ldots\end{array}$ & $\begin{array}{r}\frac{1}{\frac{1}{8}} \\
\frac{1}{3} \\
1^{\frac{1}{2}}\end{array}$ & $\begin{array}{l}138.6 \\
196.5 \\
311.0 \\
439.2\end{array}$ & $\begin{array}{l}18.5 \\
26.0 \\
41.4 \\
58.5\end{array}$ & $\begin{array}{l}2.25 \\
3.19 \\
5.05 \\
7.13\end{array}$ \\
\hline $\begin{array}{l}6 \\
6 \ldots \\
6 \ldots \\
6 \ldots \\
6 \ldots\end{array}$ & $\begin{array}{r}\frac{1}{1} \\
\vdots \\
\frac{1}{2} \\
1^{\frac{1}{2}}\end{array}$ & $\begin{array}{l}221.4 \\
313.1 \\
494.8 \\
699.4\end{array}$ & $\begin{array}{l}29.5 \\
41.7 \\
65.9 \\
93.2\end{array}$ & $\begin{array}{l}2.51 \\
\text { 3. } 55 \\
5.61 \\
7.93\end{array}$ \\
\hline $\begin{array}{l}7 \\
7 \\
7 \\
7\end{array}$ & $\begin{array}{r}\frac{1}{b} \\
\frac{1}{1} \\
\frac{1}{1} \\
1^{2}\end{array}$ & $\begin{array}{r}328.5 \\
465.6 \\
735.1 \\
1,040.7\end{array}$ & $\begin{array}{r}42.8 \\
62.0 \\
98.0 \\
137.7\end{array}$ & $\begin{array}{l}\text { 2. } 73 \\
\text { 3. } 87 \\
\text { 6. } 11 \\
8.65\end{array}$ \\
\hline $\begin{array}{l}8 \\
8 \\
8 \\
8 \\
8\end{array}$ & $\begin{array}{r}\frac{1}{1} \\
\frac{1}{4} \\
\frac{1}{2} \\
1^{2}\end{array}$ & $\begin{array}{r}463.0 \\
656.0 \\
1,037.0 \\
1,468.0\end{array}$ & $\begin{array}{r}61.8 \\
87.4 \\
138.3 \\
195.6\end{array}$ & $\begin{array}{l}\text { 2. } 94 \\
4.16 \\
6.58 \\
9.31\end{array}$ \\
\hline $\begin{array}{l}10 \\
10 \\
10 \\
10\end{array}$ & $\begin{array}{r}\frac{1}{k} \\
\frac{1}{3} \\
\frac{1}{2} \\
1^{\frac{1}{2}}\end{array}$ & $\begin{array}{r}814.0 \\
1,149.0 \\
1,819.0 \\
2,572.0\end{array}$ & $\begin{array}{l}108.6 \\
153.2 \\
242.5 \\
343.0\end{array}$ & $\begin{array}{r}3.33 \\
4.70 \\
7.44 \\
10.52\end{array}$ \\
\hline $\begin{array}{l}12 \\
12 \\
12 \\
12\end{array}$ & \begin{tabular}{r|r}
$\frac{1}{3}$ \\
$\frac{1}{4}$ \\
$\frac{1}{2}$ \\
$1^{2}$
\end{tabular} & $\begin{array}{l}1,300.0 \\
1,838.0 \\
2,905.0 \\
4,034.0\end{array}$ & $\begin{array}{l}173.4 \\
245.0 \\
387.3 \\
537.8\end{array}$ & $\begin{array}{r}3.68 \\
5.20 \\
8.22 \\
11.62\end{array}$ \\
\hline
\end{tabular}


Tables for steady flow are not strictly applicable to the conditions of intermittent flow encountered in house drains. However, the component of the entrance velocity from the stacks in the direction of flow in the house drain is invariably greater than the velocity for steady flow, hence the tendency is toward a greater capacity than that given in the tables. Any increase in capacity due to an entrance velocity operates as a factor of safety.

The necessity of a house drain of ample capacity can not be overemphasized. The development of a head that extends up into the vertical stacks produces detrimental effects difficult to prevent, and in extreme cases even impossible to prevent by any system of venting.

STACKS

We have found no formula, tables, or data applying to the flow of water in partially filled vertical pipes. Therefore, independent determinations of stack capacities, based again on the assumption that no static head is developed in the stack itself, have been made.

In vertical stacks a static head can develop only after the stack has become filled at some point. With the water introduced at a given rate by volume, this will first occur at the point of lowest velocity, evidently at a point of entrance. Since the vertical component of the entrance velocity is less than the maximum velocity attained in the stack, the velocity increases from the point of entrance until the maximum is reached. The vertical component of the entrance velocity depends on the rate of flow by volume, the cross-sectional area of the inlet, and the angle of entrance. This points to the capacity of the fitting as a measure of the "practical capacity" of the stack.

We will define the capacity of the fitting as the rate of flow in gallons per minute at which the water just begins to build up in the vertical part of the fitting above the inlet branch of the fitting. This is then taken as a measure of the practical capacity of the stack constructed with that fitting. With any rate of flow not exceeding this value then the stack, barring stoppage or marked retardation, will not be completely filled at any point.

Determinations were made with different fittings on both 2 and 3 inch stacks as follows: The fittings were set in the top of the stack and water introduced at known rates through a trap and the fitting inlet (fig. 39), observation being made in the open upper end of the fitting. So long as the water flowed freely with no appreciable retard in the fitting, the rate was considered below that fitting capacity. The rate at which the first tendency to back vertically into the fitting above the level of the inlet appeared, was taken as the fitting capacity. When the water stood above the level of the inlet, even temporarily during the sustained rate of flow, it was considered that the capacity had 
been exceeded. This last condition in the case of only one inlet to the stack would do no particular harm, and it should be noted that the rate of flow that causes the water to stand in the fitting is greatly in excess of the rate at which the tendency to build up first appears, double the rate in some cases. The flow was maintained for from 15 to 30 seconds by means of the tanks, thus giving ample time for observation and for any effect from lower portions of the stack to be transmitted. Various lengths of stacks from 30 to 45 feet both with and without house drains were employed, but as no modifying effect from the part of the system below the fitting was observed in any case only the fitting and tank connections are illustrated in Figure 39, showing a double $\mathrm{Y}$ fitting with water introduced simultaneously at both inlets.

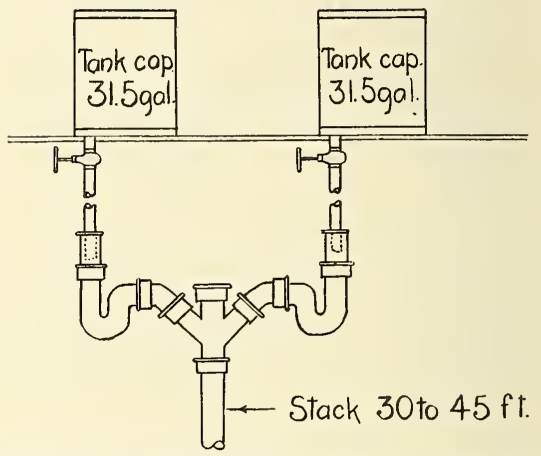

Fig. 39-Supply tanks at top of stack for determining the capacity of fittings and stack

The preceding description applies to capacities with entrance at one level with either one or two inlets. For entrance at two levels two fittings of the kind under test were set at two points in the stack approximately 11 feet apart, and a 1-inch glass tube bent in $L$ shape was set in a side inlet in the lower of the two fittings and water introduced simultaneously at known rates through the main inlets of the two fittings as before. Any retard or interference in the lower fitting sufficient to cause a slight back flow, neglecting splashes, into the glass $L$ tube was taken as exceeding the capacity of the fitting under these conditions. As might be expected, the tendency is toward an increase in capacity with the water introduced at two levels. This is essentially different from the effects in pipes flowing full. It therefore seems safe to assume that the capacity of a given stack with entrance points at more than one level is not less than the capacity of the same stack with entrance points at one level only. 
In fact, there is strong evidence that the capacity increases with the increase in number of entrance points at different levels, tending toward a maximum capacity measured by the stack flowing full with the maximum velocity attained by water flowing in a vertical stack of that diameter. What we have really determined is, therefore, the maximum capacity of the stack for methods of construction that give a relatively small maximum capacity compared to what might be secured by other methods or design of construction. The experiments were based on the assumption that present methods of connecting the fixtures directly to the stack through short waste or soil branches, especially for small house construction, would be continued. The possibilities of extension of the serviceable limits to which the smaller sizes of stacks might be used by some changes in the method of construction will be pointed out later.

Based on the observations described, the approximate "practical capacities" of 2 and 3 inch cast-iron stacks with entrance points at one or more levels is as follows:

TABLE 5.-Capacities of stacks, with fixtures connected direct

\begin{tabular}{|c|c|c|c|c|}
\hline \multirow{3}{*}{ Diameter of stack in inches } & \multicolumn{4}{|c|}{$\begin{array}{l}\text { Practical carrying capacity of stack con- } \\
\text { structed with single or double fit- } \\
\text { tings }\end{array}$} \\
\hline & \multicolumn{2}{|c|}{$\operatorname{San} \mathrm{T}$} & \multicolumn{2}{|c|}{$\mathrm{Y}$ or $\mathrm{T}-\mathrm{Y}$} \\
\hline & $\begin{array}{l}\text { Gallons } \\
\text { per } \\
\text { minute }\end{array}$ & $\begin{array}{l}\text { Fixture } \\
\text { units }\end{array}$ & $\begin{array}{l}\text { Gallons } \\
\text { per } \\
\text { minute }\end{array}$ & $\begin{array}{l}\text { Fixture } \\
\text { units }\end{array}$ \\
\hline 34 & $\begin{array}{r}45 \\
100 \\
180 \\
280 \\
405 \\
720\end{array}$ & $\begin{array}{r}6.0 \\
13.3 \\
24.0 \\
37.3 \\
54.0 \\
96.0\end{array}$ & $\begin{array}{r}90 \\
200 \\
360 \\
560 \\
810 \\
1,440\end{array}$ & $\begin{array}{r}12.0 \\
26.7 \\
48.0 \\
74.7 \\
108.0 \\
192.0\end{array}$ \\
\hline
\end{tabular}

1 Capacities for the 4, 5, 6, and 8 inch stacks were calculated from the equation.

The capacity of a stack is approximately expressed by capacity $=k d^{2}$, in which $d$ is the diameter of the pipe in inches and $k$, a constant, is 22.5 for $45^{\circ} \mathrm{Y}$ inlets, 11.25 for San-T inlets. There are good reasons for believing the same relation substantially holds for larger sizes.

\section{BASE FITTINGS}

The remaining point for consideration in connection with capacities-namely, the bend or turn connecting between the stack and house drain or a lateral branch to the house drain -is not readily determined by experimentation. It is evident that insufficient capacity in this part would produce effects very similar to those produced by an insufficient house drain. Ample capacity may be secured without material change in present methods. For small 
systems no special provision as to sizes is necessary. For larger systems, in which the probable peak load approaches the stack capacity, it is necessary to specify the construction in order to insure a capacity in the stack base fitting at least equal to that of the stack. In such cases the house drain will be one or more sizes larger than the stack. A requirement that the increase be made at the union of the stack and base fitting rather than at the union of the base fitting and house drain would solve the problem. In case the house drain is two sizes larger than the stack the base fitting might be the intermediate size. For example, in a system that requires a 3-inch stack and a 4-inch house drain the base fitting should also be 4 inches, or in a system which requires a 3 -inch stack and a 5 -inch house drain the base fitting should be at least 4 inches in diameter. The specification might be simplified by the requirement that in all cases for soil stacks the base fitting between the stack and house drain should be one size larger than the stack. This last would work no particular hardship when the requirement is not actually needed and would reduce the possibilities of detrimental back pressures around the base of the stack, which may occur under certain conditions even in very small installations. The same requirement should be observed whether the turn is made by means of a long sweep one-fourth bend, by means of the two $Y$ fittings or by means of a $Y$ fitting and one-eighth bend. In this connection the long sweep one-fourth bend with reducing hub will give the desired connections with one less fitting than if an ordinary long sweep bend is used. We have used this bend with 3-inch stack and 4 -inch house drain in test installations with decidedly better results than were obtained with 3 -inch stack, 3 -inch base fitting, and 4-inch house drain.

\section{CHARACTERISTICS OF FLOW OF WATER IN PARTIALLY FILLED VERTICAL PIPES}

The character of the flow of water in a partially filled vertical pipe varies with the extent to which the pipe is filled. Limited opportunity for direct observation of the flow was offered in the experimental work. Opportunity was given to observe the flow past glass sections set near the point of entrance and near the base of the stack, the flow from the open lower end of a vertical stack, and in a few cases through the stack itself. For small volumes of flow amounting to little more than a trickle the flow is entirely on the inner wall of the stack. With increase in volume the adherence of the flow to the wall continues up to the point where the frictional resistance of the air causes it to diaphragm across the pipe, temporarily forming a short slug of water which descends as a slug filling the stack until increased air pressure breaks through, the water forming the slug 
either being thrown again to the wall or falling for a short distance as separate streamlets in the center of the pipe. This diaphragming and forming slugs probably first appears in a 3-inch stack when the stack is from one-fourth to one-third full. As the volume of flow increases, the slugs thus formed are more frequent and more persistent and in a stack open at the lower end may not be broken through. This intermittent rate partially accounts for the rapid erratic oscillations of pressure in a plumbing system.

\section{SPIRAL FLOW}

There is a decided tendency for the water to spiral with very low volumes of flow, evidently due to the variable frictional resistance encountered. The direction of the spiral motion is dependent on the resistance of the uneven surface. With increased volume the spiral motion is less evident and was not detected at all with volumes sufficient to entirely cover the wall of the pipe. If such spiral motion does occur, it is not sufficiently marked to justify its being taken into account.

\section{VELOCITY OF FLOW}

Investigation of the velocities attained by water falling in partially filled vertical pipes leads to some interesting results that may be of considerable importance in their application. It is a well-known fact that a body moving under a constant force against a resistance that varies as the square of the velocity tends toward maximum constant velocity as the resistance and the moving force approach the same value. This is illustrated by bodies falling in the air and is especially apparent with bodies of relatively low density. Wellestablished principles of hydraulics show that the frictional resistance in water pipes increases approximately as the square of the velocity and that it is independent of the pressure. In vertical pipes the resistance evidently varies in about the same manner, and in partially filled vertical pipes the flow is mainly on the wall. The resistances for the full and for the partially filled pipe are not materially different.

Calculations made, assuming a full pipe and frictional resistance given by the hydraulic formula for loss in head due to friction $=\frac{f l v^{2}}{D 2 g}$, gave a maximum velocity for a 3 -inch cast-iron pipe of 24.6 feet per second. Similar calculations for 2 and 4 inch pipes gave, respectively, 16 and 29 feet per second. While these results are not dependable they indicate the magnitude of velocities to be measured in experimental determinations. Such determinations were made for 2 and 3 inch vertical stacks, with open ends at the top and bottom, flowing partially full with volumes equal to the "practical capacities" and one-half the "practical capacities" as previously determined. 
The differential equation for a falling body when the frictional resistance varies as the square of velocity is

Substituting

$$
\text { Force }=m a=m \frac{d^{2} s}{d t^{2}}=m\left[g-k\left(\frac{d s}{d \bar{t}}\right)^{2}\right]
$$

$$
v=\frac{d s}{d t}, v d t=d s \text { and } \frac{d v}{d t}=\frac{d^{2} s}{d t^{2}}
$$

and transforming, we get

Integrating (2) gives

$$
\frac{v d v}{d s}=g-k v^{2} \text { or } \frac{v d v}{g-k v^{2}}=d s
$$

$$
-\frac{\log \left(g-k v^{2}\right)}{2 k}=s+\log C=s \log e+\log C
$$

Transforming (3) gives

When

$$
g-k v^{2}=C^{-2 \mathbf{k}} e^{-2 \mathbf{k s}}
$$

$$
s=o, v=v_{0}, \text { then } C^{-2 \mathrm{k}}=g-k v_{0}{ }_{0}
$$

Substituting this value for $C^{-2 \mathrm{k}}$ in (4)

or solving (5) for $v$

$$
g-k v^{2}=\left(g-k v_{0}^{2}\right) e^{-2 \mathbf{k s}}
$$

$$
v=\sqrt{g / k-\frac{g / k-v_{0}^{2}}{e^{2 \mathrm{ks}}}}
$$

the general equation for a falling body with the resistance varying as the square of the velocity in which $v$ is the velocity at any height, $g$, the acceleration of gravity, $k$, a constant depending on the resistance, $v_{0}$, the vertical component of the entrance velocity, $e$, the base of the Naperian system of logarithms, and $s$, the height of fall.

To plot the velocity curve for any height of stack from this equation it is necessary only to determine the value of $k$ and $v_{0}$ for that stack and volume of flow.

Employing a vertical 3-inch cast-iron stack 45 feet in height, open at top and bottom, water was introduced at the top through a $45^{\circ}$ double $Y$ fitting as shown in Figure 39 and the velocities determined by means of a Pitot tube (fig. 40) set in the stream at the open lower end of the stack. The Pitot tube was kept full of water by means of the flask reservoir and correction made for rise of water in the flask under impact. The purpose of the air reservoir in the flask was to damp out rapid fluctuations and overthrows in the manometers, enabling a more accurate reading. The flow was sustained for 17.5 seconds, allowing sufficient time for the manometer to reach and stand at the maximum. The velocity was obtained from the equa- 
tion $h d g=1 / 2 d_{1} V^{2}$, in which $h$ is the length of the supported column of mercury, $d$, the density of mercury, $g$, the acceleration of gravity, $d_{1}$, the density of water, and $V$, the velocity of impact of water. Velocity curves, plotted from the equation with $k$ and $V_{0}$ determined experimentally, for the 3-inch stack, with volumn-of-flow of 100 and 200 gallons per minute, and the velocity curve for a free fall with the constant acceleration, $g$, are shown in Figure 41.

Numerous other determinations of velocities with various heights from 5 to 45 feet of 3 -inch stack gave values that fell on the curve plotted within the estimated errors of the determinations. Similar less accurate determinations of velocities in a 2-inch cast-iron stack up to 30 feet in length with volumes of flow of 90 and 45 gallons per minute gave maximums of 24 and 18.5 feet per second, respectively, attained in a fall of 20 feet. The work is still incomplete, but the results are conclusive in some respects, namely, (1) that water falling

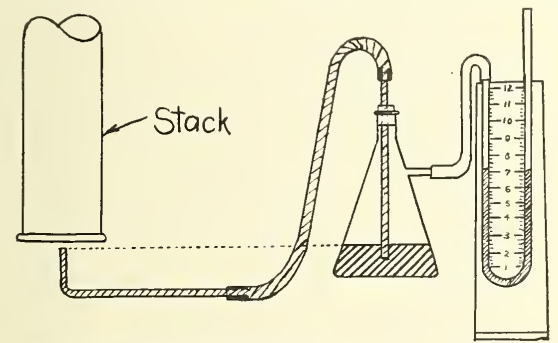

Fig. 40-Pitot tube for measuring veloeity of water at base of stack

in vertical stacks reaches an approximate maximum in a comparatively short fall; (2) that in a given stack the maximum increases with increased volume of flow; (3) that in a given stack the approximate maximum is attained in a shorter fall with lower volumes of flow; (4) that with volumes of flow proportional to the areas of the cross sections - that is, proportional to the "practical capacities"the maximum is smaller and is attained in a shorter fall in the smaller of two given stacks; and (5) that with equal volumes of flow the maximum is greater and a greater fall is required to attain the maximum in the smaller of two given stacks. The conclusions are all on the assumption that while the stack is only partially filled the volumes of flow are sufficient to completely cover the walls of the stacks. If the walls are not completely covered, the maximum velocity is practically independent of the size of the stack, is very small, and is attained in a very short fall. If the stacks are completely filled and flowing under their own head, the maximum velocity and the height in which it is attained increases with increased size of stack. 
It should be noted that, with volumes of flow of 90 gallons per minute in a 2 -inch stack and 200 gallons per minute in a 3 -inch stack, slugs of water completely filling a short length of the stack are occasionally formed and that the maximum velocity attained by such slugs approaches the maximum velocity for a completely filled stack. As the maximum indicated by the manometer used with the Pitot tube was used in the determinations the velocity curve for a completely filled 3 -inch stack will not differ materially from the one

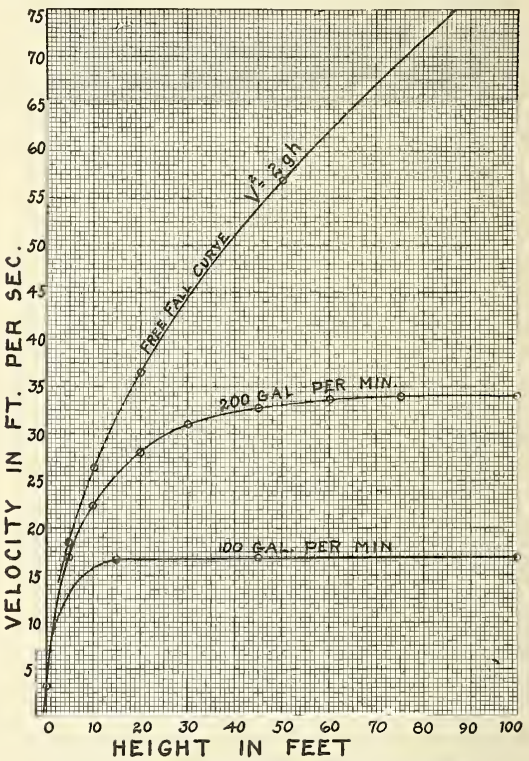

Fig. 41.-Curves showing velocity of fall in a 3-inch stack

plotted (fig. 41), for the 3-inch stack with volume of flow of 200 gallons per minute.

The fact that the air resistance encountered in an actual plumbing installation, due to the influence of the horizontal house drain, was not present in the determinations from which the curves were plotted, should also be noted. Evidently the air resistance offered in a partially closed system, such as presented by a complete plumbing installation, increases more rapidly than the square of the velocity. Therefore, the velocity not only approaches the maximum more rapidly than indicated by the curves, but probably reaches an absolute 
maximum within the distances indicating approximate maximum velocities in the curves. There have been some indications of a slight decrease in velocity toward the base when measurements were made in the open end of a long sweep one-fourth bend set on the lower end of the vertical stack. A marked decrease in velocity could be produced only with the base of the system completely. closed to the passage of air. This is again getting away from practical conditions, for, if the house drain may become closed to the passage of air, the fixture inlets and vents offer an outlet with a relatively small increase in pressure. Even the small increase in pressure necessary to produce circulation of air through vents will have some effect on the kind described.

It therefore seems reasonable to assume that the approximate maximum velocity of 32.8 feet per second attained in a 45 -foot length of 3-inch stack open at the top and bottom will not be exceeded in a 3-inch soil or waste stack of any height in the partially closed system presented by a complete plumbing installation.

The only apparent application of this data is on the point of limitation of height of stack of given diameter. For example, if a 3 -inch stack in which a height to the highest group of fixtures of 20 feet is permitted, there is slight reason, on the grounds of increased velocity, for placing any limitation on the height allowed. The velocity attained in a fall of 20 feet in a 3 -inch stack open at both ends is 29 feet per second. That attained in a fall of 100 feet will be 34.2 feet per second.

The maximum velocity attained in a given vertical stack is apparently a linear function of the volume rate of flow; that is, the maximum velocity is proportional to the volume rate of flow. Evidently this relation holds only with volume rates of flow between that which will completely cover the wall of the pipe and that which continuously completely fills the pipe. Below the former limit the flow becomes a trickle on the wall of the pipe and the resistance is relatively greater. Above the latter limit a static head is developed in the pipe and the equation no longer holds.

No doubt the velocities could be reduced by the introduction of devices, such as spiral sections or fittings, that would hold the water on the wall of the pipe. There has been no time or opportunity offered yet for investigation of such devices. The effects of such fittings on the system in other respects are problematical, and we offer no opinion as to general effects of special fittings without a thorough investigation by experiment and test.

\section{VENT REQUIREMENTS}

There are three principal effects produced in a plumbing system which must be relieved through venting in order to insure its efficient functioning, namely, back pressure, or increase above atmospheric 
pressure, partial vacuum, or decrease below atmospheric pressure, and self-siphonage, a purely local phenomenon. To these may be added the possible concentration of corrosive gases at certain points in the system. In general, a relief of the first three conditions will largely prevent the last. In any event it should be treated as a separate consideration.

The fact that back pressures and partial vacuums do not occur in their maximum intensities in the same part of the system, and, in general, where they do occur alternately are of relatively small intensity, suggests a separate consideration of the requirements to relieve each.

\section{PRESSURE EFFECTS}

Numerous air-pressure measurements were made with sensitive pressure gauges at various points from the base of the stack upward in the plumbing test installations used. In all cases back pressures only were encountered at the base of the stack. The region of back pressures extended upward as the volume of the discharge was increased. In the upper portions of the stack below the entrance point of the discharge partial vacuums only were encountered. Between these two is a region in which the pressure alternates between positive and negative pressures measured from atmospheric pressure as the zero.

Figures 42 and 43 illustrate the pressure effects in a 3-inch stack, unvented except by the open stack top. The stack connected into a 4-inch house drain, 38 feet developed length, consisting of two straight sections connected by a return bend, inclined at an angle of $45^{\circ}$. The connection from the stack was made by a 3-inch $Y$ set in a 4 by 3 inch $Y$ of the house drain. These pressures, especially the partial vacuums, are not necessarily those in the center of the stack, but rather the pressures that would be produced in an unvented branch line connecting at that point. The two lower points were measured in 3-inch branches of fittings, the upper points by tapping a one-fourth-inch gas cock in the pipe at that point. The small orifice does not give the same results as the larger fitting opening, the values being sometimes higher and at other times lower than measurements taken in a 2 or 3 inch fitting inlet at the same level. However, they are sufficient to show the general characteristics, and as no direct application was made of measurements taken through small orifices the degree of accuracy is not important. In later experiments where results have been applied all pressure measurements were made in or through branches of a fitting. In the figures solid lines connect points for which actual records of maxima or minima were obtained and dotted lines, portions interpolated from observations of fluctuations in the pressure gauges in reaching the maximum or minimum. 


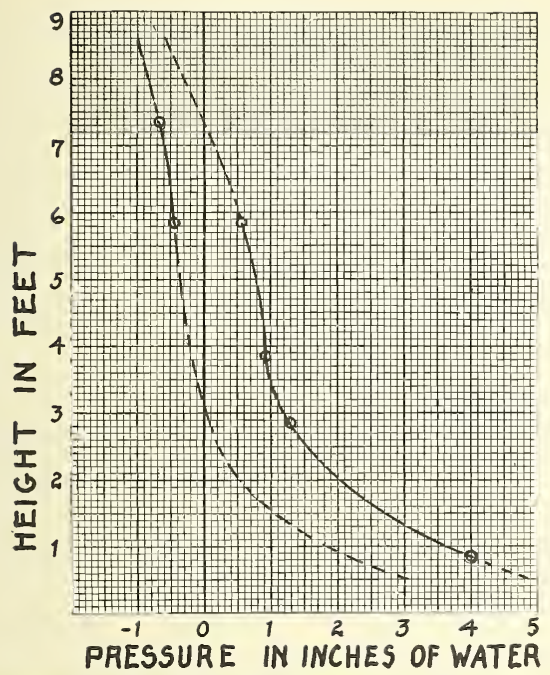

FIG. 42.-Pressure eurves near base of a 3 -inch stack with house drain, volume rate of water 66 gallons per minute

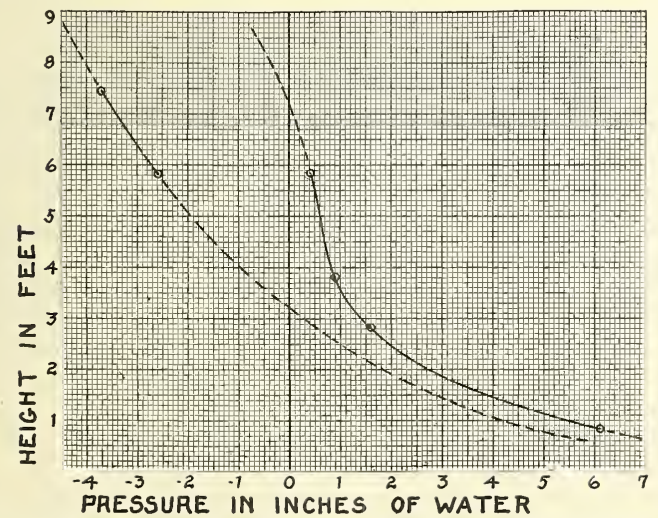

Fig. 43.-Pressure curves near base of a 3-inch stack, volume rate of water 108 gallons per minute 
Several types of pressure gauges were used, U-tube manometers, both water and mercury, and a sensitive differential pressure gauge. Figure 44 illustrates the principle of the last. It consists of two shallow drums with flexible diaphragms attached to two light circular plates of equal area connected at their centers by a small aluminum rod. The mid-point of the connecting rod is attached to the end of a short lever balanced on a pivot. To the other end of the lever two light coiled springs are attached. A light stylus attached to the pivot above the lever records the deflection on a drum rotated by clockwork. The gauge was calibrated to 0.01 inch of water and for small deflections is sensitive to that degree, being particularly free from overthrows under rapidly fluctuating pressures.

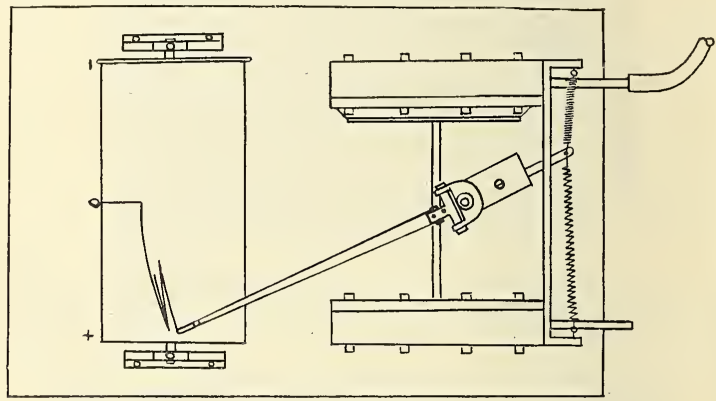

FIG. 44.-Recording pressure gauge

Figure 45 shows an arrangement of water manometers giving a maximum and minimum pressure gauge. The valves in the bulbs were constructed of sheet rubber and automatically closed, stopping the back flow from the highest point. The scale was graduated to 0.1 inch with the possibility of estimating 0.01 inch. The same principle in a modified form was used with mercury manometers. The operation of the valves was fairly dependable. By careful observation any failure could be detected and the experiment repeated. The records are given to the nearest 0.1 inch of water and for the lower ranges are accurate to this degree. In the higher ranges with the drum gauge the absolute accuracy decreases, while the relative accuracy remains the same.

In view of the characteristics of pressure fluctuations produced in a plumbing system and of the accuracy of established laws of flow of gases in pipes under pressure, it is evidently possible to calculate the requirements in sizes of vents necessary to relieve detrimental conditions, provided a starting point for the calculation is given, 


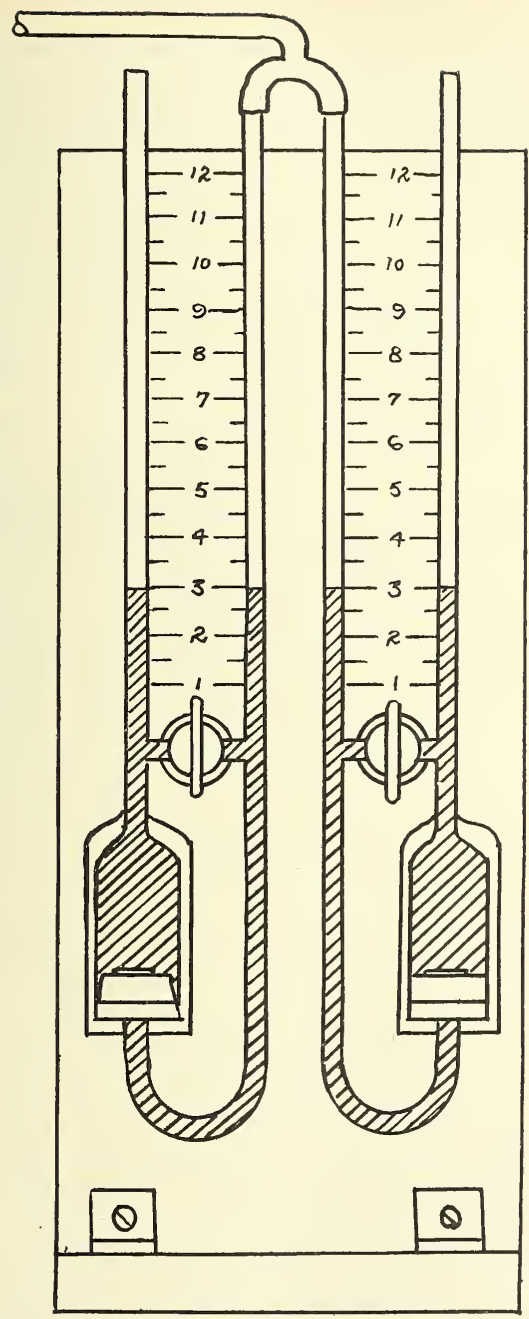

Fig. 45.-Maximum and minimum pressure gauge 
This starting point we have established on the following assumptions: (1) That the stack is carrying its full "practical capacity," 200 gallons per minute (26 fixture units), for the 3 -inch stack or a known fraction of this; (2) that a vent which will relieve the pressure effect at the point of maximum effect is ample for all other points; and (3) that no positive or back pressure greater than 1 inch and no negative pressure or partial vacuum less than 1 inch of water, measured from atmospheric pressure as the zero, is to be developed in any branch drain connecting to the stack above the house drain. It should be kept in mind that pressure variations in the stack which can not possibly be transmitted to a fixture trap have no bearing on the problem. We are only concerned with the pressure effects in the branches, whether vented or unvented.

The most widely distributed pressure effect is the production of partial vacuums, and it should receive first consideration. The partial vacuums are generally due to the aspirating effect of the stream of water in the stack flowing past the opening of a branch waste or soil pipe. The magnitude of the effect is evidently a function of the volume of water per unit length and its velocity. However, the most practical way, considering the many modifications of conditions to be encountered, seems to be to work for the size of vent required to relieve the effect for the conditions producing the maximum effect.

Evidently, since the aspirating effect increases with increase in velocity, the maximum will be obtained with a vertical stack open at the bottom. With the stack closed at the top it is possible to produce vacuums limited only by the vapor tension of water. J. E. Denton at Stevens Institute, about 1890, under these conditions produced vacuums equivalent to 25.25 inches of mercury. Such results have no application except to show the necessity of keeping the stack top open. We have, therefore, experimented with the stack top open or only partially closed to simulate frost closure.

Pressure Effects in a Stack-Vented System.-With the 3 -inch stack 33 feet long (fig. 46) unvented except through the open top water was introduced through a $P$ trap and $Y$ fitting at the rate of 200 gallons per minute and measurements taken in 3-inch $Y$ fittings at intervals of 5 feet 10 inches, beginning at a point 10 inches below the entrance point. The mean of two independent sets of measurements is plotted in Figure 47. The maximum of any individual pressure reading was 31.3 inches of water vacuum at the point 10 inches below the entrance point. Measurements taken in a 2 -inch stack at a point 7 inches below the entrance gave a maximum of 28.5 inches of water vacuum when water was flowing into the stack at 90 gallons per minute, 12 fixture units. Other measurements in $Y$ and sanitary $T$ branches indicate that there is slight difference in the aspirating effects produced at $Y$ or sanitary $T$ branch inlets with 
branches either 2 or 3 inches diameter. Figure 48 shows the curve of pressures obtained in the 2 -inch stack 34 feet high open at both ends and water introduced at one point 29 feet from the bottom at. the rate of 90 gallons per minute. Figure 49 is the curve of pressures for the same 2-inch stack with water introduced simultaneously at

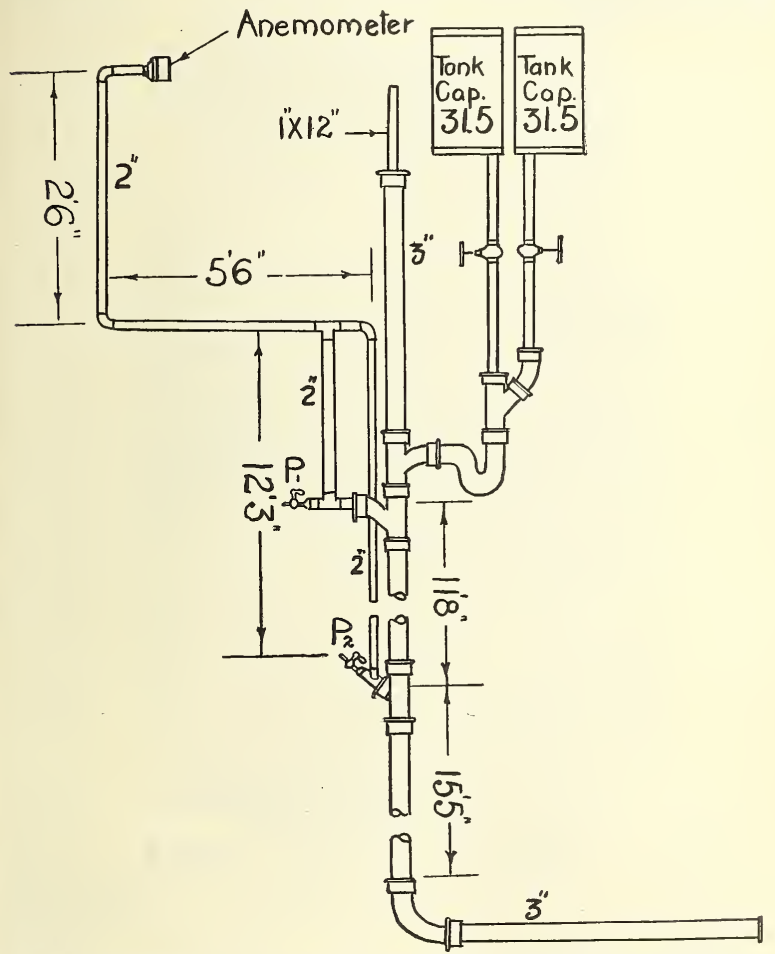

Fig, 46.- Experimental stack and vent system for determining air movements in a plumbing system

two points $P_{1}$ and $P_{2} 12$ feet 4 inches apart, each at the rate of 45 gallons per minute. These determinations show conclusively that the maximum aspirating effect under these conditions is below and near a point of entrance and were made principally for the purpose of verifying this fact.

Partial Vacuums and Vent Requirements.-The next step and the most important consideration in this connection is the deter- 
mination of the minimum size vent of a given length required to hold the vacuum, produced in a branch waste connecting to the stack at a point of maximum effect, below a given value fixed upon as allowing a sufficient factor of safety, namely, 1 inch of water. (See discussion of factor of safety in a later part of the report for justification of this.)

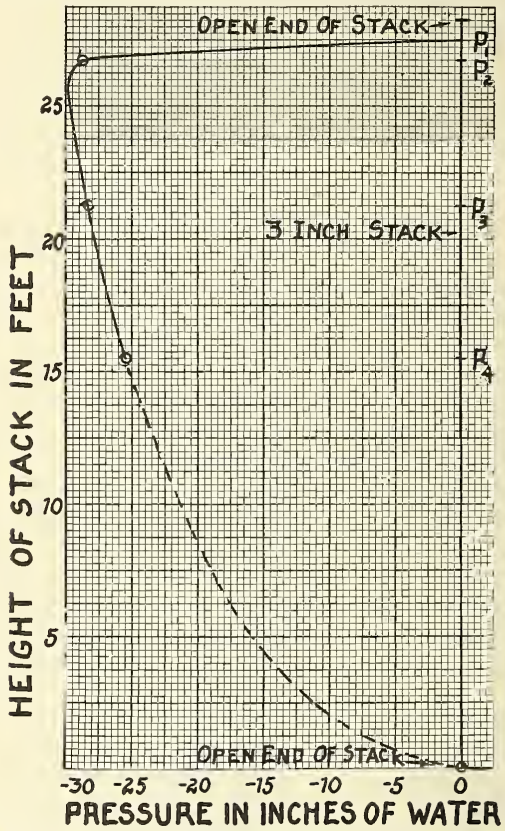

Fig. 47.- Pressure curve for a 3-inch stack, water introduced at $P_{1}$ at rate of 200 gallons per minute, pressure measurements at $\mathrm{P}_{2}$ and $\mathrm{P}_{3}$

Numerous arrangements of vent pipes of various sizes and lengths were attached to the 2 and 3 inch stacks, with vents connecting at one or two levels, and water introduced at different rates at one or two levels. Pressure measurements were made in the vents near their connections with the stack in each arrangement. Further rriations were made by partially closing the stack tops in imitaof frost closure and by adding short horizontals to the lower the stack. An anemometer was set in the end of the vent e to determine the velocity of air in the vent. 
Figure 46 shows a typical arrangement for a 3 -inch cast-iron stack with 2-inch wrought-iron vent connected to stack at two levels, with stack top closed to 1-inch diameter and 3-inch long

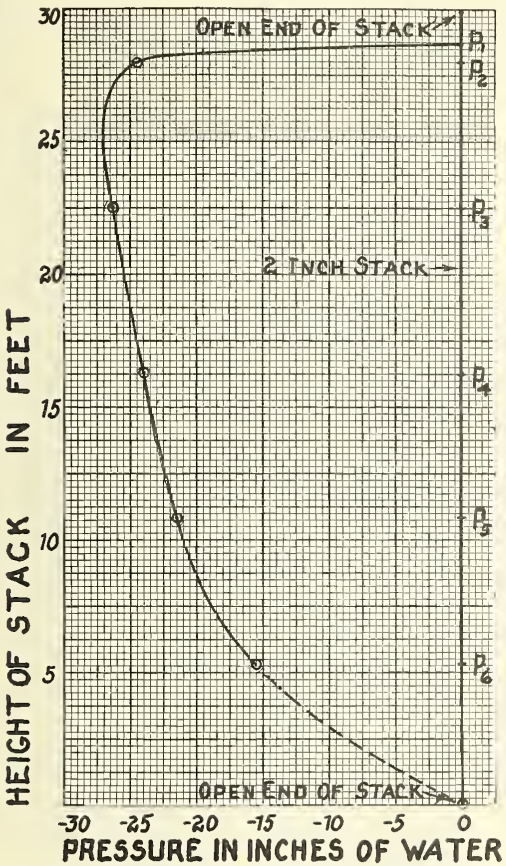

F1G. 48.-Pressure curve for a 2-inch stack, water introduced at $\mathrm{P}_{1}$ at rate of 90 gallons per minute, pressure measurements at $\mathrm{P}_{2}, \mathrm{P}_{3}, \mathrm{P}_{4}, \mathrm{P}_{5}$, and $\mathrm{P}_{6}$

sweep bend and 5-foot length of horizontal laid approximately 1 in 48. Following are the data for this arrangement:

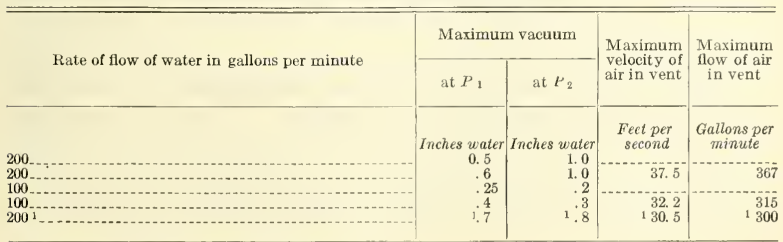

\footnotetext{
1 With stack top open full 3 inches in diameter.
} 
Without going into details of other determinations we may summarize the results for 2 and 3 inch stacks as follows: A 2-inch vent 20 feet long with 3 elbows, equivalent to approximately 36 feet of straight pipe is sufficient to prevent a vacuum in a branch from a 3-inch stack greater than 1 inch of water, with the stack carrying 200 gallons per minute. A $1 \frac{1}{2}$-inch vent 14 feet long with 3 elbows

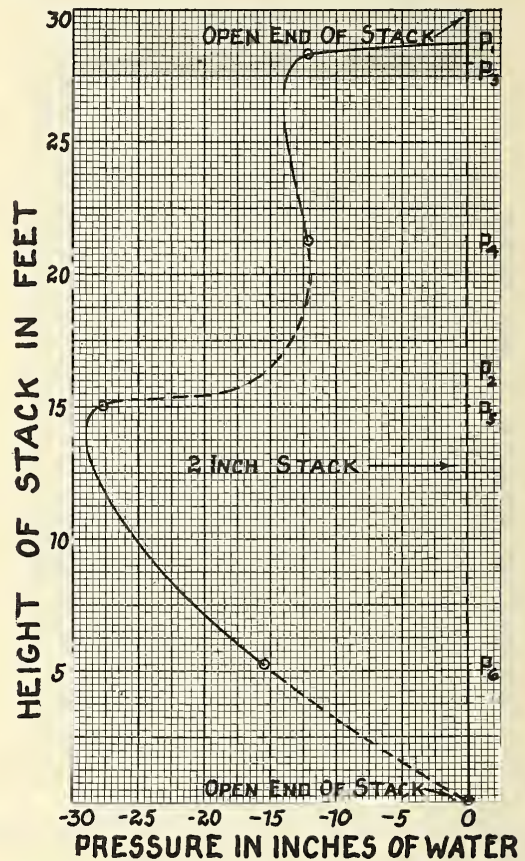

Fig. 49.-Pressure curve for a 2-inch stack, water introduced at rate of 45 gallons per minute each at $P_{1}$ and $\mathrm{P}_{2}$, pressure measurements at $\mathrm{P}_{3}, \mathrm{P}_{4}, \mathrm{P}_{3}$, and $\mathrm{P}_{6}$

equivalent to 23 feet of straight pipe is sufficient to prevent a vacuum in a branch from a 3 -inch stack greater than 1.0 inch of water, with the stack carrying 100 gallons per minute. A 1-inch pipe 22 feet long with 1 elbow, equivalent to 24 feet of straight pipe, is sufficient to prevent a vacuum in a branch from a 2 -inch stack greater than 0.5 inch of water, with the stack carrying 90 gallons per minute. 
The above values in connection with rates of air flow in the vents measured simultaneously, and laws of flow of gases under pressure enable a fairly close approximation of requirements for main vents to relieve the aspirating effects in 2 and 3 inch stacks within the measured limits of stack capacities. The laws of flow of gases referred to are expressed by the equation: $V=K \sqrt{\frac{P D^{5}}{l d}}$ in which $V$ is the velocity or volume per unit time, the value depending on the units employed, $P$ the drop in pressure, $D$ the diameter of the pipe, $l$ the length of the pipe, $d$ the density of the gas, and $K$ a constant whose value depends on the units employed. Allowing the development of a vacuum equal to 1 inch of water gives a drop in pressure through the vent of 1 inch of water. Evidently the intensity of the vacuum produced is dependent on the intensity of the aspirating effect and on the rate at which the vent pipe will deliver air to the point of connection under the drop in pressure thus created. Therefore, pipes that will deliver air at the same rate under the same drop in pressure are equivalent in venting effects.

Calculations made from the preceding data and other data not herein recorded indicate that a straight vent pipe 36 feet long 0.9 inch in diameter would prevent the production of a vacuum in a branch from a 2 -inch stack greater than 1 inch of water, with thestack carrying 90 gallons per minute. The result is believed to be dependable, since similar calculations made for other sizes of pipes were checked very closely by measurements of the kind employed.

A 0.9 inch vent, if available, is an impractical size to employ, and the data are valuable only for purposes of calculation. There appear to be good reasons for not employing any vent less than $1 \frac{1}{4}$ inch in diameter.

The following tables, adapted from tables for flow of gases under low pressures, are presented as a basis for extension of the data obtained. The calculations for short lengths of pipe have been carried through on the assumption that the short length in question is a part of a longer pipe in which the pressure gradient is as indicated. In other words, no correction has been made for the end effects observed in fluid flow through short pipes which would decrease the rate of flow somewhat. 
TABLE 6.-Volume of air transmitted by pipes of various lengths and diameters under a difference in pressure of 1 inch of water

\begin{tabular}{|c|c|c|c|c|c|c|c|c|c|c|c|c|}
\hline \multirow{2}{*}{$\begin{array}{l}\text { Length of } \\
\text { pipe in feet }\end{array}$} & \multicolumn{12}{|c|}{ Air flow (in gallons per minute) for various diameters (in inches) - } \\
\hline & $\frac{7}{8}$ & 1 & $1_{4}^{\frac{x}{4}}$ & $1 \frac{1}{2}$ & 2 & $2 \frac{1}{2}$ & 3 & $3 \frac{1}{2}$ & 4 & 5 & 6 & 8 \\
\hline $\begin{array}{l}1 \ldots \\
4 \ldots \\
9- \\
16- \\
20 \frac{1-}{4}\end{array}$ & $\begin{array}{r}181 \\
90 \\
60 \\
45 \\
41\end{array}$ & $\begin{array}{r}236 \\
118 \\
78 \\
59 \\
52\end{array}$ & $\begin{array}{l}520 \\
260 \\
173 \\
130 \\
115\end{array}$ & $\begin{array}{l}805 \\
402 \\
268 \\
201 \\
179\end{array}$ & $\begin{array}{r}1,633 \\
816 \\
544 \\
408 \\
362\end{array}$ & $\begin{array}{r}2,672 \\
1,336 \\
890 \\
668 \\
638\end{array}$ & $\begin{array}{l}4,866 \\
2,433 \\
1,622 \\
1,218 \\
1,081\end{array}$ & $\begin{array}{l}7,212 \\
3,606 \\
2,404 \\
1,803 \\
1,603\end{array}$ & $\begin{array}{r}10,187 \\
5,093 \\
3,395 \\
2,546 \\
2,263\end{array}$ & $\begin{array}{r}18,550 \\
9,275 \\
6,183 \\
4,637 \\
4,190\end{array}$ & $\begin{array}{r}30,225 \\
15,112 \\
10,075 \\
7,556 \\
6,869\end{array}$ & $\begin{array}{l}61,562 \\
30,781 \\
20,520 \\
15,390 \\
13,990\end{array}$ \\
\hline $\begin{array}{l}25 \\
30 \frac{1}{4} \\
36 \ldots \\
49_{-} \\
64 .\end{array}$ & $\begin{array}{l}36 \\
33 \\
30 \\
26 \\
22\end{array}$ & $\begin{array}{l}47 \\
43 \\
39 \\
33 \\
29\end{array}$ & $\begin{array}{r}104 \\
94 \\
86 \\
74 \\
65\end{array}$ & $\begin{array}{l}161 \\
144 \\
134 \\
115 \\
100\end{array}$ & $\begin{array}{l}326 \\
297 \\
272 \\
223 \\
204\end{array}$ & $\begin{array}{l}534 \\
485 \\
445 \\
381 \\
334\end{array}$ & $\begin{array}{l}973 \\
884 \\
811 \\
695 \\
608\end{array}$ & $\begin{array}{r}1,442 \\
1,311 \\
1,202 \\
1,030 \\
901\end{array}$ & $\begin{array}{l}2,037 \\
1,852 \\
1,697 \\
1,455 \\
1,273\end{array}$ & $\begin{array}{l}3,710 \\
3,315 \\
3,091 \\
2,650 \\
2,318\end{array}$ & $\begin{array}{l}6,045 \\
5,495 \\
5,037 \\
4,317 \\
3,525\end{array}$ & $\begin{array}{r}12,312 \\
11,192 \\
10,260 \\
8,794 \\
7,695\end{array}$ \\
\hline $\begin{array}{l}81-- \\
100- \\
144- \\
169-\end{array}$ & $\begin{array}{l}20 \\
18 \\
15 \\
14\end{array}$ & $\begin{array}{l}26 \\
23 \\
19 \\
18\end{array}$ & $\begin{array}{l}57 \\
52 \\
43 \\
40\end{array}$ & $\begin{array}{l}89 \\
80 \\
67 \\
62\end{array}$ & $\begin{array}{l}181 \\
163 \\
136 \\
125\end{array}$ & $\begin{array}{l}296 \\
267 \\
222 \\
205\end{array}$ & $\begin{array}{l}540 \\
486 \\
405 \\
374\end{array}$ & $\begin{array}{l}801 \\
721 \\
601 \\
554\end{array}$ & $\begin{array}{r}1,132 \\
1,018 \\
848 \\
783\end{array}$ & $\begin{array}{l}2,061 \\
1,855 \\
1,545 \\
1,407\end{array}$ & $\begin{array}{l}3,358 \\
3,022 \\
2,518 \\
2,340\end{array}$ & $\begin{array}{l}6,840 \\
6,156 \\
5,130 \\
4,735\end{array}$ \\
\hline $\begin{array}{l}196 \ldots \\
225 \\
400 \\
625\end{array}$ & $\begin{array}{r}13 \\
12 \\
9 \\
7\end{array}$ & $\begin{array}{r}16 \\
15 \\
11 \\
8\end{array}$ & $\begin{array}{l}37 \\
34 \\
25 \\
20\end{array}$ & $\begin{array}{l}57 \\
54 \\
40 \\
32\end{array}$ & $\begin{array}{r}116 \\
108 \\
81 \\
65\end{array}$ & $\begin{array}{l}190 \\
178 \\
133 \\
107\end{array}$ & $\begin{array}{l}347 \\
324 \\
243 \\
194\end{array}$ & $\begin{array}{l}515 \\
482 \\
361 \\
288\end{array}$ & $\begin{array}{l}727 \\
679 \\
509 \\
407\end{array}$ & $\begin{array}{r}1,325 \\
1,236 \\
927 \\
742\end{array}$ & $\begin{array}{l}2,158 \\
2,015 \\
1,511 \\
1,209\end{array}$ & $\begin{array}{l}4,397 \\
4,104 \\
3,078 \\
2,462\end{array}$ \\
\hline
\end{tabular}

TABLE 7.-Equivalent lengths of pipe in venting capacity, under a pressure difference of 1 inch of water

Equivalent lengths (in feet) for pipe of various diameters (in inches) -

\begin{tabular}{|c|c|c|c|c|c|c|c|c|c|c|c|}
\hline$\frac{7}{8}$ & 1 & $1 \frac{1}{4}$ & $1 \frac{1}{2}$ & 2 & $2 \frac{1}{2}$ & 3 & $3 \frac{1}{2}$ & 4 & 5 & 6 & 8 \\
\hline 1 & $\begin{array}{l}1.7 \\
1\end{array}$ & $\begin{array}{l}8 \\
4.8\end{array}$ & $\begin{array}{l}20 \\
11\end{array}$ & $\begin{array}{l}81 \\
48\end{array}$ & $\begin{array}{l}218 \\
128\end{array}$ & $\begin{array}{l}720 \\
424\end{array}$ & & & . & & \\
\hline & & 1 & 2. 3 & 10 & $\begin{array}{l}26 \\
11\end{array}$ & $\begin{array}{l}87 \\
36\end{array}$ & $\begin{array}{r}192 \\
80\end{array}$ & $\begin{array}{l}376 \\
170\end{array}$ & $\begin{array}{r}1,220 \\
529\end{array}$ & & \\
\hline - & & & & 1 & 2. 6 & 8.7 & 19 & 36 & 129 & 242 & 1,465 \\
\hline & & & & & 1 & 3. 3 & 7. 3 & 14 & 46 & 128 & .529 \\
\hline & & & & & & 1 & 2.2 & 4.4 & $\begin{array}{r}14.5 \\
6\end{array}$ & 38 & 160 \\
\hline & & & & & & . & & 1 & $\begin{array}{l}6.6 \\
3.3\end{array}$ & $\begin{array}{r}17.5 \\
8.7\end{array}$ & $\begin{array}{l}72 \\
36\end{array}$ \\
\hline & & & & & & & & & 1 & 2. 6 & 13 \\
\hline & & & & & & & & & & & 4. 1 \\
\hline
\end{tabular}

TABLE 8.--Length of straight pipe equivalent in resistance to one elbow or tee of equal diameter

\begin{tabular}{c|r|r|r|r|r|r|r|r|r|r|r}
\hline Diameter (inches) & 1 & $1 \frac{1}{4}$ & $1 \frac{1}{2}$ & 2 & $2 \frac{1}{2}$ & 3 & $3 \frac{1}{2}$ & 4 & 5 & 6 & 8 \\
\hline $\begin{array}{l}\text { Length in straight pipe equiva- } \\
\text { lent to one elbow or tee (feet)-- }\end{array}$ & 2 & 2.5 & 3 & 5 & 7 & 9 & 11 & 13 & 19 & 24 & 35 \\
\hline
\end{tabular}

This last table is intended for use in determining the length of straight pipe equivalent to a vent pipe made up of straight sections, elbows, and tees. For example, a 2-inch vent pipe 30 feet long with two elbows and one tee in that length is equivalent to $30+(3 \times 5)=45$ feet of straight pipe of the same diameter. The lengths given in the other tables are lengths of straight pipes.

Back Pressures and Vent Requirements.-The maximum back air pressures can not be readily determined by experiment due to 
the tendency to develop a head of water in the lower part of the stack as the conditions producing maximum air pressures are approached. However, it may be shown theoretically, that, in general, the vent required to relieve maximum aspirating effects is sufficient to prevent detrimental back pressures, provided the house drain and stack base fitting have the proper capacity to prevent back-water effects.

Assuming a condition in which the house drain is closed to the passage of air from the stack and an inflow of air, then the volume rate at which air must be removed from the lower portions of the stack, in order that the pressure may not rise above 1 inch of water measured from atmospheric pressure, will be equal to the rate of displacement by the discharge into the stack; that is, equal to the rate of inflow into the stack. The "practical capacity" (see p. 101) determined for the type of construction under consideration, was used as a basis for determining vent requirements for the relief of maximum aspirating effects. On the same basis under the assumed condition the vent required for a 3 -inch stack to prevent the production of a back pressure greater than 1 inch of water must be capable of carrying air under the difference of pressure at a volume rate equal to the "practical capacity" of the 3 -inch stack, namely, 200 gallons per minute. Reference to Table 6 shows that a $1 \frac{1}{2}$-inch pipe 16 feet long, a 2-inch pipe 64 feet long, a $2 \frac{1}{2}$-inch pipe 169 feet long, or a 3 -inch pipe 600 feet long have approximately that capacity.

It is conceivable that in rare instances a condition might occur in which a piston effect would be produced, driving the total volume of air in the stack through the vent. Under this condition the volume of air passing through the vent would not be greater than the difference between the total volume of air in the stack ahead of the piston and the water content in the same portion of the stack. Allowing a maximum velocity, 30 feet per second of fall to be attained in a 3 -inch stack in a two or three story building, the maximum rate at which air would have to be removed would be $660-200=460$ gallons per minute. Under a pressure difference of 1 inch of water the lengths of $1 \frac{1}{2}, 2,2 \frac{1}{2}$, and 3 inch pipe that will remove air at that rate are $3,12,39$, and 110 feet, respectively. In this connection it should be kept in mind that with vent connections at each floor level below the top floor the vent stack is not called upon to function throughout its entire length as a relief to back pressure but only in the first 10 or 20 feet at its base, since aspirating effects are produced. in the upper portions of the stack when back pressures are produced at the base. The portion operating in relief to back pressure may thus be under a greater difference in pressure than the 1 inch of water allowed. To illustrate, suppose $P_{2}$ in Figure 46 is near the base of the stack, and that water is flowing in the stack at a rate sufficient 
to produce back pressure, or a positive pressure measured from atmospheric pressure as zero, equivalent to +1 inch of water, at the same time $P_{1}$, being higher on the stack and near the point of entrance of water, will be under reduced pressure; that is, under a negative pressure measured from atmospheric pressure as zero. Suppose this negative pressure is equivalent to -1 inch of water, then the difference of pressure in the vent between $P_{2}$ and $P_{1}$ will be $+1-(-1)=$ +2 inches of water, and there will be a flow of air from $P_{2}$ to $P_{1}$ under a differential head of 2 inches of water. The effective pressure in the vent is measured between the absolute pressure at $P_{2}$ and another absolute pressure somewhat lower than atmospheric. There is thus produced, in systems in which both aspiration and back pressure are present, a certain amount of recirculation of air in the lower portions of the system giving greater relief in this region than is obtained when the entire length of vent stack is functioning in one direction only. It is impossible to assign any definite value to the extent of the relief due to recirculation of air, since it will vary with conditions of installation and volume of water discharged. However, the extent of recirculation of air without doubt increases as the intensity of back pressure increases with volume of discharge.

It is therefore concluded that the vent required to relieve maximum aspirating effects if extended down undiminished into the region of back pressures is sufficient to relieve the latter effect, except under conditions where a static head due to back water is developed in the stack. This last condition is one that must be avoided by a proper proportioning of the house drain and base fitting to the peak discharge of the system.

Self-siphonage and Vent Requirements.-The vent required to prevent self-siphonage may be considered on a similar basis. Any vent that will supply air to the waste-or soil line at a volume rate equal to that of the fixture discharging through the line will prevent a siphon pull on the trap greater than the pressure difference necessary to produce this rate of flow in the vent line. Reference to the table on flow of air in pipes shows that under a difference of pressure of 1 inch of water a 1-inch pipe 16 feet long will deliver air at the rate of 59 gallons per minute, a rate greater than the rate of discharge of any single fixture in a dwelling. In fact, with a vent of this size and length the pull on the trap of such a fixture would be much less than 1 inch of water, since the vent pipe will begin to deliver air as soon as a difference in pressure begins to develop. It is evident then that the vent of the size most practical to install will be ample to prevent any loss in the trap seal of the fixture from self-siphonage.

For convenience we have plotted the results in Figure 50, giving a chart from which the size of vent stack required for the 3-inch soil stack may be read when the peak load or probable maximum dis- 
charge and the total developed length of the vent stack are known. For example, the coordinate point for an estimated peak load of 180 gallons per minute, 24 fixture units, and a developed length of vent stack of 100 feet lies between the curves for a 2 -inch and a $2 \frac{1}{2}$-inch vent, therefore, for such an installation a $2 \frac{1}{2}$-inch vent stack is required for a 3 -inch soil stack of this height and peak load.

The curves are plotted from results of rough measurements in some respects, but calculations made from these measurements check measurements on rate of flow of air made at the same time so closely, to the nearest unit in many cases, that the results are believed to be more accurate than a casual review would imply. At any rate they are believed to be sufficiently accurate, in view of the rigid

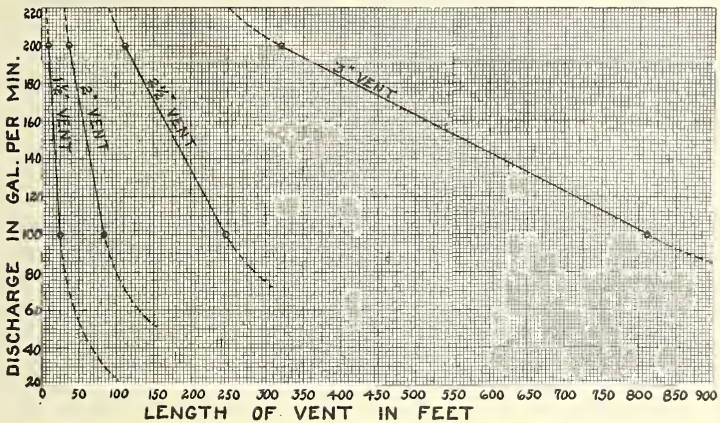

FIG, 50,-Chart for determining the permissible length of main vent of a given diameter for a 3-inch soll or waste stack when the maximum discharge through it is known

restriction imposed and the fact that only rough approximations are possible in the application.

The method may readily be extended to other and larger sizes of soil stacks if the demand justifies, and certain refinements in methods of measurements are also possible if closer approximations are desired.

It is interesting to note the relation of vent requirements for the 2 and 3 inch stacks with volumes of flow equal to their rated capacities, 90 and 200 gallons per minute, respectively. For vents of the same developed total length the requirements are approximately expressed by $\frac{d^{2}}{d_{1}^{2}}=\frac{D^{4}}{D_{1}^{4}}$ or $\frac{d}{d_{1}}=\frac{D^{2}}{D^{2}}$ in which $d$ and $d_{1}$ are the diameters of required vents, respectively, for stacks of diameters $D$ and $D_{1}$. There are good reasons for believing that the same relation holds for largersized stacks. 
The relation of rates at which air is moved through the vents during the discharge is also interesting and may serve to answer some questions raised with reference to the use of the 3-inch soil stack. With equal volumes of flow in the 2 and 3 inch stack and with vents that allowed approximately the same vacuum to be produced at the point of connection of the vent to the stack, the ratio of the rates by volume at which air was drawn through the vents was found to be 1 to 5 . The ratio of the fourth powers of the diameters of the stacks $2^{4} / 3^{4}=16 / 81=1$ to 5 , approximately. This not only checks the preceding equation for vent requirements for 2 and 3 inch stacks carrying their full practical capacities (see p. 101), but also indicates the requirement of a larger vent for the 3 -inch stack when the two stacks are carrying equal volumes, provided the volumes approach the practical capacity of the 2 -inch stack. A similar relation may be expected for 3 and 4 inch or 5 and 6 inch stacks, probably more marked than for the small stacks, since with 1 inch difference in diameter the ratio of the smaller to the larger cross section of two pipes increases with increase in size.

\section{MODIFYING CONDITIONS}

Numerous conditions are encountered in service which may produce sufficient modifying effects on the functioning of a plumbing system to justify special provisions. Among these the effects of heavy rains, of submerged sewer outfall, of strong winds over the stack tops, and of closure or partial closure of stack tops by frost or snow have received special attention and have been made the subject of experi-

- ments to determine the magnitude of the effects and a means of preventing or alleviating them. These are grouped together here for discussion and for convenience of reference.

All the experiments were made on complete plumbing test installations, and specific data for some will be found in the report on such test installations.

Heavy Rarns.- The only direct effect of heavy rains on a plumbing system is encountered when a combined sewer system is employed. There is no doubt that a complete separation of storm and sewage mains greatly simplifies the problem of house drainage. When the street mains are combined sewers, the problem would be simplified to a lesser degree by separate connections to the street main.

Means of introducing water into the house drain at known rates was provided. Figure 51 shows a typical arrangement providing for the introduction of the water through rain leader $A$ ahead of the stack, or through rain leader $B$, beyond the stack, or simultaneously through both rain leaders. The worst conditions were encountered with storm water introduced ahead of the stack discharge as through $A$, Figure 51. The effects in the stack were only slightly less with 
storm water at the same total rate equally divided between $A$ and $B$. The effects were appreciably less with storm water introduced at the same rate through $B$ alone. Only one distance, approximately 6 feet between soil stack and rain leader $B$ connection to the house drain, was employed. It is evident that the farther from the soil stack the rain-leader connection on the sewer side is removed, the less the effects of storm water will be felt in the plumbing stacks.

The effect of storm water in all cases is an increase in back pressures around the base of the stack, the effects increasing rapidly with increase in the rate of introduction of storm water. This is true even with a house drain of sufficient capacity to carry off the total discharge from stack and rain leaders if it were introduced to the house drain at one point only. The apparent decrease in carrying
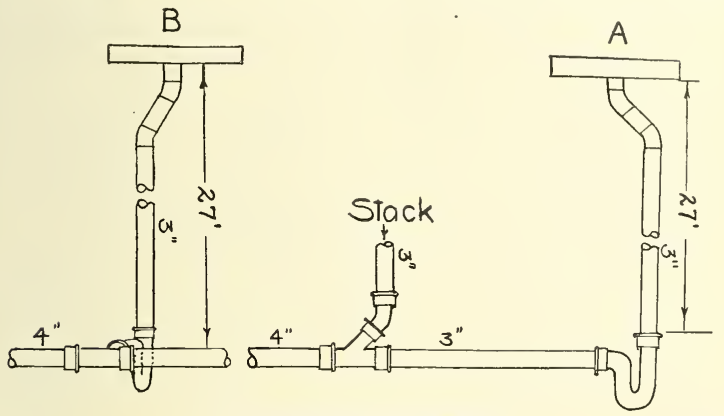

Fig. 51:-Experimental rain leader system

capacity of the house drain is evidently due to two or more streams entering it from different directions. If the combined discharge from the stacks and rain leaders exceeds the carrying capacity of the house drain under its own head, the result is backwater into the base of the stack. When the backwater extends upward into the stack above the level of the lowest fixtures, it is impossible to protect the traps of such fixtures completely by venting. It is necessary, therefore, to look for the cure by insuring an ample capacity in the house drain. Detrimental effects may be further reduced or rendered less liable to occur by giving the greatest possible vertical distance between the lowest level of fixture inlets and the house drain when this distance is short. Whether the combined or separate sewer systems are employed, there is a distinct advantage in having a vertical distance of at least 3 feet between the lowest fixture inlet to the stack and the house drain, the distance increasing with the height of the stack and volume of discharge through it. 
The plumbing committee has agreed that an allowance for a rainfall of 4 inches per hour is liberal, and that an allowance for 1,500 square feet of roof or drained area was sufficient to include all types of the small dwelling house under consideration in its report. Before this agreement had been reached many tests had been made allowing for a rainfall of 6 inches per hour over 1,200 square feet of roof area. If these rates seem too high to some, it should be remembered that a much lower rate of rainfall for an extended period under certain conditions, in low-lying territory, etc., may prove as detrimental as the higher rate for a short period of time.

$A$ rate of rainfall 4 inches per hour discharges water to the sewer at the rate of approximately 1 gallon per minute for every 24 square feet of drained area, which is equivalent to 1 fixture unit for every 180 square feet of drained area. The house drain should have sufficient capacity to carry off the combined estimated peak discharge from the stacks and the discharge from the drained area. It is true there is small chance of the two maximum discharges occurring together, but the effects from the combined sewer are so detrimental and the conditions encountered so varied that this allowance in capacity will not give an unnecessarily large margin of safety in low-lying territory and regions of frequent heavy rains.

Submerged Drains.- The effects arising from a submerged house drain or submerged outfall of house drain are very similar to those produced by an overcharged house drain in the combined sewer system. Tests were made with submerged outfall (fig. 52), from 2 inches up to 3 feet depth, the latter giving backwater in the house drain to the base of the soil stack. Increase in the size of the house drain will afford slight, if any, relief to this latter condition. The only complete protection seems to be to specify construction that will insure the lowest fixtures being well above the level of submergence, otherwise such fixtures will be forced out of service during periods of submergence. The problem is not to be solved by experimentation.

House Traps.- The effects of a house trap (fig. 53), or running trap, in the house drain are similar to those arising from a partially submerged drain. Whether the house trap is vented or unvented the first effect is a decrease in the carrying capacity of the house drain due to the added resistance. In the British "Report of the Departmental Committee on the use of Intercepting Traps in House Drains," ${ }^{1}$ following thorough investigation, both experimental and by observation on systems in use, the advantages and disadvantages of intercepting traps are fully discussed.

1 This report was published in 1912 by H. M. Stationery Office, printed by J. Truson \& Son (Limited), London, Eng. 
Our experiments have shown that the effect of an unvented trap in the house drain is similar to that of partial submergence. For heavy discharges with the trap either vented or unvented the effect is similar to that of a considerable degree of submergence. With the trap vented on the house side, for small discharges not sufficient to fill the house drain to the point of closing the vent, the effect is practically that of an open house drain. There seems to be no case in which the house trap increases the capacity of the system.

OfFsets in STacks.-Many questions have been asked concerning the effects of offsets in soil or waste stacks. We may answer these questions as far as the data at hand and theoretical considerations justify conclusions. If the offset is above the highest fixture connections to the stack, there can be but slight effect on the functioning of the system. If the offset is below the lowest point of fixture connections to the stack, the effect will be similar to that from a house drain at the same level as the offset. The longer the offset

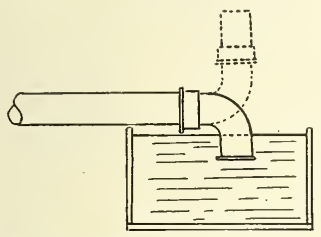

Fig. 52.--Submerged outfall of house sewer

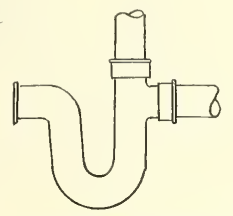

FIG. 53.--Vented running trap

the more nearly the effects will approach those of a house drain at the same level. The farther the offset is placed below the lowest fixture connection the more nearly the effect will approach that of the straight stack. The effect of offsets in the stack between levels of fixture connections to the stack is problematical and will doubtless be found to vary with different installations. This last is a condition of construction which should be avoided when possible and which, if impossible to avoid, should be safeguarded by additional vent connections to the stack at the fixture levels on either side of the offset.

WInds.-The effect of winds was obtained by directing an air current over the stack tops by means of a motor-driven fan of the propeller type (fig. 54). By means of rheostats the velocity could be varied up to 45 miles per hour (55 miles per hour U. S. Weather Bureau rating). The frame carrying the motor was constructed to permit adjustment directing the current horizontally or at an inclination of $30^{\circ}$ to the horizontal in either direction. The effect of air currents was studied in connection with complete plumbingtest installations. All of the tests involving wind effects were made 
on systems with 3 -inch soil stacks, 2 -inch waste stacks, and 4-inch house drains.

With the system idle, the 2-inch waste line closed and the end of the house drain open the maximum effect obtained by a 45 -mile per hour air current directed horizontally over the 3-inch stack top was a decrease in pressure in the system of 0.2 inch of water. With the end of the house drain submerged, giving a system closed at the lower end, a decrease in pressure of 0.36 inch of water was produced by a 45-mile per hour current directed horizontally and 0.4 inch of water by a 45 -mile per hour current directed upward at $30^{\circ}$ to the horizontal.

With fixtures on the system discharging, the wind effect was generally masked or shut off from unvented fixture branches below the

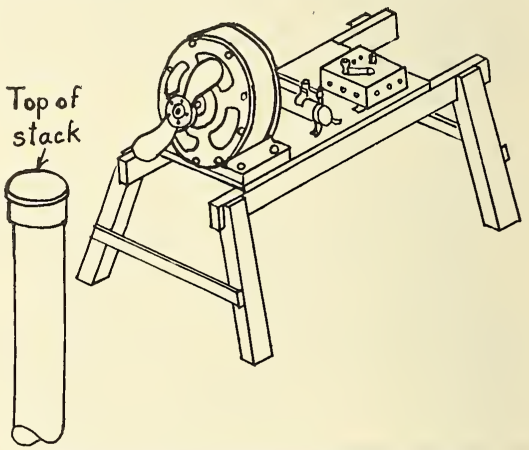

FIG. 54.-Apparatus for producing air current over stack top

point of discharge. In individually vented branches and unvented branches above the point of discharge the combined effect was the sum of the separate wind and fixture effects. In no case was a combined effect observed greater than that indicated by the additive relation.

There seems to be no ready means of protecting against wind effects when the vent stack or vent lines are connected into the soil stack before passing through the roof, since they are transmitted more readily to vented than to unvented fixtures during use and as readily during idle times. In view of the small effects encountered, it seems reasonable to assume that in the small dwelling house they will be taken care of by factors of safety referred to elsewhere.

A considerable degree of protection would be afforded in tall buildings or other buildings exposed to very high winds by running the soil stacks and vent stacks separately through the roof and con- 
necting them together above the highest fixture inlets and branchvent connections, thus giving an opportunity for relief of pressure differences above the fixture connections. Then only when the effect was of the same kind and intensity over both stacks would the full intensity reach the fixture traps.

Frost Closure.-Frost closure was simulated by setting sections of pipe of various diameters and length into the stack tops. No measurable effect was produced by setting a $1 \frac{1}{2}$-inch pipe 20 inches long into the tops of the 3-inch stacks of the different systems. A 1-inch pipe 12 inches long set in the 3 -inch stack only slightly increased the vacuum produced by a heavy discharge from the fixtures. No doubt the effect would be felt more with an increase in the volume of discharge. With a complete closure of the stack top the watcr was sucked from one or more traps by the discharge of a single water-closet on the system. This occurs whether the traps are individually vented or not provided the stack tops are completely closed.

Floor Drains.-The floor drain, though not itself a modifying condition, is considered in this connection because the type and position in which it may be installed will be determined by such modifying conditions. No tests were made with true floor drains. However, tests were made with traps connected to the soil stack near its base and connected into the house drain on the sewer side.

There seems to be no reason why a floor drain might not be connected into a soil or waste stack when conditions permit, subject to the same requirements in venting, etc., as a fixture connecting into the stack at the same point. If the house drain is sufficient in size for the system and located high enough to be free from backwater effects, a floor drain might connect directly to a nominally horizontal house drain at a point 5 feet or more from the base of the stack on the sewer side without danger from aspiration or back pressure, and, hence, need not be separately vented unless its form is such as to induce self-siphonage or for other good reasons. The velocity of flow attained in a house drain is insufficient to produce aspiration, and the head is not great enough at such a point to produce sufficient back pressure to endanger the trap seal. In all places where there is any danger of backwater or overcharged sewers the floor drain, if installed, should be fitted with a suitable backwater valve.

\section{SIPHONAGE OF FIXTURE TRAPS}

The subject of trap siphonage is somewhat more complicated than expected from a casual consideration. Whether the effect is due to self-siphonage or siphonage by aspiration or a vacuum transmitted to the trap from some other part of the system, the extent of siphon- 
age is evidently dependent on the intensity of the pull and a quantity factor or, in other words, the energy that may be expended on the trap. In the case of aspirating effects the energy is great, and a considerable volume of air must be moved into the system to protect the trap when the intensity is equal to or greater than the pressure represented by the seal depth of the trap. The venting of a branch line on which a trap is placed prevents, by the introduction of air, the intensity of the vacuum produced from rising above a fixed value. The problem of venting to protect against aspiration and back pressure was taken up in an earlier section. These same considerations enter into the problem of self-siphonage.

Self-siphonage.-The intensity of the pull in self-siphonage is determined by two different causes which may be present at the same time. The first is an unbalanced column of water as represented in the common siphon. The second is the momentum pull exerted by the moving column of water, which is present whether the pipe is horizontal, vertical, or inclined and its intensity is dependent on the length of the column or length of filled pipe and its velocity. In vertical pipes the former cause is predominant. In pipes approaching the horizontal the latter is predominant. The quantity factor is dependent on the volume of the pipe, hence, on the length of the pipe. The volume of pipe inducing the siphonage effect is in small fixture traps relatively small, hence, a small volume of air introduced is sufficient to prevent the intensity from rising to a point that endangers the seal of the trap.

Before taking up the discussion of self-siphonage in detail we desire to call attention to some very pertinent facts in connection with wide-bottom fixtures, such as bathtubs, kitchen sinks, and laundry trays. In the discharge from such fixtures a swirl is formed before the fixture is empty which draws air through the trap, tending to reduce the intensity of the pull toward the end of the discharge. There is a long trail discharge from such fixtures during which the velocity in the waste pipes is reduced with a resultant reduction in the pull due to velocity. Refer to Figure 55 for illustration of the effects of swirl and trail discharges. In no case, using flat-bottom fixtures, have we been able to reduce the final seal materially below the normal full seal and in no case with such fixtures set in place on a test system have we detected any reduction in seal.

With oval-bottom fixtures tending toward a funnel shape, as the washbasin, it is essentially different. In such fixtures the discharge ends abruptly with a very short swirl. Self-siphonage is almost certain when an unvented waste has a vertical section greater in length than the seal depth of the trap and followed by a horizontal section of near the same diameter (fig. 56). If the entire waste from the trap is nominally horizontal (fig. 57) the momentum pull in its 


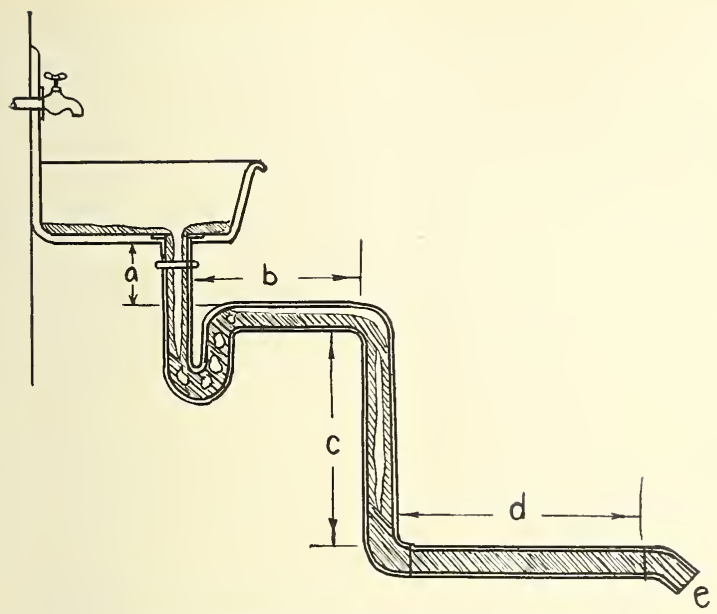

FIG. 55.-Illustration of trail discharge from a flat-bottom fixture

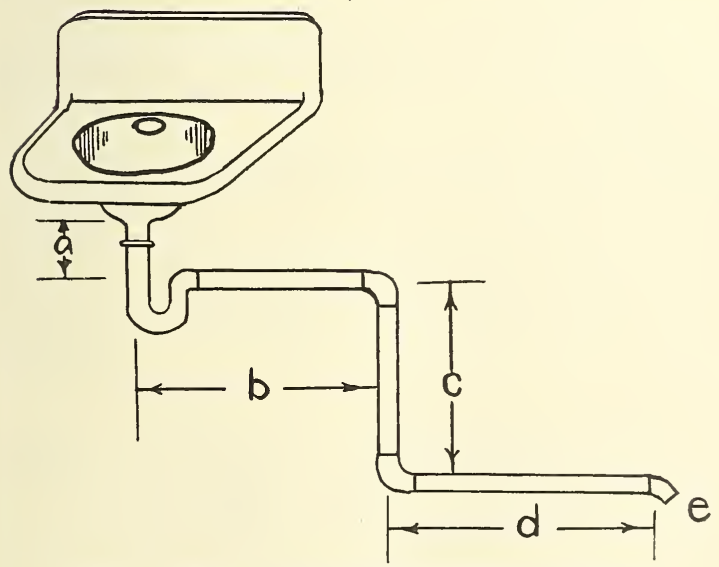

FIG. 56.-Arrangement of waste pipe to produce self-siphonage of a fixture trap 
full intensity is exerted at the end of the discharge. In a " $P$ " trap a part of the water invariably flows back from the horizontal part of the trap. At least a partial seal is always left. Any seal left is theoretically sufficient to prevent air circulation from the plumbing system to the room, except where the waste connects low on the stack within the region of back pressure. It of course may be completely destroyed by evaporation. The degree of protection of traps connecting to the stack above the region of back pressures is therefore dependent on the frequency of use as well as on the seal depth.

Because of the differences in siphonage effects in wide and ovalbottom fixtures, except for a few independent tests to verify the facts regarding wide-bottom fixtures, the laboratory tests were confined to self-siphonage in washbasins. Including a number of tests on fix-

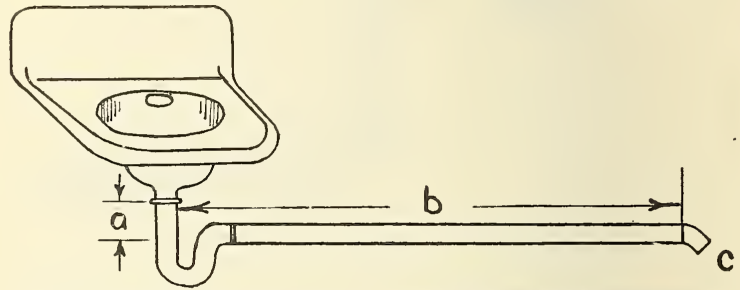

Fig. 57.-Fixture and waste pipe to study effect of length of horizontal pipe on self-siphonage

tures set in place on the test installations, several hundred tests were made. Space will only permit detailed description of a few of the most pertinent.

1. To determine the effect on self-siphonage of size of outlet orifice relative to size of waste pipe, an oval washbasin was arranged with nominal $1 \frac{1}{2}$-inch waste in a form to induce strong self-siphonage (fig. 56), $a=9$ inches, $b=17$ inches, $c=26$ inches, $d=26$ inches, $e=\frac{1}{8}$ bend fitting, actual internal diameter of waste $=1 \frac{9}{16}$ inches. Capacity of basin $=1 \frac{1}{2}$ gallons, discharged each time by lifting plug

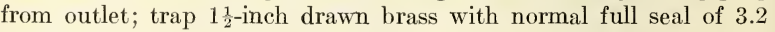
inches.

\begin{tabular}{|c|c|c|c|c|}
\hline & \multirow[b]{2}{*}{ Internal diameter of outlet (inches) } & \multicolumn{2}{|c|}{ Seal left- } & \multirow[b]{2}{*}{$\begin{array}{l}\text { Velocity in } \\
\text { waste pipe }\end{array}$} \\
\hline I & & $\begin{array}{l}\text { Mean of } \\
\text { five deter- } \\
\text { minations }\end{array}$ & $\begin{array}{l}\text { Minimum } \\
\text { of five } \\
\text { determin- } \\
\text { ations }\end{array}$ & \\
\hline $1 \frac{1}{13}$ & $\cdots$ & $\begin{array}{r}\text { Inches } \\
1.92 \\
.96 \\
.86\end{array}$ & $\begin{array}{r}\text { Inches } \\
1.2 \\
.8 \\
.7\end{array}$ & $\begin{array}{r}\text { Ft. per sec. } \\
4.2 \\
4.5 \\
4.9\end{array}$ \\
\hline
\end{tabular}


The unbalanced column of water in the waste is the same in each case. Evidently, then, the reduction in self-siphonage with reduction in size of outlet orifice is due to the slight reduction in velocity thus produced. An outlet orifice and tailpiece slightly less in diameter than the trap and waste only slightly reduces the velocity in the waste pipe, so does not materially affect the scouring effects. At the same time there is an increased velocity through the tailpiece itself, giving a better scouring in this part which is always exposed to the room. It therefore seems reasonable and offers many advantages to allow the tailpiece of a fixture to be the nominal size smaller than the trap, convenient for making a slip joint between the two.

2 . To determine relative resistance to self-siphonage of unvented plain $P$ traps of various seal depths, tests were made with the fixtures connected to a 3-inch stack plumbing test installation. The oval washbasin and bathtub were served by a common waste, $1 \frac{1}{2}$ inches from the bathtub and $1 \frac{1}{4}$ inches from the basin. The basin waste was 26 inches vertical from the outlet end of the trap to its connection into a recessed $T-Y$ in the $1 \frac{1}{2}$-inch bath waste 2 feet 6 inches from the stack. The horizontal distance from the basin outlet to the trap connection with the vertical waste was 15 inches. The exact arrangement is unimportant, the point being to secure a strong siphonage effect on the basin trap. The data following represents the effect of the combined discharge of the washbasin and bathtub, which is stronger than that of the basin alone. The intensity and quantity pull were practically the same for each of the traps. The tailpiece of the basin had an internal diameter of $1 \frac{1}{8}$ inches, the internal diameter of the traps and basin waste were approximately the same, $1 \frac{5}{16}$ inches.

Cast brass, 1 -inch $P$ trap

Lead, $1 \frac{1}{4}$-inch $P$ trap

Do.

Seal left-

\begin{tabular}{|c|c|c|}
\hline \multirow[b]{2}{*}{$\begin{array}{l}\text { Nominal } \\
\text { seal }\end{array}$} & \multicolumn{2}{|c|}{ Seal left- } \\
\hline & $\begin{array}{l}\text { Mean of } \\
\text { five deter- } \\
\text { minations }\end{array}$ & $\begin{array}{l}\text { Minimum } \\
\text { of five } \\
\text { determina- } \\
\text { tions }\end{array}$ \\
\hline $\begin{array}{r}\text { Inches } \\
2.6 \\
4.0 \\
7.0\end{array}$ & $\begin{array}{r}\text { Inches } \\
0.88 \\
1.56 \\
2.62\end{array}$ & $\begin{array}{r}\text { Inches } \\
0.8 \\
1.4 \\
2.1\end{array}$ \\
\hline
\end{tabular}

These data, supported by other observations on seals retained by traps of various seal depth of from 2 to 7 inches on different waste lines, indicate a retained seal proportional to the depths of the normal full seals. Other considerations enter into the question of permitted depths of seal. The effect of seal depth on scouring properties has not been specifically investigated. However, it is evident that the scouring properties decrease with depth of seal, especially with reference to heavy materials. The very shallow seal in addition to 
offering less resistance to self-siphonage is less resistant, because of smaller volume of water, to loss of seal by evaporation. We therefore suggest a minimum normal seal of 2 inches and a maximum of 4 inches as serviceable limits. From a consideration of all tests our personal inclination is toward a nominal seal depth of 3 inches for washbasins not separately vented.

3. To determine effect of length of unvented waste on self-siphonage (fig. 57): Oval basin capacity $1 \frac{1}{2}$ gallons discharged by lifting plug from full basin. Diameter of outlet orifice and tailpiece $=1 \frac{1}{8}$ inches, diameter of waste $1 \frac{7}{16}$ inches, $a=7$ inches, $c=\frac{1}{8}$ bend open end turned down.

[Normal full seal of $11 / 2$-inch lead $P$ trap $=2.2$ inches]

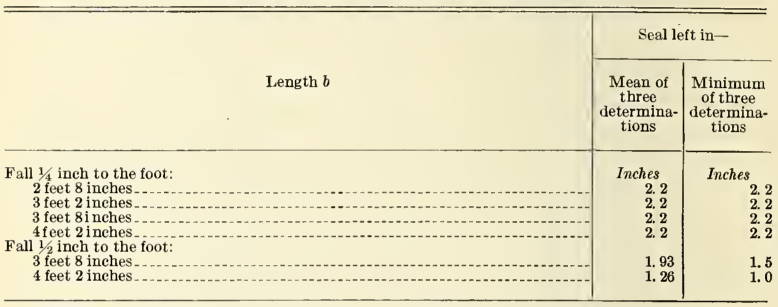

Diameter of outlet orifice and tailpiece $=1 \frac{9}{16}$ inches.

[Normal full seal of $11 / 2$-inch lead $P$ trap $=2.3$ inches]

\begin{tabular}{|c|c|c|}
\hline & \multicolumn{2}{|c|}{ Seal left- } \\
\hline Length $b$ & $\begin{array}{l}\text { Mean of } \\
\text { three } \\
\text { determina- } \\
\text { tions }\end{array}$ & $\begin{array}{l}\text { Minimum } \\
\text { of three } \\
\text { determina- } \\
\text { tions }\end{array}$ \\
\hline $\begin{array}{l}\text { Fall } 1 / 4 \text { inch to the foot: } \\
2 \text { feet } 2 \text { inches. } \\
2 \text { feet } 8 \text { inches. } \\
3 \text { feet } 2 \text { inches } \\
4 \text { feet } 2 \text { inches. }\end{array}$ & \begin{tabular}{r|} 
Inches \\
2.13 \\
1.13 \\
.87 \\
.80
\end{tabular} & $\begin{array}{r}\text { Inches } \\
2.0 \\
1.0 \\
.8 \\
.7\end{array}$ \\
\hline
\end{tabular}

One-fourth bend fitting set in horizontal section (fig. 58); diameter outlet orifice and tailpiece $=1 \frac{9}{16}$ inches, $a=7$ inches, $b=12$ inches, $c=2$ feet 2 inches.

[Normal full seal lead P trap=2.2 inches]

\begin{tabular}{|c|c|c|c|c|}
\hline & \multirow[b]{2}{*}{ Length $b$ and $c$} & \multirow[b]{2}{*}{. } & \multicolumn{2}{|c|}{ Seal left- } \\
\hline & & & $\begin{array}{c}\text { Mean of } \\
\text { three } \\
\text { determina- } \\
\text { tions }\end{array}$ & $\begin{array}{l}\text { Minimum } \\
\text { of three } \\
\text { determina- } \\
\text { tions }\end{array}$ \\
\hline $\begin{array}{l}\text { Fall } 1 / 4 \text { inch to the foot: } \\
3 \text { feet } 2 \text { inches...... }\end{array}$ & , & & $\begin{array}{l}\text { Inches } \\
1.7\end{array}$ & $\begin{array}{r}\text { Inches } \\
1.6\end{array}$ \\
\hline
\end{tabular}


4. To determine effect of fall or inclination of waste on selfsiphonage (fig. 58):

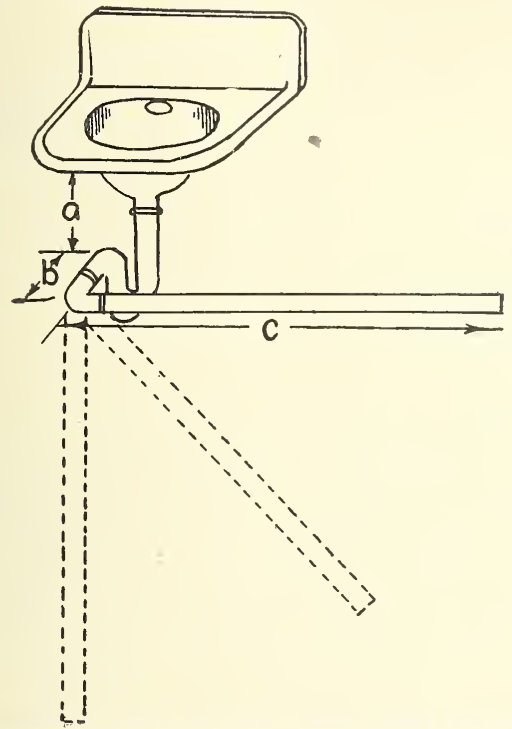

FIG. 58.-Fixture and waste pipe to study effect of inclined waste pipe on self-siphonage

Diameter of outlet orifice and tailpiece $=1 \frac{9}{16}$ inches. $11 / 2$-inch lead $\mathrm{P}$ trap, $a=9$ inches, $b=13$ inches, $c=5$ feet 2 inches, diameter $c=1 \frac{7}{16}$ inches.

[Normal seal $=2.0$ inches]

Fall in section $c$ :

$1 / 4$ inch to the foot $1^{\circ}+$

1 inch to the foot $5^{\circ}$

$10^{\circ}$ to horizontal.

$15^{\circ}$ to horizontal

$20^{\circ}$ to horizontal

$25^{\circ}$ to horizontal.

$30^{\circ}$ to horizont a

Sealleft-

\begin{tabular}{r|r}
$\begin{array}{c}\text { Mean of } \\
\text { two } \\
\text { determina- } \\
\text { tions }\end{array}$ & $\begin{array}{c}\text { Minimum } \\
\text { of two } \\
\text { determina- } \\
\text { tions }\end{array}$ \\
\cline { 2 - 2 } Inches & \multicolumn{2}{|c}{ Inches } \\
1.7 & 1.5 \\
.65 & .6 \\
.75 & .7 \\
1.70 & 1.7 \\
1.90 & 1.8 \\
2.00 & 2.0 \\
\hline
\end{tabular}


With diameter of outlet orifice and tailpiece $=11 / 8$ inches, $11 / 4$-inch cast brass $P$ trap, $b=10$ inches, $c=5$ feet, diameter $c=11 / 4$ inches.

[Normal seal depth $=3.0$ inches]

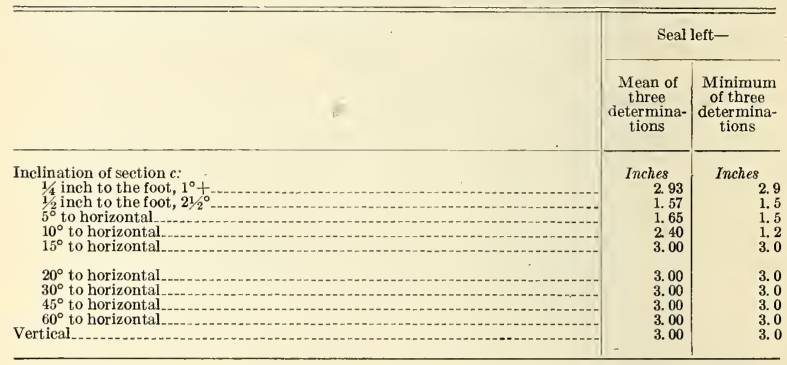

5. To determine the influence on self-siphonage of a $90^{\circ}$ elbow in a nominally horizontal unvented waste (fig. 58) several independent experiments were conducted. No more specific conclusions follow from these data than may be drawn from other experiments in which such an elbow was employed. It is sufficient to state that an elbow in a nominally horizontal waste at a horizontal distance from the vertical inlet arm of the trap not greater than 18 to 20 inches reduces the self-siphonage effect. This means that from the standpoint of self-siphonage alone a greater length of pipe may be permitted when an elbow is placed within these limits than where the waste pipe is straight from the trap to its connection with the stack or a vented branch.

6. To determine the effect of fouled waste pipes on self-siphonage: The experiments conducted for this purpose were not wholly satisfactory because of the difficulties of securing representative fouling of the waste pipes. If extreme fouling is assumed, such as to reduce the cross section of the waste materially below that of the fixture outlet orifice and of the trap, the self-siphonage is much greater than if we assume a slight degree of fouling in which the cross section of the waste is not reduced below that of the fixture outlet orifice. The whole question of degree of fouling that takes place in traps and small waste pipes in service is one that must be decided from extended observation and specific records under actual service conditions. Time and facilities have not permitted such observations. The alternative is to require construction that will tend to reduce fouling of wastes to a minimum and assume that under such conditions the fouling that takes place will not reduce the cross-sectional area of the trap and waste below that of the 
fixture outlet orifice and tailpiece. On this assumption the data would permit an approximation of allowable length of horizontal unvented waste. It is necessary further to arbitrarily assume some permissible degree of self-siphonage. If no reduction of seal is permitted, it leads to one conclusion. If any other remaining seal depth is assumed, it leads to another conclusion. The plumbing committee fixed on a minimum remaining seal of 1 inch as representing the limit of satisfactory conditions in tests for traps with nominal 2-inch full seals. Any reduction in seal below this value was considered unsatisfactory. In this connection we wish to say that we believe this is a fair limit for a trap with a 2-inch normal seal. In general, a remaining seal of not less than, one-half the normal full seal would more nearly represent the dividing line between safe and unsafe conditions than an arbitrarily fixed value irrespective of normal seal. An $S$ or a $P$ trap seal may be drawn to the point of breaking the seal with a loss of approximately onehalf its full seal, after which it may be subjected repeatedly to the same or a smaller strain with no further loss of seal.

Reference to the data shows that with a fixture-outlet orifice equal to the cross section of the waste a clean straight waste laid one-fourth inch fall to the foot and 2 feet 8 inches long measured from the center of the inlet arm of the trap did not reduce the nominal 2 -inch seal of trap below 1 inch; and that with a $90^{\circ}$ elbow 13 inches from the trap and 5 feet 2 inches of clean waste laid one-fourth inch fall to the foot beyond the elbow did not reduce the nominal 2-inch seal below 1.5 inches. It is a fact, although not shown in the data, that an increase in the length of the section beyond the elbow produces slight, if any, increase in self-siphonage effect until the outlet end of the waste falls below the dip of the trap.

No specific recommendations are made as to the allowable length for an unvented horizontal waste from a washbasin. We desire, however, to call attention again to certain modifying conditions: A slight reduction in the size of the outlet orifice of a washbasin appreciably decreases the self-siphonage; a decrease in the size of the waste by fouling or other causes tends to increase self-siphonage. In general, if a washbasin is placed in a region of no or slight back pressure, there is no particular danger if the seal left is reduced below 1 inch, except as it may be affected by the factor of evaporation. The washbasin is, in general, the most frequently used fixture of the bathroom group and the factor of evaporation is usually negligible.

On the grounds of self-siphonage an increase in depth of normal seal would permit a proportional increase in allowable length of unvented waste. There is no necessity for limiting the length of an unvented horizontal waste laid with a fall of one-fourth inch to the 
foot from a bathtub, kitchen sink, and laundry tray on the grounds of self-siphonage, except as it is limited by the requirement that the outfall end may not be below the dip of the trap. A long sloping waste (fig. 59) with the sloping section of the same cross section as the trap and horizontal section will not produce self-siphonage when the angle of inclination from the horizontal is greater than $30^{\circ}$, provided the horizontal section is not in itself sufficient to induce self-siphonage. This is true in service only if the cross section of the inclined part does not become materially reduced by fouling. Whether it is a practical form of installation or not depends on its liability to foul to such an extent.

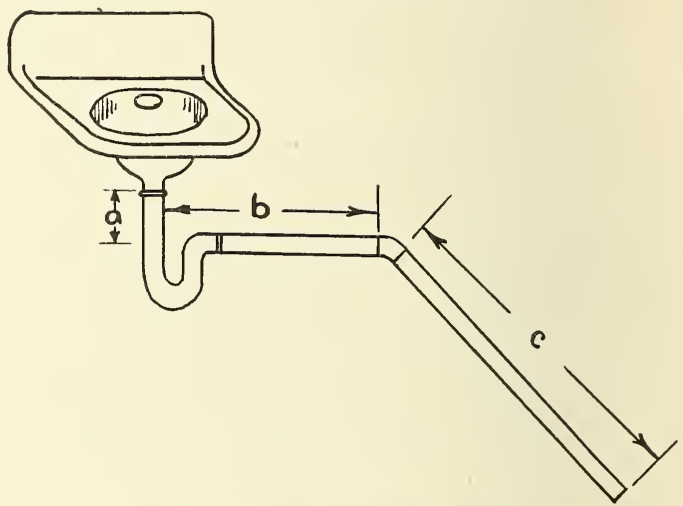

FIG. 59,-Fixture and waste pipe to study effect of combined horizontal and inclined waste pipes

Permissible Lengti of Unvented Horizontal Branch Waste Pipes.-Four reasons for limiting the length of an unvented horizontal waste or soil branch have been advanced. These are increased danger of self-siphonage, increased corrosion due to decreased circulation of air, increased liability to stoppage or fouling due to decreased velocity of flow and increased cooling and fouling area and decreased facility of use of fixtures due to sluggish action in long horizontals. If the reasons advanced were all of the same weight and supported by uncontrovertible evidence of the effects claimed, the problem would be immediately limited to the one placing the greatest restriction. As it stands there is some uncertainty, especially concerning the effect of long unvented branches on corrosion. There are no data bearing directly on this effect available. The opinions expressed by practical men are based for the most part on the fact 
that long unvented branches have been found badly corroded in many cases. There is no evidence at hand that a vented branch in the same position and service would not have corroded to the same or greater extent, or that the corrosion was due to lack of air circulation in the branch. Experiments conducted at Harvard University during the past year for the plumbing committee have shown that induced circulation of air in an unvented horizontal $1 \frac{1}{2}$ inches in diameter takes place up to a length of about 2 feet, due to the circulation of air in the stack to which the unvented branch is connected. The same and other earlier experiments show a fairly rapid change of air by convection currents and diffusion up to a much greater length. It would seem, then, that if the contention that lack of air circulation hastens corrosion were granted there would still be slight grounds for

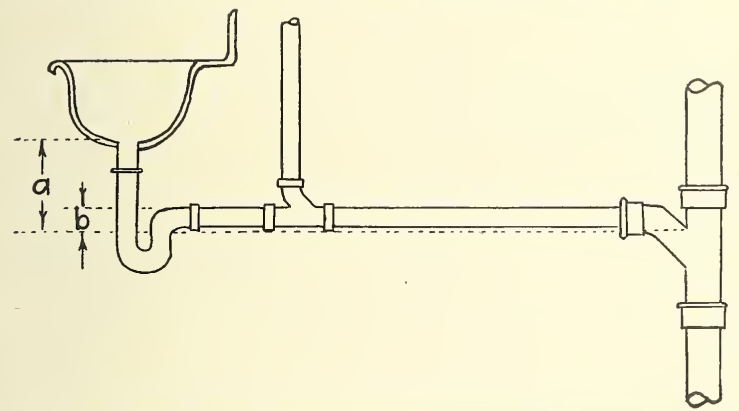

Fig. 60.-Diagram to illustrate the effect of horizontal waste pipe on velocity and scour

limiting the length of an unvented branch to less than 6 feet. The same arguments might be applied to any unvented branch whether horizontal or vertical. In any event, it is a question of the life of the pipe rather than one of functioning until the pipe has corroded through or has corroded to the extent of materially reducing the cross-sectional area.

The questions of stoppage, fouling, decreased rate of flow apply also to all horizontal wastes and drains whether they are vented or not. In fact, the general effect of a vent in a branch waste is to decrease the rate of flow. Compare Figures 60 and 61 to the same wastes unvented. With the vents shown in the waste lines the effective head on the horizontal waste will be measured by $b$. In the same systems unvented the effective head will be measured by $a$. It is evident, without experimentation to show the magnitude of the effects, that from the standpoint of drainage alone long wastes leading 
directly from the trap on the horizontal or with small gradient are bad practice and should be reduced to the minimum consistent with other requirements.

As to self-siphonage and its relation to the limit of the allowable length of an unvented horizontal waste pipe, our experiments indicate that the slope should be confined between the limits of a fall of onefourth inch to the foot and one-half inch to the foot, and that the outlet end should not extend below the dip of the trap. It will be observed that from a consideration of self-siphonage effects alone there are so

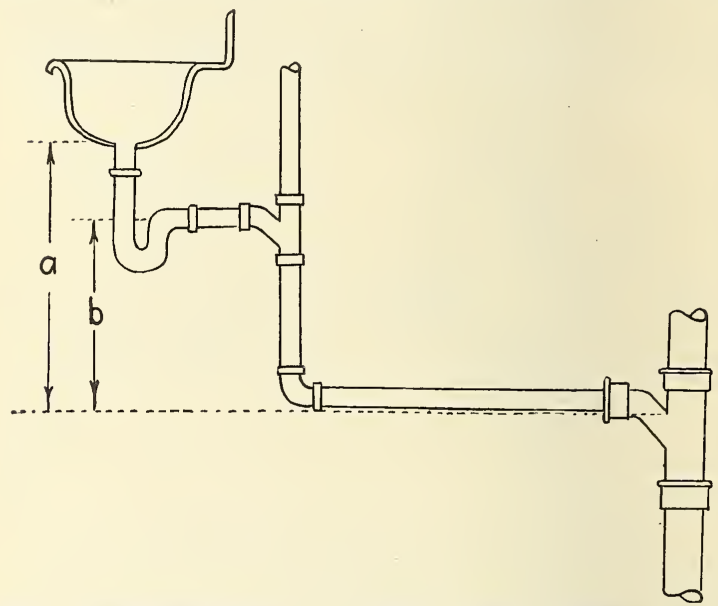

Fig. 61.-Diagram to illustrate the effect of a vertical section of waste pipe on velocity and scour

many conflicting elements that any conclusion is largely a matter of judgment. For these reasons and because of the uncertainty of the effect of long unvented branches on corrosion it is difficult to make specific recommendations. However, the following table summarizes the results of the experiments, giving what are believed to be safe maximum lengths for nominally horizontal unvented wastes from fixtures connected to a stack or vented branch at points where they are free from detrimental aspirating or back-pressure effects. It is to be understood that they refer to self-siphonage only. Possible increase in self-siphonage due to fouling has been taken into account. 
TABLE 9.-Lengths of nominally horizontal unvented waste pipes believed to be safe against self-siphonage

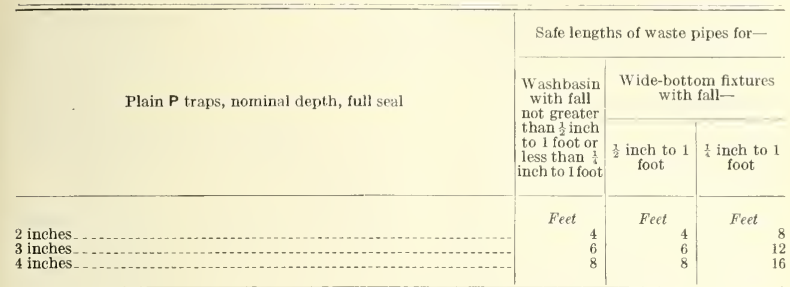

These lengths are from the center of the trap to stack or larger vented branch waste and would permit one $90^{\circ}$ elbow in the waste at a distance not greater than 18 inches from the inlet arm of the trap. Elbows in other positions or added elbows should be counted as equivalent lengths of pipe.

Resealing Traps.-It should be noted that the preceding restrictions refer to the use of plain $\mathrm{P}$ traps. The experiments with "resealing," so-called "antisiphon" traps, owing to difficulties encountered in satisfactorily fouling the traps and in determining the kind and degree of fouling to be expected in different kinds of service, have not been completed.

The tests have shown that "resealing" traps when clean retain a greater seal under a suction test and are more resistant to back pressure with the seal left after the suction test than clean unvented plain $P$ traps of the same full seal depth when subjected to the same suction and pressure tests. The same is true to a lesser degree for resealing traps of the better types, fouled by artificial means.

The tests so far indicate that there is a field in which a judicious use of the better types of resealing traps would be found a distinct advantage, such as in places where there is danger of self-siphonage or of aspiration and back pressure within certain limits and where structural difficulties are encountered that make the venting of the plain trap costly or impractical. The data are not yet at hand to determine to what extent "resealing" traps may be used with safety. With data available it will be found difficult to state in a general way the extent of their use without opening a way for misuse under certain conditions. Where an unvented plain trap will serve there is no special advantage gained in using a "resealing" trap at an added cost, and there is no advantage gained by the use of "resealing" traps in places where it is necessary to vent individually regardless of the kind of trap used.

It is obvious that, tied up as the question of the use of "resealing" traps is, with efficiency of functioning and economy of construction 
and surrounded, as it is, by strong prejudices both for and against their use, any general regulations must be administered with considerable latitude of discretionary powers if full advantageous use of "resealing" traps is to be obtained and no abuse is to result. Such discretionary powers would, of course, assume a complete knowledge of the subject on the part of the administrative officer and might easily lead to special privileges. 'It is unfortunate that the data are not available to enable us at least to state the limits beyond which resealing traps may not be used with safety.

The same questions are bound to rise with respect to other usages in plumbing work; for example, that of individual venting of fixtures. With any rules that may be applied generally with safety many places will be found where we could go beyond the limits stated in the rules with perfect safety were there a competent authority to prescribe the limits for the condition encountered.

Baск Venting.- - In connection with the employment of individual or group vents as a protection against siphonage and pressure effects

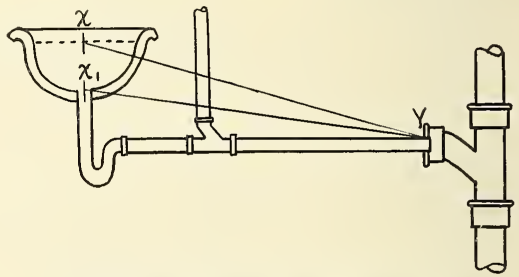

FIG, 62.-Diagram to illustrate type of venting liable to clog

or as a means of insuring air circulation, it is of extreme importance that the position and manner of making the vent connection receive special attention and be safeguarded by regulations. The experiments on fouling conducting at the Bureau of Standards and numerous instances cited for service installations indicate that there is a strong liability of a vent line becoming completely closed near its junction with the waste line when conditions for fouling are favorable.

It has been shown that vents are required at certain points in a complex plumbing installation of two or more floors in order to protect the trap seals. It is evident that a vent poorly installed has not met the condition and that one that has become completely stopped in service is as bad as if no vent had been installed. The method of crown venting has been generally prohibited because of liability of closure by fouling. Some forms of continuous waste and vent may give rise to conditions quite as bad as crown venting.

The "continuous waste and vent" has been favored by the plumbing committee. As "continuous waste and vent" is defined it would 
permit the vent being taken off the top of a horizontal waste or the continuation of a horizontal waste as a vent. For illustration of three distinct effects, all of which fall within the definition of "continuous waste and vent," refer to Figures 62, 63, and 64. Figure

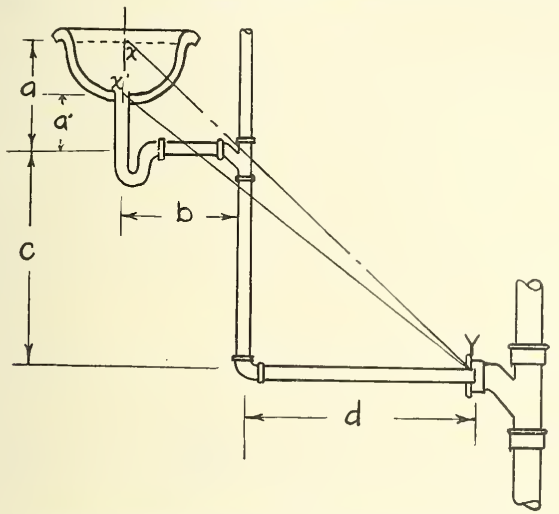

FIG, 63.-Diagram to illustrate type of venting least liable to clog

62 represents a nominally horizontal waste vented from the top of a $\mathbf{T}-\mathrm{Y}$ in the horizontal waste line in which the waste and vent are in the same vertical plane. Assuming the same cross sections of trap and waste throughout $x-y$ represents the approximate hy-

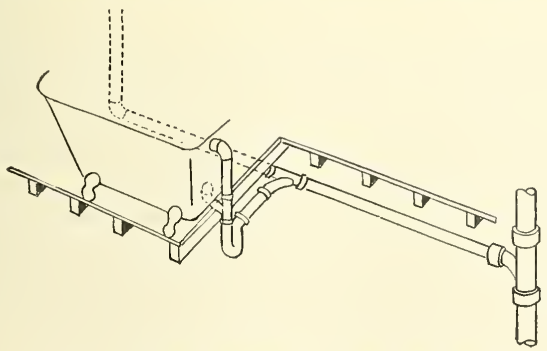

FIG. 64.-Diagram to illustrate type of venting liable to clog

draulic gradient when the waste line is flowing full under the head in the fixture. Evidently in an arrangement of this kind there will be periodic back flow into the vent and strong liability to stoppage in the vent. Figure 63 represents a waste, with a corresponding hori- 
zontal distance between the fixture and stack, in which there is a vertical section, $c$, following the point of venting. Here the vent connection lies above the hydraulic gradient, $x-y$, therefore the vent line is protected against back flow and consequent stoppage. When venting is necessary to protect trap seals, the type of venting represented in Figure 63 is believed to be the best possible; that is, a "continuous waste and vent" in which the vent is a continuation of a vertical section of the waste. The restriction necessary to insure protection against back flow into the vent or vent connection would be that $\frac{c}{d}$ is equal to or greater than $\frac{a}{b}$. Referring again to Figure 63 , $a$ would represent the vertical distance from the level of the fixture overflow to the level of the outlet of the first horizontal section, $b$ the horizontal distance from the fixture outlet to the first

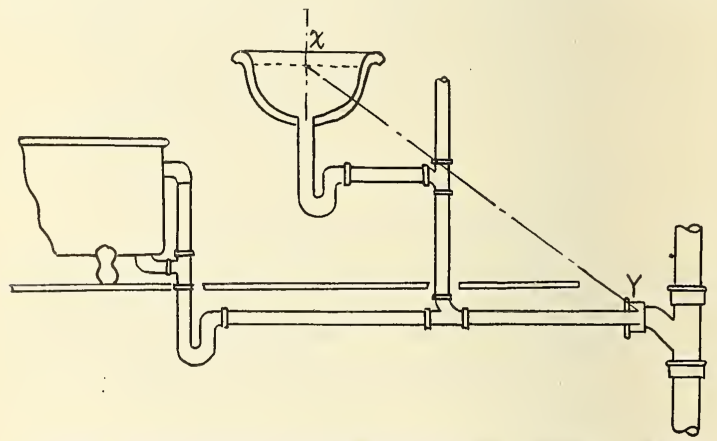

FIG, 65,-Diagram to illustrate type of group venting in which vent is protected from clogging

vertical section or to the vent connection, $c$ the length of the vertical section from the vent connection to the level of the outlet of the second horizontal section, and $d$ the length of the second horizontal section. For small fixtures, a washbasin or kitchen sink, $a$ might be measured from the top of the fixture outlet with perfect safety, since by the time the waste has become filled by the discharge the fixture will have practically emptied. Call this new distance $a^{1}$ then the new hydraulic gradient is $x^{1} y$. It will be observed that the direction at which $b$ leads into $c$ makes no difference. To apply concretely to a practical case suppose a washbasin with trap set close to the fixture and the waste from the trap leading directly into the wall, thence vertically to the floor, and thence horizontally through the floor to the stack. Suppose $a^{1}=6$ inches measured from the basin 
outlet, $b=12$ inches, and $c=17$ inches, then to hold the relation $\frac{c}{d}$ is equal to or greater than $\frac{a}{b}, d$ can not exceed 34 inches. It is recognized that in the case of bathtubs and other fixtures which set low on the floor it is impractical to attempt to hold any relation between verticals and horizontals, such as suggested when a long waste leads through the floor on which the fixture is set. Figures 62 and 64 show that in this case the vent connection is always below the hydraulic gradient for a full fixture and a full waste line. Figures 65

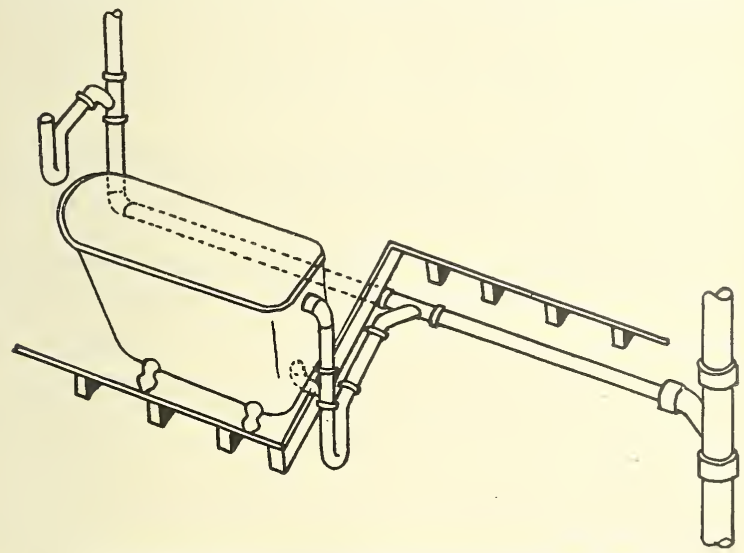

FIG. 66.--Diagram to illustrate type of group venting in which the vent is protected

and 66 represent types of "group venting" in which it would be possible to hold the relation $\frac{c}{d}=\frac{a}{b}$ so far as the dry vent is concerned. The wet vent portion would be kept open by the discharge of the fixture that it serves as a waste. For this reason these types of group venting are believed to be better than individual venting when the one vent fully protects the traps of the two fixtures.

The preceding discussion has been based on the assumption that the trap and its waste would be of the same nominal cross section throughout. If a gradation of sizes were employed in which the horizontal section beyond the point of vent connection were increased over that of the parts preceding, the results would be modified. The purpose has been to emphasize the necessity of limiting permitted lengths of vented horizontals if the vent is to be surrounded by condi- 
tions favorable to its continuous operation in service and if the best scouring effects in the waste lines are to be secured.

It is not to be inferred that the following opinions and recommendations are based entirely on the above theoretical reasoning. The effects were observed in a general way during the experiments. There seems to be little chance of obtaining new data on the subject more suitable for general application than the direct application of the principles of hydraulies.

Recommendations.-From a consideration of the subject of limitation of length of small waste branches from all standpoints, facility of drainage, self-scouring of waste lines, circulation of air, self-siphonage, stoppage of vents, some of which are mutually conflicting in their requirements, the following is suggested as a solution:

1. That the developed length of an unvented horizontal waste be limited to 6 feet.

2. That the developed length of an unvented horizontal waste from a washbasin or other oval-bottomed fixture be limited to 4 feet for traps with nominal 2-inch seals and 6 feet for nominal 3 -inch, or more, seals. ${ }^{2}$

3. That a horizontal section of the vented portion of a waste be limited to 6 feet, except when the vent is the continuation of a vertical portion of the waste, in which case it may be extended to $d=\frac{b}{a} c$ (see fig. 63), section $b$ being in general the length necessary to make the connection from the fixture to the vertical section, $c$, in the partition or wall, limited always by the condition pertaining to an unvented horizontal waste.

4. That whenever practical a vent be the continuation of a vertical section of the waste.

\section{THE FACTOR OF SAFETY IN A PLUMBING SYSTEM AND DETER- MINATION OF THE UPPER LIMIT OF SERVICE FOR A 3-INCH SOIL STACK}

The determination of the allowable upper limits of service of a given soil stack - that is, the determination of the number of fixtures of different kinds or number of fixture units that may with safety be drained into the stack-involves a consideration of all parts of the plumbing system in their relation to each other and unless extreme care is exercised may lead to inconsistencies. It is necessary to know the maximum carrying capacity of the stack under the conditions involved and the "peak load" determined or estimated from the total number of fixtures of different kinds that are to be drained into the stack. The former has been determined for certain con-

${ }^{2}$ The plumbing committee later agreed on a maximum developed length of 5 feet permissible for horizontal unvented waste pipes for all fixtures. 
ditions by observation of known rates of discharge into the stack. It is proposed to estimate the latter from predetermined maximum rates of discharge from individual fixtures and probable coincident discharge of these fixtures. Before combining these it is necessary to establish a reasonable factor of safety and to determine some boundary lines for frequencies of coincidence that need or need not be accounted for in estimating the "peak load."

\section{ESTABLISHMENT OF A FACTOR OF SAFETY}

The establishment of a factor of safety is difficult because in reality not one, but many factors of safety are involved. With reference to the pneumatics of the system the fixture traps are the weak points. The variations in air pressure in the stacks themselves is of no importance, as this is not transmitted to the traps. In the determinations for vent requirements a factor of safety of 2 against aspirating effects has been proposed by the plumbing committee and used for traps of 2-inch normal seal depth. Recommended methods of construction by which branches would be connected to points of minimum aspirating effect, rather than at point of maximum effect, as was done in determining vent requirements; the method employed of always keeping the estimated peak discharge from a permitted installation under the rated capacity for the stack; and the method of always employing a vent of the nearest size larger than the calculated required size to give this factor of safety, all operate to give a factor of safety greater than the assumed one of 2 . The same applies to back pressures, except that in regions where there is no aspirating effect, as is generally the case where there are strong back pressures, the initial assumed factor of safety becomes 4 instead of 2 with trap seals of 2 inches employed. In both aspects an increase in normal seal depths of traps employed would increase the factor of safety proportionally.

FUNCTIONAL FACTOR OF SAFETY DISTINGUISHED FROM STRUCTURAL

It should be kept in mind that this is a factor of safety in functioning and that it materially differs from a structural factor of safety. A strain on the system sufficient to use up the entire factor of safety can result in no more than a temporary decrease in efficiency of functioning and no structural depreciation, except in the matter of overflowing or flooding, which has no direct connection with the matter of venting. It is evident from the maximum carrying capacity of stacks, which is greatly in excess of the rated "practical capacity" used in fixing the limits of service for a stack, that the factor of safety would have to be greatly exceeded before any material reduction of efficiency of functioning occurred. Apparently, then, the only danger is from overflowing or flooding, and this only when the estimated "peak load" for the system approaches the maximum 
carrying capacity of the stack, which is three or more times the rated practical capacity. The matter of local flooding of lateral branches must be considered separately from the requirements for stack vents and house drains. The greatest danger of overflowing or flooding, except local, is from complete stoppage of the stack or house drain, which may occur even with any size of stacks and even with small loads. In view of the preceding relations and in view of certain relations of frequencies of occurrence in the probability tables, it seems reasonable to assume that an estimated "peak load" occurring once in the order of one year is ample allowance for fixing the size of stacks, vents, and drains to the nearest size, and to assume that a coincident discharge occurring once in the order of 10 or 100 years may be neglected. Referring to Table 2, it will be observed for systems up to 12 water-closets that if the probability of coincidence of a given number of water-closets is of the order of once in one year the probability of coincidence of one more than this number is of the order of once in 100 years. Also, from a consideration of the equations from which the tables were computed, the chance that if a given number of water-closets in coincidence is exceeded it will be exceeded by one and not more than one is of the order of 100 to 1 .

A concrete illustration may be made for the 3-inch stack. Reference to Table 2 shows that allowing for a rush period of one hour daily the probability of overlapping coincidence of 4 out of 12 waterclosets on a system is once in 336 days, the probability of 5 out of 12 once in 56 years.

\section{LIMITS OF SERVICE FOR A 3-INCH SOIL STACK}

The rated "practical capacity" of the 3-inch stack for the type of construction in which a part, at least, of the waste pipes from the small fixtures connect directly into the stack falls between the combined discharge of 4 water-closets and that of 5 water-closets. It is therefore concluded that a 3 -inch soil stack with properly proportioned house drain, lateral branches, and vents will efficiently serve in this type of construction for 12 water-closets or their equivalent. The requirements in house drain and vents may be taken from the tables or charts for this or any smaller number of water-closets or their equivalent. This is far in excess of the requirements for any separate dwelling and would permit its use to include a maximum of 72 fixture units, or 8 complete bathroom groups of fixtures.

Increased By Methods of Construction.-We have previously mentioned the possibility of extension of the limits of service of the 3 -inch or other stacks by a slight change in methods of construction. No doubt the limits could be extended without change in methods of construction by increasing the size and number of vents. 
It will be remembered that the "practical capacity" of the 3-inch stack was rated on the assumption that the stack may not flow full at any point. If the construction is made such that no fixture is connected directly onto the stack, then there is no reason why the stack may not be permitted to flow full and even under a slight head.

Experiments have shown that a velocity of 30 feet per second in a 3 -inch stack is attained in a fall of between 25 and 30 feet with a possible maximum velocity of about 35 feet per second. A 3-inch stack flowing full with a velocity of 30 feet per second will carry

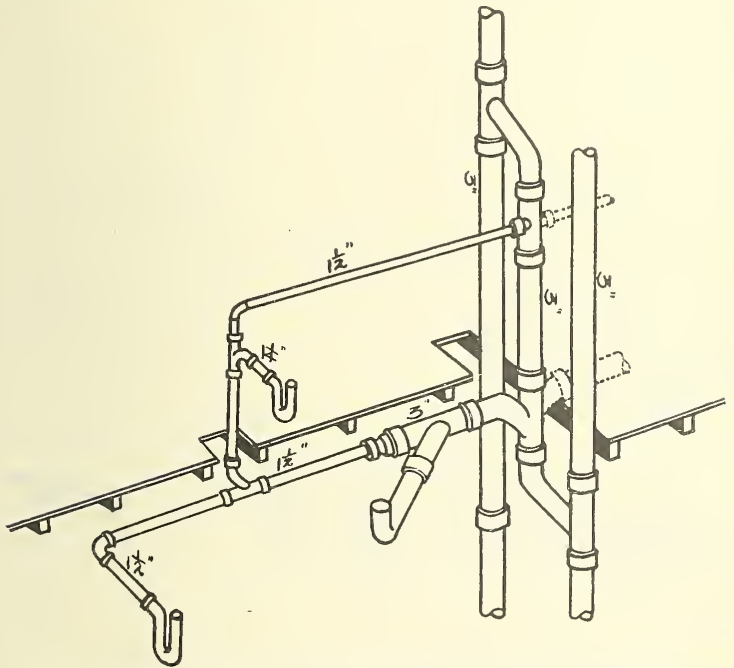

FIG. 67.-Diagram to illustrate type of yoke venting tending to increase the capacity of a system

water at the rate of 660 gallons per minute, approximately equivalent to the combined discharge of 15 water-closets. Reference to Table 2 shows that a carrying capacity of this amount would allow 100 waterclosets with an ample margin of protection against flooding or overflowing. It would seem, then, that the service to which the 3 -inch stack may be adopted for certain types of buildings is practically unlimited.

Figures 67 and 68 illustrate a step in this direction, representing single floors for two types of buildings which may be duplicated on any number of floors up to the limit of service of the 3-inch stack. With such an arrangement the soil stack will scrve only as a carrier 
during heavy discharges, each floor approximating the effects in a separate small system. No specific tests have been made with such construction, but the data at hand enables us to approximate the limits to which the 3-inch vent may be employed by extension of the curves in Figure 50. With bathroom units in corresponding positions on successive floors in apartment houses or hotels the type of construction represented in Figure 67 might be carried to any height with a 3-inch soil stack, the only precaution necessary being that of insuring sufficient capacity in the house drain and base of stack con-

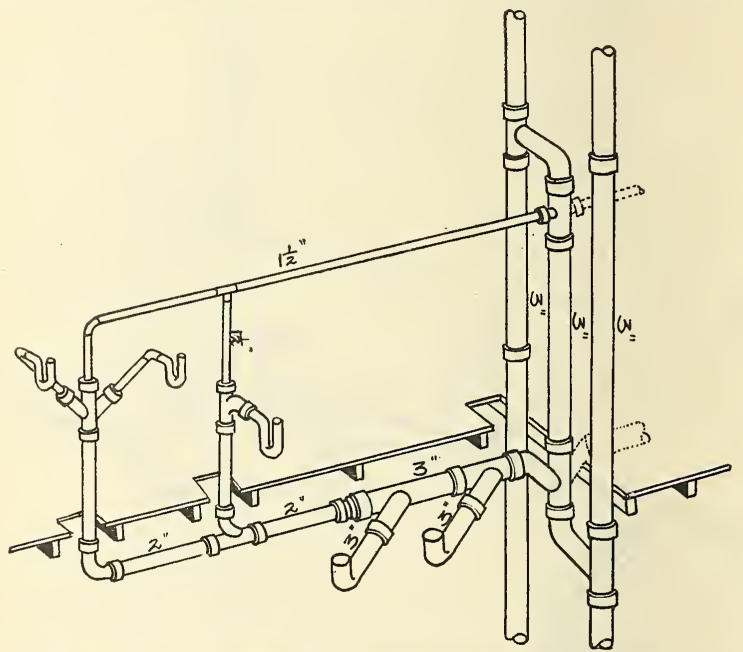

FIG. 68.-Diagram to illustrate type of yoke venting applied to larger toilet rooms

nection to the drain, one that is necessary regardless of the size of stack employed. There are limits to the height to which a 3 -inch vent stack might be employed. Estimates made on the basis of Table 2 for probable coincident discharge and an extension of the 3 -inch vent curve in Figure 50 to include higher rates of discharge give an approximate maximum length of 3-inch vent stack of 150 feet. Allowing for elbow or other reductions and for length of vent above level of fixtures indicates a limitation of height for a 3 -inch vent to about 12 stories. Up to this height the construction might be a 3 -inch soil stack, a 3 -inch vent stack, and 3 -inch main vent connection on each floor. Above that height an increase in size of vent stack only would be required. With lower structures on the same 
plan both the vent stack and main vent connection might be reduced below 3 inches. The construction would serve equally well in duplex, as indicated by dotted branch of double $Y$ and branch rent connection, with only a small reduction in limited heights. Figure 68 represents the same method applied to office building toilet-room construction.

As indicated these are very rough estimates, based as they are on the extension of data obtained for vent requirements with smaller "peak loads" than would be encountered in these larger systems. However, we have elaborated to a considerable extent merely to emphasize the possibilities of service of the 3-inch stack. Before any definite recommendation can be made it will be necessary to make further determinations and test the results thoroughly.

It should be observed that there are limitations for the employment of 3-inch stacks imposed by 3 -inch lateral branches leading to the stack for types of construction in which the number of fixtures emptying into the stack on the same floor exceeds approximately six water-closets, or their equivalent in fixture units, because of the liability to local flooding. No such restriction need be placed on the employment of 4-inch stacks and 4-inch lateral branches to the stack in the same plan of construction (fig. 68). With a 4 -inch horizontal and water-closets set 30 inches apart the holding capacity of the pipe and closet bends is approximately equal to the total discharge from all the water-closets thus placed on any 4-inch horizontal. There is therefore no danger of flooding from local causes and the run-off during the discharge will practically insure proper functioning with any possible combination of discharges of water-closets on such a line, always assuming that it is properly vented to protect it against pneumatic effects. It would seem, therefore, that there is no necessity for using a soil stack larger than 4 inches in diameter for any building, provided the construction is such as to protect the fixture traps from the pneumatic effects produced in the stack itself. Here, again, definite recommendations are dependent on further experiments and a complete testing of the plan.

The size of main vents or vent stacks required by the proposed plan would be about the same as now commonly employed with the 4 -inch soil stack. The required size of the house drain would be dependent on the total number of fixtures on the system and the kind of use for which it is intended.

\section{SIMPLIFICATION OF PLUMBING CONSTRUCTION}

The degree to which plumbing construction may be simplified and the resultant reduction in cost depend to a large extent on the planning for such simplification. The planning to secure the greatest 
degree of simplification should begin with the architects design and extend throughout to the completion of the plumbing work. It is not to be expected that the architect will plan the building around the plumbing system. It is not, however, too much to expect that he should be familiar with the plumbing requirements of the place for which the building is designed and that he should keep in mind (1) that the plumbing is an integral part of the completed building, and (2) that the mere location of the position of the fixtures without any consideration to the possible location of the stacks and branch drains is not sufficient.

It is a fact, so evident as to be almost an axiom, that the shorter and more direct the drainage pipes in a plumbing system are, consistent with pneumatic effects produced, the more efficient the drainage will be. The most direct system of pipes will be secured by grouping the fixtures closely around the stack serving them. In a few cases the necessity of venting against pneumatic effects may be accentuated by the close grouping, but this will be more than balanced by a corresponding simplification of the vent system, by decrease in length of connecting vent pipes, etc. These points are especially true of the small dwelling house, with only one bath, in which it is possible by close grouping of the fixtures to install the plumbing system with no venting except the soil stack and at the same time secure more efficient and safer drainage of the fixtures than if they were individually back vented. The same principle applies in a lessened degree to systems of two or more bathrooms and other fixtures.

Minor considerations in the design of the building that will frequently serve the above ends may be here pointed out. Bathrooms should be located, if possible, so that the soil stacks may be placed in or adjacent to the walls of it. The fixtures should be located in the bathroom so as to reduce the length of wastes and branch vents, when required, to a minimum. Where such an arrangement is not practical or desirable, an arrangement should be made that will permit the installation of a simple system of wastes and branch vents within the limits of length governing such installations. It is hardly necessary to add that the paths of wastes and vents through the walls or floors from the fixtures to the stacks must be kept in mind in the location of the fixtures.

\section{SEPARATE FLOOR LAYOUTS TESTED}

With these points on efficiency of drainage and simplicity of construction in mind several different arrangements and methods of connecting wastes to the soil stack were installed in complete plumbing test installations. These are considered separately from the rest of the installation for purposes of illustration and discussion, and 
the advantage and defects of each design are pointed out. The vent lines shown in the sketches are not to be considered as required, since gate valves were installed in the lines to enable cutting out portions of the vent line not needed and the form of connecting the vents to main vents or stacks is not always recommended as a desirable one. The point was to determine when individual vents were and were not needed. Specific data applicable to each sketch will be found in connection with the tests on complete installations in which the same design was used.

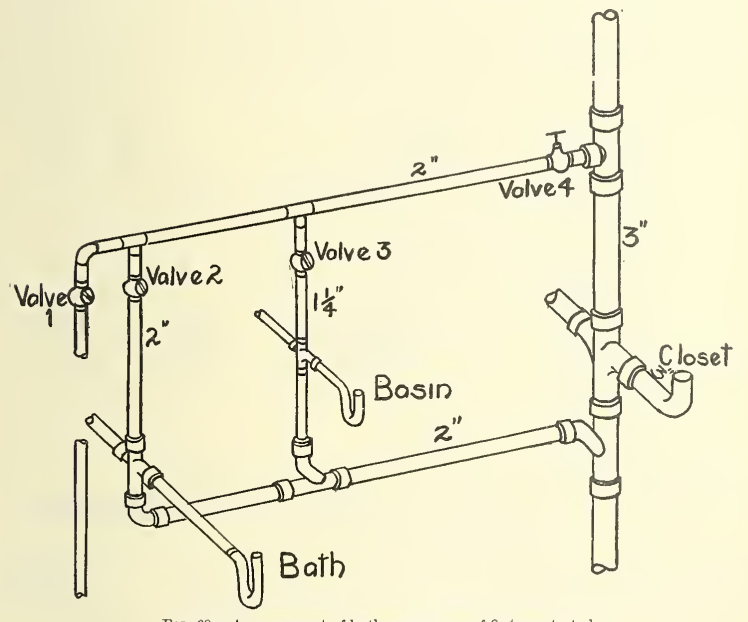

FrG. 69.-Arrangement of bathroom group of fixtures tested

Figure 69 shows a design employed on the top floor in a one story and basement construction with a water-closet and laundry trays installed in the basement. It is shown here, as used, with double branch fittings in the stack and waste lines, thus giving opportunity to throw the same into a duplex system with two bathroom groups of fixtures set back to back. During the tests for a single system the $Y$ branches opposite the water-closet and bathtub were plugged and a deep seal glass trap set in the fitting branch opposite the washbasin. With all valves in the vent closed, the discharge of the washbasin and bathtub together almost completely siphoned the washbasin trap. With valves 3 and 4 only open there was no loss in either the bath or basin traps by self-siphonage from the single or combined discharge of the two. With all valves in the vents closed, one of the 
traps would practically lose its seal from the discharge of the watercloset. This is due to aspirating effect of the water-closet discharge flowing past the waste opening into the stack. With the vent valves 3 and 4 open no measurable loss of seal in either the basin or bath trap was produced by any combination or order of discharge of the three fixtures. At times a very slight back pressure was observed in the bath trap when the basin was discharged.

With the duplex installation it was found necessary to vent each pair of fixtures, the baths by the "common vent" (2); the basins by the common vent (3), the water-closets being "stack vented." With a pair of fixtures thus placed back to back the valve in the "common vent" for the pair closed the discharge of one of the pair invariably pulled the seal from the other trap. The effect was not
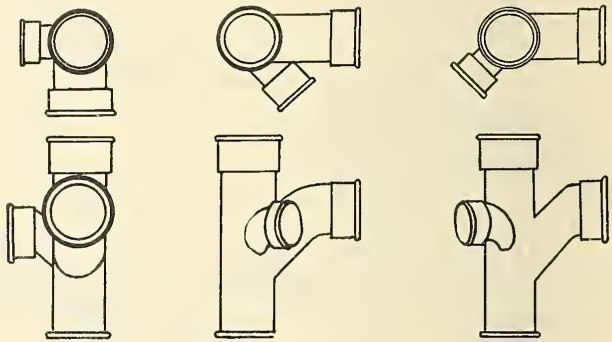

\section{$90^{\circ}$ side outlet $45^{\circ}$ side outlet}

\section{$135^{\circ}$ side outlet}

FIG. 70.-Illustration, crowfoot fittings

as great with the pair of bathtubs as with the pair of washbasins, yet was sufficient to reduce the trap seal materially.

The plan of connecting the bath and basin common waste into a fitting below the water-closet fitting was also tested with $1 \frac{1}{2}$-inch waste from the bathtub with similar results. These results, verified by later pressure measurements in similar positions on a straight 3inch stack, indicate that the waste pipe connection to the stack was made near the point of maximum aspirating effect of the water-closet discharge. One result is to require a larger vent to protect the traps against the aspirating effect than would be required to protect against self-siphonage alone. The employment of a side inlet termed a "crowfoot" fitting was suggested by the plumbing committee as a practical means of protecting fixture traps from the aspirating effects produced by water-closets on the same floor. The "crowfoot" fitting is illustrated in Figure 70, showing elevation and plan views of these fittings with side inlets at 45,90 , and $135^{\circ}$ to the main inlet branch. The fitting may readily be made right and left for all 
three types, as well as with two or more side inlets at different angles if required.

The special advantages of the "crowfoot" fitting for small-house construction will become evident from the applications made in the tests. Pressure measurements made in the complete plumbing test installations and in straight 3 -inch stacks at points on the stack above the inlet through which water was introduced in to the stack showed no measurable effects when the stack top was open. At

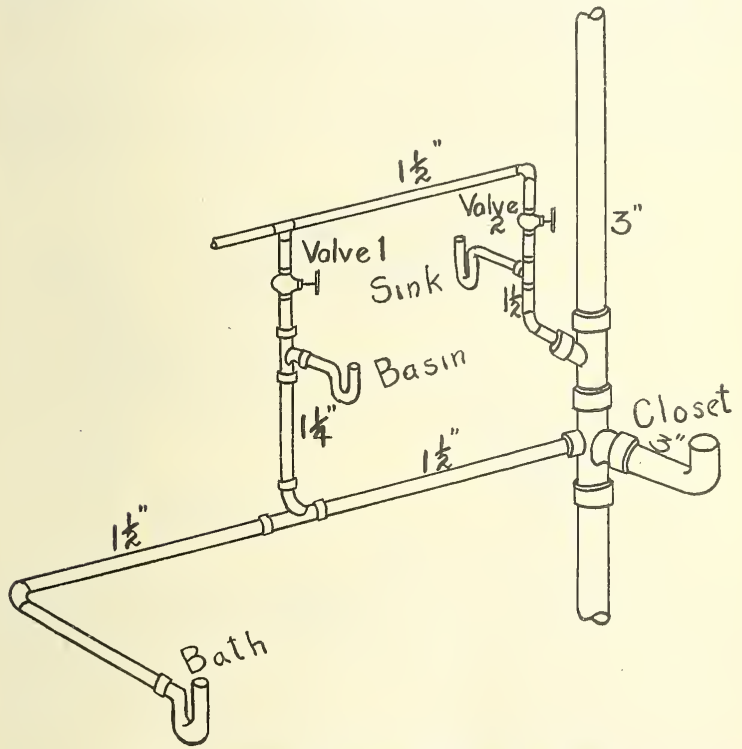

Fig. 71.-Arrangement of bathroom and kitchen-sink group tested

the same level as the inflow only very slight suctions or back pressures were produced. The use of the "crowfoot" fitting affords almost complete protection from aspirating effects produced by the discharge of fixtures on the same floor. The "crowfoot" fitting, as described, is not a patented fitting. Its use somewhat simplifies the venting necessary to protect from the aspirating effects of discharges from higher floors.

Figure 71 shows an arrangement of fixtures similar to Figure 69 with a kitchen sink added. This was tested as the highest floor on the system. 
With valves (1) and (2) closed the arrangement illustrated in Figure 71 showed no measurable loss of seal in any trap of the group from aspirating effect, with fixtures discharged in any combination and in any order when the group is the highest on the system. There was the usual loss of seal in the basin trap by siphonage when the basin and bath were discharged together, and some loss in seal from self-siphonage when the basin discharged alone. There was no measurable loss of seal in any trap when valve (1) was opened. Therefore, to completely protect the traps of the group from all local effects a small vent from the basin branch is necessary.

The same arrangement of fixtures (fig. 71) was completely tested as the first floor of a two story and basement structure with 10 feet 10 inches between first and second floors with the fixtures arranged as shown in Figure 72 installed on the second floor. The discharge

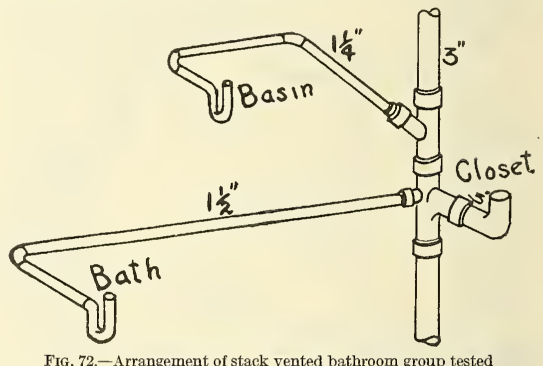

FIG. 72.-Arrangement of stack vented bathroom group tested

from the water-closets was varied by adjustment of supply devices up to a mean rate of discharge of 60 gallons per minute. The tests show that the venting with valves (1) and (2) open (fig. 71) is sufficient and needed to completely protect the bath, basin, and sink traps in that particular layout against the aspirating effects produced by the combined discharge of a water-closet with paper and soil, a bathtub, a washbasin, and a kitchen sink from the floor above. Repeated tests with a heavy discharge from the second-floor fixtures in conjunction with the discharge of the washbasin on the first floor in various orders of sequence failed to produce any measurable loss of seal in the bath trap on the first floor. Apparently the interval between the closing of vent (1) by the washbasin discharge and the closing of the horizontal waste from the bath is too short to permit the transmission of aspirating effects to the bath trap. Once the horizontal waste is filled the bath trap is completely protected from aspirating effects. With valve (2) closed a complete loss of seal was produced in the sink trap by a heavy combined discharge or by the repeated discharge of a single water-closet from the floor above. 
The protection offered the water-closet trap by the venting with valves (1) and (2) open is not complete. A heavy discharge from the second floor, in conjunction with either or both the washbasin and bathtub on the flrst floor discharging, produced a measurable loss of seal in the water-closet trap on the first floor. A repeated discharge of a water-closet with paper and soil, washbasin, bathtub and kitchen sink from the top floor in conjunction with either or both the basin and bathtub on the first floor left approximately 0.7 inch seal in the closet trap on the first floor, starting with a normal full seal of 4 inches in the water-closet trap. A single discharge of the same fixtures did not reduce the water-closet seal on the first floor

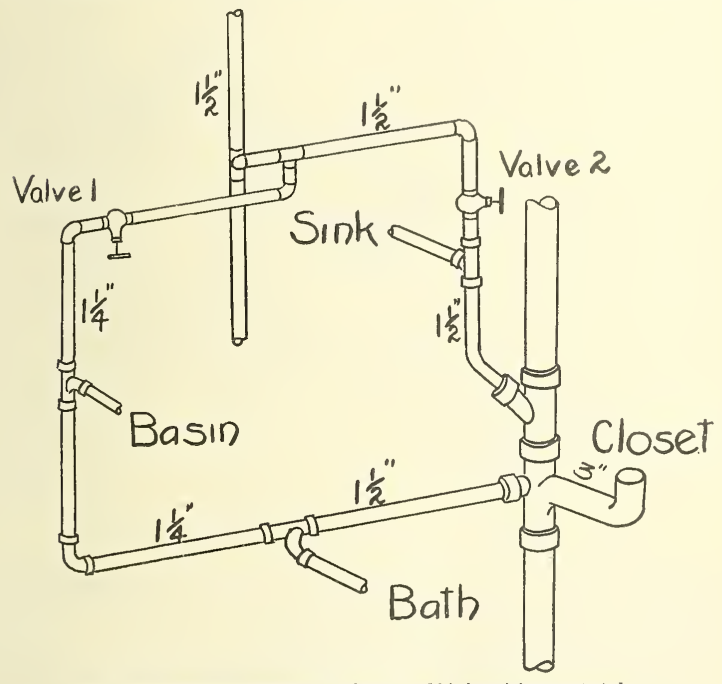

FIG. 73.-Alternate arrangement of bathroom and kitchen-sink group tested

below 1 inch. The conclusions to be drawn with reference to layout (fig. 71) with a bathroom group, or bathroom group and kitchen sink, on a floor above are: (1) That each small waste connecting independently into the stack must be vented; (2) that considering the slight probability of all the fixtures of the group above discharging at the same time as the basin or bathtub in the lower group, the water-closet may be left without a separate vent with comparative safety; and (S) that with possible heavier discharges from above than described the water-closet should be separately vented.

Figure 73 represents a plan of rearrangement of the fixtures of the group (fig. 71), interchanging the relative positions of the wash- 
basin and bathtub. It was tested in the same position on the 3-inch stack and in the same manner as for layout (fig. 71). With valve (1) only open no loss of seal in any trap of the group was produced by any combination or order of discharge of the fixtures within the group itself. With valves (1) and (2) open and the discharge of a watercloset, washbasin, bathtub, and kitchen sink from the floor above in conjunction with the washbasin of the lower group the seal of the bathtub trap was materially reduced, leaving in one instance only 0.2 -inch seal of a normal 2.0-inch full seal. The conclusions are: (1) That for the highest group of fixtures on a stack a vent from the

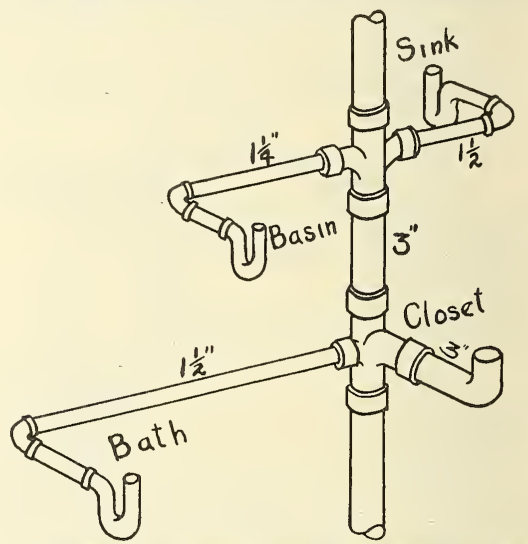

FIG. 74.-Arrangement ofs tack vented bathroom and kitchen-sink group tested

basin waste is sufficient, and (2) that for a lower floor the vent requirements are the same as for the plan in Figure 71 with the addition of a separate vent for the bathtub waste.

To eliminate the necessity of any except stack venting for a singlefloor group or the highest group of fixtures on the stack, the arrangement of fixtures shown in Figure 74 was installed and tested. With this layout no measurable loss of seal was produced in any trap of the group by any combination or order of discharge of the fixtures of the group itself, or in conjunction with other fixtures lower on the stack. The combined discharge from a washbasin and kitchen sink into a 3-inch stack is not sufficient to produce aspirating effects great enough to cause measurable loss of seal in traps whose unvented wastes connect to the stack at points below.

The conclusion is that within the limits of permitted length and fall of unvented wastes it is unnecessary to individually vent any 
fixture of a group installed on this plan (fig. 74). It will be observed that with "crowfoot" fittings a great variety of arrangement and spacing of fixtures within the limits of permitted lengths and fall of unvented wastes may be secured without in any way affecting the general results indicated. The preceding layouts of construction (figs. 69 and 74), though closely representing the installations as tested, are not drawn to scale and are not to be considered as approved in detail. A number of detailed drawings representing approved application of the plans and principles involved are given later.

\section{TESTS OF COMPLETE PLUMBING INSTALLATIONS}

As has been previously indicated, the final test of any plumbing design or detail of plan of construction must be its satisfactory operation in service. While much of the preceding investigation has a wider application, a full knowledge of the principles thus disclosed are believed essential for an intelligent interpretation of test results on small-house installations.

In order to hasten the work, the following tests of complete test plumbing installations, covering one story, one story and basement, and two story and basement dwellings were carried on parallel to the general investigations of the hydraulies and pneumaties of a plumbing system. The result has been that many tests were made which might well have been omitted as having no direct bearing on small-house plumbing. In this report an attempt has been made to condense into small space the results of elaborate tests on plumbing installations by omitting all data, except results of "critical tests" and a few additional tests which serve to emphazise the principles disclosed in the general investigations or stated in that connection from theoretical considerations.

\section{CRITICAL TESTS}

The term "critical test" may be defined as any combination or sequence of discharge of fixtures on a given installation which may occur frequently enough and which in conjunction with modifying conditions may prove detrimental to the functioning of the plumbing system. It is evident that there may be many "critical tests" for the same system and that in this connection the discharge of a single fixture may be of more importance in some cases than the combined discharge of several fixtures on the same system.

Almost any plumbing installation, either test or service, may be shown good or bad according to the severity of the modifying conditions imposed or assumed and according to the severity of the test in the matter of combined discharge from fixtures to which it is subjected. Just what constitutes a fair test in the way of combined discharge and severity of imposed modifying conditions and what is 
a fair measure of satisfactory results must be decided as matters of judgment. Any decision reached by an individual or group of individuals readily lends itself to adverse criticism from unsympathetic reviewers, who may be prejudiced by personal interest or a narrow point of view.

For large installations the matter of coincdent discharge constituting a maximum fair test might be determined from tables of probable coincident discharge similar to Tables 2 and 3. For small installations consisting of two or three bathroom units and other small fixtures the arbitrary method of selection (Table 10) adopted by the plumbing committee is believed more applicable for the types of buildings under consideration.

TABLE 10.-Assumed simultaneous discharges compared with possible maximum discharges in typical installations illustrated in Figures 90 to 92

BUNGALOW TYPE, ONE-STORY, ONE-FAMILY

\begin{tabular}{|c|c|c|c|c|c|c|c|c|}
\hline \multirow{3}{*}{$\begin{array}{l}\text { Type reference } \\
\text { to Figures } 90 \\
\text { to } 92\end{array}$} & \multirow{3}{*}{ Number of stacks } & \multicolumn{2}{|c|}{$\begin{array}{l}\text { Total of all fix- } \\
\text { tures discharged } \\
\text { together }\end{array}$} & \multicolumn{5}{|c|}{$\begin{array}{l}\text { An assumed simultaneous discharge for deter- } \\
\text { mining venting requirements and size of house } \\
\text { drain }\end{array}$} \\
\hline & & \multirow{2}{*}{$\begin{array}{l}\text { Gallons } \\
\text { per } \\
\text { minute }\end{array}$} & \multirow{2}{*}{$\begin{array}{l}\text { Equiv- } \\
\text { alent } \\
\text { units }\end{array}$} & \multirow{2}{*}{ Fixtures } & \multirow{2}{*}{$\begin{array}{l}\text { Gallons } \\
\text { per } \\
\text { minute }\end{array}$} & \multirow{2}{*}{ Units } & \multicolumn{2}{|c|}{$\begin{array}{l}\text { Total to house } \\
\text { drain }\end{array}$} \\
\hline & & & & & & & $\begin{array}{l}\text { Gallons } \\
\text { per } \\
\text { minute }\end{array}$ & Units \\
\hline $1 \ldots$ & 1 soil ..... & 90 & 12 & $\begin{cases}1 & \mathrm{~W} \cdot \mathrm{C} \\
1 & \mathrm{~B} \cdot \mathrm{T}\end{cases}$ & $\begin{array}{l}45 \\
15 \\
\end{array}$ & 6 & 82.5 & 11 \\
\hline 2. & _......do_. & 146. 3 & $19 \frac{1}{2}$ & 1 B.T & $\begin{array}{l}40 \\
15\end{array}$ & 2 & 82.5 & 11 \\
\hline 3. & $\{\ldots d o$ & 67.5 & 9 & $\left\{\begin{array}{lll}1 & \vec{W} & \mathrm{C} \\
1 & \mathrm{~B} & \mathrm{~T}\end{array}\right.$ & $\begin{array}{l}45 \\
15\end{array}$ & $\begin{array}{l}6 \\
2\end{array}$ & 60 & 8 \\
\hline \multirow{5}{*}{4.} & l1 water... & 22.5 & 3 & $1 \mathrm{~L} . \mathrm{T}$ & 22,5 & 3 & 22.5 & 3 \\
\hline & \multirow{4}{*}{$\begin{array}{l}1 \text { soil } \\
1 \text { water................... }\end{array}$} & 90 & 12 & \multirow{4}{*}{$\begin{array}{lll}1 & \mathrm{~W} \cdot \mathrm{C} \\
1 & \mathrm{~B} \cdot \mathrm{T} \\
1 & \mathrm{~L} \cdot \mathrm{T} & \mathrm{T}\end{array}$} & \multirow{4}{*}{$\begin{array}{l}45 \\
15 \\
22.5\end{array}$} & \multirow{4}{*}{$\begin{array}{l}6 \\
2 \\
3\end{array}$} & 82.5 & 11 \\
\hline & & 112.5 & 15 & & & & 60 & 8 \\
\hline & & 33.8 & $4 \frac{1}{2}$ & & & & 22.5 & 3 \\
\hline & & 146.3 & $19 \frac{1}{2}$ & & & & 82.5 & 11 \\
\hline
\end{tabular}

TWO-STORY, ONE-FAMILY TYPE

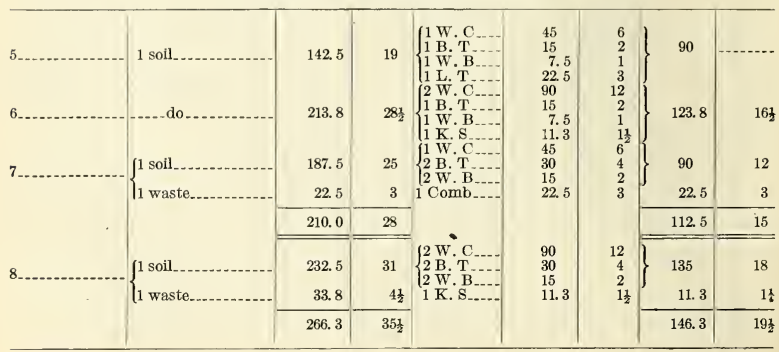


TABLE 10.-Assumed simultaneous discharges compared with possible maximum discharges in typical installations illustrated in Figures 90 to 92-Continued.

TWO-STORY, TWO-FAMILY TYPE (SUPERIMPOSED)

\begin{tabular}{|c|c|c|c|c|c|c|c|c|}
\hline \multirow{3}{*}{$\begin{array}{l}\text { Type reference } \\
\text { to Figures } 90 \\
\text { to } 92\end{array}$} & \multirow{3}{*}{ Number of rtacks } & \multicolumn{2}{|c|}{$\begin{array}{l}\text { Total of all fix- } \\
\text { tures discharged } \\
\text { together }\end{array}$} & \multicolumn{5}{|c|}{$\begin{array}{l}\text { An assumed simultaneous discharge for deter- } \\
\text { mining venting requirements and size of house } \\
\text { drain }\end{array}$} \\
\hline & & \multirow{2}{*}{$\begin{array}{l}\text { Gallons } \\
\text { per } \\
\text { minute }\end{array}$} & \multirow{2}{*}{$\begin{array}{l}\text { Equiv- } \\
\text { alent } \\
\text { units }\end{array}$} & \multirow[b]{2}{*}{ Fixtures } & \multirow{2}{*}{$\begin{array}{l}\text { Gallons } \\
\text { per } \\
\text { minute }\end{array}$} & \multirow[b]{2}{*}{ Units } & \multicolumn{2}{|c|}{$\begin{array}{l}\text { Total to house } \\
\text { drain }\end{array}$} \\
\hline & & & & & & & $\begin{array}{l}\text { Galions } \\
\text { per } \\
\text { minute }\end{array}$ & Units \\
\hline $10 \ldots$ & 1 soil... & 292.6 & 39 & $\left\{\begin{array}{l}2 \mathrm{~W} \cdot \mathrm{C} \\
2 \mathrm{~B} \cdot \mathrm{T} \\
1 \mathrm{Comb}\end{array}\right.$ & $\begin{array}{l}90 \\
30 \\
22.5 \\
90 \\
30 \\
11.3\end{array}$ & $\begin{array}{r}12 \\
4 \\
3 \\
12 \\
4 \\
1 \frac{1}{2}\end{array}$ & 153.8 & $20 \frac{1}{2}$ \\
\hline 11. & $\left\{\begin{array}{l}1 \text { soil } \ldots . . . \\
1 \text { waste. }\end{array}\right.$ & $\begin{array}{r}135 \\
45\end{array}$ & $\begin{array}{r}18 \\
6\end{array}$ & $\begin{cases}2 & \mathrm{~W} \\
2 & \mathrm{~B}, \mathrm{C} \\
1 & \mathrm{~T} \\
\mathrm{Comb}\end{cases}$ & $\begin{array}{l}90 \\
30 \\
22.5\end{array}$ & $\begin{array}{r}12 \\
4 \\
3\end{array}$ & $\begin{array}{l}120 \\
22.5\end{array}$ & $\begin{array}{r}16 \\
3\end{array}$ \\
\hline \multirow{4}{*}{12.} & & 180 & 24 & \multirow{4}{*}{ 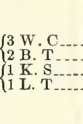 } & \multirow{4}{*}{$\begin{array}{l}135 \\
30 \\
11.3 \\
22.5\end{array}$} & \multirow{4}{*}{$\begin{array}{c}18 \\
4 \\
1 \frac{1}{2} \\
3\end{array}$} & 142.5 & 19 \\
\hline & $\int 1$ soil... & 225 & 30 & & & & 165 & 22 \\
\hline & 1 wast & 67.6 & 9 & & & & 33.8 & $4 \frac{1}{2}$ \\
\hline & & 292.6 & 39 & & & & 198.8 & $26 \frac{1}{2}$ \\
\hline
\end{tabular}

\section{TEST CONDITIONS}

To illustrate the number of variations of modifying conditions to be considered in connection with complete tests and to guide in outlining and classifying tests, Table 11 was prepared by the plumbing committee. It is not to be understood that all combinations given were tested with each installation or that the table represents all possible combinations of conditions. It is possible to strike out many and reserve only certain ones which may be referred to as critical test conditions, for example, the occurrence of a high wind, frost closure, and a heavy rain at the same time is so unlikely that it need not be considered.

TABLE 11.-Possible combinations of natural conditions affecting each plumbing installation, which may vary independently in degree or intensity

$[\mathrm{N}=$ means normal full opening at stack tops; $\mathrm{O}=$ free and unobstructed discharge through the house drain; $\mathrm{F}=$ stack tops reduced to simulate frost closure; $\mathrm{S}=$ the discharge end of house drain submerged; $\mathrm{T}=\mathrm{a}$ running trap and fresh air inlet in the house drain; $W=$ a current of air over stack tops to simulate winds; $\mathrm{R}=$ water discharged into the house drain through a rain leader; ()$=$ combinations of conditions considered unlikely to occur.]

\begin{tabular}{|c|c|c|c|c|c|c|c|c|}
\hline \multirow{2}{*}{$\begin{array}{c}\text { Weather } \\
\text { condi- } \\
\text { tions }\end{array}$} & \multicolumn{8}{|c|}{ Combinations of weather conditions and status of plumbing system } \\
\hline & $\mathrm{N}-\mathrm{O}$ & $\mathrm{F}-\mathrm{O}$ & NS & FS & NTO & FTO & NTS & FTO \\
\hline $\begin{array}{l}\text { Wind .... } \\
\text { Rain }\end{array}$ & $\begin{array}{l}\text { WNO } \\
\text { RNO }\end{array}$ & $\begin{array}{r}\text { WFO } \\
\text { (RFO) }\end{array}$ & $\begin{array}{l}\text { WNS } \\
\text { RNS }\end{array}$ & $\begin{array}{c}\text { WFS } \\
\text { (RFS) }\end{array}$ & $\begin{array}{l}\text { WNTO } \\
\text { RNTO }\end{array}$ & $\begin{array}{c}\text { WFT } \\
\text { (RFT) }\end{array}$ & $\begin{array}{l}\text { WNTS } \\
\text { RNTS }\end{array}$ & $\begin{array}{l}\text { WFTO } \\
\text { RFTO }\end{array}$ \\
\hline $\begin{array}{l}\text { Wind and } \\
\text { rain }\end{array}$ & WRNO & (WRFO) & WRNS & (WRFS) & WRNTO & (WRFT) & WRNTS & (WRFTO) \\
\hline
\end{tabular}


The manner of making tests and interpreting the results of tests is another matter that is dependent on judgment. Assuming that the condition in which the trap seals are left by the test is the best criterion for determining satisfactory and unsatisfactory results, and that a minimum remaining seal representing satisfactory results has been established, the question of repeating tests without restoring the trap seals to normal is still undecided. It is evidently a fair test in all respects to repeat the discharge of a single fixture on a system any number of times without restoring the trap seals. It is manifestly an unfair test of normal service to repeat the coincident discharge of several fixtures, of which the chance of coincidence is very remote, without between tests restoring the trap seals to normal or to the seal left by some less severe test that is likely to occur frequently in ordinary service.

The preceding points in reference to "critical tests," "critical conditions," and manner of making the tests should all be kept in mind in the interpretation of results.

The validity of results obtained from clear water tests is frequently questioned. In this connection we wish to point out that these tests have not been entirely clear-water tests. Many tests were made using toilet paper and imitation fecal matter, hereafter referred to as "soil," in the water-closet discharge. With this type of discharge from a single water-closet a marked, though somewhat erratic, effect was produced. With the discharge of two or more water-closets with imitation "soil" in conjunction with other fixtures on the system the added effect of "soil" became less marked and was usually lost, evidently because in the latter case the imitation "soil" is at once separated and carried forward in small separate units by the increased volume of discharge. The use of foul water in a clean system could not possibly materially change the results of clear-water tests. With reference to the effect of fouled waste pipes, it should be remembered that, in general, the first effect of such fouled waste pipes must necessarily be a decreased rate of discharge from the fixtures served by them and that the general requirements for venting would not be materially changed thereby. It will be observed, too, that most fixtures used in the tests were adjusted to give higher rates of discharge than the rates on which minimum requirements have been calculated. A test that holds under these rates would more surely hold under the lower service rates of discharge. The matter of the effect of fouled waste pipes on self-siphonage has been discussed in an earlier part of the report and should be treated as a separate consideration.

As has been before stated the data which follow are a small part of the total obtained from plumbing-test installations. An attempt has been made to arrange the data given into a form rendering 
interpretation more easy. From the nature of the case it will be observed that there is a different "critical test" for the highest group, for the lowest group, and for a middle group of fixtures on a system, and frequently a different "critical test" for each fixture within a group. For these reasons the data have been arranged in series and groups, a series, in general, being all the tests on an installation, and a group, the "critical tests," for each floor of the installation. The data given are, in general, for the test showing the greatest effect when there was a choice between several tests. To the "critical tests," which are intended to cover normal, heavy service conditions, other tests giving heavier discharges have been added to test for possibilities of flooding or overflowing. It is believed that the latter should not be considered in connection with vent requirements but only in the connection stated.

\section{NOTATION}

The following notation will serve as a key to the illustrations of test installations and tabulated data for tests on the same:

$B$ denotes a bathtub or bathtub trap; $C$ denotes a water-closet or water-closet trap; $L$ denotes a lavatory (washbasin) or lavatory trap; $S$ denotes a kitchen sink or kitchen-sink trap; $T$ denotes a laundry tray or laundry-tray trap.

Subscripts are used with the above letters to designate the floor on which the fixture was installed; thus $C_{0}$ denotes a water-closet in the basement, $C_{1}$ a water-closet on the first floor, and $C_{2}$ a watercloset on the second floor. A prime denotes that the fixture was installed on a waste stack; thus $S_{2}{ }_{2}$ is a kitchen sink on the second floor connected to a waste stack. Quotation marks are used to denote a second fixture of the same kind on the same floor; thus " $G_{0}$ " denotes a second water-closet on the basement floor. $R$ denotes a trapped rain leader connected to the house drain at the base of the stack, and with subscript the rate of rainfall used in the test. $R^{\prime}$ denotes a trapped rain leader connected to the house drain on the sewer side, and with subscript the rate of rainfall used in the test; thus in the tabulated data $R_{i}^{\prime}{ }_{4}$ denotes water introduced through rain leader $R^{\prime}$ at a rate equivalent to a rainfall of 4 inches per hour over a drained area of 1,500 square feet. $D$ denotes submerged outfall of house drain with subscript to denote extent of submergence in inches. $F$ denotes partial closure of stack tops simulating frost closure with subscript to denote the diameter of free opening in inches. $W$ denotes a wind current of 45 miles per hour over the stack tops directed horizontally unless otherwise stated. $V_{1}, V_{2}$, etc., denotes valves in vent lines numbered from left to right and from the top floor down. $G_{1}, G_{2}$, etc., denotes gate valves in horizontal waste pipes or horizontal drains numbered from the highest 
down and from right to left on each floor. "Soil" denotes toilet paper and imitation fecal matter added to the water-closet discharges.

TEST INSTALLATION NO. 1

Experimental plumbing installations with framework and platforms to carry the pipes and fixtures were installed in an 8 by 12 foot elevator shaft. The different installations are described in considerable detail. The first installation for which data are recorded in this report is shown in Figure 75 . The house sewer of 4 -inch castiron pipe was carried in line with the house drain, at a fall of onefourth inch to the foot, to a return bend (fig. 76), 22 feet from the base of the 3-inch soil stack and then back to the pit of the elevator shaft with the same fall in the straight run, where it discharged through an open or submerged end as the imposed conditions demanded. The return bend in the house sewer, composed of two 4inch short sweep one-fourth bends, was set at an angle of $45^{\circ}$. The total developed length of house drain and house sewer was 38 feet. The fittings taking the fixture discharge were double "sanitary tees" of which one side was plugged flush with the inner wall of the fitting when employed as a single house installation, with the exception of the two deep seal glass traps shown. These were also plugged in the trap during tests in which the pressure changes were great enough to break the trap seals. The valves in the vent lines were of the cockvalve type, giving cross-sectional openings equal in area to the pipes in which they were installed. The valves in the branch horizontals of the house drain were gate valves.

The traps of the individually trapped fixtures were $1 \frac{1}{2}$-inch lead $P$ traps with nominal 2-inch seals except the lavatory, which was a $1 \frac{1}{4}$-inch cast brass trap with a nominal 2.5 -inch seal. The traps were fitted with glass windows and scales (fig. 77) to enable the reading of the seal depth at any time.

Air-pressure measurements were made at various points in the 3 -inch stack and in the vent lines during the tests. These pressure measurements have but little value in judging the defects or advantages of a particular system, hence have been discussed elsewhere in conncction with the pneumatics of plumbing systems.

The data are to be considered typical of the type of tests made and representative of maximum effects under the assumed "critical tests" and "critical conditions" imposed. Practically every group of tests, as well as individual tests, was repeated at least once. Other tests giving discharges near the assumed "critical test" rate were made in most cases. Many slight modifications were made in the different installations, of which only those showing appreciable changes in results of tests are recorded in detail. 


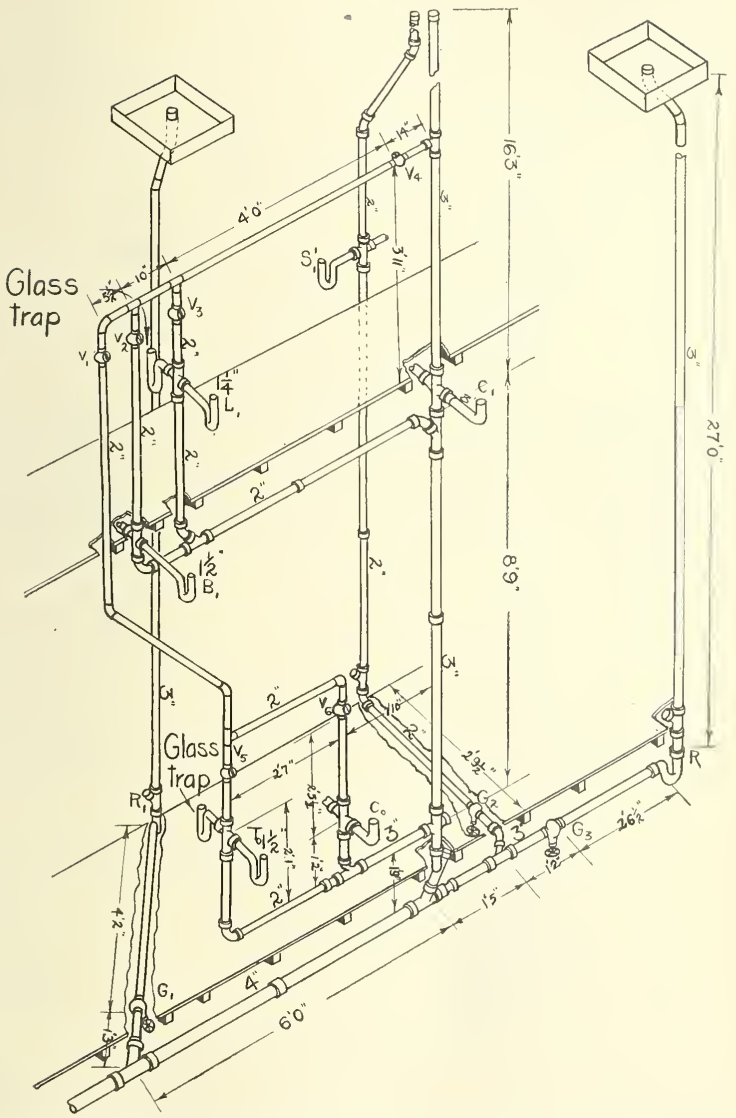

FIG. 75.-Experimental plumbing system showing arrangement of pipes and location of fixtures 
The data of series 1 were obtained with full free opening at stack tops and open free discharge at the end of the house sewer beyond the return bend. Column 1, giving the number of the test and successive discharges of the same fixtures or group of fixtures or of different groups of fixtures under one number, indicates that the whole constituted one test and that the traps in question were not

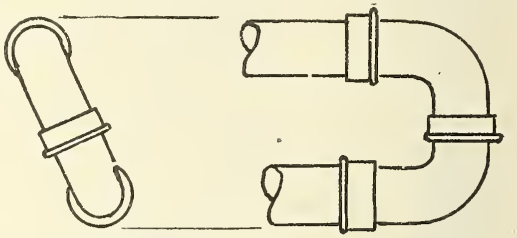

Fig. 76.-Return bend used in house sewer of Figure 75

refilled during the test unless they were automatically refilled by the discharge of the fixture itself. Column 2 gives the fixtures discharged in each test, those in line being discharged together, with repetitions in the same test in column. Conditions imposed when not applying to the whole group are also given in column 2 in con-

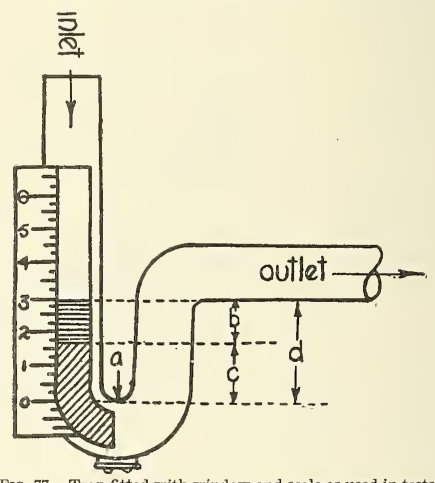

FIG. 77.-Trap fitted with window and scale as used in tests

nection with the part to which they apply. Column 3 gives the vent-line valves and drain-gate valves that were open, it being understood that all other valves on the system were closed for that test. The remaining columns give the condition in which the trap seals are left after each test, showing also the cumulative effect when the test consisted of repeated discharges. 
Series 1, group 1, upper floor tests

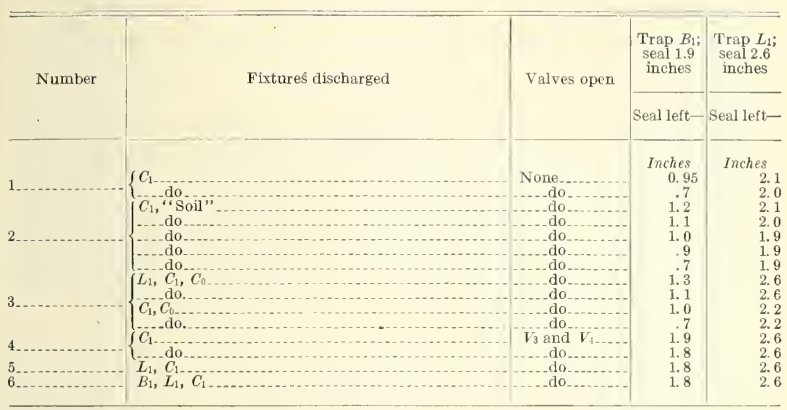

Group 2, basement tests

\begin{tabular}{|c|c|c|c|c|}
\hline \multirow{2}{*}{ Number } & \multirow{2}{*}{ Fixtures discharged } & \multirow[t]{2}{*}{ Valves open } & $\begin{array}{l}\text { Trap to } \\
\text { seal } 2.0 \\
\text { inches }\end{array}$ & $\begin{array}{l}\text { Trap } C_{0} \\
\text { seal } 5.7 \\
\text { inches }\end{array}$ \\
\hline & & & Seal left- & Seal \\
\hline . & $\begin{array}{l}B_{1}, L_{1}, C_{1} \\
B_{1}, C_{1}, T_{0} \ldots \\
B_{1}, C_{1}, C_{0} \\
B_{1}, C_{1}, T_{0}, R_{5}, \ldots \\
B_{1}, C_{1}, S^{\prime}, R^{\prime}{ }_{5} \ldots \\
B_{1}, C_{1}, S_{1}^{\prime}, R_{5} \\
B_{1}, L_{1}, C_{1}, S_{1}^{\prime}, T_{0}, R_{5-} \\
\end{array}$ & $\begin{array}{l}V_{3} \text { and } V_{4} \\
V_{3}, V_{4}, \text { and } G_{1} \\
V_{3}, V_{1}, G_{1}, \text { and } G_{2} \ldots \\
V_{3}, V_{1}, G_{2}, \text { and } G_{3} \\
V_{1}, V_{3}, V_{4}, V_{5}, G_{2}, \text { and } G_{3} \\
V_{1}, V_{3}, V_{4}, V_{6}, G_{2}, \text { and } G_{3} \ldots \\
\end{array}$ & \begin{tabular}{c|} 
Inches \\
1.8 \\
2.0 \\
1.75 \\
1.8 \\
1.7 \\
1.7 \\
2.0 \\
2.0
\end{tabular} & $\begin{array}{l}\text { Inches } \\
\text { Steady. } \\
\text { Do. } \\
\text { Full seal. } \\
\text { Blown. } \\
\text { Do. } \\
\text { Do. } \\
\text { Do. } \\
\text { Steady. }\end{array}$ \\
\hline
\end{tabular}

NoTE-The partial Ioss of seal in trap $T_{0}$ in tests 3,5 , and 6 was evidently due to waving from back pressure. The term "blown" in column 5 indicates that water was thrown up into the closet bowl by back pressure. The term "steady" indicates a steady, slight oscillation in the water-closet trap C $C_{0}$. In all cases even when "blown" there was only a slight loss of seal in trap $C_{0}$.

Conclusions.-1. For the installation as represented (fig. 75) with separate sewer system a single loop vent from the washbasin branch is required and is sufficient to prevent a material loss in any trap seal on the system. It should be noted, however, that the horizontal branch from the laundry tray and water-closet in the basement connect to the stack near the point of minimum pressure variation, and that a connection either closer to or farther from the house drain would be more in need of back venting. Therefore, in many cases a back vent from the lowest horizontal branch would be necessary for complete protection of trap seals, preferably in this case the vent represented by $V_{\mathrm{B}}$ from the water-closet $C_{0}$.

2. With a combined sewer system a vent line represented by line when $V_{6}, V_{1}, V_{3}$, and $V_{4}$ are open is required and is sufficient to protect the trap seals. 
3. The different waste and soil stacks of a system may be considered independently so far as vent requirements are concerned, provided the house drain and house sewer are sufficient in capacity for the system.

Tests were made on the same system with the stack tops partially closed to represent frost closure, with a wind current over the stack tops, with a vented running trap in the house drain, and with a submerged outfall of the house sewer. The general effects of a running trap in the house drain have been described in connection with modifying conditions. Data from later installations show the effects to be expected from partial frost closure, wind, and submerged outfall of house sewer to better advantage.

TEST INSTALLATION NO. 2

The installation (fig. 78) was constructed by remodeling the 3 -inch stack and vent system of the first installation (fig. 75), the house drain, house sewer, 2-inch waste stack, and rain leader systems being left as before. The water-closets were connected to "crowfoot" fittings as shown, and small fixture waste lines were connected to side inlets or to fittings above the water-closet branch fittings. The waste and vent lines were reduced to what was believed to be the smallest convenient serviceable size from all considerations for general construction in dwelling houses. Flush valves were installed to supply the water-closets and adjusted to give a mean rate of supply of approximately 60 gallons per minute for periods varying from 6 to 10 seconds. Under these conditions the maximum rate of discharge from the water-closet does not materially differ from the rate of supply (see curves of discharge and discussion in the first part of the report). The kind of supply is not an essential factor in the test work, the purpose of the high rates being to prove and emphasize the adequacy of the pipe system as installed for the same fixtures with satisfactory service rates of supply. The strainers were removed from all the separately trapped smaller fixtures, hence the rates of discharge from these were also slightly higher than those given in Table 4.

Series 2, group 1, tests on the second floor

\begin{tabular}{|c|c|c|c|c|}
\hline \multirow[t]{2}{*}{ Number } & \multirow[t]{2}{*}{$\begin{array}{l}\text { Fixtures } \\
\text { discharged }\end{array}$} & \multirow[t]{2}{*}{$\begin{array}{c}\text { Valves } \\
\text { open }\end{array}$} & $\begin{array}{l}\text { Trap } B_{2} \text {; } \\
\text { seal } 2.1 \\
\text { inches }\end{array}$ & $\begin{array}{l}\text { Trap } L_{2} \\
\text { seal } 2.6 \\
\text { inches }\end{array}$ \\
\hline & & & \multicolumn{2}{|c|}{ Seal left- } \\
\hline $\begin{array}{l}1 . . \\
2 .\end{array}$ & $\left\{\begin{array}{l}S \\
L_{2} S_{2} \\
\ldots \ldots \mathrm{dc}\end{array}\right.$ & $\begin{array}{l}\text { None } \\
\text { do. }\end{array}$ & $\begin{array}{r}\text { Inches } \\
2.1 \\
2.0 \\
2.0\end{array}$ & $\begin{array}{r}\text { Inches } \\
2.6 \\
2.6 \\
2.6\end{array}$ \\
\hline
\end{tabular}

Note.-The discharge of any single fixture on the floor produced no measurable loss of seal in the trap of that fixture. The discharge of the water-closet $C_{2}$ produced a very slight oscillation in the trap of the bath tub and no noticeable effect on any other trap in the group. 


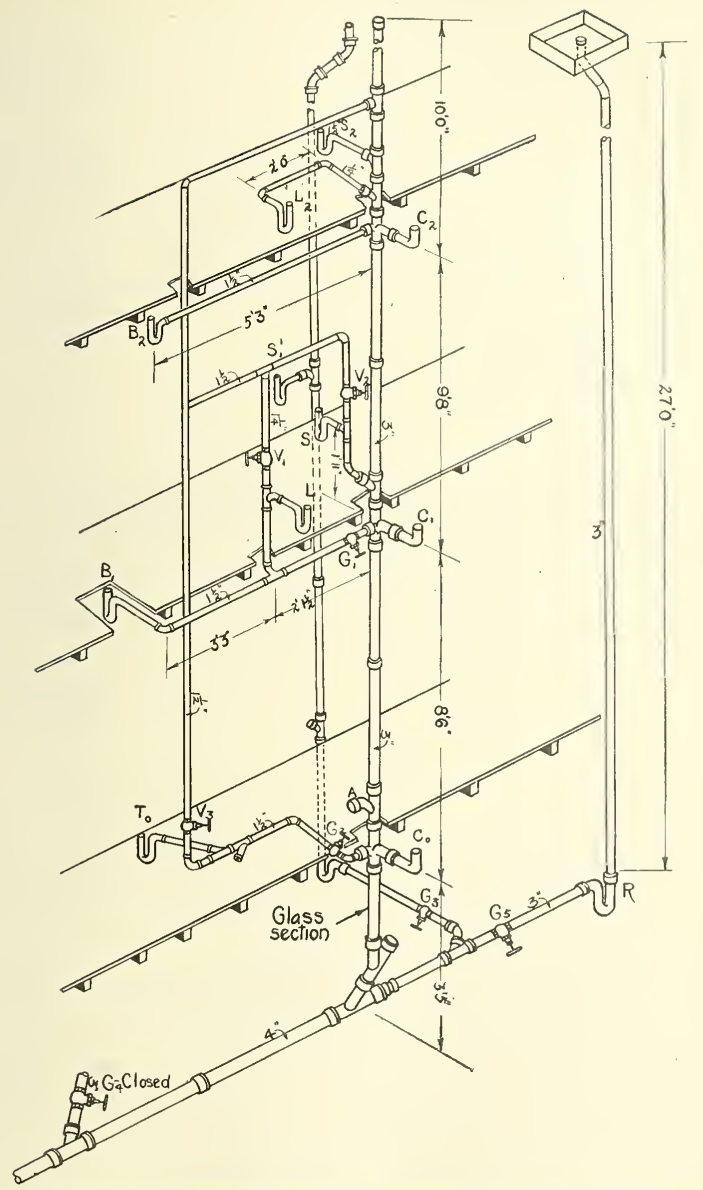

FIG. 78.-Experimental plumbing system showing arrangement of pipes and location of fixtures 
Series 2, group 2, tests on the first or middle floor of the system for local effects with the second floor and basement idle

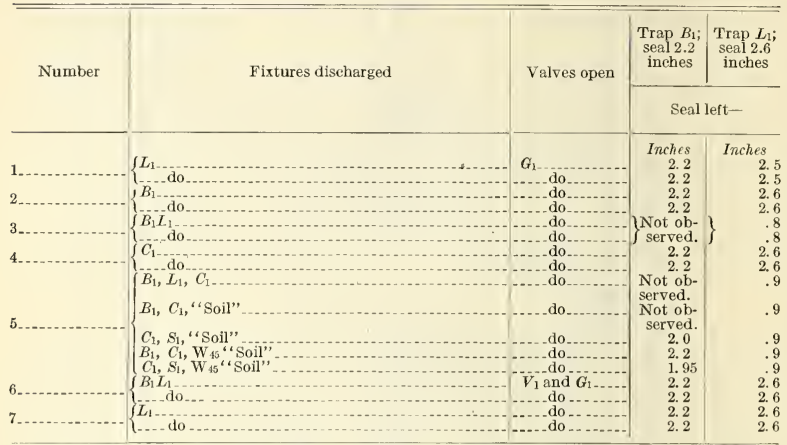

NOTE.-The discharge of any single fixture on this floor produced no appreciable loss in the trap seal of the fixture itself, except the lavatory $L_{1}$. Therefore, a continuous waste and vent from the lavatory is sufficient to protect completely the group installed in this manner when it is the highest group on the system.

Series 2, group 3, tests on first or middle floor of the system with a full bathroom group and kitchen sink in use on the floor above $V_{2}$ closed and sink $S_{2}$ outlet plugged

$\left[(-)\right.$ denotes an interval of time between starting the fixture discharges. $F_{1}$ denotes closure of 3-inch stack to 1-inch diameter to a depth of 15 inches]

\begin{tabular}{|c|c|c|c|c|}
\hline \multirow[t]{2}{*}{ Number } & \multirow[t]{2}{*}{ Fixtures discharged } & \multirow[t]{2}{*}{ Valves open } & $\begin{array}{c}\text { Trap } B_{1} \\
\text { seal } 2.2 \\
\text { inches }\end{array}$ & $\begin{array}{l}\text { Trap } C_{1} \\
\text { seal } 4 \\
\text { inches }\end{array}$ \\
\hline & & & \multicolumn{2}{|c|}{ Seal left- } \\
\hline & $\left\{\begin{array}{l}L_{1}-L_{2}, C_{2}, F_{1} \ldots \\
L_{2}, C_{2}, L_{1}, F_{1} \\
L_{2}, C_{2}, S_{2}, L_{1}, F_{1} \\
B_{2}, C_{2}, L_{2}, S_{2}, R_{5} \\
B_{2}, C_{2}, L_{2}, S_{2}, \text { "Soil },\end{array}\right.$ & \begin{tabular}{r}
$V_{1}$ and $G_{1}$ \\
\hdashline do \\
$V_{1}, G_{1}, \ldots$ and $G_{5}$ \\
$\ldots$ do \\
$\ldots$
\end{tabular} & \begin{tabular}{r|} 
Inches \\
2.2 \\
2.2 \\
2.2 \\
2.2 \\
2.2 \\
2.2 \\
2.2
\end{tabular} & $\begin{array}{r}\text { Inches } \\
\text { 2. } 0 \\
\text { 1. } 2 \\
\text { 1. } \\
\text { 1. } \\
4.0 \\
\text { 3. } \\
\text { 3. } 0\end{array}$ \\
\hline
\end{tabular}

Note.-Trap $C_{1}$ seal was temporarily broken by the last run of test 1.

Series 2, group 4, test on first or middle floor of the system with sink and water-closet only connected, $G_{1}$ being closed

\begin{tabular}{|c|c|c|c|c|}
\hline \multirow[t]{2}{*}{ Number } & \multirow[t]{2}{*}{ Fixtures discharge ${ }^{\prime}$} & \multirow[t]{2}{*}{ Valves open } & $\begin{array}{l}\text { Trap } S_{1} \\
\text { seal } 2.2 \\
\text { inches }\end{array}$ & $\begin{array}{c}\text { Trap } C_{1} ; \\
\text { partial } \\
\text { 2.0-inches } \\
\text { seal }\end{array}$ \\
\hline & & & \multicolumn{2}{|c|}{ Seal left- } \\
\hline ... & $\begin{array}{l}C_{2} \\
C_{2}, S_{2} \ldots \ldots\end{array}$ & None & $\begin{array}{r}\text { Inches } \\
0.3 \\
.0\end{array}$ & $\begin{array}{r}\text { Inches } \\
1.5 \\
1.0\end{array}$ \\
\hline
\end{tabular}


It is apparently impossible to destroy permanently the seal of water-closet $C_{1}$ by discharges from above, when the side inlet branch waste is vented. With 10 feet or more of straight stack below the water-closet there is slight danger of it being subjected to back pressure from the stack. The only danger of air leakage through the water-closet is therefore from complete loss of the trap seal by evaporation. It is necessary to back vent each small waste branch connected independently to the stack on a middle floor.

Series 2, group 5, tests on basement fixtures (fig. 78) with separate sewer system; that $i s, G_{3}, G_{4}$, and $G_{5}$ were closed

[ $D_{3}$ recorded with fixtures discharged in column 2, indicates the end of the house sewer was submerged to a depth of 3 inches and $W_{45}$ indicates that a 45 -mile per hour wind current was directed horizontally over the stack top.]

\begin{tabular}{|c|c|c|c|c|}
\hline \multirow{2}{*}{. Number } & \multirow[t]{2}{*}{ Fixtures discharged } & \multirow[t]{2}{*}{ Valves open } & $\mid \begin{array}{c}\text { Trap } \mathrm{T}_{0} \\
\text { seal } 1.8 \\
\text { inches }\end{array}$ & $\begin{array}{c}\text { Trap Co; } \\
\text { seal } 4 \text { inches }\end{array}$ \\
\hline & & & Seal left- & Seal \\
\hline $1 \ldots \ldots$ & $\left\{\begin{array}{l}B_{2}, C_{2}, L_{2}, \text { "soil,", } D_{3} \\
B_{2}, L_{2}, S_{2}, \text { "soil," } D_{3} \ldots \\
B_{2}, C_{2}, S_{2}, " \text { soil," } D_{3} \ldots \\
B_{2}, C_{2}, L_{2}, S_{2}, \text { "soil," } D_{3} W_{45} \ldots \\
B_{2}, C_{2}, L_{2}, S_{1}, T_{0}, \text { "soil" } \ldots\end{array}\right.$ & $\begin{array}{c}V_{1}, V_{2}, V_{3}, G \text { and } G_{2} \ldots \\
\text { do do }\end{array}$ & $\begin{array}{r}\text { Inches } \\
1.6 \\
1.5 \\
1.4 \\
1.4 \\
1.8\end{array}$ & $\begin{array}{l}\text { Steady. } \\
\text { Do. } \\
\text { Do. } \\
\text { Do. } \\
\text { Blown. }\end{array}$ \\
\hline
\end{tabular}

Series 2, group 6, tests on the basement fixtures with combined sewer system

\begin{tabular}{|c|c|c|c|c|}
\hline \multirow[t]{2}{*}{ Number } & \multirow[t]{2}{*}{ Fixtures discharged } & \multirow[t]{2}{*}{ Valves open } & $\begin{array}{c}\text { Trap } \mathrm{T}_{0} \\
\text { seal } 1.8 \\
\text { inches }\end{array}$ & $\begin{array}{l}\text { Trap } \mathrm{C}_{0} \\
\text { seal } 4.0 \text { inches }\end{array}$ \\
\hline & & & Seal left- & Seal \\
\hline & $\begin{array}{l}B_{2}, L_{2}, C_{2}, S_{1}, R_{5}, D_{3} \\
B_{2}, L_{2}, C_{2}, S_{1}, C_{1}, R_{5}, D_{3} \\
L_{2}, C_{2}, S_{1}, R_{5}, D_{3} \ldots \\
L_{2}, C_{2}, S_{1}, T_{0}, R_{5}, D_{3} \ldots \\
B_{1}, L_{1}, C_{1}, S_{1}, R_{5}, D_{3} \ldots\end{array}$ & $\begin{array}{l}V_{2}, V_{3}, \text { and } G_{2} \ldots \\
V_{1}, V_{2}, V_{3}, G_{1}, \text { and } G_{2}\end{array}$ & $\begin{array}{r}\text { Inches } \\
1.8 \\
1.8 \\
1.8 \\
1.8 \\
1.7\end{array}$ & $\begin{array}{l}\text { Blown. } \\
\text { Poor refill. } \\
\text { Small bubble. } \\
\text { Large bubbles. } \\
\text { Small bubbles. }\end{array}$ \\
\hline
\end{tabular}

Note.-The term "steady" means steady fluctuation in the trap seal under back pressure. "Blown" means water thrown up from the closet bowl or out of the bowl by back pressure. "Bubble" or " bubbles" means a small quantity of air forced back through the trap by back pressure.

Evidently much of the trouble from back pressures in test groups 5 and 6 is directly due to insufficient capacity of the house drain and house sewer. The presence of the return bend in the house sewer and submerged outfall impose rather severe conditions and the volume of water discharged is somewhat greater than the same fixtures would give in ordinary service. Attention has been called to the fact that the water-closet discharge approached or exceeded 60 gallons per minute. The carrying capacity of the 4-inch drain has been estimated at 108 gallons per minute when laid with a grade of onefourth inch per foot and flowing full under its own head. The combined rate of discharge for most of the tests exceeds this value; for example, No. 1, group 6 gives a combined rate of discharge to the house drain, including that from the rain leader, of nearly 200 gal- 
lons per minute. In order to show the presence of backwater in the stack the 2-inch T-Y branch $A$ in the stack above the watercloset $C_{0}$ was opened up, $V_{3}$ closed, the water-closet $C_{0}$ stopped in the trap and the following discharged into the stack and drain, $B_{3} L_{3} C_{3} S_{1} T_{0^{-}}$$R_{5} D_{3}$ giving a total estimated discharge of 215 gallons per minute. The water spurted from the branch of the fitting to a distance of 3 or 4 feet, showing that, the stack was flowing under considerable head above that point. Therefore, the tests of group 6 mean but little in connection with vent requirements and serve only to emphasize the need of an adequate house drain. The tests of group 6 do show

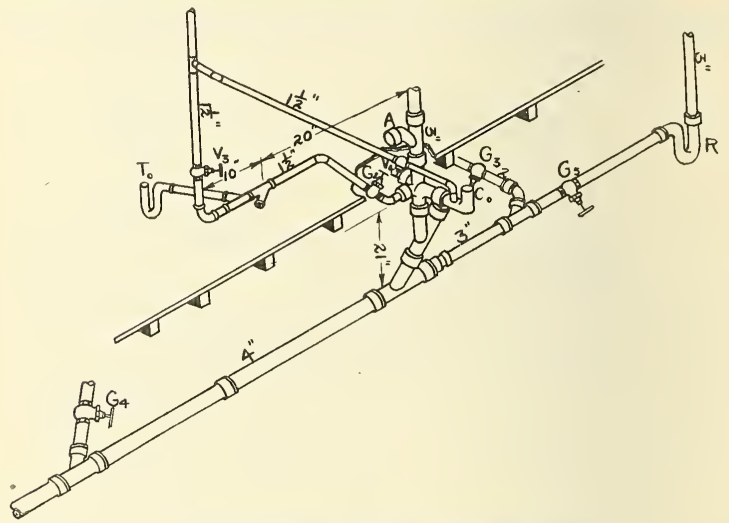

FIG. 79.-Change in arrangement of basement fixtures of Figure 78

the danger from back pressure when fixtures are connected near the base of the stack. In order further to test these effects, the basement fixtures of installation (fig. 78) were lowered to a vertical height of 21 inches between the center of the house drain and center of the $T-Y$ branch taking the basement water-closet. (See fig. 79.) A $1 \frac{1}{2}$-inch vent was carried from the top of the closet bend as shown, the stack and upper floor fixtures remaining as in Figure 78.

Series 2, group 7 , tests of Figure 79 basement fixtures

\begin{tabular}{|c|c|c|c|}
\hline Number & Fixtures discharged & Vents open & 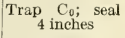 \\
\hline 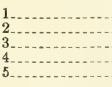 & $\begin{array}{l}B_{2} L_{2} C_{2} S_{1} T_{0} R_{4} D_{4} \\
B_{1} L_{1} C_{1} S_{1} T_{0} R_{4} D_{4} \\
L_{2} C_{2} S_{2} L_{1} C_{1} S_{1} T_{0} D_{4} \\
B_{2} L_{2} C_{2} S_{2} B_{1} L_{1} C_{1} S_{1} T_{0} D_{4} \\
B_{2} L_{2} C_{2} S_{1} T_{0} R_{4} D_{4}\end{array}$ & $\begin{array}{l}V_{2} V_{3} V_{4} G_{2} \text { and } G_{5} \\
V_{2} V_{3} V_{4} G_{1} G_{2} \text { and } G_{5} \\
V_{2} V_{3} V_{4} G_{1} \text { and } G_{2} \\
V_{2} V_{3} \text { and } G_{2}\end{array}$ & $\begin{array}{l}\text { Steady. } \\
\text { Do. } \\
\text { Do. } \\
\text { Blown. } \\
\text { Do }\end{array}$ \\
\hline
\end{tabular}

With the installation represented by Figure 78 and basement installation (fig. 79), the house drain was disconnected at rain leader 
$R^{\prime}$ connection and discharged vertically at that point through a one-fourth bend submerged to a depth of 6 inches in a tank. The total horizontal distance from the center of the 3-inch stack to the center of the vertical part of the one-fourth bend was 7 feet 3 inches.

Series 2, group 8, tests of basement fixtures (fig. 79) with submergence near the base of the stack

\begin{tabular}{|c|c|c|c|}
\hline Number & Fixtures discharged & Valves open & Trap $\mathrm{C}_{0}$ \\
\hline & $\begin{array}{l}B_{2} L_{2} C_{2} S_{1} T_{0} D_{6} \\
B_{2} L_{2} C_{2} B_{1} S_{1} T_{0} D_{6} \\
B_{2} L_{2} C_{2} S_{1} T_{0} D_{6} \\
B_{2} C_{2} T_{0} D_{6} \\
C_{2} T_{0} D_{6}\end{array}$ & $\begin{array}{l}V_{2} V_{3} V_{4} \text { and } G_{2 \ldots} \\
V_{2} V_{3} \text { and } G_{2} \\
\text { do }\end{array}$ & $\begin{array}{l}\text { Small bubbles. } \\
\text { Blown. } \\
\text { Do. } \\
\text { Do. } \\
\text { Small bubbies. }\end{array}$ \\
\hline
\end{tabular}

Tests of groups 7 and 8 show that with fixtures connecting near the base of the stack it is necessary to back vent each branch separately, and that with inadequate house drain or submergence near the base of the stack it is difficult if not impossible in extreme cases to protect completely the trap seals of fixtures thus located.

\section{TEST INSTALLATION NO. 3}

The final tests on small-house plumbing systems were made on an installation (fig. 80), erected for the purpose of permitting anyone interested in the work to witness or make any test desired. In a measure it embodies the better features of the earlier installations. The system as displayed consisted of a two story and basement structure with a bathroom group of fixtures on the upper or second floor, a bathroom group on the first or middle floor, and two waterclosets on the basement or lower floor, all connected to the 3-inch soil stack, and in addition two batteries of two laundry trays each on the basement floor and one kitchen sink on each of the first and second floors connected to a 2-inch waste stack. Gate valves were installed in the vent lines so that the fixtures below the upper floor might be back vented or not as desired.

Data for only a few representative "eritical tests" are given. The construction and tests for the upper floor were so nearly the same as that in Figure 78 that no data are given. It was impossible to reduce the seal of any trap on this floor materially by any combination or sequence of discharge of fixtures on the system. Likewise, it is unnecessary to consider one stack in reference to the other for floors above the basement. Basement floor fixtures on one stack may be affected by discharge into the other stack. The water-closets in the system (fig. 80) were installed with low-tank supply giving rates of discharge approaching that given in Table 4. The strainers were removed from the separately trapped fixtures, hence the rates of discharge were slightly higher than given for the same fixtures in Table 4. 


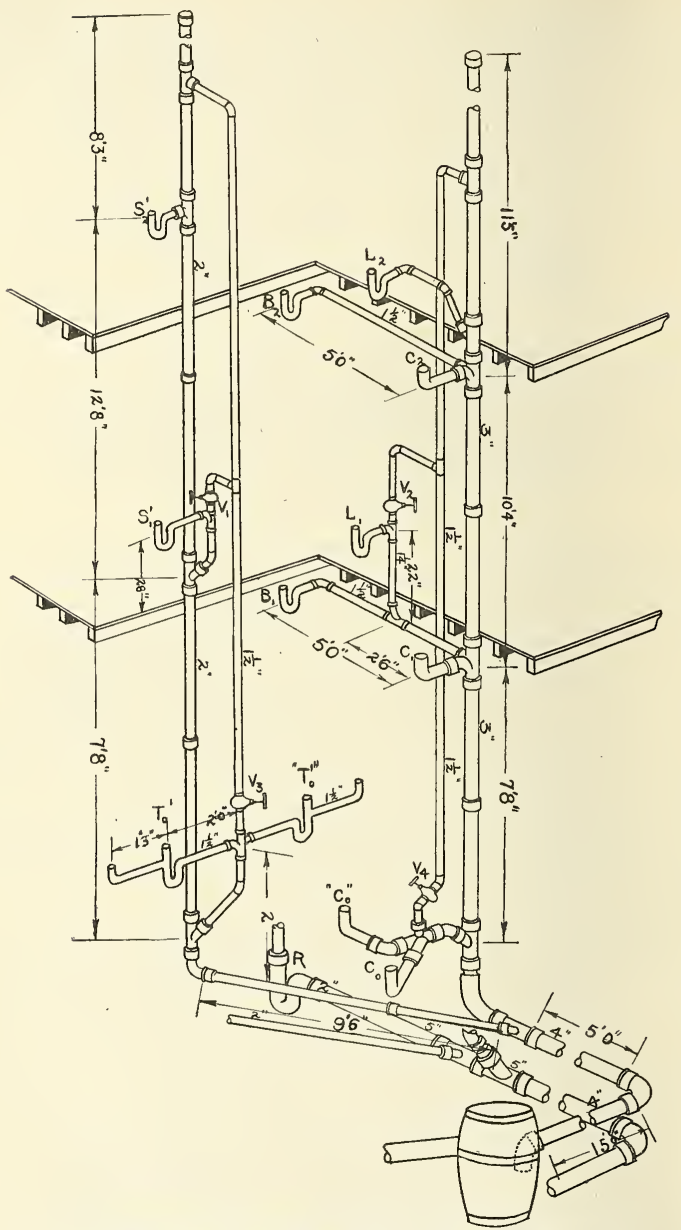

FIQ. 80.-Experimental plumbing system erected for demonstration purposes 
Series 3 , group 1, tests on first or middle floor of the system for local effects

\begin{tabular}{|c|c|c|c|c|}
\hline \multirow[t]{2}{*}{ Number } & \multirow[t]{2}{*}{ Fixtures discharged } & \multirow[t]{2}{*}{ Valves open } & $\begin{array}{c}\text { Trap } B_{1} \\
\text { seal } 1.4 \\
\text { inches }\end{array}$ & $\begin{array}{c}\text { Trap } \mathrm{L}_{1} ; \\
\text { seal } 2.5 \\
\text { inches }\end{array}$ \\
\hline & & & \multicolumn{2}{|c|}{ Seal left- } \\
\hline 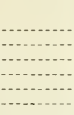 & $B_{1} L_{1}$ do ${ }_{1}$ & 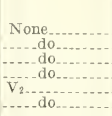 & $\begin{array}{l}\text { Inches } \\
1.4 \\
\text { 1. } \\
1.4 \\
1.4 \\
1.4 \\
1.4\end{array}$ & $\begin{array}{l}\text { Inches } \\
\text { 2. } 5 \\
\text { 2.5 } \\
\text { 1. } 25 \\
\text { 1. } 25 \\
2.5 \\
2.5\end{array}$ \\
\hline
\end{tabular}

Note.-There was no appreciable loss of seal in trap $C$ of the water-closet at any time.

Series 3, group 2, tests on the first floor as the middle floor of a two story and basement structure

\begin{tabular}{|c|c|c|c|c|}
\hline \multirow[t]{2}{*}{ Number } & \multirow[t]{2}{*}{ Fixtures discharged } & \multirow[t]{2}{*}{ Valves open } & $\begin{array}{c}\text { Trap } B_{1} ; \\
\text { seal 1.4 } \\
\text { inches }\end{array}$ & $\begin{array}{c}\text { Trap } C_{1} \\
\text { seal } 4 \\
\text { inches }\end{array}$ \\
\hline & & & \multicolumn{2}{|c|}{ Seal left- } \\
\hline $\begin{array}{l}1 \ldots \\
2 \ldots \\
3 \ldots \\
4 \ldots\end{array}$ & $\left\{\begin{array}{l}C_{2} L_{2} \mathrm{~S}_{2} \\
B_{2} C_{2} L_{2} \mathrm{Sl}_{2} \\
B_{2} C_{2} L_{2} L_{1} \\
B_{2} C_{2} L_{2} B_{1} \mathrm{~L}_{1} \\
B_{2} C_{2} B_{1} \text { " soil }\end{array}\right.$ & $\begin{array}{l}\text { None } \\
\mathrm{V}_{2} \text { and } \mathrm{V}_{4} \ldots \\
\end{array}$ & $\begin{array}{r}\text { Inches } \\
1.4 \\
1.4 \\
1.4 \\
1.4 \\
1.4\end{array}$ & $\begin{array}{c}\text { Inches } \\
\text { Steady. } \\
1 \\
2 \\
1 \\
2\end{array}$ \\
\hline
\end{tabular}

Note.-There was no loss of seal in trap $L_{1}$ in tests 2,3 , and 4.

Series 3, group 3 , tests on the basement or lower floor of the installation

[Under columns trap $C_{0}$ and trap $T_{0}$ effects given are for either of the pair of water-closets or either of the laundry tray traps]

\begin{tabular}{|c|c|c|c|c|}
\hline Number & Fixtures discharged & Valves open & $\begin{array}{c}\text { Trap Co; } \\
\text { seal } 4 \text { inches }\end{array}$ & $\begin{array}{l}\text { Trap } \mathrm{T}_{0} \\
\text { seal } 2.1 \\
\text { inches }\end{array}$ \\
\hline 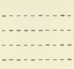 & $\begin{array}{l}B_{2} C_{2} \mathrm{~L}_{2} \mathrm{Sl}_{2} D_{1} \\
B_{2} C_{2} \mathrm{~L}_{2} \mathrm{~S}_{2} D_{4} \\
B_{2} \mathrm{C}_{2} L_{2} \mathrm{Sl}_{2} D_{4} \\
B_{2} C_{2} L_{2} S_{2}{ }_{1} \text { soil " } D_{4}\end{array}$ & $\begin{array}{l}\text { None } \\
V_{4} \\
V_{2} \text { and } V_{4} \\
V_{1} V_{2} V_{3} \text { and } V_{4 \ldots}\end{array}$ & $\begin{array}{c}\text { Blown } \\
\text { Steady } \ldots . . . . \\
\text { do } \\
\text { do }\end{array}$ & $\begin{array}{l}\text { Blown. } \\
\text { Do. } \\
\text { Do. } \\
\text { Steady. }\end{array}$ \\
\hline
\end{tabular}

Not E.-The blowing of the seals of the laundry-tray traps in test No. 3 was evidently due in part to overcharging of the horizontal drain from the 2-inch stack. There was only slight permanent loss of seal in either laundry tray or water-closet traps in any of the tests of groups even when the seals were "blown" by back pressure.

The tests of the installations represented by Figures 75 and 78 showed the deterimental effect to be expected in a combined sewer system when the house drain is insufficient in capacity to carry both the storm water and discharge from the stacks. To test the eflects with an adequate house drain, the 5-inch house drain and house sewer represented at the bottom of Figure 80 were connected in place of the 4-inch drains shown connected in the drawing. The rain leader was 3 -inch diameter, 22 feet long, with box arranged at the top as before described.

The tests on the upper floors did not differ in results from those with 4-inch drains and separate sewer system, hence no data for these are reported. 
Series 3, group 4, tests on the basement or lower floor with combined sewer system

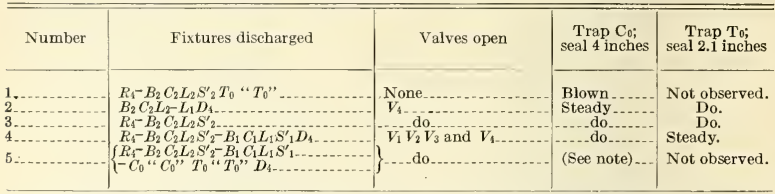

Note,-Test No. 5 was made merely to determine whether or not the system would drain with the total possible discharge from the fixtures in combination with storm water. The dashes $(-)$ inserted with fixtures discharged indicates an interval of time between starting discharges on the different floors in order to obtain a greater volume rate of discharge into the house drain. There was a poor flush in the basement water-closets in No. 5, the water rising in the bowls to about 1 inch of the top then flowing out as the water receded from the house drain. The test is abnormal, and, as stated, shows only the degree of safety against flooding or overflowing during any normal heavy use. The total rate of discharge into the house drain was slightly in excess of 300 gallons per minute.

\section{GENERAL CONCLUSIONS}

The results of the preceding tests in connection with other experiments justify a number of general conclusions which may safely be applied to all dwelling-house plumbing, namely:

1. The 3-inch stack is adequate for all separate dwelling house plumbing.

2. It is possible by close grouping of the fixtures around the soil stack to obtain safe and efficient drainage for a single floor and for the highest floor of a more complex system without back venting any of the fixtures.

3 . It is necessary to back vent individually or in groups all small branch waste lines connecting directly into the stack below a watercloset on the same stack to protect fully the seals of traps on such branches.

4. A back-vented side-inlet branch to a "crowfoot" fitting on a middle floor offers a degree of protection that makes it unnecessary to back vent the water-closet individually, provided the possible discharge does not exceed that from one bathroom group plus a kitchen sink or $10 \frac{1}{2}$ fixture units.

5. In cases where the possible discharge from floors above exceeds $10 \frac{1}{2}$ fixture units it is necessary to back vent each separate branch individually, including water-closet branches, on a middle floor.

6. It is necessary to back vent each separate branch connection individually on the lower floor including water-closet branches, unless there is 3 feet or more of straight stack below the fittings taking such branches, in which case the rules for a middle floor may be applied with safety.

7. In a combined sewer system it is necessary to make ample provision in the size of house drain and house sewer in order to protect fixtures set low on the stack, even when such fixtures are individually back vented.

The above conclusions are based on the assumption of the use of plain traps and with the realization that in practice considerable departure from any fixed conditions assumed for test purposes may 
occur. The conclusions embodied in the recommended desings are of construction which follow, Figures 81 to 89 .

\section{RECOMMENDED CONSTRUCTION DETAILS}

Figures 81 to 89 represent details of construction in which the principles and requirements, as determined by the experimental
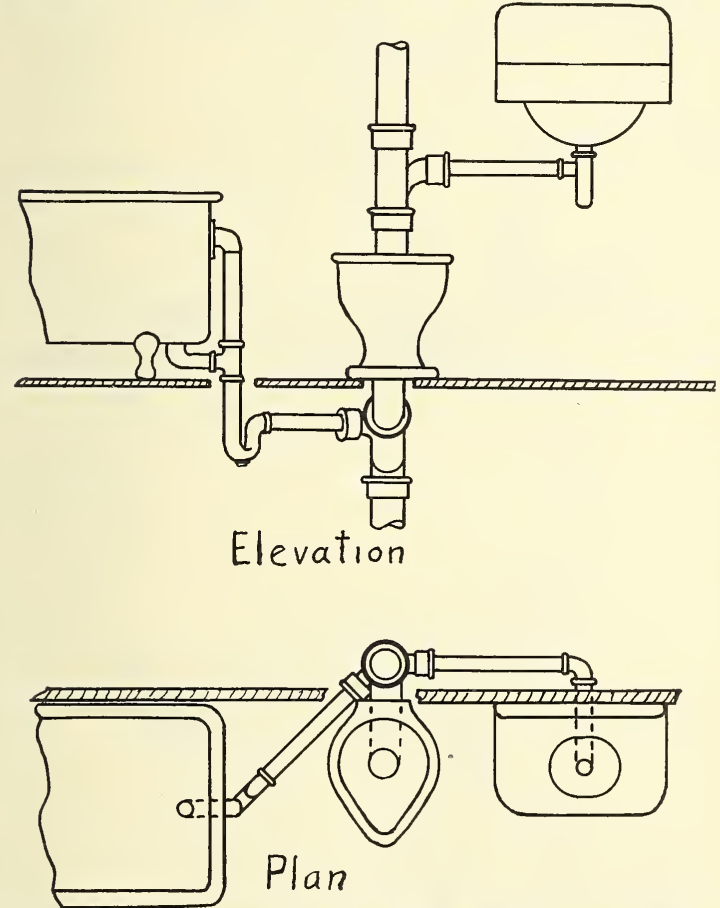

FIG. 81 (Design A).-A pproved design for a stack vented bathroom group of fixtures (the highest group of fixtures on the stack)

work, are applied to the types of buildings under consideration, namely, small dwelling houses. The layouts were originally prepared by the plumbing committee, but have been modified and elaborated with their full approval to bring out certain features in venting and to illustrate possible variations that may be made by use of properly designed "crowfoot" fittings. They by no means show all the variations that may be made with the more elaborate systems composed $94877^{\circ}-24-13$ 
of two or more bathroom groups and other fixtures, but are believed to be sufficient to indicate other variations that might be made to meet different structural conditions encountered without in any way changing the general results or in any way lessening the efficiency of the system.
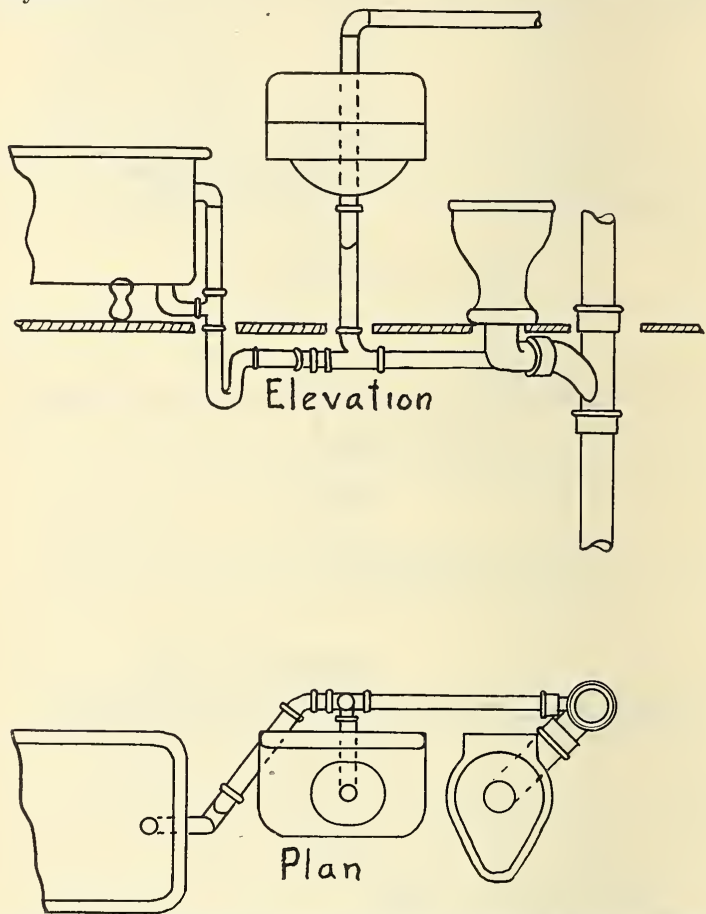

Fig. 82 (Design $B$ ).-Approved design for stack and group vented fixtures. (See text for restrictions in location)

We have pointed out that the most efficient drainage will be secured with the most direct wastes consistent with the general requirements to protect the trap seals. It follows that an individual vent installed where one is not needed is not only an added expense but may prove a detriment by reducing the velocity of flow and consequently the scour in the waste or soil pipe thus vented. For these reasons we have given preference to the plan involving the simplest venting. This, in general, involves a close grouping of fixtures about the stack, assuming that the stack will be located so as to make possible such 
grouping within the limits of allowable length of unvented wastes. It is recognized that such grouping and arrangement will not always be possible, and alternate plans in the order of preference are given for each type of building represented. The types go from the simplest to the more complex, and, in general, a plan for one type will serve equally well in the same position in a simpler type of building.

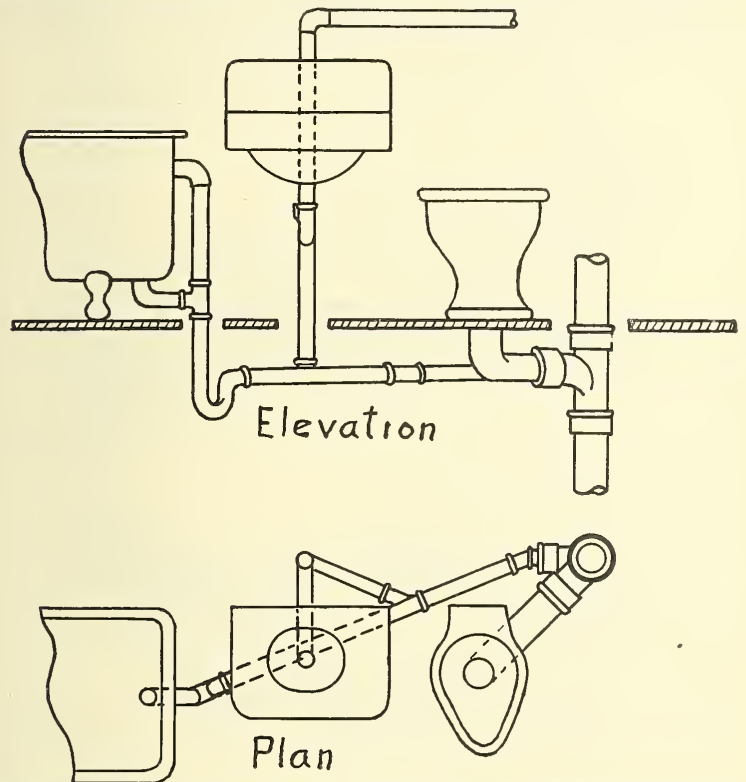

Fig. 83 (Design $C$ ).-Approved design showing one alternative arrangement of waste pipes for Figure 82 It will be observed that the plans (figs. 81 to 89 ) in connection with Figures 90 to 92 graphically represent a summary of conclusions in so far as they apply to small dwelling-house construction. The maximum developed length of all horizontal unvented waste branches is limited to 5 feet with slopes of one-fourth to one-half inch per foot. In general, the drawings are shown for wrought-iron construction in waste and vent pipes. Any approved material may be used within the same limits. For the most part dimensions are omitted from the drawings, since the same construction applies to any sized soil stack and required vent and waste pipes.

Design $A$ (fig. 81 ) is suitable for the highest group of fixtures on the soil stack. A kitchen sink, with an independent waste branch 
connecting to the stack above the water-closet branch, may be added to the group without other change. It will be observed that the design offers great flexibility in the matter of spacing and order of arrangement of fixtures by the selection of the proper "crowfoot" fitting, the principal restriction being the limitation of unvented horizontal waste branches to a maximum developed length of 5 feet. Still greater flexibility may be secured by a proper location of the stack relative to the desired fixture positions.
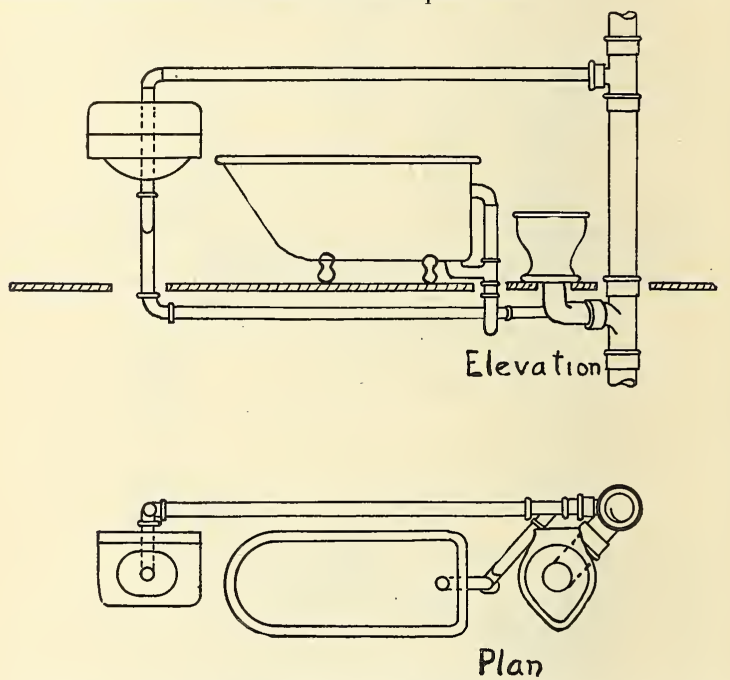

Fıg. 84 (Design D).-Approved design for stack-vented and group-vented fixtures. (See text for restrictions in location)

Design $B$ (fig. 82), design $C$ (fig. 83), and design $D$ (fig. 84) are alternative layouts recommended for the highest group of fixtures when the desired location of fixtures can not be secured with design $A$. These are not adapted to as many variations in order of arrangement as design $A$, but permit some which can not be secured in design $A$, such as the location of the lavatory on the opposite side of the bathroom from the soil stack. A kitchen sink may be added to the group with the same restrictions as before. Design $B$ will also serve with comparative safety on a lower floor when the possible discharge from above does not exceed one bathroom group plus a kitchen sink or $10 \frac{1}{2}$ fixture units. Design $E$ (fig. 85) may be used on a lower floor under the same conditions. Design $F$ (fig. 86) may be used on a lower floor when the possible discharge from above exceeds $10 \frac{1}{2}$ 

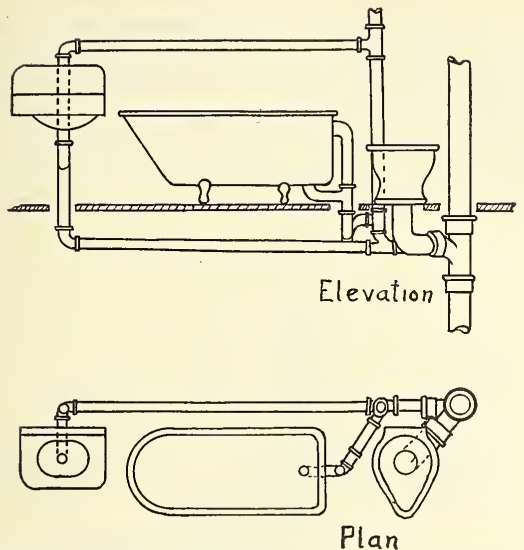

FIG. 85 (Design E).-Approved design for lower floor. (See text for restrietions in location)
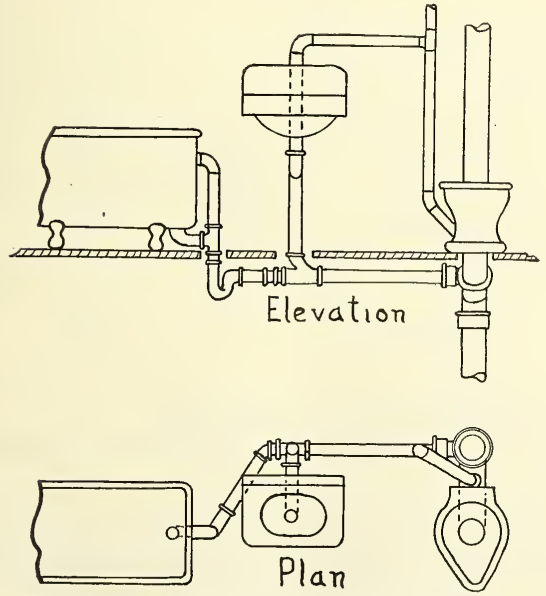

FIG. 86 (Design F),-Approved design for lower-floor bathroom group 
fixture units. Design $G$ (fig. 87) represents approved duplex arrangement for the highest group. Two kitchen sinks or two combination fixtures with wastes connecting above the water-closet branches may be added without other changes. Design $H$ (fig. 88) shows approved venting of a lavatory and water-closet group on a lower floor.

Figure 89 represents approved forms of venting single fixtures, with wastes connecting independently to the stack to be employed when necessary to vent in any position and approved forms of venting
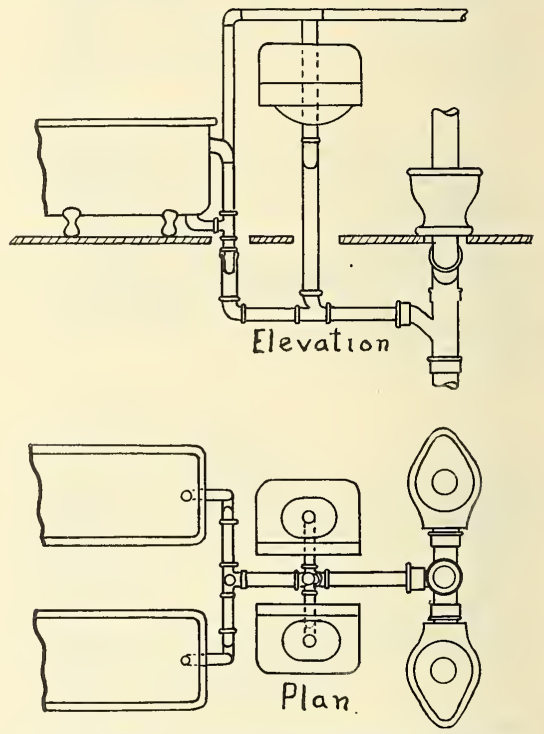

FIG. 87 (Design $G$ ).-Approved design for duplex bathroom group

water-closets when connected to the stack near the base and when connected independently to the house drain.

Figures 90 to 92 represent types for small dwellings which we believe to be sufficiently varied to illustrate all types within the scope of the present report. Many variations of each type might be made without in any way changing the principles or the requirements. In general, a fixture or a group of fixtures may be omitted from a lower floor of any type without changing the requirements in venting for other fixtures on the same floor or floors above.

Types 1 and 3 may use any one of the designs $A$ to $E$ with variations within the limits prescribed elsewhere for installing the fixtures. 
Types 2 and 4 may use any one of the same designs for the upper floor, with the basement fixtures vented as indicated in any of the approved methods of venting for the position.

Types 5 and 6 may use on the second floor any of the approved designs for the highest floor of a system and designs $B, E$, or $F$, with the sink or combination fixture vented in approved manner as indi-

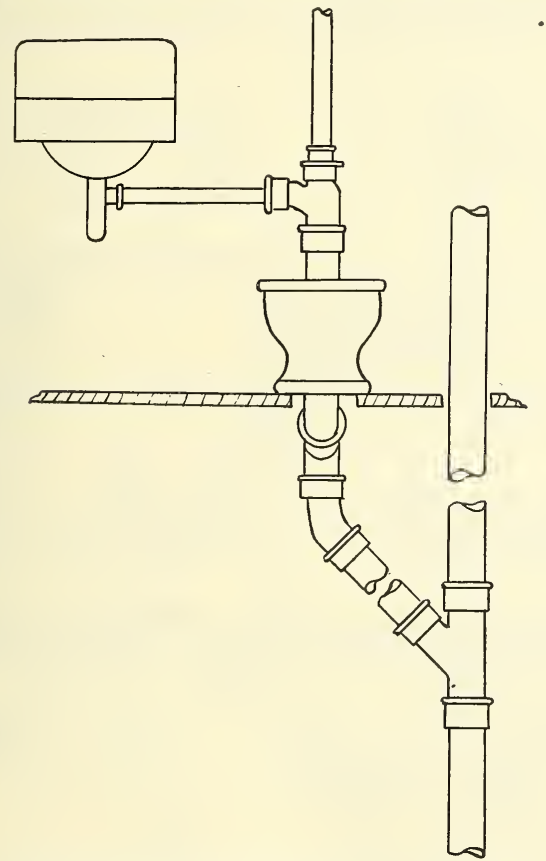

FIG. 88 (Design $H$ ).-Approved venting for lavatory and water-closet

cated, and the basement fixture in type 6 , vented in approved manner.

Types 7 and 8 may use design $G$ (fig. 86) or any equivalent variation for the upper floor within prescribed limits of permitted lengths and design $H$ (fig. 88) or an equivalent variation for the first floor with the basement water-closet type 8 vented in an approved manner.

Types $9,10,11$, and 12 , two story and two story and basement two-family houses, may use any one of the approved designs for the second or top floor. 
Types 9 and 10 may use any of designs $B, E$, or $F$ on the first floor with the sink or combination fixture vented in an approved manner as indicated.

Types 11 and 12 may use any designs $B, E$, or $F$ on the first floor for the main stack, with fixtures on the waste stack vented in an approved manner.

It is impossible to describe or illustrate all possible variations in design in which the same general characteristics can be maintained.
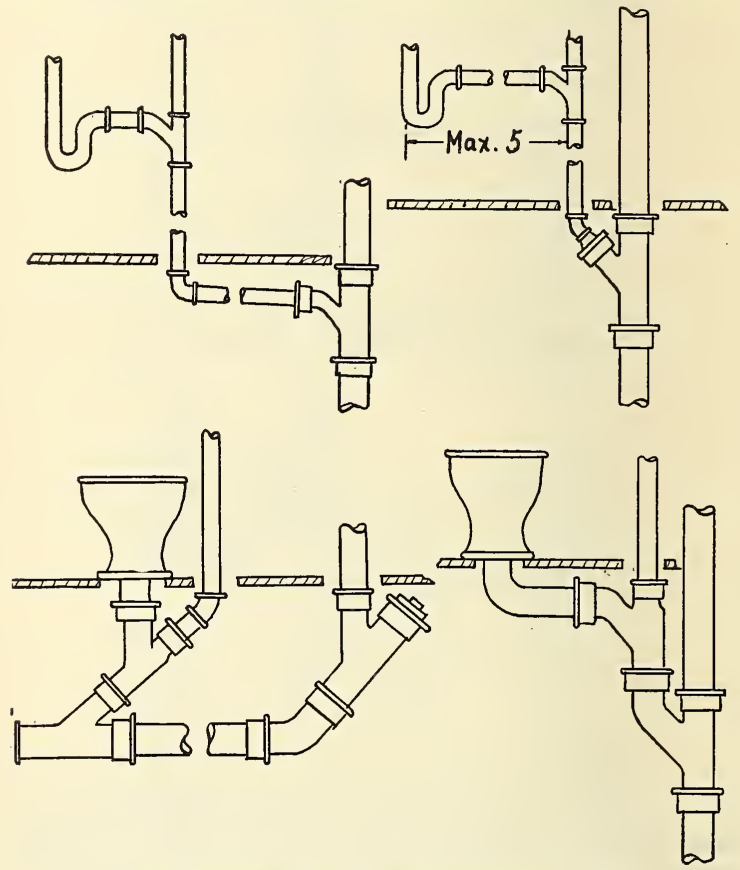

FIf. 89.-Approved forms of venting single fixtures

The preceding construction has been described in considerable detail to illustrate the flexibility of the designs given to meet different conditions. It has been previously pointed out that there is considerable flexibility in the designs themselves. Figures 81 to 89 are limited always by the permitted lengths of wastes and by venting requirements for the position in which the layout is to be installed. 
Preference has been given in all illustrations to the simplest form of venting that we believe will be safe for general application because (1) from the drainage standpoint it will, in general, be more efficient; (2) there is less chance for depreciation in service in the simple

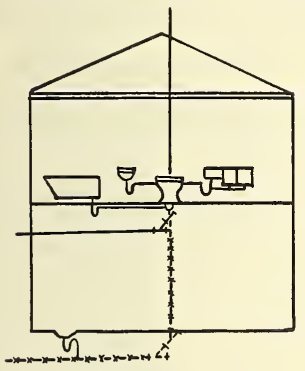

Type 1

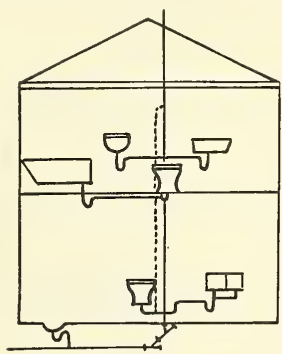

Type 2

Symbols used in Types 1 to 12 inclusive
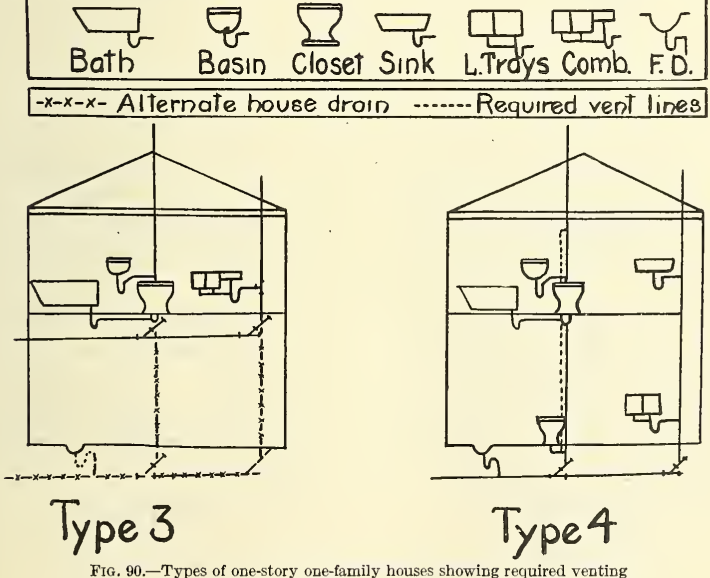

system; and (3) the work can generally be installed with a saving in material, labor, and space.

The designs and requirements in venting are given for the 3 -inch soil stack. This is not to be interpreted as a requirement for the use of a 3-inch soil stack. It has been found to be serviceable 
beyond the requirements for any of the types of buildings within the scope of the plumbing committee's report, and its employment in preference to a 4 -inch soil stack introduces a saving in material, labor, and space. It has been suggested that the employment of a 4-inch soil stack would permit a reduction in the venting required
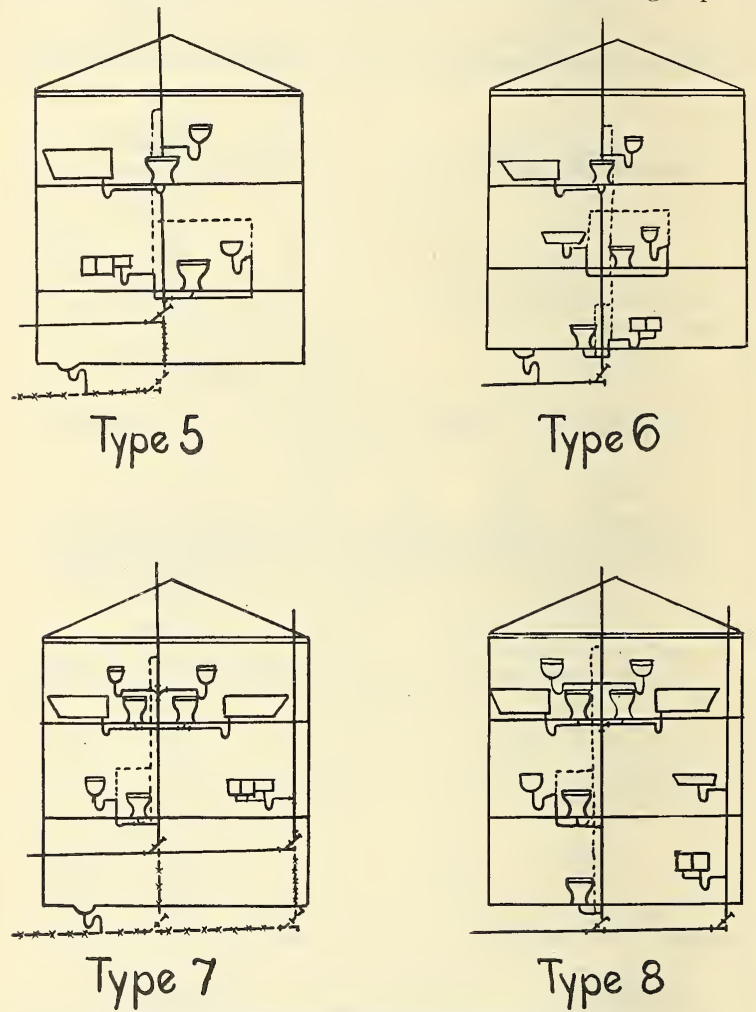

Fig. 91.-Types of two-story one-family houses showing required venting

for a 3 -inch stack. The experiments so far indicate that this would not be true and that, in general, where vents are required for a 3-inch stack they would also be required for a 4 -inch stack. Theory indicates that in many cases larger vents would be required for a 4-inch than for a 3-inch stack with the same fixtures installed on both. 
The 3-inch soil stack offers distinct advantages over the 4-inch stack, which have not yet been sufficiently emphasized in the matter of saving space and in being more readily worked into walls or

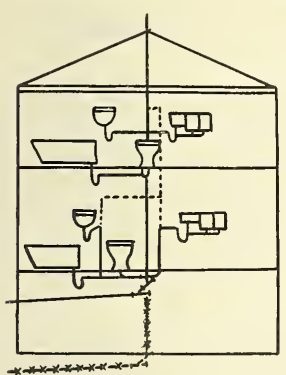

\section{Type 9}

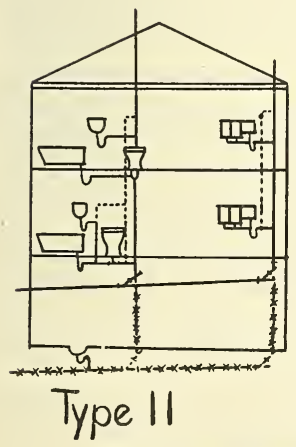

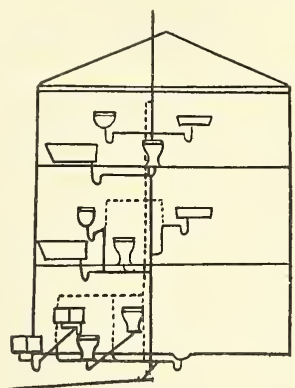

Type 10

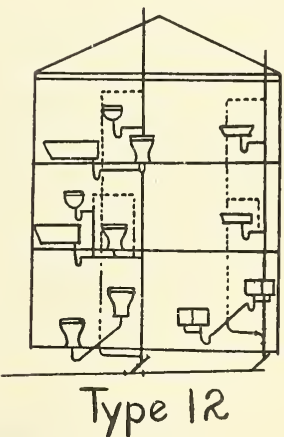

Type 12

FIG. 92.-T ypes of two-story two-family houses showing required venting

partitions. The saving may be small in the single small dwelling, but in the aggregate the saving in material and labor in these particulars will be very great. 


\section{CHAPTER 7.-STANDARDIZATION OF PLUMBING MATERIALS}

The standardization of the various materials used in plumbing and the elimination of many articles and devices infrequently used should reduce the cost of plumbing. Even if standardization be confined to dimensions and roughing-in measurements much may be accomplished; but matters of this sort do not directly affect the public health. Standardization must be brought about by agreement between all the parties interested. Standardization is for the public benefit, irrespective of the police power.

While admitting that there are some real, though minor, disadvantages in standardization, yet, if not carried to unreasonable lengths, standardization should be a benefit to manufacturer, distributor, sanitary engineer, architect, plumber, municipal authority, and owner. It should, in the long run, reduce production costs; lessen the stock required to be transported, stored, and sold, thus saving overhead expenses, and increasing the turnover of stock; lessen the time required to make plans and estimates of plumbing work; facilitate installation and repairs; reduce the original cost of installation and the cost of maintenance and depreciation. The Department of Commerce is already making excellent progress in bringing about simplification of practice in various lines of business, and it is the opinion of the committee that this work may be profitably extended to the plumbing industry.

The basis of standardization must be the "Standard Plumbing Rules," or the plumbing code, as it is commonly called. While the Federal Government can not dominate the States in the exercise of police power it can give advice and it can set up model laws, the acceptance of which by States and cities will result in effective uniformity.

It seems certain that the standardization of fixture dimensions would result in material economies. The only way that this standardization can be brought about is by the concerted action of manufacturers, distributors, sanitary engineers, plumbers, and governmental authorities.

The committee took steps to ascertain what had already been done in this matter. If found that many efforts have been made by various associations connected with the plumbing industry, and that, in general, there is now a strong desire on the part of manufacturers of plumbing supplies, plumbers, and others to have stand- 
ardization brought about in some way. Some, however, are indifferent nd a few are opposed.

The plumbing industry is highly differentiated. There are many kinds and qualities of materials used in plumbing - cast-iron pipe, steel and wrought-iron screw pipe, vitrified-clay pipe, brass pipe and fittings; porcelain ware, enameled iron ware, wooden ware, etc. Minor matters of standardization affect a single branch of the industry, and much has already been accomplished by associations representing the several industries. But there are items of standardization which affect more than one branch of industry; hence, there is need for a broader cooperation than has existed thus far. If there were no variance in plumbing rules, it would be a relatively easy matter for the different associations representing the industries to get together and adopt standards, but in the face of rules which vary widely in different parts of the country it is well-nigh impossible for the parties interested to agree.

It seems evident to the committee that no satisfactory standardization or simplification can be effected unless the parties to the agreement include not only manufacturers, but State and municipal authorities, architects, engineers, house builders, master plumbers, journeymen, and others. Time did not permit the committee to undertake such an extended program, but it is hoped that the Department of Commerce will arrange to have the necessary conferences held in order that simplification in plumbing practice may be established.

It is suggested that those interested in standardization might well take advantage of the facilities extended by the United States Department of Commerce for furtherance of such activities. There has been organized in this department a division of simplified practice, which offers its services to the various industries in bringing together those interested in standardization programs, in making the necessary arrangements for cooperation of the various groups, and in following up the projects agreed upon. Similar measures have been carried out by other industries through aid of the division of simplified practice with marked success, and it is felt that the plumbing industry should also avail itself of the opportunity. 


\section{CHAPTER 8.-ADMINISTRATION}

The committee has considered the subject of plumbing administration and has studied the various laws by which plumbing regulations are now being put in force. The subject is so complex, affects so many different interests and classes of people, involves so many legal matters which differ in different parts of the country and in communities differently constituted that the committee has felt itself incompetent to make definite recommendations. It presents the following ideas as a basis of possible further investigation:

\section{THE PLUMBING BUSINESS}

Plumbing developed first as a craft. The early simple plumbing codes were based on the idea of protecting health by assuring good craftsmanship and were sufficient. Present conditions are different; plumbing is more elaborate; factory-made plumbing supplies have replaced those made in the shop and on the job; the business element has increased; cities have increased in size and changed in character; the relations between owner and plumber, between employer and employed, between buyer and seller, are less personal and more artificial than formerly; plumbing is still highly technical; knowledge of plumbing design is even more important than in former days; good workmanship is still necessary.

To-day the so-called "master plumber" may be both a business man and a craftsman. As a business man he is related to the jobber and the manufacturer from whom he obtains supplies; as a craftsman he is related to the journeymen and apprentices whom he employs. Competition is keen. Journeymen are continually rising into competition with the master plumbers. In so far as they are qualified this is desirable, but the incompetent journeymen are often those most eager to force themselves into the plumbing business. Without a shop, without capital, without business responsibility, men ill-fitted by experience are undertaking to do plumbing workbuying their supplies and installing them in such a way as to pass inspection with the least margin. It is largely because of this situation that present-day plumbing regulations need to be more detailed than formerly. The people do not understand this situation and naturally look with disfavor on rules and regulations which seem to them to have only one purpose - that of making plumbing more expensive. This element of the problem needs to be more thoroughly studied. 


\section{ENFORCEMENT OF PLUMBING REGULATIONS}

The enforcement of plumbing regulations affects three classes of people: (a) The owner and his agents, $(b)$ the plumber, and $(c)$ the public official. The relations between these parties should be clearly and definitely set forth in the laws and ordinances. Without attempting to formulate these in legal terms the committee is of the opinion that the following items should be considered:

\section{THE OWNER AND HIS AGENTS}

1. The owner, or his agents-that is, architect, engineer, contractor and subcontractor, foreman, and employee-should be prohibited from installing plumbing contrary to regulations, but the owner should not be prevented from personally installing plumbing in accordance with the code, provided this is done subject to permit and inspection. Consideration should also be given to a plan for having the owner file a bond at the time of taking out a permit.

2. Owner or agent (person, firm, or corporation) should be required to have permit issued after (a) filing of application, with plan and specification; (b) approval of plan and specification before signing of contract; and $(c)$ payment of fee.

3. Owner or agent (person, firm, or corporation) should be entitled to receive a certificate of approval of the plumbing work done after (a) receipt of permit; (b) application for inspection; and (c) approval by inspector.

4. Penalties should be provided for: (a) Failure to take out permit; (b) failure to apply for inspection; and (c) noncompliance with regulations and should result in refusal to issue certificate of approval or in a fine in case plumbing is used without certificate of approval.

\section{THE PLUMBER}

1. The status of the plumber (master plumber, contracting plumber, or employing plumber-all agents of the owner) should be provided for by registration in one of the following three ways: (a) By certificate of competency; $(b)$ by license; and $(c)$ by bond.

2. Plumber should be prohibited from installing plumbing contrary to the regulations or without a permit for the work.

3. As agent of the owner, he should (a) file application for permit, with plans and specifications; $(b)$ pay fee; $(c)$ receive permit; $(d)$ install work in accordance with regulations; $(e)$ apply for inspection and test; and $(f)$ deliver certificate of approval to owner.

4. Penalty for failure to comply with the law should be $(a)$ loss of certificate of competency or license or forfeiture of bond, and $(b)$ fine.

\section{PROPER ADMINISTRATIVE AUTHORITY}

1. Jurisdiction in the enforcement of plumbing regulations should be committed to the board of health, building department, or other municipal department. 
2. Under this jurisdiction a department or division of plumbing should be organized to enforce the regulations, the official in charge being called the plumbing inspector.

3. Duties of the plumbing inspector should be definitely assigned. They should include such matters as $(a)$ examination of application for plumbing, examination and approval of plans and specifications issuance of permits and collection of fees; $(b)$ inspection of plumbing and conduct of tests; $(c)$ issuance of certificates of approval; $(d)$ arrest and prosecution of offenders; $(e)$ office records and reports; and $(f)$ advisory service to the public in the matter of plumbing regulations.

4. Qualifications and status of plumbing inspector should include such matters as $(a)$ competency in plumbing; $(b)$ nonengagement in the plumbing business or in the manufacture or sale of plumbing supplies; $(c)$ bond; $(d)$ compensation; and $(e)$ authority to enter buildings.

5. A schedule of fees should be established, the total of which should approximately pay for the enforcement service, the individual fees being graded according to the magnitude of the work.

6. Provisions should be made for enforcing the penalties upon each of the three clauses of persons referred to.

7. The penalties for failure of plumbing inspector to perform his duties should be loss of position, fine, or other appropriate penalty.

8. Limitation of discretionary power should be provided.

\section{STATE PLUMBING LAWS}

While the methods for the local enforcement of plumbing regulations may be readily standardized and are, in fact, quite uniform at the present time, the present State laws in regard to plumbing vary greatly. The committee is of the opinion that the following provisions should be included in the statutes:

1. All plumbing throughout the State should conform to the basic plumbing principles set forth in chapter 3 . These state results, not methods. They should be written into the statutes.

2. The State board (or department) of health should adopt a plumbing code in conformity with the basic plumbing principles and revise the same when necessary.

3. Every city, town, or other subdivision of a State having a public water supply should be required to have a plumbing code and should either accept the State code or adopt a code of its own, subject to approval by the State board (or department) of health. In places where there is no public water supply the acceptance or adoption of the code should be permissive.

4. In places where no code is accepted or adopted the basic plumbing principles of the statutes should be enforced by State, county, 
or local boards of health. If enforced by the State, the authority should be vested in the division of sanitary engineering of the State department of health.

5. Owners or plumbers doing plumbing work within the State should be responsible for its compliance with the basic plumbing principles.

\section{LICENSES $v$. CERTIFICATES OF COMPETENCY}

The license is a crude governmental device for assuring the public that plumbing work will be done satisfactorily and in accordance with legal regulations. It was originally intended to guarantee craftsmanship and knowledge of the regulations. It can do no more, and it does not always do that. It does not always stimulate a plumber to improve his knowledge after his license has been secured. It was not intended and, indeed, can not assure business competency or reliability, and to-day the business side of plumbing is important. The distinction between journeymen's license and master plumbers' license is vague and differs in quantity rather than in kind.

Furthermore, the license, which debars the competent nonlicensed man from doing plumbing work, is not for the interest of the country, for desirable individual competition is prevented.

The committee is of the opinion that the time has come for a thorough study of the license system, with the idea of possibly substituting for it a system of certificates of competency-a system that would tend to improve the status of the plumber by causing him to be stimulated by competition both in business and craftsmanship, and that would give greater protection to the public against faulty plumbing. Under a system of certificates of competency the owner would desire to choose a certified plumber, whereas under the license system he would be compelled to choose a licensed plumber.

What is needed is some plan to give the public confidence in the persons who are engaged in the plumbing business. If plumbers will actively take up the problem of raising their own status on the basis of competency, a great deal can be accomplished in establishing the confidence of the public in the plumbing industry.

The committee wishes to place on record its appreciation of what the plumbing industry has done to improve the living conditions in American homes. People generally do not appreciate the extent to which house plumbing has improved the public health. The influence has often been indirect rather than direct, and for that reason it has not always been easy to recognize. Public water supplies would lose much of their value were it not for the opportunity to use water at convenient fixtures. The disposal of fecal matter, the greatest sanitary problem in the world, is best solved by the introduction of the modern water-closet.

$94877^{\circ}-24-14$ 


\section{CHAPTER 9.-EXPLANATORY NOTES AND COMMENTS}

In further explanation of various matters discussed in the report, and in answer to questions which were raised by those who submitted comments on the tentative report, the committee has prepared the following series of notes.

\section{NOTE 1. DATA OBTAINED BY QUESTIONNAIRE}

The tentative report included a compilation of data relating to plumbing regulations in different cities and States and a statistical analysis of various items found in 81 plumbing codes. The data were secured as a result of a questionnaire sent out before the committee began its work. Many correspondents criticized these data because of their incompleteness and their nonrepresentative character. The committee, therefore, decided not to publish these statistics with its final report. Only one conclusion could be drawn from the facts collected, namely, that the present situation with reference to plumbing laws and codes is nothing less than chaotic.

\section{NOTE 2. PURITY OF WATER SUPPLY}

If the water supply is from a public source, the individual householder has no responsibility except as a citizen. If the supply is from a local source, such as a well, the responsibility rests upon nim to provide pure water, and the health department may exercise control, under the police power, if the supply is not safe. The plumber, by using proper methods of sewage disposal, thereby preventing the pollution of the soil, can do much to safeguard local water supplies. There is no reason why rural dwellers should not enjoy safe and comfortable living conditions more nearly like those of the city dweller than is now the case.

Some of the committee's correspondents have called attention to the possibilities of injury to health through the use of lead watersupply pipes or of lead joint compounds for the installation of pipes. In this connection the nature of the local water supply should be given careful consideration. The subject of corrosion, including the use of lead, is discussed at length in Appendix B.

\section{NOTE 3. DUAL SOURCES OF WATER SUPPLY}

It sometimes happens that there are two or more supplies of water-a pure water for drinking and an impure or unsafe water for flushing. This creates a dangerous condition, as an unsafe water, if 
available, is liable to be used through ignorance or by mistake. Cross connections between pure and impure systems under such circumstances are always hazardous and should not be permitted except under special conditions. Preferably all water supplied to buildings should be pure.

\section{NOTE 4. ADEQUACY OF WATER SUPPLY}

If the water supply in a building is not adequate, the fixtures will become foul, insanitary, and dangerous to health. The problem of insuring an adequate water supply for each building is not a simple one. There are three major factors which affect the supply of water available at fixtures, namely, the pressure in the mains, the size and length of supply pipe, together with the number of changes in its course, and the number of fixtures which probably will be operated simultaneously. There is much evidence that the rule-of-thumb methods so often used by builders and plumbers have not resulted satisfactorily.

The combination of small pipes and large faucets should be avoided. Pipes of corrodible material, such as steel or wrought iron, should be large enough to allow for the effects of interior rusting, especially in localities where the water is known to be corrosive. Small-sized pipes and interior corrosion reduce the water pressure available at faucets, and householders frequently complain of low pressure in the mains when the trouble is really with their own plumbing systems. The custom in some places of using service pipes as small as one-half inch in diameter does not admit of adequate service to several fixtures simultaneously. Use of the garden hose, for example, or the operation of a flush valve may, for the time being, absorb all or nearly all the supply of a building, and lack of adequate flushing water may set up insanitary conditions in water-closets. The tendency of the day is to use larger service pipes than formerly.

In some places water-supply pressures are too great, resulting in water waste and in unnecessary wear of valve seats with resulting continuous leakage. It is possible, however, to use pressure-reducing valves.

Attention is called to the fact that flush valves if used without supply tanks make greater demand on the system than do tank closets because they use water at a higher rate. Where flush valves are used without a tank the supply pipes in the building, and even the service pipe in the street, should be of larger size than where tank closets are used. It is possible, however, to use supply tanks in connection with flush valves. The problem is one of balancing the cost of larger pipes with the cost of a supply tank. 


\section{NOTE 5. PRESSURE RELIEF FOR WATER-HEATING APPARATUS}

Serious results from the explosion of hot-water heaters or boilers are frequently reported and are found due in almost every case to stoppage of the hot-water pipes, overheating, or the lack of provision for pressure relief. Overheating of the copper used for boilers reduces its strength. Boilers should be provided with relief valves or with one or more relief faucets which will automatically open under high pressure. Under some circumstances hot water may be forced back into the cold-water supply pipe and service pipe, and, if there is a meter on the system, moving parts made of hard rubber will be damaged thereby. To protect meters, check valves are sometimes placed on the supply line inside the meter, but this only increases the danger of boiler explosion. When these check valves are used the need for adequate relief valves becomes all the greater.

\section{NOTE 6. DESIRABILITY OF SEWER CONNECTIONS}

Privies, cesspools, and other means for the disposal of fecal matter are so frequently the cause of insanitary conditions that they should not be permitted to exist where public sewers are available. The advisability of sewer connections wherever possible and the need of a separate house sewer for each building have been strongly emphasized by the committee's correspondents.

\section{NOTE 7. PROVISION OF WATER-CLOSETS}

The reason for specifically requiring at least one water-closet for each family is that if one closet is used by more than one family lack of responsibility for its upkeep leads to uncleanliness and indecency. The question has been raised by correspondents whether this provision should not be included in a housing code rather than as a part of the plumbing regulations. While from one point of view this may be logical, yet for administrative purposes better results will be secured by making it a plumbing requirement.

\section{NOTE 8. FIXTURE DESIGN}

From a health point of view it is essential that plumbing fixtures shall be of smooth, nonabsorbent material, as free as practicable from concealed fouling surfaces, and set free of inclosures. They should be suitably designed for their respective uses and for convenience in cleaning. This will help greatly to avoid dirt accumulation and continual dampness, will prevent growth of insects and fungi, and minimize odors due to existence of insanitary conditions.

A number of the committee's correspondents have called attention to the insanitary possibilities of the device known as the "standing waste and overflow." This device is now made so that it is devoid of its former objectionable features. 
Many plumbing fixtures now on the market exhibit inconsistencies that do not seem to be justified. The clear area of opening in strainers, plugs, fixture couplings, tailpieces, and traps is not such as to insure equivalent flow at these points for any individual fixture. At present the relations of these elements of fixture design appear to be illogical and open to improvement. The plumbing regulations of many cities prescribe the size of traps required for different kinds of fixtures without prescribing the sizes of fixture outlets or prohibiting constrictions between the trap and fixture. Some distinction should be made between fixtures which drain rapidly and those which drain slowly.

The rules for plumbing in many cities fix the sizes of drainage and vent pipes required for the service of different kinds and numbers of fixtures but do not prescribe the maximum permissible rate of flow or discharge from the fixtures, the only controlling feature fixed by the rules being the size of the trap or waste. The discharge through them may vary greatly with different types, design, and method of installation.

There are believed to be possibilities of economy in use of water by a more efficient design of water-closets. These have been designed almost entirely from the manufacturers' point of view, with the object of insuring successful operation but with small regard for the amount of water used. Users also have, in general, disregarded this consideration. Through a mistaken idea that large quantities of water are necessary to clean the bowl thoroughly and operate the system effectively, some codes have required fixtures to be designed for comparatively large quantities of water. The fact should not be lost sight of, however, that water is needed to transport solids to the sewer as well as to flush closets.

The provision of an adequate water supply is in many cases difficult and in all cases a serious item of municipal expense and deserves attention. The committee is of the opinion that by improvement of water-closet design the quantity of water necessary for satisfactory operation of such fixtures may be materially reduced. It is recommended that as a matter of national economy a thorough investigation of these possibilities be undertaken by the manuiacturers of water-closets.

Owing to the lack of time, the committee has not made a thorough study of fixtures, but finds that many are not well designed. A special study of fixture design could well be made by manufacturers in order to determine the practical elements best adapted to secure sanitary and efficient fixtures of moderate cost. 


\section{NOTE 9. VELOCITY OF WASTE WATER IN DRAINAGE SYSTEMS}

The dangers of clogging are serious, and a well-designed house drainage system should remove from the building as quickly as possible the waste water and all the materials it conveys without unnecessary fouling of the pipes and appliances. The fouling of pipes may be caused by the adhesion of greasy and sticky materials to the walls of the pipes, or by the deposit of material carried in suspension in the waste water, or by both of these causes. The results of fouling are a decrease in the carrying capacities of the pipes, stoppages either partial or complete in drainage and vent pipes, which may impair the service or stop it altogether, the production of deleterious and corrosive gases through the decomposition of organic matter, the development of bacterial and fungus growths on the organic matter in the pipes, and the production of noxious odors. A well-designed system of house drainage should aim to reduce these ill effects to a minimum, but they can not be completely eliminated. Furthermore, a slight coating on the interior of the pipes sometimes offers some protection against corrosion.

It is realized that the subject is charged with variable and conflicting elements. If the pipes are of a size to scour under the discharge of a single fixture, they may be too small for proper service under simultaneous discharge from several fixtures. If designed for several coincident discharges, they may not scour under the discharge from a single fixture, and scour will occur only periodically when favorable coincident discharges take place. If the waste pipes run full, the aspirating and self-siphonage effect on fixture traps will be increased, and venting protective for partial flow will be inadequate for full flow.

It is possible in this connection that more efficient fixture design elsewhere suggested may render feasible reduction in size of branch drain and vent pipes now generally specified without reducing their convenient and useful service or increasing the danger of stoppage.

\section{NOTE 10. USEFUL LIFE OF SYSTEM}

Leakage is, perhaps, the greatest danger to be guarded against. This is influenced by the kind and strength of materials, the nature of joints, the method of attaching the pipes to the building, the depth of pipes in the soil, air circulation and diffusion, methods of passing pipes through building walls or foundations, etc.

In view of the stress placed upon plumbing design and construction as a matter affecting health, the committee thinks that it is only logical to insure, so far as possible, the permanence of the protection thus secured, and that such materials and workmanship should at all times be required as will produce a plumbing system as nearly as possible equal in life to that of the structure inclosing it. This is 
specially important in the case of pipes placed in walls or otherwise not readily accessible for inspection or repair.

Aside from care in construction there are other factors affecting the useful life of plumbing systems. Inadequate foundations and unskillful framing of buildings sometimes cause settlement with resulting structural failures in plumbing systems which no precautions as to design, materials, or workmanship would prevent. Ignorance and carelessness as to the proper use of plumbing are often responsible for corrosion or clogging of pipes and improper use of fixtures.

\section{NOTE 11. LIMITATIONS TO THE USE OF CLEAN OUTS}

Clean outs on plumbing systems are important and useful for three purposes - to remove any stoppage of the pipes, to provide means for testing the separate parts of a drainage system by the use of water or air, and to make it possible to give the system a final air-pressure test after the fixtures have been installed. Clean outs should be accessible and so made that the ordinary householder can open and replace them. They should be as few in number as is consistent with these requirements. Because of the danger that clean-out caps will be removed and not replaced some cities have discouraged and even prohibited their use. The committee does not approve this prohibition.

\section{NOTE 12. TRAPPING OF FIXTURES}

The effectiveness of traps in preventing access of vermin to drains and the escape of sewer air into rooms is partially sacrificed when more than one fixture is connected to the same trap. There is generally a greater length of untrapped waste pipe exposed, and dirty water is liable to flow from one fixture to another. Laundry trays or a sink and tray can safely be thus connected, but greater satisfaction will be obtained if each fixture is separately trapped.

\section{NOTE 13. GREASE-TRAP REQUIREMENTS}

Some cities require grease traps to be installed on kitchen sinks in residences as well as in hotel and restaurant kitchens. While they undoubtedly are desirable for these larger installations, the committee thinks that in private residences the danger of neglect offsets their beneficial qualities and recommends that they be omitted, except where sewage is disposed of in small septic tanks or under private auspices.

The operation of septic tanks, such as are commonly used with rural homes, is seriously hindered by the presence of grease in quantity, and wherever possible in such cases the kitchen wastes should be disposed of separately from fecal matter. 
The clogging of waste pipes with grease, hair, lint, or other matter is generally due to improper sizes of piping and faulty construction rather than carelessness of the housewife. The committee contends that a plumbing system properly designed with pipes, fittings, and connections that form a smooth interior waterway which gives opportunity to carry off any solids or semisolids in suspension can not and will not become clogged under ordinary usage. Wherever a small horizontal waste pipe discharges into a pipe of considerably larger area, which makes it impossible to secure the proper scouring action, there is a likelihood of stoppage. The quick change in temperature and the greater area of the pipe forms a natural grease receptacle. The use of caustic soda or soda lye in drains should be discouraged, as it makes a hard soap and may increase the clogging. There are several instances on record where workmen have been burned and blinded due to ignorance and criminal carelessness in the use of this substance. Potash or potash lye is sometimes used advantageously prior to flushing with hot water as it makes a soft soap which will not clog the pipes. Properly sized waste pipes will minimize stoppages and the necessity of the use of any foreign materials.

\section{NOTE 14. AIR CIRCULATION IN PLUMBING}

Fixture drains should be designed so as to prevent self-siphonage of traps. Ventilation of drainage systems tends to prevent the growth of the fungi which produce "slime" and to retard corrosion by the evaporation of moisture.

Chief reliance for ventilation of the drainage system and for relief of pressure changes set up by fixture discharge is placed upon a free course of air from street sewer to roof terminal. Effects of frost closure as determined by experiments apparently are so slight as to be negligible if a clear opening is left at the top of the stack equal in area to a circle $1 \frac{1}{2}$ inches in diameter. A diameter of 4 inches at the roof line has been found adequate under most conditions, but in some parts of the United States and in Canada severe climatic conditions require increasers 2 inches wider than the pipe diameter below the roof. Extension of such pipes above the elevation of possible snowdrifts has been found unnecessary, as the escaping air "honeycombs" the snow sufficiently to prevent obstruction. It also has been found that vent pipes which extend but a few inches above the roof are less subject to frost closure than longer lengths. This, however, sometimes increases the effect of wind pressure on the trap seals.

\section{NOTE 15. SIMULTANEOUS DISCHARGES}

The committee's assumptions as to proportion of fixtures likely to be discharged simultaneously were presented in the tentative report and were received without criticism. One or two reviewers pointed 
out that these assumptions erred on the side of safety, if at all. As elsewhere stated, much thought was given to this subject and a valuable body of data and computations has been accumulated, bearing on similar questions in large buildings.

\section{NOTE 16. ADMISSION OF DESTRUCTIVE SUBSTANCES}

Substances such as gasoline and oil from garages, acids, steam, grease in large quantities, liquids containing silt, hairs, fibers, etc., ought not to be admitted to plumbing systems or to sewers. While the abuse of plumbing systems can not, of course, always be prevented, connections plainly intended for the admission of such substances can be forbidden.

\section{NOTE 17. LIGHTING AND VENTILATION OF WATER-CLOSET COM- PARTMENTS}

The requirement that water-closet compartments be well lighted and ventilated to the outer air, as submitted in the tentative report, was somewhat severely criticized. The committee thinks, however, that for the type of building under consideration - namely, the small dwelling house- the requirement involves no hardship to the owner.

It is the general observation, furthermore, that direct lighting and ventilation tend to prevent carelessness in the use and maintenance of fixtures in cases where living standards are not of the highest. If the compartments are dark, the fixtures are likely to become soiled from neglect. Ventilation is important in order to prevent odors and to dilute any air accidentally escaping through the fixtures.

The provision of a window opening directly to the outer air is apt to be omitted only in the case of speculative builders selling or renting a cheap type of house, and under such circumstances the improved sanitary conditions resulting from direct lighting and ventilation are well worth while.

\section{NOTE 18. SEWAGE DISPOSAL}

Precautions should be taken to prevent the possible pollution of wells or other sources of water supply and the escape of sewage on the surface of the ground. Local soil conditions are an important factor, and so many conditions may exist that an inspection of each situation is necessary. Requirements must vary according to soil and climate. The committee has not felt called upon to discuss the subject of local sewage disposal in detail, especially as the matter is now being considered by the board of excreta disposal of the United States Public Health Service. The methods adopted must vary according to local conditions. Many State departments of health, the United States Public Health Service, and the United States Department of Agriculture have issued bulletins giving information on this subject. 


\section{NOTE 19. OMISSION OF THE MAIN HOUSE TRAP}

The committee finds that this trap and the fresh-air inlet are in most cases a needless expense. Experimerts under the committee's supervision have shown that the house trap interferes with the flow of sewage and air movements in the house drain. It increases the possibility of trouble from back pressure in the soil stack. Its omission gives opportunity of inoffensively ventilating the street sewers through a multiplicity of outlets. Where the sewage is discharged into a septic tank, a trap and a foot vent on the house side of it is thought by some to be desirable in order to prevent the escape of the tank air and to maintain a circulation of air in the house system, but with the septic tank properly designed it is not necessary.

The recommendation in the tentative report that installation of the main or house trap and fresh-air inlet be discontinued aroused much discussion. Of the respondents who discussed this matter in particular the greatest number favor the omission of the house trap, a few would retain it, and a few seem to think that its advantages and disadvantages are about equal. The committee's reasons for advocating its omission have already been given. The chief arguments of those who would retain it are as follows:

It is argued that fixture traps and floor-drain traps do occasionally siphon in spite of all precautions and that leaks in the pipe system occur because of structural failures and settlements, thermal expansion, and poor workmanship. In such cases the house trap affords an additional barrier against admission of sewer air, insects, etc. To this it may be said that conditions within the house system give rise to emanations fully as objectionable as those from the sewer.

It has been shown conclusively that in very cold climates the increased circulation of air through the house system results in closing roof vents completely with hoar frost, and the use of house traps has been found absolutely necessary.

It is argued that in cities where house traps are now generally in use the installation of systems not thus equipped exposes occupants of neighboring buildings to concentrated fumes from sewer systems otherwise unvented. This may, under certain circumstances, justify the requirement of a house trap, but where a reasonable distance intervenes between roof vent and neighboring windows the committee thinks that use of the house trap should be optional.

Careful observations made in England have disclosed that sewer systems are, in general, much more thoroughly ventilated through manhole leakage, etc., than is popularly supposed, and that the presence or omission of house traps has at most a minor influence on the atmospheric conditions in sewers. In this connection it should also be remembered that the fresh air inlet, as an indispensable adjunct 
to the house trap, may be a very real nuisance to those in its neighborhood.

It is argued that the main house trap prevents incursions of rats from the main sewer system. Observations both in this country and in England show that rats can pass readily through large house traps, and the usefulness of the traps in this respect, therefore, is questionable. The best protection against rats is the small fixture trap, and since soil pipes are no longer customarily made of lead the danger of rats passing from sewers to the house system is not as important as formerly.

\section{NOTE 20. PLUMBING AS RELATED TO BUILDING DESIGN}

The practice of fixing the location of plumbing fixtures on the floor plans without taking into consideration the importance of supply and drainage pipe construction very often results in poor, undesirable, and costly installation. Whether in walls or partitions or beneath floors, sufficient piping space must be provided to eliminate complicated and undesirable construction and the use of unnecessary nittings, which add to the cost of labor and material without increasing the efficiency of the system.

In designing the plumbing and drainage system architects and engineers should bear in mind that adequate piping space must be provided in order that the system may be installed in an efficient and economical manner.

Type of building construction, fixtures to be served, and location of supply and waste pipes are equally important and can not be divorced. It must be remembered always that the highest type of plumbing fixtures will not function properly without efficient water supply and drainage.

\section{NOTE 21. THREE-INCH SOIL STACKS}

The use of the 3 -inch soil stack, tentatively recommended in the committee's first report, was very thoroughly discussed in the letters received regarding that report. Nearly all respondents expressed unqualified approval of 3-inch stacks for small dwellings, most of these reporting satisfactory experience with such systems in practice. A few opposed the use of 3-inch stacks on the grounds that they are more likely to clog and that pressure disturbances are more serious, but only two of these mention actual observation of the 3-inch systems in use. Several raised the question as to whether lack of ventilation and increased back pressure would occur with the smaller pipe. In answer to these doubts it may be stated that experiments and computations have shown that the 3 -inch stack is less subject to undesirable pneumatic conditions than the 4 -inch stack, for the reason that 
the quantity of air moved in a 3-inch is less than in a 4-inch stack. There is less ventilation of the street-sewer system through the 3 -inch soil stack, but this is a minor consideration in view of other advantages.

\section{NOTE 22. VITRIFIED CLAY PIPE}

The committee decided that the use of vitrified clay pipe should be prohibited for house drains - that is, for use inside of dwellingson the basis of history, experience, and weight of authority. The committee favors the idea of having arrangements made for a thorough study of its safety and fitness for use in house drains.

\section{NOTE 23. SIZES OF DISTRIBUTION PIPE}

The proper sizes for the water pipes leading to the various fixtures depend upon several factors, such as the material of the pipe, the water pressure, the length of the pipe, the size of the faucet, and the rate at which water needs to be used. The figures given in the recommended code as minimum sizes will ordinarily be sufficient in dwelling houses where the service pressure is as high as 35 pounds per square inch and when the pipes are unobstructed with rust. They are safe for use where brass pipe is used or for wrought iron or steel pipe where the water is hard or noncorrosive. If the water is corrosive, wrought iron or steel pipes, even though galvanized, are liable to rust and clog, so that their carrying capacity is diminished. The rate at which rusting occurs depends upon the character of the pipe, the corrosiveness of the water, the oxygen in the water, the temperature, the quantity and velocity of water flowing through the pipe, etc. Pipes carrying water which has been softened by the use of lime often become incrusted, and some allowance needs to be made for this factor.

The loss in capacity of iron or steel pipe through rusting is an important consideration. Actual data are difficult to obtain hence experiments on this subject would be useful. The following figures show the approximate relative equivalents of pipe suitable for use under different conditions, but not all of the sizes given are commercially obtainable.

Nominal sizes

\begin{tabular}{|c|c|c|c|}
\hline \multirow{2}{*}{$\begin{array}{l}\text { Brass or lead } \\
\text { pipe, any } \\
\text { water }\end{array}$} & \multicolumn{3}{|c|}{ Wrought-iron or steel pipe } \\
\hline & Hard water & Soft water & $\begin{array}{c}\text { Corrosive water } \\
\text { or softened } \\
\text { water }\end{array}$ \\
\hline 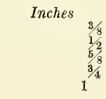 & $\begin{aligned} & \text { Inches } \\
& 3 / 8 \\
& 1 / 2 \\
& 5 / 8 \\
& 3 / 4 \\
& 1\end{aligned}$ & Inches $\begin{aligned} & \\
& 1 / 2 \\
& 5 / 8 \\
& 3 / 4 \\
& 11 \\
& 11 / 4\end{aligned}$ & $\begin{array}{l}\text { Inches } \\
\qquad \begin{array}{r}5 / 8 \\
3 / 4 \\
1 \\
11 / 4 \\
11 / 2\end{array}\end{array}$ \\
\hline
\end{tabular}




\section{NOTE 24. CAST-IRON PIPE}

The committee has had no opportunity to investigate the quality and weight of plumbing materials, and its recommendations are conventional, following the best average practice of the present time. In the case of cast-iron pipe referred to in section 29 of Article III, reference is made to the American Society for Testing Materials Standard Specifications for Cast-Iron Soil Pipe and Fittings. These specifications call for the so-called extra heavy pipe, the dimensions of which are based on a wall thickness of one-fourth inch, whereas so-called standard pipe is based on a thickness of only one-eighth inch. The committee is of the opinion that extra heavy pipe is unnecessarily heavy, but that standard pipe is too light for the great majority of plumbing uses. The tonnage of iron which is used in soil pipe is great enough to warrant a thorough scientific study of the whole subject in the interest of the best engineering practice and the conservation of natural resources. The committee favors the idea that the manufacturers of soil pipe, in cooperation with the American Society for Testing Materials, should investigate the question of reducing the wall thickness of cast-iron soil pipe to some thickness between one-eighth and one-fourth inch, and if such reduction is found desirable and practicable, to standardize the same and allow cast-iron pipe of the new dimensions to take the place of the extra heavy and standard pipe now in common use. A thickness of threesixteenth inch for straight pipe has been suggested, but the committee is of the opinion that the actual dimensions of both pipe and fittings should be based on tests of strength and quality of metal and other involved factors and should not be the result of compromise or offhand opinion. The committee recommends also that manufacturers of cast-iron pipe make and list sizes smaller than are commonly sold to-day, namely, $1 \frac{1}{2}$ and $1 \frac{1}{4}$ inch in diameter.

\section{NOTE 25. SIMPLIFICATION AND COST REDUCTION}

The chief objectof the simplifications and modifications of plumbing rules recommended by the committee has been to secure to the owner of a dwelling a better and more durable plumbing system and to accomplish this, if possible, at a lessened first cost. It is believed that if the recommended rules are generally applied both of these objects will be secured, and that both of them will be of financial value to the building owner. It would be interesting, if it were possible, to express these benefits in dollars and cents, but because of the widely varying plumbing regulations in different parts of the country, because of different unit prices of materials, different freight costs and labor costs, any attempted comparison would be far from accurate and would have only an illustrative value. In spite 
of this fact, it seemed desirable to attempt a comparison to show the effect of simplification on the first cost of plumbing.

Estimates were made of the probable number of dwellings likely to be built during the next 10 years in order to replace old buildings, to make up for the lack of building during the war, and provide for the increasing population.

The computations were interesting and suggestive. In many localities the first cost of plumbing will be materially reduced if the recommended code is adopted in place of those now in force. In localities without plumbing codes the quality of plumbing will be improved at a slightly increased cost. On the whole, the adoption of the committee's recommendation should save to the people who build dwelling houses very large sums of money, the figures probably amounting to several million dollars per annum. Furthermore, these savings in first cost do not tell the whole story. Lessened bills for maintenance and repairs and lower depreciation of the plumbing systems are important matters to the householder, but there are no data upon which to estimate them even approximately.

In this matter of cost the committee wishes to emphasize the fact that good designing in plumbing will do as much, and, perhaps, more, to save money to the house owner than simplified regulations. Plumbing systems should be made safe and permanent regardless of legal requirements. The competent plumber can save money for the owner by advising him in the choice of fixtures and by laying out the work carefully with full knowledge of the regulations. The architect can save money by arranging rooms in which plumbing fixtures are placed in such a way that fixtures are located near the stacks and that the number of stacks is reduced to a minimum. In order to have simple plumbing, the buildings themselves must be simple.

The committee believes that uniformity in plumbing regulations will tend to promote economy, as it will facilitate design, reduce "overhead" costs of plumber and architect, and lay the foundations for standardization and simplified practice, and that the substitution of the "certificate of competency" for the "license" will secure better plumbing and ultimately reduce costs by developing greater competency in those who design and install plumbing. 


\section{PART IV.-APPENDICES}

\section{APPENDIX A.-MINORITY REPORT}

When the tentative report, to which reference has been made, was prepared for distribution, one member of the committee did not approve the stand taken by the rest in regard to the question of venting. His objections were presented in the form of a minority report which was duly presented with the tentative draft of the majority report for general discussion. His report is as follows:

\section{MINORITY REPORT BY WILLIAM J. SPENCER}

JULY 24, 1922.

As a member of the subcommittee on plumbing of the Building Code Committee, I regret to inform you that I find it necessary to express disagreement with the report of the committee only with regard, however, to section 4 of the summary, which reads:

4. Separate venting - that is, an individual vent for each trap-is not necessary. Group venting - that is, providing one vent for the group of fixturesis safe under certain conditions designated in the report. Adequate provision, however, must be made for air circulation.

I disagree with the committee in the first statement: "Separate venting-that is, an individual vent for each fixture-is not necessary." It therefore becomes necessary on my part to file a minority report in connection with this matter.

As a journeyman plumber, with an experience upward of 35 years, I feel free to say that I possess practical knowledge as to the utility and necessity for direct or separate venting. My experience has been such as to warrant an unshaken conviction in the popular practice of modern high-grade plumbing for the employment of direct or separate vent as a preventative against siphonic action.

It is freely admitted in the majority report that the official tests conclusively proved up the generally accepted theory on siphonagethat is to say, in a battery of fixtures the discharge of one was shown to siphon the trap of another-and as a corrective, ventilation is recommended.

It is further admitted that the tests were conducted with clear water discharging through a clear system, and that resulted siphonage might be intensified after constant household use, yet this actual condition was given no consideration evidently in the expressed opinion that direct or individual venting is not necessary.

The experimental tests conducted by the committee were abnormal in the sense that the bore of the traps and waste lines were perfectly clear and, therefore, free of the fouling matter as found in the system subjected to use by occupants of the property, which naturally reduces the bore of the trap and waste line, yet the tests proved, under certain conditions, that without vent a fixture filled to capacity when discharged produced siphonic action in the trap.

A waste trap is in its final analysis a cesspool intended to arrest the discharge of polluted air from the house drain into the room where the fixture is installed. When the trap has siphoned either through the 
force of the fixture it serves or that of another connected with the system, then it has ceased to function as a measure of protection against the introduction of noxious gases. Under these circumstances it must be plain that we can not afford to take a chance with such a delicate and vital question as the public health, nor are we justified in modifying a condition that has received popular approval for upward of 40 years.

Permit me to draw your attention to the fact that malignant epidemics have been practically eliminated in our country, and we stand preeminently as the most healthful nation on the earth. Sanitation has played its part in not only banishing the terrors of plagues from our country, but from those neighboring States over which we have been privileged to exercise some measure of sanitary authority. For nearly half a century the preponderating opinion of the thousands upon thousands of those having to do with sanitation has favored direct or separate vents as a means of preventing waste-trap siphonage. Therefore, direct vents have been accepted as an integral part of a plumbing system. Those favoring high-grade plumbing have a right to claim equal credit with all others whose efforts have been helpful in producing the sanitary conditions herewith referred to.

Loop venting as a substitute for the direct method is tantamount to an acceptance of the minimum, and minimum rule is sometimes dangerous. As an instance of proof, permit me to draw your attention to a certain theater ${ }^{1}$ in this city that was erected under the minimum rule; that is, established conditions were not observed; cost, perhaps, was reduced by noncompliance with the building code, without regard to the safety of patrons. You will recall that as a result of failure to afford proper protection against accident nearly 100 lives were sacrificed.

This is one of hundreds of cases that might be cited where minimum rule has exacted toll when chance was taken with human life, and yet it is proposed in the majority report that a system of venting be adopted likely to place in jeopardy the life of our entire urban population as against one which has assisted in the elimination of pestilential ravages.

In careful, orderly, well-kept homes loop or group venting may not be considered dangerous, but in these hideous disease does not lurk. All homes, however, are not well kept; indeed, the contrary is the case in many, while in many, many more filth abounds and pestilence finds its origin in filth. For this reason the maximum rule has been invoked in preference to the minimum, with credit to its sponsors.

Believing it to be unnecessary to further discuss my objection to section 4 (mentioned above) contained in the summary of the majority report, I, therefore, feel called upon to submit to you this statement in the form of a minority report and protest to that filed by Chairman George C. Whipple, under date of June 16, 1922, and beg leave to add that in other respects the report of the subcommittee on plumbing meets with my approval.

(Signed)

WM. J. SPENCER.

\section{REPLY TO MINORITY REPORT}

In replying to the minority report the committee wishes to explain that when Mr. Spencer wrote his report the experiments made at the

1 The Knickerbocker Theater in Washington, D. C. 
Bureau of Standards had not been completed and his resignation from the committee prevented him from having advantage of the results subsequently obtained. Inasmuch as the recommendations of the committee given in the tentative report remain practically unchanged in the final report as to the matter upon which he took issue-namely, the necessity of venting every trap separately-and as about half a dozen of those who commented on the tentative report supported the minority report in its contention, the committee thinks that a frank explanation of its position should be made.

The committee holds that every fixture trap should be protected from siphonage and back pressure, and that air circulation be assured by means of a vent pipe. The committee is of the opinion that complete venting of fixture traps is necessary, but that separate venting - that is, an individual vent for every trap - is unnecessary. The minority report held that an individual vent for each trap is necessary. The issue is clear cut.

In everyday practice, and that which has been approved for more than 30 years, 2 sinks, 2 lavatories, 2 bathtubs, or 2 water-closets, which are located on the same floor back to back on opposite sides of partitions, have been served by a common waste and vent pipe. Separate or individual venting of these fixture traps is not necessary. Adequate protection from self-siphonage and back pressure have been afforded and air circulation assured. Again, it has been considered good practice for years to stack-vent top fixture traps. This is sound practice in which complete and adequate venting is provided, but this could not be classed as separate or individual venting.

It is true that most of the experimental tests of the committee were abnormal in the sense that they were clear-water tests, but there was consistency in the size of the fixture opening, the trap and waste pipe in which scouring action was assured, and the probability of fouling being reduced to a minimum. It should also be remembered that stoppages in the waste pipe of a fixture affect only that part of the horizontal vent pipe above the fixture branch and below its water level, and should stoppage occur in the waste or vent pipe it would have the same effect on the separate or individual vent as on the common vent. The probability of a partially clogged branch waste pipe serving a bathtub and a lavatory affecting the water seals of either trap would only occur on the coincident discharge of both fixtures, with the result that the bathtub trap would be subject to siphonage. The length of time required to discharge a lavatory is so much shorter than that required to discharge a bathtub that the possibility of the loss of trap seal in either fixture is almost negligible. The partial stoppage of the horizontal waste pipe between the fixture trap and vent pipe will have a greater effect on the loss of trap seal than individual or separate vents. If the fixture has a separate or individual vent, a partial stoppage in a long horizontal waste pipe between the trap and its vent will be responsible for the loss of the trap seal.

That part of the minority report which concerns the relation between plumbing and sewer air needs no comment, as the committee expressed its view fully in chapter 1 , to which Mr. Spencer agreed. In fact, it should be noted that the minority report raised but one controversial issue - the necessity of a separate vent for each trap.

$94877^{\circ}-24-15$ 


\section{APPENDIX B.-CORROSION OF METALS IN PLUMBING SYSTEMS}

[A memorandum prepared for the subcommittee on plumbing, by Prof. George C. Whipple]

The corrosion of metals is the greatest factor in shortening the life of plumbing systems. In spite of its importance and in spite of innumerable investigations and a vast amount of scientific study the phenomena are still imperfectly understood, but out of the researches conducted by physical chemists and engineers definite theories which appear to be sound are taking shape. If these are substantiated and further developed, they ought to be useful in many ways-in improving the quality of materials, in helping to choose the best metals for a given service, and in making better plumbing designs to avoid corrosive conditions. It is the purpose of this memorandum to explain in as simple language as possible some of the newer theories as to how corrosion takes place.

Chemistry has greatly changed in recent years, and modern scientific writers on the subject of corrosion employ terms which are not well understood by those who studied chemistry a generation ago. Only the fundamental conceptions will be described. No attempt will be made to discuss the great variety of conditions under which corrosion takes place. The following is a list of topics considered:

1. The rusting of pure iron in pure water.

2. The effect of nonferrous constituents of iron.

3. The effect of substances dissolved in water.

4. The corrosion of nonferrous metals.

5. Corrosion of different metals in contact.

6. The corrosion of iron in air.

\section{THE RUSTING OF PURE IRON IN PURE WATER}

Pure iron will rust in pure water exposed to the air. Water, as almost everyone knows, is composed of the elements hydrogen and oxygen chemically combined. It used to be called $\mathrm{H}_{2} \mathrm{O}$, but there are advantages in regarding it as $\mathrm{H} . \mathrm{OH}$. H. means an atom of hydrogen, but if written $\mathrm{H}^{+}$it means that the atom carries a charge of positive electricity and is called a hydrogen ion. In the same way $\mathrm{OH}^{-}$ stands for what is called the hydroxyl ion, and the combination of these two atoms carries a negative electrical charge. When the two ions join together, the positive and negative electrical charges neutralize each other, and the result is a molecule of water, H.OH, which is electrically inert. But in water, even if it be distilled and redistilled, not all of the $\mathrm{H}^{+}$and $\mathrm{OH}^{-}$ions are united; some remain in the water as free ions, which, because of their electrical charges, are in such a state of motion that they exert a pressure against the walls of the container, or against whatever is in the water, in a manner similar to gas pressure. This separation of the ions is known as dissociation. 
It has been learned that pure distilled water contains something like 1 gram $\mathrm{H}^{+}$in $10,000,000$ liters of water; hence, the amount of $\mathrm{H}^{+}$ in pure water resulting from dissociation is 0.0001 part per million by weight. The number $10,000,000$ may be written $10^{7}$; that is, 10 to the seventh power, 7 being the logarithm of $10,000,000$. It will be noticed that the power 7 is equal to the number of ciphers. Sorenson, the Swedish chemist, first represented this hydrogen ion concentration by the letters $\mathrm{Hp}$ (hydrogen potential), but now it is usually written $\mathrm{pH}$; hence, the $\mathrm{pH}$ value for pure distilled water is 7 . The hydroxyl ion concentration of pure water is also 7 , but in matters of corrosion we are not so much interested in this as we are in $\mathrm{H}^{*}$, because it is this little actively moving hydrogen ion which so aggressively attacks metals. Now, there may be hydrogen ions in water derived from other sources, so that instead of 1 gram in every $10,000,000$ liters there may be one in 100,000 liters, or one in $10^{5}$; that is, $\mathrm{pH}=5$ instead of 7 . The more $\mathrm{H}^{+}$there is the lower the figure for $\mathrm{pH}$.

Old time chemists used the words acid and alkaline very loosely. The modern chemist is more exact. With him the "hydrogen ion concentration" stands for acidity and "hydroxyl ion concentration" stands for alkalinity. Pure water has a $\mathrm{pH}$ value of 7 (the hydroxyl ion concentration also being 7) and is neutral. If the water contains such substances that the $\mathrm{pH}$ is less than 7 , the water is acid and the lower the $\mathrm{pH}$ value the more acid it is. If the $\mathrm{pH}$ value is above 7 , the water is alkaline and the higher the $\mathrm{pH}$ the greater the alkalinity. The sum of the $\mathrm{pH}$ value and the $\mathrm{pOH}$ value is always 14 . If the $\mathrm{pH}$ value is 5.5 , the $\mathrm{pOH}$ value is 8.5 . Hence, modern chemists do not use the expression $\mathrm{pOH}$, but think of acidity and alkalinity both in terms of $\mathrm{pH}$, values lower than 7 indicating acidity, and values higher indicating alkalinity.

It will be noticed that water when it dissociates does not yield atoms of oxygen and hydrogen but hydroxyl $\left(\mathrm{OH}^{-}\right)$and hydrogen $\left(\mathrm{H}^{+}\right)$ions. When water is exposed to the air, it absorbs oxygen gas. Most natural waters contain "dissolved oxygen." Without it fish could not breathe. There are limits to the amounts of oxygen which water can absorb. Water is said to be saturated with oxygen when it holds in solution all that it can hold at a given pressure and temperature. The higher the temperature the less oxygen it can hold in solution and the higher the pressure the more it can hold. Books on water chemistry give the saturation values for different temperatures and pressures. Oxygen gas dissolved in water is invisible, but oxygen gas may be present in excess of the saturation point, in which case it may appear as little bubbles of gas. The nitrogen of the air dissolves in water in the same way but not to the same extent. If cold water saturated with air is warmed, air bubbles will be driven out. In a closed pipe or tank they may rise to the top as air.

Let us now consider the phenomena involved in the rusting of pure iron in contact with pure water. We have already been introduced to the chief actors in the play-water (H.OH), the hydrogen ion $\left(\mathrm{H}^{+}\right)$, and oxygen gas $\left(\mathrm{O}_{2}\right)$. Iron itself (called $\mathrm{Fe}$, from the Latin word ferrum) needs no introduction, but let it be said that just as the $\mathrm{H}^{+}$has a pressure which pushes it against the iron, so $\mathrm{Fe}$ has a solution pressure which makes it try to go into solution. 
The action takes place as follows: Two aggressive little hydrogen ions $\left(\mathrm{H}^{+}\right)$move rapidly to the exposed metal and give their charges to an atom of iron. This latter enters the water as a double-charged iron ion $\left(\mathrm{Fe}^{++}\right)$, while the hydrogen atoms, their charges lost, remain on, or are "plated out" on, the iron in a "nascent"; that is, a very active chemical condition. The hydrogen thus plated out would tend to protect the metal from further attacks of $\mathrm{H}^{+}$were it not for the fact that dissolved oxygen $(\mathrm{O})$ steps in, unites with the two hydrogen atoms forming water (H.OH), and thus clears the metal for further attacks. Meantime the iron ion $\left(\mathrm{Fe}^{++}\right)$unites with two hydroxyl ions $\left(\mathrm{OH}^{-}\right)$to form the insoluble ferrous hydrate $\mathrm{Fe}(\mathrm{OH})_{2}$. As the $\mathrm{H}^{+}$attacks the iron, more water is dissociated, more $\mathrm{H}^{+}$and $\mathrm{OH}^{-}$are formed, and the corrosion proceeds. If the water is not exposed to the air and there is no other source of oxygen, the corrosion will stop when the oxygen has been used up; but the oxygen does something else. It, together with a molecule of water, unites with the ferrous hydrate, $\mathrm{Fe}(\mathrm{OH})_{2}$, to form ferric hydrate, $\mathrm{Fe}_{2}(\mathrm{OH})_{3}$, a more thoroughly oxidized condition of the iron. It will be seen, therefore, that the hydrogen ion and the dissolved oxygen are copartners in crime. The hydrogen ion is the thief, the oxygen is the receiver of stolen goods. It is not far from the truth to say that the hydrogen ion causes the corrosion, the oxygen causes the rusting. If the water has little or no motion, most of the rust remains on the iron, covering it with a yellowish-brown (partly ferrous) or reddish-brown (nearly all ferric) coat of rust. If the water is in motion, some of the rust may be distributed through the water. There is an intermediate oxide, magnetic oxide of iron, black in color. Different colors of iron rust are due to the different mixtures of these oxides as well as to various enmeshed impurities.

\section{THE EFFECT OF NONFERROUS CONSTITUENTS IN THE IRON}

In the foregoing paragraph it was said that the hydrogen ion was "plated out" on the iron, an expression often used in connection with electric batteries. It is a fact generally known that if strips of copper and zine are put into a slightly acid water-that is, one containing hydrogen ions-hydrogen ions will "plate out" on the copper and zinc will be eaten away, the hydroxyl ion acting chemically on the zine, forming zine hydrate. This movement of the electrical charges of the ions sets up a "current" of electricity. The metallic elements may be arranged in a series, the higher in electromotive properties at one end, the positive end, and the lower at the other, or negative end. If any two of the metals are put into water which contains hydrogen ions, the latter will plate out on the metal lower in the series, and the metal higher in the series will be corroded instead of the other. The following is a list of the metals in the electromotive series. The figures given in the last column are not very accurate. and published lists do not agree exactly. 
Potential series of metals

[Based on data given in "Electrolytic Dissociation Theory," by Talbot and Blanchard; 1907; and "Theoretical and Physical Chemistry," by Bigelow; 1912]

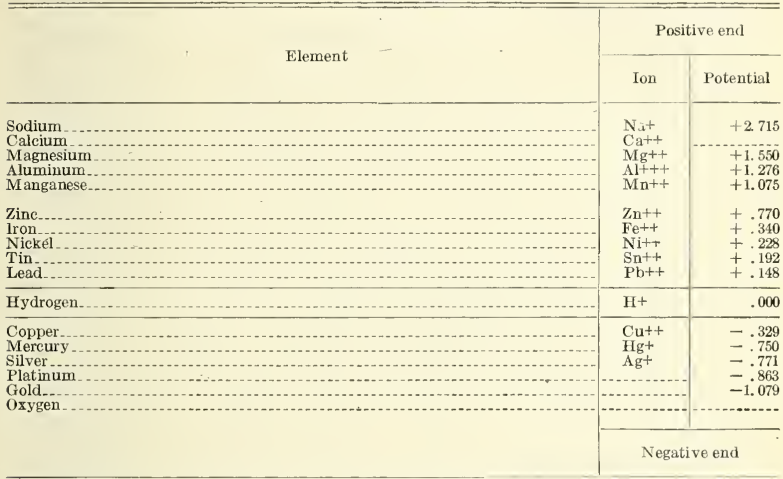

Note.-In the second column each cross after the chemical sy mbol stands for one "charge" of electricity on the ion. In the third column the + sign indicates that the solution is charged positively with respect to the metal. The potential of the hydrogen ion is taken as zero, and the potentials of the other metals are referred to it. If referred to the "calomel electrode" the potential of hydrogen would be - 0.277 (though -0.283 is, perhaps, more accurate).

The higher the potential the higher the solution pressure of the metal, and, in general, the greater the chemical activity.

Let us now suppose that there is a bit of zine in the iron. The hydrogen ions will plate out on the iron instead of on the zinc, because the zinc is higher in the series. The zinc will be corroded and the iron "protected." This explains why a "zinc fish" used to be put into a boiler to prevent corrosion, why zinc bars are attached to the iron gates of the Panama Canal locks, and why pipe is galvanized or otherwise coated with zinc.

But suppose that the foreign substance in the iron is below iron in the series, as, for example, a bit of mill scale. This time the hydrogen plates out on the scale and the iron corrodes. Where such an impurity exists the action is more localized than elsewhere and the corrosion extends deeper into the metal; a pit may be found in place of a more general corrosion. Some kinds of organic matter also act to produce local corrosion.

\section{THE EFFECT OF SUBSTANCES DISSOLVED IN WATER}

Pure water is not found in nature. If water is exposed to the air, it absorbs carbonic acid gas $\left(\mathrm{CO}_{2}\right)$. This gas reacts with the water itself, forming carbonic acid $\left(\mathrm{HCO}_{3}\right)$ and $\mathrm{H}^{+}$, the hydrogen ion. Therefore, when $\mathrm{CO}_{2}$ is dissolved the hydrogen ion concentration is increased; that is, the $\mathrm{pH}$ value is lessened. This increased hydrogen ion concentration means that the force of the hydrogen ion attack on iron is increased. Hence, it is said that $\mathrm{CO}_{2}$ causes iron corrosion. Just as before the $\mathrm{H}^{+}$makes the attack, but this time the carbonic 
acid $\left(\mathrm{HCO}^{-}\right)$seizes the iron ion $\left(\mathrm{Fe}^{++}\right)$and ferrous bicarbonate is formed, a substance soluble in water. In the absence of dissolved oxygen this iron salt remains in solution, but oyygen changes it to iron rust. Actually the chemistry of the process is somewhat more complicated, but what has been said is typical of what usually occurs.

In the same way hydrochloric acid $(\mathrm{HCl})$ added to water increases the hydrogen ion concentration and so do all acids. In other words, acids corrode iron because they yield $\mathrm{H}^{+}$in water. If the hydrogen ion attack is very severe, hydrogen may be plated out so fast that it leaves the iron as bubbles of gas without waiting for the depolarizing action of dissolved oxygen. In other words, very acid waters may corrode iron badly even if little or no dissolved oxygen is present. This condition is seldom an important one in natural waters.

If lime $(\mathrm{CaO})$ is added to water, the hydroxyl ions are increased, the water is made alkaline, the hydrogen ions are decreased, (that is, the $\mathrm{pH}$ value increased) and the rusting action is checked. In a general way, therefore, alkalies tend to check rusting.

If an acid salt, such as aluminum sulphate or magnesium chloride (found in sea water), is added to water it is dissociated and the hydrogen ion concentration of the water increased. Such solutions increase corrosion.

Natural waters usually contain great varieties of chemical substances in varying proportions. There may be mineral and organic substances which increase the hydrogen ion concentration; there may be substances which unite chemically with the iron. The matter is one of great complexity. But from the standpoint of corrosion the complex factors reduce themselves to the hydrogen ion concentration, the dissolved oxygen, the hydroxyl ion, and the solubility of the iron compounds produced by their action.

It should be noted that both oxygen and carbonic acid are always present in the atmosphere, that carbonic acid results from decomposition of organic matter and from the exhalations of animals, and that both are lavishly distributed in nature. Most public water supplies are saturated with oxygen or nearly so, and the hydrogen ion concentration is the critical factor in corrosion. Thus soft waters ( $\mathrm{pH}$ values low) are more corrosive than hard waters ( $\mathrm{pH}$ values high), colored waters containing organic acids are corrosive, salty waters are very corrosive, well waters which derive $\mathrm{CO}_{2}$ from the ground air are corrosive. On the other hand, oxygen is sometimes the critical factor. If it is not present, rusting ceases; as, for example, in closed hot-water heating systems. Of two waters which have the same $\mathrm{pH}$ value one may be more corrosive than the other, for, as already stated, the dissolved mineral matter is an important factor, but one which has not yet been sufficiently studied. From the standpoint of water analysis the corrosiveness of water involves chiefly the determinations of alkalinity, free $\mathrm{CO}_{2}$, the $\mathrm{pH}$ value, dissolved oxygen, and the mineral constituents.

In most waters the determination of "alkalinity" gives a measure of the carbonates and bicarbonates of calcium and magnesium. The test is commonly made and is fairly accurate. The common test for $\mathrm{CO}_{2}$ is accurate in most cases, but sometimes far from accurate. The test for dissolved oxygen is quite accurate. The $\mathrm{pH}$ test is relatively new and fairly accurate. It is not often made but is coming into use. 


\section{VARIOUS CONDITIONS AFFECTING THE CORROSION OF IRON}

In general, heat increases the rate of corrosion of iron, because with higher temperatures $\mathrm{H}^{+}$is formed more rapidly and because the diffusion of oxygen in the water is increased. On the other hand, heating water drives air (both oxygen and nitrogen) out of solution. In hot water oxidation of ferrous iron takes place more rapidly. Rusty hot water, sometimes called the red water plague, is due to the corrosion of pipes. It is most likely to occur in soft waters, especially if colored or alum treated. It seldom occurs with hard waters, even though iron pipes be used for water distribution.

An increased flow of water in a pipe increases rusting, provided there is a sufficiency of $\mathrm{H}^{+}$, because it brings larger volumes of dissolved oxygen into contact with the iron. It follows from this that small pipes will corrode and become filled with rust more rapidly than large pipes. This is an argument for the liberal sizing of iron pipes in a plumbing system. Low velocities which allow the water to flow quietly in parallel lines cause less rusting than higher velocities which give a more turbulent flow, bring more oxygen in contact with the sides of the pipe, and wash off the rust which is formed.

If metallic iron is fully protected from the water, corrosion will not occur. Coating an iron pipe with coal tar, asphalt, or similar preparations is intended to do this and does so fairly well. In cast iron the crystals of metallic iron are bound together by graphite and cementite, which largely prevents rusting. In "genuine wrought iron" the crystals of iron are protected somewhat better than in steel, and hence the corrosion on the whole is less, but this is by no means always the case. Some steels resist corrosion better than some genuine wrought irons, and the difference is probably not as great as is commonly thought.

Service pipes are often protected from corrosion by lining them with cement. 'This acts in two ways - first, by keeping the water away from the metal; second, by reducing the hydrogen ions which reach the metal, the cement being alkaline. It is an excellent method, deserving further development.

Uniformity in the structure of the metal makes for uniformity in corrosion. Impurities in the metal tend toward localized corrosion, that is, pitting. Cast iron seldom pits. Genuine wrought iron and steel both pit. The removal of mill scale from steel reduces pitting. Pitting is worse than uniform rusting, because it causes leaks in pipes or holes in sheet iron.

Going back to the explanation of corrosion and rusting, let us consider what happens to the rust formed. If the movement of water is rapid and turbulent, the iron rust may be carried along with the water and, perhaps, deposited somewhere. If the movement of the water is gentle, it may remain near the point of formation and form a sort of film or membrane. This membrane acts as a sort of sieve. It allows the hydrogen ions and gases to pass through but holds back iron rust. Consequently, iron rust accumulates back of the film. If a piece of iron pipe is placed in a trough through which water is slowly flowing, this film forms quickly and attains considerable size. It forms in the inside of a pipe as well as on the outside. It may be easily ruptured by increasing the flow of water beyond the critical velocity-that is, beyond the 
point when flow in straight lines is changed to a turbulent flow. Even where the flow is rapid the film may form, but in this case it holds close to the pipe or is localized. Iron rust deposited back of such film accumulates in "tubercles." After a time the "film" becomes a substantial deposit of iron, but apparently continues to act as a sieve, letting aggressive hydrogen ions, oxygen, and water pass to the iron pipe, but holding back the oxide of iron formed. If water contains organic matter, it may be deposited on this film or precipitated by the sticky iron oxide on the walls of the pipe, in either case tending to build up and hold together the deposit of iron oxide. The bacterial decomposition of organic matter yields $\mathrm{H}^{+}$, and hence tends to increase corrosion. Animal forms, such as the fresh-water sponge or pipe moss found in large water mains, also give off $\mathrm{CO}_{2}$. It is a well-known fact that the raw water pipes of a filtration plant become more tuberculated than the pipes carrying filtered water, beeause in the latter case the pipes contain less organic matter and no pipe moss. On the other hand, some deposits are thought to protect the metal against the action of the water.

\section{THE CORROSION OF NONFERROUS METALS IN WATER}

The principal nonferrous metals used by themselves in plumbing systems are lead, zinc, tin, and copper, and they are obtainable in a fairly pure state, while commercial iron always contains foreign substances. In general, it may be said that pure metals resist corrosion better than two or more different metals mixed or alloyed or in contact with each other. Reference to the potential series will show that zinc, lead, tin, and iron are higher in the series than hydrogen. Their solution pressures are higher and they are more susceptible to attack by the hydrogen iron. Copper, on the other hand, is lower in the series than hydrogen and than most of the other metals used in plumbing work. Consequently, it is not attacked by the hydrogen ion under ordinary conditions. Oxygen is lower in the series than copper and therefore may attack it. Inasmuch, however, as the copper oxide found is insoluble in water, it will protect the metal against further action unless it is physically removed or dissolved by some acid or ammonia. The atmosphere of a city usually contains carbonic acid and sulphurous or sulphuric acid. These are absorbed by the rain and may thus play a part in the corrosion of copper roofing. When copper is used in connection with urinals, the ammonia will dissolve the copper oxide, exposing the metal to further oxygen attack and thus contribute to its corrosion. In the same way the ammonia resulting from the droppings of pigeons and other birds on roofs may contribute to the corrosion of sheet copper. It is a well-known fact that copper is corroded readily when ammonia is present. It will be noticed that zinc and iron are much higher in the potential series than tin and lead. The solution pressure of zinc and iron greatly overbalances the osmotic pressure of their ions, a fact which adds to the facility with which they are corroded; but there is another factor which has an important influence on corrosion, namely, the solubility of the substances produced by corrosion. If the resulting salt is not readily soluble in water, it is likely to be deposited upon the metal and will protect it against further corrosion, while if the resulting salt is soluble in water it will not be so deposited and the metal will be exposed to 
new attacks by the colroding forces. A few examples may serve to make this clear.

When pure iron is put into water which contains free carbonic acid gas but no dissolved oxygen, ferrous bicarbonate is formed and this is soluble in water. This action may take place when an iron pipe carries well water rich in $\mathrm{CO}_{2}$ but poor in dissolved oxygen. If oxygen is present in the water, the ferrous carbonate will be oxidized to ferric hydrate (iron rust) and in so far as it deposits on the metal it tends to protect against corrosion.

If the acid is hydrochloric instead of carbonic, ferrous chloride is formed and that, too, is soluble; and in the same way sulphuric acid may act on iron and form ferrous sulphate, also soluble. But in the case of tin in water containing $\mathrm{CO}_{2}$ the situation is different. There is no bicarbonate or even carbonate of tin formed. Any tin salts formed are relatively insoluble. This is one of the reasons why block tin is so commonly used in soda-water fountains to carry water highly charged with carbonic acid.

The action of different waters on lead may be explained along these lines. In soft waters, and especially soft colored waters, the hydrogen ion content is large (that is, $\mathrm{pH}$ is well below 7). Lead pipes exposed to such waters are attacked with the formation of lead carbonate which is quite soluble. The result is that the metal is left bare for further attacks, while the water containing the dissolved lead may cause lead poisoning if used for drinking. This is why soft well waters high in $\mathrm{CO}_{2}$ and poor in oxygen ought not to be conveyed through lead pipes. If, however, the water has a high alkalinity (high temporary hardness) and little carbonic acid, the hydrogen ion content will be relatively low and the attack on the lead will also be low. Under these conditions a basic lead carbonate will be formed by the oxygen present. As this substance is insoluble, it tends to coat the walls of the pipe and protect the lead from further corrosion. In such waters there may be deposits of calcium carbonate which add to the protection. To some extent silicates in the water protect lead and also iron against corrosion.

Another example is worth mentioning because of its frequent occurrence. When soft waters are treated with alum, as in the process known as mechanical filtration and sometimes even with slow sand filtration, their corrosive action on the seams of watercloset tanks has often been noticed. The addition of alum to water changes calcium carbonate, an alkaline salt, to calcium sulphate and also produces carbonic acid. The hydrogen ion concentration is therefore increased (the $\mathrm{pH}$ value lowered) unless some alkali is also added. The soldered joints of copper-lined tanks are thus likely to be more seriously attacked than by the same water without alum treatment, zinc by virtue of its position in the potential series being dissolved. Zinc sulphate is more soluble in water than zinc carbonate. If the latter is formed, as may be the case when the calcium carbonate in the water is very large in proportion to the calsium sulphate, it will not readily dissolve but remains on the zinc as a protective coating. If, however, the calcium sulphate is large in proportion to the calcium carbonate, there would appear to be a greater tendency for zinc sulphate to be formed, which will dissolve in the water, leaving the metal free for further galvanic action. 
It is evident, therefore, that corrosion depends not only upon the hydrogen ion alone, although that is the attacking agent, nor upon the hydrogen ion and dissolved oxygen together, but also upon the nature of the various acids, bases, and salts which may be present in water in varying proportions. No wonder, then, that different waters act differently upon different metals! No wonder that experiments are conflicting! No wonder that plumbers are confused in regard to a subject upon which even chemists themselves are confused!

\section{THE CORROSION OF DIFFERENT METALS IN CONTACT}

It has already been explained that a bit of zinc in contact with iron will cause the hydrogen to be plated out on the iron, the zinc to be corroded, and the iron protected. In general, it may be said that when any two metals are in contact in water containing hydrogen ions, the one higher in the series will be the most corroded, while the one lower in the series will be protected. Thus zinc protects iron in a galvanized pipe, the zinc itself corroding. Thus also iron protects lead in a lead-lined pipe, the iron itself corroding. Iron protects tin; tin protects copper, the tin itself not being much corroded, however, because the resulting salts of tin are relatively insoluble. Even in such an alloy as brass the zinc protects the copper and the larger the proportion of zinc the more the brass (really the zinc in the brass) is corroded.

Another important principle is that a metal in the presence of water containing hydrogen ions will corrode more rapidly if in contact with a metal lower in the series than if present in the water alone. Thus, zine will corrode more rapidly if in contact with iron; iron will corrode more rapidly if in contact with lead; zine will corrode more rapidly if in contact with solder (tin and lead) than if present alone. It is for these reasons that joints of different metals are especially liable to be corroded. When two metals are thus brought into contact in acid water (one containing hydrogen ions in excess of hydroxyl ions), the exchange of electric charges of the ions causes an electric "current" (called in this case a galvanic current), and it is sometimes said that the corrosion is due to galvanic action, a satisfactory explanation if one understands how the galvanic action results from the potential differences of the elements in the series.

A few examples of this "galvanic corrosion" may be cited. In the case of a galvanized steel pipe, the protection of the iron would be excellent if the zinc coating were perfect and entire. Actually it is not perfect. For one reason or another the iron is exposed and a contact of zinc and iron in water results. The zinc dissolves and iron is left bare, and then corrodes as it would do if no zine were present. Galvanized pipes often have to be cut and threaded, and where the cut is made the iron is laid bare. Water is carried by capillarity into the threaded joint, a couple results, and corrosion proceeds rapidly.

Tin plate, such as that used for roofing, is iron coated with tin. If the tin is removed at some spot the iron will rust faster than if it had not been tinned. If iron pipe is lined with lead and if a pinhole exists in the lead coating, water may come in contact with both metals, and if the water has a low $\mathrm{pH}$ value the iron will suffer a rapid local corrosion and a hole in the pipe may result. Similar 
corrosion is likely to occur at the joints where it is difficult to secure a continuity of lead lining.

A brass coupling or a brass faucet attached to a piece of iron pipe tends to increase the corrosion of the iron, and the effect is not limited to the point of contact but may extend to a considerable distance from the joint. In the case of brass piping, the fittings are of different composition from that of the pipe itself; hence, brass piping not infrequently gives out at the joints.

It must not be forgotten that in most cases of galvanic corrosion the action is greater in waters having a high hydrogen ion concentration (a low value of $\mathrm{pH}$ ). Thus, a water which has had its hydrogen ion concentration increased by the use of alum (sulphate of alumina) in connection with filtration may cause more severe cases of galvanic corrosion than the same water before filtration. The addition of liquid chlorine to water also tends to increase the hydrogen ion concentration and hence to increase the galvanic corrosion, but the quantity of chlorine added is usually very small.

\section{THE CORROSION OF IRON IN AIR}

Thus far only corrosion in water has been discussed. It remains to consider the corrosion of metals in air, and as before iron may be considered first.

In perfectly dry air iron does not rust at all. Water is necessary. Air usually contains moisture, sometimes only a little, sometimes enough to saturate or supersaturate it. Clean iron exposed to a film of moisture rusts rapidly. An excellent example is the rust which appears on a bright iron rail of a railroad track a few hours after a shower. The principles of rusting are the same as before, a corrosive attack by $\mathrm{H}^{+}$and an oxidation by oxygen. Be it remembered that the air contains $\mathrm{CO}_{2}$ and oxygen, that $\mathrm{CO}_{2}$ is very soluble, and that a thin film of water may dissolve oxygen from the air and (although the rate of diffusion of oxygen in water is very slow) transmit it quickly to the metal because the film is thin. Thus, although the $\mathrm{CO}_{2}$ and oxygen in a drop of water may be small, the drop may easily replenish its supply, if used up, from the atmosphere.

In a soil or drain-pipe deposits of organic matter decompose with the formation of $\mathrm{CO}_{2}$, and this may be dissolved by a film of water or drops of water attached to the pipe. Sulphur compounds may also dissolve in drops and films of water on the interior of drain pipes. Acid substances in the sewage or water discharged may increase the hydrogen ion concentration of the water which remains attached to the walls of the pipe. On the other hand, soap and grease deposits may be alkaline and may protect against corrosion both mechanically and chemically.

In horizontal waste pipes that are infrequently used drops of water often collect near the top of the pipe, absorb $\mathrm{CO}_{2}$ from the drain air, and cause vigorous corrosion in the upper half of the cross section. If the drains are used frequently and are fully flushed, the collected drops of water, rich in $\mathrm{CO}_{2}$, will be replaced by other drops lower in $\mathrm{CO}_{2}$, and rusting will be less rapid. When rust is once formed, its porosity causes it to absorb moisture, so that rust on the interior of drains is usually moist.

Vertical soil or drain stacks corrode less rapidly than horizontal drains because moisture is less likely to collect upon them. Deposits of grease upon the inner walls of soil pipes tend to protect them from 
corrosion by mechanically preventing water from reaching the metal. Yet grease on decomposition yields organic acids, which like other acids furnish hydrogen ions; and if, for any reason, the metal becomes exposed, these hydrogen ions will attack it. Vent pipes are not protected in this way by grease deposits, and should small amounts of grease reach them by accident corrosion would be stimulated instead of being prevented. A small amount of grease may do a great amount of damage.

The air of cities contains more $\mathrm{CO}_{2}$ than the air of the country. City air also contains sulphurous acid gas $\left(\mathrm{SO}_{2}\right)$ from the burning coal, and it seems probable that the use of oil instead of coal will increase this still further. Mexican oil, at any rate, contains much more sulphur than most of the American oils. Air near the seacoast contains more salt than air farther inland, and so does rain near the seacoast. The air of a seacoast city may be, therefore, much more corrosive than that of an inland rural district.

\section{PRACTICAL CONSIDERATIONS}

The above statement of the scientific theory of corrosion is by no means complete, no reference whatever being made to colloids and surface phenomena; but even as it stands it might be regarded as too technical if it did not lead to certain practical results, which may be stated as follows from the plumber's standpoint:

1. The plumber ordinarily has to take a public water supply as it is and adjust his choice of materials to it. In doing so, he should remember that:

(a) Acid waters are more corrosive than alkaline waters. The $\mathrm{pH}$ value of a water is a measure of its acidity. If less than 7.0, the water is acid; if more than 7.0 , it is alkaline. Colored waters contain organic acids and usually carbonic acid.

(b) Soft waters are more corrosive than hard waters. Waters on the Atlantic seacoast are generally softer and more corrosive than the waters of the middle States.

(c) Well waters are usually harder than surface waters of the same region, but they often contain carbonic acid. The corrosive powers of well waters differ. If they are relatively soft and contain much carbonic acid, they may attack iron or lead vigorously; but if they are hard and the carbonic acid is low, the action may be slight or negligible. If high in silicates, corrosion may be slight.

(d) There are two types of hardness in water-carbonate hardness and sulphate hardness. The former tends to protect metal pipes from corrosion, the latter does not.

(e) A water analysis is required to tell in advance whether or not a water is corrosive.' To-day the waters of most cities are analyzed by State departments of health, but the analyses are made principally from a health point of view and do not always include the data necessary to determine corrosiveness.

(f) The rusting of iron by water requires both an acid and dissolved oxygen. Most public water supplies are saturated with oxygen and need the oxygen in order to be palatable.

2. The plumber should know the effect on the corrosiveness of water of certain processes commonly used for water purification.

(a) Aeration tends to remove carbonic acid, and thus reduces the corrosiveness of water. On the other hand, it assures saturation with oxygen, and if acids are present rusting will occur. 
(b) The addition of whiting or lime neutralizes the carbonic acid and reduces the corrosiveness of water.

(c) Softening water does not increase corrosiveness. Softening is never used unless the water is excessively hard.

(d) The use of alum in connection with filtration tends to increase corrosiveness. There are ways to counteract this to some extent, but they are not always employed.

(e) The use of liquid chlorine as a disinfectant tends to increase the corrosiveness of water, but the effect is usually unappreciable.

$(f)$ The process of "deactivation" removes oxygen from water. It tends to prevent rusting and corrosion. The addition of sodium silicate to hot water is said to prevent the corrosion of pipes by forming a film on the metal which prevents the attack of the hydrogen ions.

3. Where the water is soft and contains much carbonic acid, or where for other reasons the water is corrosive, the choice of metals is important.

(a) For service pipes lead should be avoided because of the danger of lead poisoning; iron or steel should be galvanized or, what is better, protected by an inner cement lining.

(b) Iron or steel pipe used for distribution in the house should be galvanized and made of ample size to allow for rusting. Lead should not be used.

(c) Brass pipe used for hot-water distribution should contain at least 67 per cent of copper. If it contains too large a percentage of zinc, this metal is likely to be corroded in spots and at the joints, causing the pipe to leak. As brass pipe does not clog with rust, smaller sizes may be used than with iron or steel.

(d) Cast-iron water backs rust badly, produce "red water," and may become clogged.

(e) Cast iron serves better for the drainage system than wrought iron or steel.

4. Where the water is hard, the choice of metal is less important and may depend upon other factors than corrosion. Even with hard water cast iron serves best for drainage systems because of the development of corrosive gases in the pipes.

5. In any water, but especially in soft corrosive water, two metals when in contact are likely to be affected by galvanic action. The metals are attacked in a definite order-zinc before iron, iron before lead, lead before copper.

(a) A brass which contains much zine corrodes more than one which contains less. Bronze corrodes less than brass, and copper corrodes less than bronze.

(b) Soldered seams in water-closet tanks are corroded by an acid water. This is often noticed in an alum-treated water. Covering the seams with a wash or paste of tar or asphalt mixed with cement should prove beneficial.

\section{BIBLIOGRAPHY OF CORROSION}

In 1909 the Carnegie Library, of Pittsburgh, published a Bibliography of Corrosion, and in 1915 a supplement to it was published in the Proceedings of the Engineer's Society of Western Pennsylvania. Recently (1923) a Bibliography of the Corrosion of Metals and its Prevention was published by Nathan Van Patten, assistant librarian, Massachusetts Institute of Technology, Cambridge, Mass. 


\title{
APPENDIX C.-A STUDY OF AIR CURRENTS IN A HORI- ZONTAL WASTE PIPE
}

\author{
By Warren E. Howland
}

This memorandum covers a series of experiments made in the laboratory of the department of sanitary engineering of Harvard University as a part of a study of conditions which affect the corrosion of metals used in plumbing systems. It relates to the movements of air and gases in unvented horizontal waste pipes; that is, horizontal waste pipes connected with a vertical stack at one end and having a trap (or a plug) at the other end. Four kinds of air movement may occur in an unvented horizontal waste pipe. They are:

1. Eddy currents induced by an upward draft in the vertical stack to which the horizontal waste pipe is connected or by down rushes of water in the stack.

2. Movements due to diffusion.

3. Convection currents in the pipe itself; that is, movements of the air due to temperature differences.

4. Displacement of the air in the pipe by the discharge of the fixture connected with it.

The experiments were not carried to such a point that definite quantitative conclusions can be drawn, but the following inferences appear to the writer to be sound:

1. Movements of air in the stack induce eddy currents of air in the horizontal waste pipe for only a short distance from the stack, say, for 1 or 2 feet.

2. Diffusion is the most important factor in causing gases to spread through or from the horizontal pipe. If gases, such as carbonic acid gas or sulphuretted hydrogen, are formed in a horizontal run, they will become more concentrated in a long pipe than in a short pipe, the maximum concentration varying approximately as the square of the length of the pipe. In other words, gas will leave a short pipe more quickly than a long pipe. On the other hand, oxygen from the stack will diffuse into a long pipe with more difficulty than into a short pipe. These statements are true regardless of the diameter of the pipe.

3. Convection currents, caused by temperature differences, are likely to be present throughout the whole length of the horizontal waste pipe, but such currents are of small magnitude.

4. Displacement of the air in the pipe occurs whenever the discharge of water completely fills it; but if the discharge of water does not fill the pipe, the displacement of air is also incomplete. (This was not studied experimentally.)

The gases likely to be found in the air of unvented horizontal waste pipes in plumbing systems are, first, the oxygen, nitrogen, and carbonic acid gas (present in small amounts) of the atmosphere; second, water vapor, or humidity; third, carbonic acid gas, sulphuretted hydrogen, and other gaseous products of the decomposition of organic matter. The experiments here described have involved measurements showing the movement of several of these gases, namely, sulphuretted hydrogen, carbon dioxide, and water vapor. 
When the writer began his experiments in February, 1923, Dana E. Kepner, then assistant in sanitary engineering in Harvard University, had already done considerable work on the problem and had erected an experimental equipment which, with some additions, was used throughout the experiments. Early attempts to study air movements by the use of sulphuretted hydrogen having proved unsuccessful, a method involving the absorption of carbonic acid from the air by solutions of lime water located at different places in the pipes was tried with good results. This method, together with the evaporation of water, formed the basis of the experiments described below. Free use has been made of a report submitted by Mr. Kepner to Prof. George C. Whipple, to both of whom acknowledgments are made.

\section{DESCRIPTION OF APPARATUS}

The first pipe used was of steel, $1 \frac{1}{2}$ inches in diameter and 25 feet long, closed at one end and connected at the other end by means of
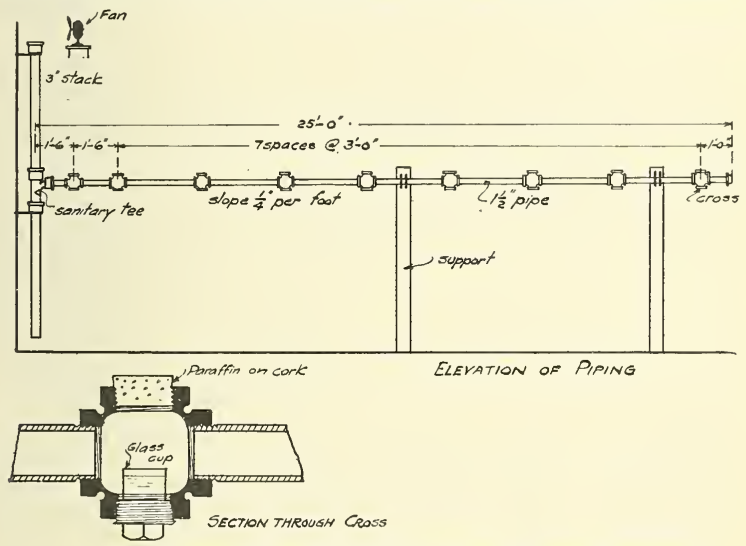

ELEVATION OF PIPING

FIG. 93.-Arrangement of piping for the study of air currents in horizontal waste pipes

a sanitary tee with a 3 -inch stack, 11 feet high. It had a slope of one-fourth inch to the foot. Crosses were placed at a point $1 \frac{1}{2}$ feet from the vertical stack and thereafter at intervals of 3 feet to the closed end. At first glass plates were placed over the ends of the crosses and silk threads suspended in such a way that any large movements of air could be detected. All results were negative. The glass plates at the tops of the crosses were, therefore, removed, corks put in and sealed with paraffin. Screwed plugs were placed at the bottom of the crosses, so that glass cups of solutions could be inserted. Figure 93 shows this arrangement. Afterwards two additional horizontal pipes, one $1 \frac{1}{4}$ inches and one 2 inches in diameter and 26 feet long, were set up on either side of the original apparatus with crosses at intervals of 3 feet. These pipes were connected to separate stacks 11 feet long. 


\section{EDDY CURRENTS}

The rapid movement of air up the vertical stack produced eddy currents for a short distance in the horizontal laterals. A glass tube 1 inch in diameter was placed in a nearly horizontal position, sloping one-fourth inch to the foot, closed at the outer end and connected with a 2 -inch vertical stack. When air was moving up the stack, movements could be detected by observing untwisted fine silk threads suspended from the top of the interior of the glass tube at distances not exceeding 7 inches from the vertical stack. Probably, however, very slight movements of air extended farther in the pipe than could be detected with the eve.

This same apparatus was used for experiments with hydrogen sulphide. Into the outer end was inserted a small porcelain boat of hydrochloric acid in which iron sulphide was dissolving and giving off hydrogen sulphide. The tube was quickly stoppered. A draft was maintained in the vertical stack. At the end of 15 minutes moist lead acetate paper previously placed in the open end of the pipe was examined for the metallic luster of lead sulphide. A similar experiment was carried on simultaneously with another glass tube, the open end of which was not exposed to a draft. The results showed that the draft in the stack hastened diffusion of the hydrogen sulphide to the open end, but the difference between the two was not great.

Indication of the presence of eddy currents was also given by the evaporation of drops of water placed in rows on the interior of steel pipes and glass tubes. Two horizontal glass tubes closed at one end were filled with water and then emptied, leaving the interior wall covered with drops. Over the end of one of these pipes a strong draft of air was allowed to play. At the end of 24 hours the drops near the open end of the pipe and to a distance of 17 inches from the end had evaporated. In the other pipe, over which no draft had been allowed to play, the drops had disappeared to a distance of 10 inches.

This experiment was repeated with a 2 -inch steel pipe, closed at one end with a water-sealed trap and connected to a 4-inch stack at the other end. A draft of 280 feet per minute was maintained in the vertical stack. After 67 hours the drops in the horizontal pipe had evaporated to a distance of 18 inches from the stack. In another pipe similarly placed, but with no draft maintained in the vertical stack, the drops had disappeared to a distance of 17 inches from the stack. In this case not only was the pipe wet with drops of water, but there was considerable water adhering to the rust particles on the walls, as shown by their moist feeling when touched with the finger. It may be concluded, therefore, that no appreciable drying of the interior of the pipe took place beyond a distance of 2 feet when the pipe was wet as often as once in 24 hours.

Experiments were made to discover whether or not minute particles in the air moving in the vertical stack would enter into the horizontal branch and thus give evidence of air currents. Smoke from smoky flames and smoke of ammonium chloride were used both hot and cold. Particles of dust were also used and culture plates for the detection of bacteria and molds were placed at intervals in the horizontal branch. In the following case only was the presence 
of particles which had come from the air in the vertical stack detected in the horizontal pipe. Smoke from a smoky flame was allowed to pass up the vertical stack for 24 hours. At the end of that time white papers previously placed on the bottoms of the crosses as shown on the before-mentioned sketch appeared as follows:

Paper in cross:

$1 \frac{1}{2}$ feet from vertical stack

100 per cent black.

3 feet from vertical stack 75 per cent black.

6 feet from vertical stack

Trace of black.

All others

No trace of black.

This effect was undoubtedly due to the convection currents set up by the higher temperature of the ascending gases, which, being lighter than the air in the horizontal pipe, tended to rise to the top of the horizontal pipe and flow toward the dead end, depositing its smoke on the way. This condition would not, of course, exist in actual plumbing systems.

It seems probable, therefore, that eddy currents are not present in the horizontal pipe beyond a distance of about 2 feet from the vertical stack. Such currents may cause a relatively complete displacement of air in the first $1 \frac{1}{2}$ feet of the pipe. This has the effect of reducing by this amount that portion of the pipe within which diffusion and convection are the chief causes of the movement of gases.

Downrushes of water in the stack will produce suction.or pressure of the air in the horizontal pipe. The effect will be a movement of the contained air, due to its change in volume and to the yielding of the trap. Assuming that the drainage system is so designed that the trap will not lose its seal, then the distance from the vertical stack within which displacement will take place may be expressed by the following formula :

$\left.\begin{array}{l}\text { Horizontal dis- } \\ \text { placement in the } \\ \text { air in inches }\end{array}\right\}=\left\{\begin{array}{l}\text { yield of } \\ \text { trap ver- } \\ \text { tical, inches }\end{array}\right\}+\left\{\begin{array}{l}\text { yield of trap } \\ 34\end{array} \times\left\{\begin{array}{l}\text { length of } \\ \text { pipe in } \\ \text { feet. }\end{array}\right.\right.$

It has been computed that in the case of a horizontal pipe 15 feet long and with a 2 -inch yield of the water in the trap only 3 horizontal inches of air might be changed. Larger movements of water in the trap and longer horizontal runs might give proportionally larger displacements. This effect does not extend as far as the eddy currents before considered and is so small and infrequent that it may be entirely neglected.

\section{DIFFUSION}

Early experiments showed that diffusion is by far the most important factor in accounting for the movement of gases in horizontal branches. The gases absorbed at various points in the horizontal pipes were measured as described beyond. It was found that drafts in the vertical stack had very little to do with this absorption. For example, the placing of a fine wire screen at the end of the horizontal pipe where it entered the vertical stack checked the eddy current but did not prevent the absorption of gases by the various solutions placed at intervals along the pipe. Other experiments confirmed the importance of diffusion.

Thirty-two experiments depending upon the absorption of carbon dioxide-that is, carbonic acid gas-by water and five experiments depending upon the evaporation of water were made. Only a few of

$94877^{\circ}-24-16$ 
these experiments will be here reported. Following them the results of a mathematical analysis of the problem is given, but the computations themselves, being somewhat involved, will be omitted.

\section{CARBON DIOXIDE EXPERIMENTS}

Small cups, each containing 10 cubic centimeters of limewater, were placed at the crosses in the horizontal pipe, as shown by Figure 93. The absorption of carbon dioxide by these solutions was determined chemically. Allowance was made for the carbon dioxide originally present in the air. The diagrams (figs. 94 to 97 , and 100) show at each cross in the pipe the amounts of sulphuric acid which was found by experiment to be equivalent to the carbon dioxide reaching that point through the stack from the outside air. The amount of carbon dioxide absorbed at each joint as shown is a measure of the concentration of the gas at that point. The diagrams, therefore, show the variation in concentration of carbon dioxide throughout the pipe.

The concentration of gases coming into the pipe diminishes rapidly on the way back from the open end and finally reaches a point beyond which further change in concentration is not noticeable. This limit of the noticeable effect of diffusion extends not much farther with a higher concentration of gas in the vertical stack than with a lower concentration. In experiment A (fig. 94) the air in the stack contained 7.6 parts per 10,000 of carbon dioxide. Absorption of this gas by the limewater in the cups was noticeable for 9 feet in the pipe. In experiment B (fig. 95) the air in the vertical stack contained 5.8 parts per 10,000 of carbon dioxide and the absorption was noticeable for about the same distance. In other experiments with $1 \frac{1}{4}$-inch, $1 \frac{1}{2}-$ inch, and 2-inch pipes the distance within which absorption took place varied from 3 to 9 feet and a veraged about 6 feet. There was no consistent relation between this distance and the diameter of the pipe.

The time allowed for absorption made very little difference with the shape of the curve. It increased the absorption within the limits of diffusion but did not increase the limits themselves. This is shown by experiments $\mathrm{A}$ and $\mathrm{C}$. The former had a duration of $20 \frac{1}{2}$ hours and the latter 44 hours, all the other conditions being practically the same, yet the results were almost identical as to the distance within which diffusion took place.

In order to show that diffusion was more active in the 6 (3 to 9 ) feet near the stack than at greater distances, an experiment was made (experiment D) in which the absorbing solutions near the stack (at $a$ and $b$ ) were omitted. Comparison was made with experiment E (fig. 97) in which these cups were retained, other conditions remaining the same. If the absorption in cups $c$ and $d$ of experiment $D$ had given results like those of cups $a$ and $b$ of experiment $\mathrm{E}$, the conclusion would have disproved what has been said above. It will be observed, however, that they did not do this, a fact which supports the contention that diffusion is limited to the distances mentioned.

Not content with the simple experiments above mentioned, even though they corroborated each other in a general way, a mathematical analysis of the problem of diffusion in a closed pipe was made and its results compared with those of the experiments. This comparison may be seen on the diagram which gives the results of experiment $\mathrm{C}$. The agreement was striking and furnished additional proof of the correctness of the deductions from the experiments. 


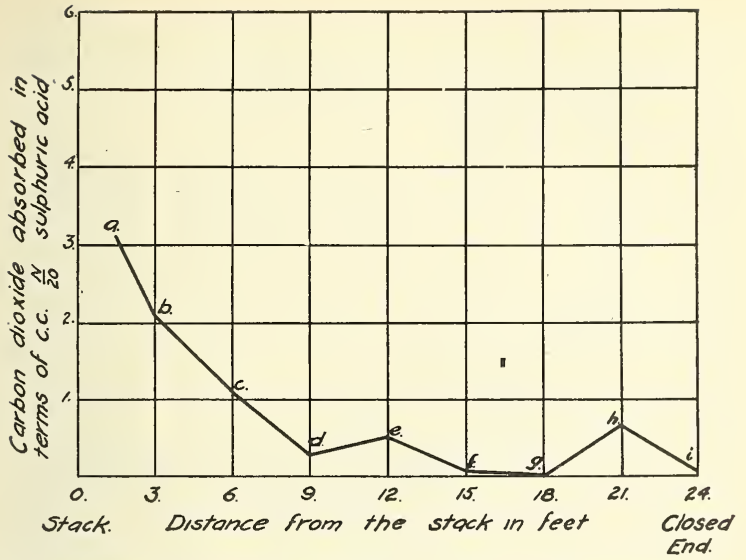

FIG. 94.-Experiment A. Diffusion of carbon dioxide in a $1 \frac{1}{2}$-inch horizontal branch connected with a vertical stack. Time, $20 \frac{1}{2}$ hours. No forced draft

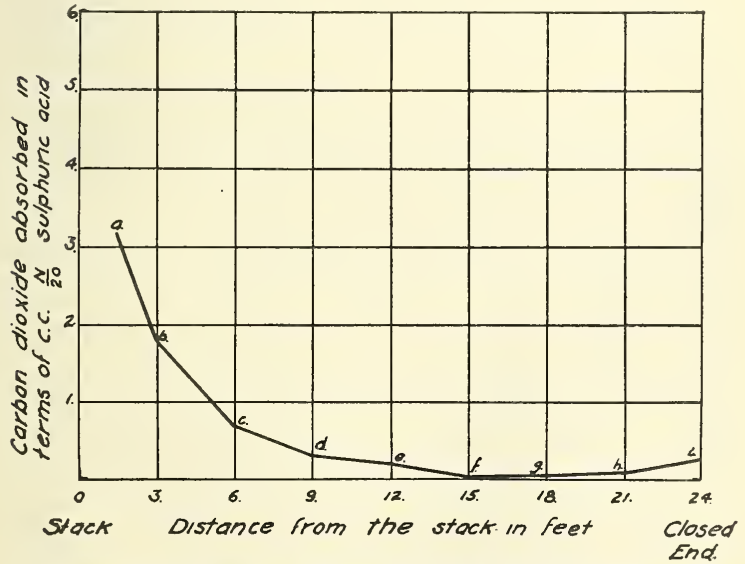

FIG. 95.-Experiment B. Diffusion of earbon dioxide in a $1 \frac{1}{2}$-inch horizontal branch connected with a vertical stack. Time, 48 hours. Draft in stack; 180 feet per minute 


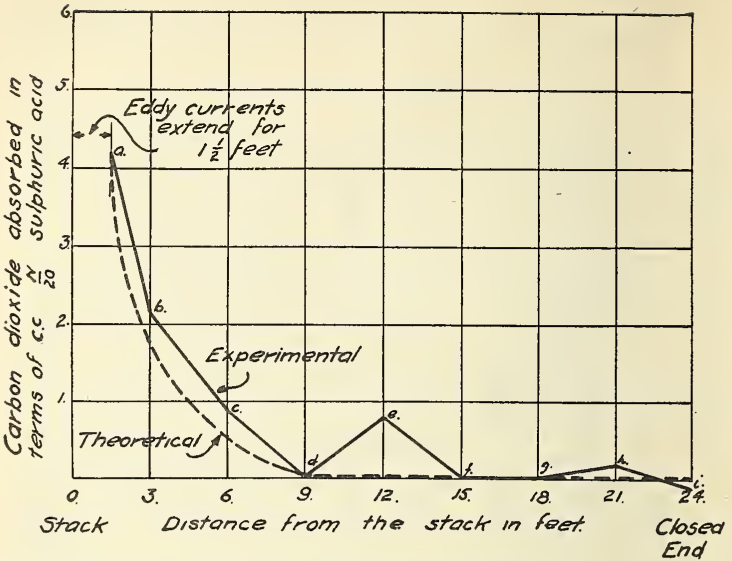

FIG. 96.-Experiment C. Diffusion of carbon dioxide in a $1 \frac{1}{2}$-inch horizontal branch connected with a vertical stack. Time, 44 hours. No forced draft

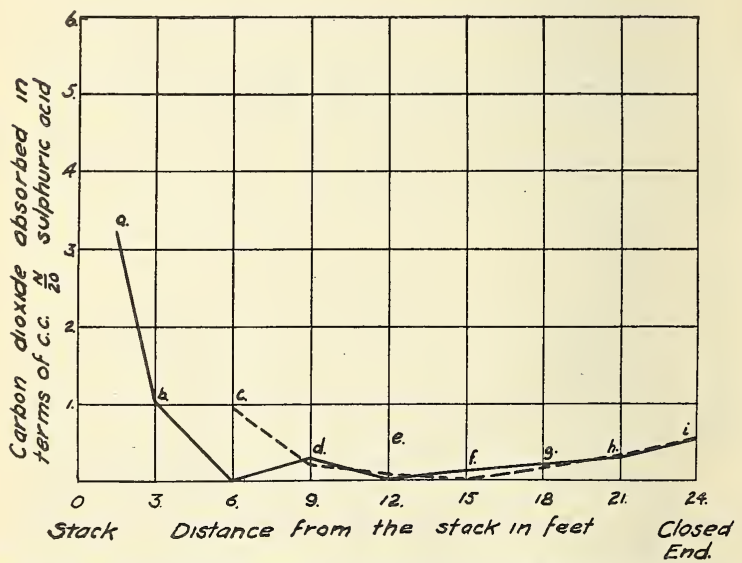

FIG. 97.-Experiments D and E. Diffusion of carbon dioxide in a 2-inch horizontal branch connected with a vertical stack. Time, 48 hours. No forced draft 
A formula was set up showing the variation of the concentration of carbon dioxide throughout the pipe for a particular set of conditions.

$$
x=\sqrt{\frac{K A}{Q} \log \frac{C+\sqrt{C^{2}-C_{\mathrm{o}}^{2}}}{C_{\mathrm{o}}}}
$$

$x=$ distance from the closed end of the pipe.

$K=$ diffusion constant for the gas in question.

$A=$ area of cross section of the pipe.

$Q=\mathrm{a}$ constant expressing the rate of absorption of the gas.

$C=$ concentration of the gas at any point.

$C_{\mathrm{o}}=$ concentration of the gas at the point where $x$ equals zero.

There are two principal ways in which the length of the pipe affects the concentration of the gas in the pipe. In the case of a gas produced uniformly throughout the length of the pipe, the greater the length of the pipe the greater will be the concentration of the gas throughout the whole pipe. For any given pipe, whether absorbing or emitting a gas, the extent to which diffusion will equalize the concentration within and without the pipe is much greater in the section of the pipe near the open end than in other parts of the pipe. For any particular case there is a limit beyond which diffusion can not be relied upon to remove appreciable amounts of an evolved gas or to convey into the pipe appreciable amounts of gases from the stack. The factors which determine the concentration of gases in a horizontal pipe and which, therefore, will determine the limit of diffusion are the following:

1. Length of the pipe.

2. Ratio of the rate of evolution (or absorption) of the gas in the pipe to the cross-sectional area.

3. The diffusion coefficient of the gas.

4. The concentration of the gas in the air of the stack.

The diffusion will depend largely upon the length of the pipe and the ratio of the evolution of the gas in the pipe to the area of cross section; that is, to the first two items mentioned above. The experiments made were confined to a particular value of this ratio; that is, the absorption of carbon dioxide by limewater in a cup of definite size. If larger cups had been used, the limit of absorption would theoretically have been less than was observed; if smaller cups had been used, it would have been larger. If the ratio referred to could be actually determined in any case, an exact limit could be computed; and if further experiments are made, they should be devoted to a study of this ratio of gas evolution (or absorption) to the cross section of the pipe.

Theory and experiment, therefore, agree in showing that diffusion is the really important element in the movement of gases in a long, horizontal pipe closed at one end. Theory also shows that if a gas such as carbon dioxide is produced uniformly along the pipe, as may be the case when deposits of organic matter decompose, the maximum concentration of this gas in the pipe will vary as the square of the length of the pipe; that is to say, in a pipe 20 feet long the maximum concentration will be four times as great as in a pipe 10 feet long, if the short length near the stack wherever eddy currents occur be neglected. 


\section{EVAPORATION OF WATER}

The same cups that were used in the previous experiments were filled with 10 cubic centimeters of distilled water and exposed to the air of the pipe as before. The cups of water were weighed before and after exposure and the loss in weight, or evaporation, recorded. Experiments $\mathrm{F}$ and $\mathrm{G}$ (figs. 98 and 99) represent typical results obtained by this method.

Calculations revealed the fact that more water was evaporated from the cups than the air in the pipe was able to retain in the form of vapor. Either the moisture must, therefore, have been removed from the air or the air itself must have been replaced by fresh air. According to the other experiment made, it seems unlikely that the air of the pipe could have been thus replaced. Moreover, calculations showed that diffusion could not have removed as much water vapor as was produced. It is probable, therefore, that the rust on the interior of the pipes absorbed some of the moisture from the air after being evaporated from the cups. The absorption of moisture by the rust on the pipe would explain the absence of a critical distance from the stack within which diffusion occurred.

\section{CONVECTION CURRENTS}

Under certain conditions temperature differences will cause convection currents in horizontal pipes. This has already been mentioned in connection with the hot smoke experiments. When the air in the stack is warmer than that in the horizontal branch, it will tend to enter the branch and push inward along the top, displacing the cooler air which will leave the branch along the bottom. In this way a convection current may be set up. Differences in temperatures along the horizontal pipe, such as may occur when a pipe extends through a warm room and the cooler atmosphere of a partition, may also set up local convection currents. These would have much the same effect as diffusion currents. Some of the experiments made show that this phenomenon occurs.

The effect of convection currents is shown by experiment $H$ (fig. 100), which ran for five days. In this case there was a relatively greater absorption of carbon dioxide at cups $h$ and $i$ because these cups were getting the relatively fresher air (higher in carbon dioxide) which had been passing along the top of the pipe for some distance. In other words, the carbon dioxide was kept away from the absorbing solutions at the bottom of the pipe until it had reached the last cup, $i$. This same effect is shown to a less degree in experiments $B$ and $D$. These temperature effects, however, are slight and erratic and can not be expected to play an important part in the movement of gases to or from the pipe.

\section{DIFFUSION OF GASES THROUGH WATER-SEAL TRAPS}

The rate at which a gas such as hydrogen sulphide in a drain below a trap will pass through the water seal into the atmosphere of a room depends upon four factors - the amount of gas in the drain, the cross section of the trap, the developed length of the trap seal, and the character of the gas with respect to its power of diffusion, the 


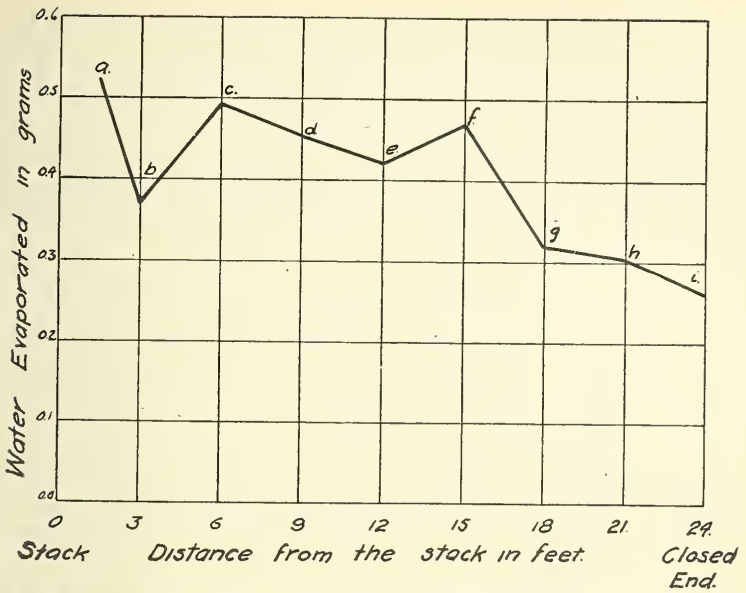

FIG. 98.-Experiment F. Evaporation of water in a $1 \frac{1}{2}$ inch horizontal branch connected with a vertical stack. Time, 46 hours. No foreed draft

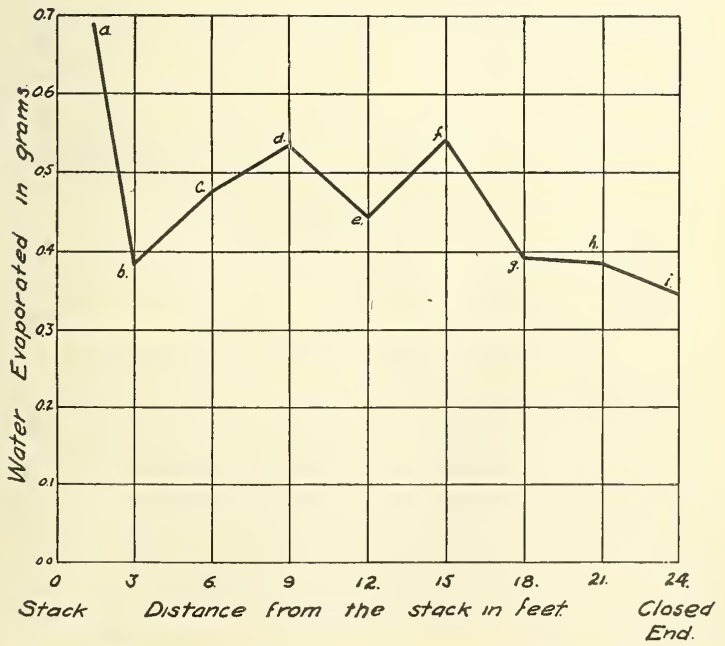

FIG. 99.-Experiment G. Evaporation of water in a $1 \frac{1}{2}$-inch horizontal branch connected with a vertical stack. Time, 48 hours. Forced draft; 100 feet per minute 
latter being known to chemists. The deeper the seal the less gas will pass; the greater the cross section of the trap and the larger the amount of gas in the drain the more gas will pass through. There is one other factor which may influence diffusion, namely, the time the water remains in the trap. The longer the time, up to a certain limit, the greater the amount of diffusion.

Computations for hydrogen sulphide, based on theoretical considerations, showed that the danger of this gas diffusing through the water from the drain to the room atmosphere is negligible. To make this computation required some experimental work.

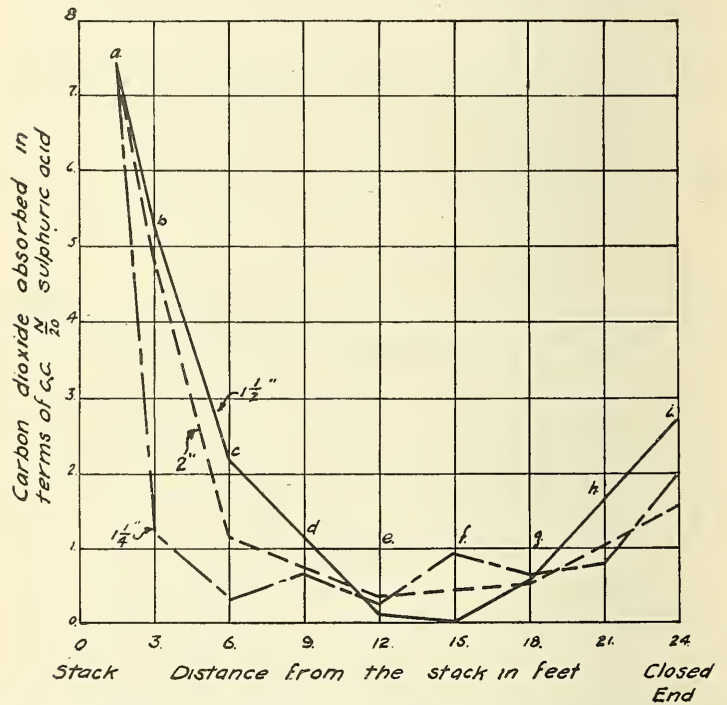

Fig. 100.-Experiment H. Diffusion of carbon dioxide in $1 \frac{1}{4}, 1 \frac{1}{2}$, and 2 inch horizontal branches connected with vertical stacks. Time, 120 hours. Forced draft; 180 feet per minute

A 2-inch half $S$ trap was tightly sealed on the side which would ordinarily be toward the drain. Two rubber tubes were led into the interior of the trap through its open end, their openings being very near to the closed end of the trap. The trap was then mounted in a horizontal position and water poured into it until there was a depth of seal of about 2 inches. Hydrogen sulphide was then led into the sealed arms through one of the rubber tubes, the other rubber tube being used to relieve the pressure. After one and one-half hours a distinct odor could be detected by placing the nose near to the water in the open end of the trap. This indicated that the gas had diffused through the water. 
Probably the concentration of the gas in the sealed arm was not far from 100 per cent. This condition would never occur in practice. If the concentration of hydrogen sulphide in the sewer air were 1 part per 10,000, an amount probably larger than ever occurs, the odor from the water of the trap on the room side would be far too small to be detected and may be regarded as entirely negligible. It may be safely said that the danger of odoriferous gases passing through a water seal trap by diffusion is negligible.

The generation of gases by the decomposition of organic material collected in the trap itself would be of greater importance. These would be proportional to the amount of decomposable matter caught in the trap. The larger the volume of water in the trap the less would be the concentration of the gas and the odor given off for a given amount of material. A large, deep trap, however, would tend to retain more sediment and offer a larger interior surface for bacterial growth. Such a trap, therefore, might slightly increase the odor on the room side.

More important than odors diffusing through the trap or being generated in the trap are those due to the decomposition of organic matter deposited on the walls of the pipe between the fixture and the trap and on the walls of the trap itself which may be exposed when the trap seal is reduced. 


\title{
APPENDIX D-STANDARD SPECIFICATIONS OF THE AMERICAN SOCIETY FOR TESTING MATERIALS
}

\author{
[Affiliated with the International Association for Testing Materials]
}

\author{
CLAY SEWER PIPE
}

\author{
Serial Designation, C 13-20
}

[Proposed as tentative, 1917; adopted in amended form, 1920]

1. These specifications cover clay products intended to be used for the conveyance of sewage, industrial wastes, and storm water.

2. Sewer pipes furnished under these specifications shall be of a single class to be designated "A.S.T.M. Clay Sewer Pipe."

\section{MATERIAL AND MANUFACTURE}

3. (a) Clay pipes shall be manufactured from surface clay, fire clay or shale, or a combination of these materials.

(b) By surface clay is meant an unstratified, unconsolidated, plastic glacial or alluvial clay, laid down by the glacial ice sheet, or on the flood plains of rivers, during the present geological epoch.

(c) By fire clay is meant a stratified clay, usually buff-burning, usually less indurated than shales, with poorly marked cleavage, laid dewn prior to the present geological epoch.

(d) By shale is meant a stratified clay, usually red-burning, more or less indurated by heat or pressure, with well-marked cleavage laid down prior to the present geological epoch.

(e) The materials shall possess such physical and chemical properties that when molded into pipes and subjected to a suitable temperature the product will be strong, durable, and serviceable, free from objectionable defcets, and in compliance with these specifications and tests.

\section{CHEMICAL TESTS AND REQUIREMENTS}

4. The consumer or purchaser may prescribe in advance special chemical requirements in cases where industrial wastes have marked acid or alkaline character, or are of abnormally high temperatures. He may make use of chemical analysis of the pipe material to ascertain whether these special requirements are met. The presence of visible grains or masses of caustic lime, iron pyrites, or any other materials which cause slaking or disintegration shall be a cause for rejection.

\section{PHYSICAL TESTS}

5. The physical tests of pipes shall include crushing test, hydrostatic pressure test, and absorption test.

6. The specimens to be tested shall be selected by the purchaser or his representative at the point or points designated by him when placing the order. The manufacturer or seller shall furnish specimens for test, without separate charge, up to 1 per cent of the number 
of pipes to be delivered or furnished in each size of pipe. The minimum number of specimens for any delivery less than 200 pieces shall be two specimens in each size of pipe.

7. Failure of 20 per cent of the specimens to meet the requirements of any of the tests imposed shall result in rejection of all the pipe in the shipment or delivery, corresponding to the sizes thus failing to comply; except that in the event of 20 per cent of the specimens in any size failing to meet the requirements the manufacturer or seller may, with the consent of the consumer or purchaser, furnish for test additional specimens from the same shipment without charge. In case more than 80 per cent of the specimens tested, including those first tested, shall show substantial compliance for each of the various tests performed, then the entire shipment or delivery for this size shall be accepted; otherwise it shall be rejected.

8. The specimens of pipes shall be sound, full-size pipe. They shall first be freed from all visible moisture. When dry, each specimen shall be weighed, measured, and inspected. The results of these observations shall be recorded and preserved as shown in Table 1.

9. Specimens which, when placed in a vertical position, do not give a metallic ring when struck with a hammer, or are observed to have fire cracks or other defects in form or dimensions in excess of the limits permitted in these specifications, shall be discarded and replaced with additional specimens from the shipment.

\section{(A) Crushing tests}

10. (a) Any prime mover or hand power which will apply the load at a uniform rate of about 2,000 pounds per minute, or in increments of not more than 100 pounds at the same rate, may be used in making the test.

(b) The pipe shall not be allowed to stand under load longer than is required to apply the load and to observe and record it.

(c) The testing machine shall be substantial and rigid throughout, so that the distribution of the load will not be affected appreciably by the deformation or yielding of any part.

(d) The bearings and the specimen shall be accurately centered so as to secure a symmetrical distribution of the loading on each side of the center of the pipe in every direction.

(e) The load shall be applied until the pipe yields by cracks passing through the shell.

11. (See figs. 1,2, and 3.) Except as otherwise hereinafter specified, the pipe to be tested shall be supported by a metallic knife bearing 1 inch wide and extended from a point just back of the socket to the spigot end of the pipe. Before the pipe is placed a fillet of plaster of Paris and sand 1 inch wide and thick enough to compensate for all the inequalities of the pipe barrel shall be cast on the surface of the knife-edge bearing. The pipe shall be placed upon the fillet while the plaster of Paris is still somewhat plastic. The load shall be applied through an upper knife bearing of the same size and length as the lower bearing. A plaster-of-Paris fillet 1 inch wide shall be cast along the length of the crown of the pipe to equalize the lower bearing before the upper one is brought into contact. 


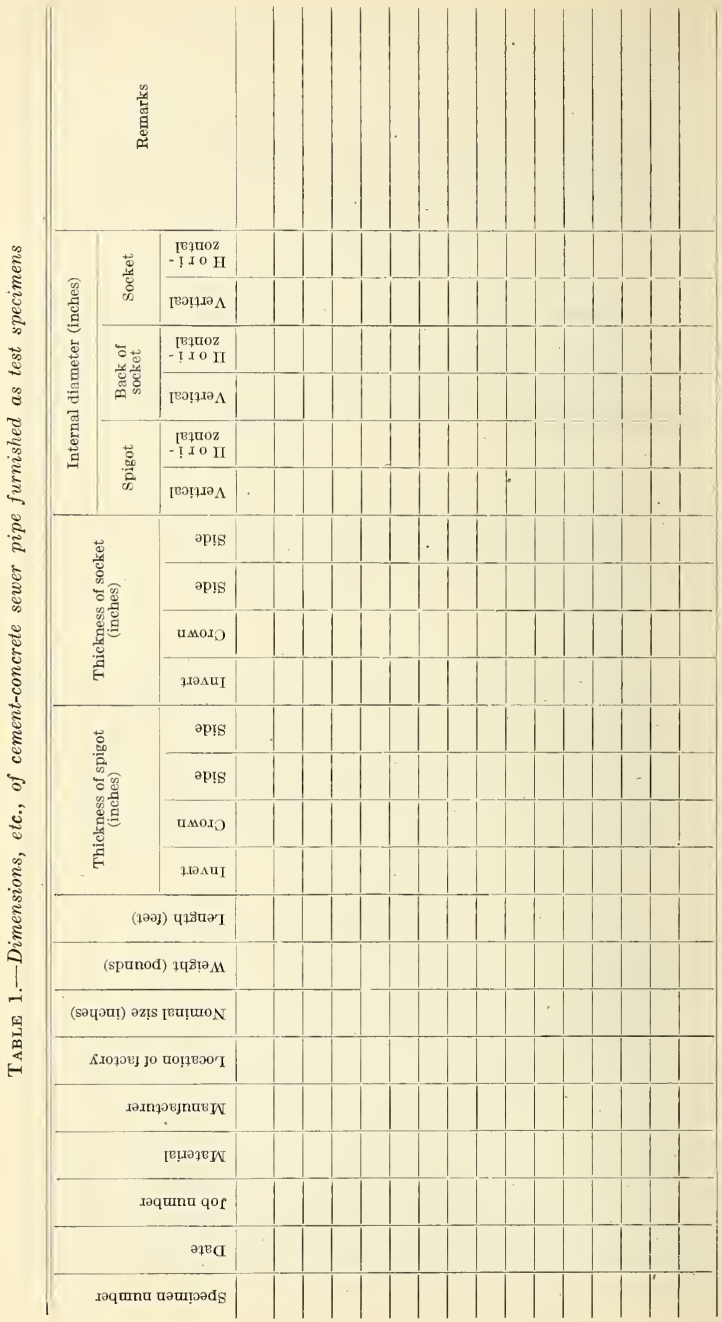


Both of the bearings shall be sufficiently rigid to transmit and receive uniform loads throughout their lengths without deflection and shall be so attached to the machine as to transmit and receive the maximum stresses produced by the tests without lost motion, vibration, or sudden shock.

At the option of the consumer or purchaser the crushing test may be applied with sand bearings or with two or three edge bearings.

The crushing strength shall be calculated by dividing the total load required to break each pipe by the net inside length of the barrel of the pipe, measuring from the bottom of the socket to the end of the spigot, and by then multiplying the quotient by the following factors:

For knife or two-edge bearings $\ldots+\frac{10}{7}$
For three-edge bearings
For sand bearings

12. (See fig. 2.) When three-edge bearings are used, the ends of each specimen of pipe shall be accurately marked in halves of the circumference prior to the test.

The two lower bearings shall consist of two wooden strips with vertical sides, each strip having its interior top corner rounded to a radius of approximately one-half inch. They shall be straight and shall be securely fastened to a rigid block with their interior vertical sides 1 inch apart.

The upper bearing shall be a wooden block, straight and true from end to end.

The test load shall be applied through the upper bearing block in such a way as to leave the bearing free to move in a vertical plane passing midway between the lower bearings.

In testing a pipe which is "out of straight," the lines of the bearings chosen shall be from those which appear to give most favorable conditions for fair bearings.

13. (See fig. 3.) When sand bearings are used, the ends of each specimen of pipe shall be accurately marked prior to the test in quarters of the circumference. Specimens shall be carefully bedded, above and below, in sand, for one-fourth the circumference of the pipe measured on the middle line of the barrel. The depth of bedding above and below the pipe at the thinnest points shall be one-half the radius of the middle line of the barrel. The sand used shall be clean, and shall be such as will pass a No. 4 screen.

The top bearing frame shall not be allowed to come in contact with the pipe nor with the top bearing plate. The upper surface of the sand in the top bearing shall be struck level with a straight edge and shall be covered with a rigid top bearing plate, with lower surface a true plane, made of heavy timbers or other rigid material, capable of distributing the test load uniformly without appreciable bending. The test load shall be applied at the exact center of this top bearing plate in such a manner as to permit free motion of the plate in all directions. For this purpose a spherical bearing is preferred, but two rollers at right angles may be used. The test may be made without the use of a testing machine, by piling weights directly on a platform resting on the top bearing plate, provided, however, that the weights shall be piled symmetrically about a vertical line through the center of the pipe, and that the platform shall not be allowed to touch the top bearing frame. 

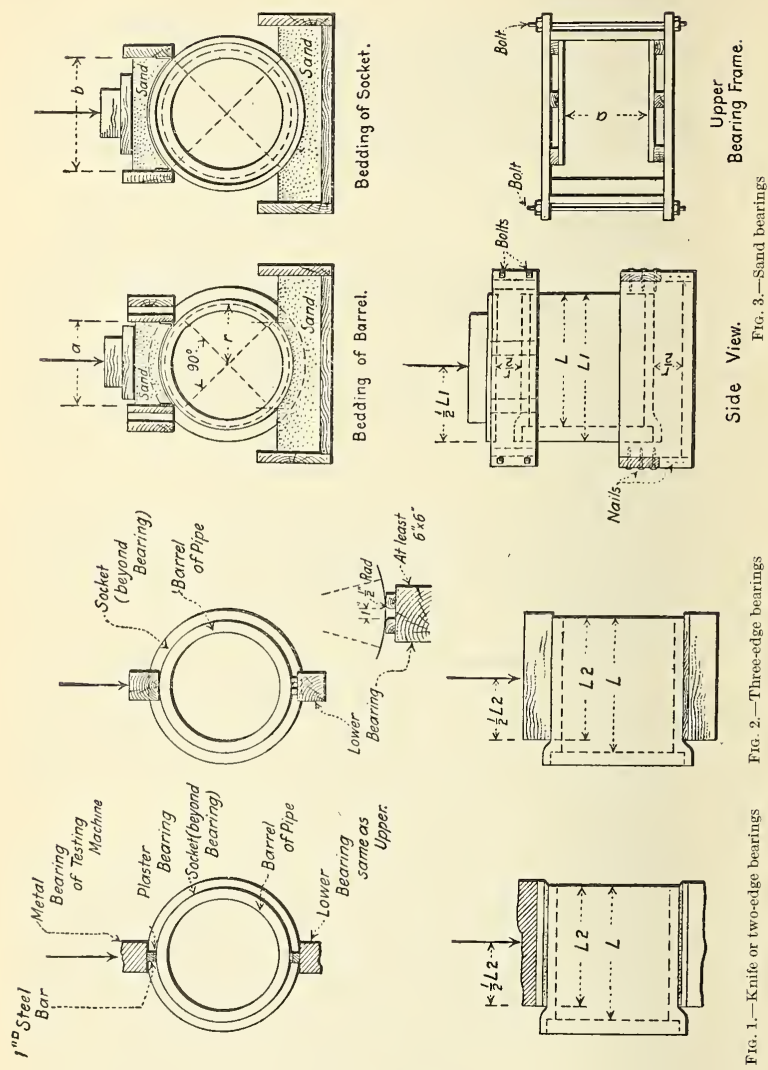
The frames of the top and bottom bearings shall be made of timbers so heavy as to avoid appreciable bending by the side pressure of sand. The interior surfaces of the frames shall be dressed. No frame shall come in contact with the pipe during the test. A strip of cloth may, if desired, be attached to the inside of the upper frame on each side, along the lower edge, to prevent the escape of sand between the frame and the pipe.

14. The crushing test shall ordinarily be applied to not less than 75 per cent of the specimens received for testing purposes.

15. Pieces of the crushed pipe may be used as specimens in making the absorption test.

\section{(B) Hydrostatic test}

16. Sound full-size pipe not exceeding about 25 per cent of the specimens received for test in each size of pipe, shall be tested for leakage under internal hydrostatic pressure.

The ends of the pipe shall be tightly closed by wooden or metallic bulkheads or covers faced with rubber or leather so that no leakage shall occur through the covers at the test pressure. One cover shall be provided with a three-fourths inch wrought iron nipple passing through the cover and held securely in place and made water-tight by means of locknuts and washers or gaskets. The outer end of the nipple shall be connected with a pump discharge or water service line.

Water pressure, as measured by a standardized gauge attached to the delivery pipe close to the specimen, shall be internally applied to the specimen as follows:

5 pounds per square inch for 5 minutes.

10 pounds per square inch for 10 minutes.

15 pounds per square inch for 15 minutes.

The specimens shall show no leakage under these pressures. Moisture appearing on the surface of the pipe in the form of patches or beads, adhering to the surface, shall not be considered leakage.

\section{(C) Absorption test}

17. The specimens shall be sound pieces, with all edges broken, and may be from pipes broken in the crushing or other tests. They shall be from 12 to 20 square inches in area and shall be as nearly square as they can be readily prepared. They shall be free from observable cracks, fissures, laminations, or shattered edges.

18. Preparatory to the absorption test, the specimen shall be first weighed and then dried in a drier or oven at a temperature of not less than $110^{\circ} \mathrm{C}$. $\left(230^{\circ} \mathrm{F}\right.$.) for not less than three hours. After removal from the drier the specimen shall be allowed to cool in dry air to a temperature of 20 to $25^{\circ} \mathrm{C}$. ( 68 to $77^{\circ} \mathrm{F}$.) and then reweighed.

If the specimen is comparatively dry when taken, and the second weight closely agrees with the first, it shall be considered dry. If the specimen is wet when taken, it shall be placed in the drier for a drying treatment of two hours and reweighed. If the third weight checks the second, the specimen shall be considered dry. In case of any doubt, the specimen shall be redried for two-hour periods, until check weights are obtained.

19. The balance used shall be sensitive to $0.5 \mathrm{~g}$ when loaded with $1 \mathrm{~kg}$, and weighings shall be read to the nearest gram. When other 
than metric weights are used, the same degree of accuracy shall be obtained.

20. The specimen after final drying, cooling, and weighing shall be placed with other similar specimens in a suitable wire receptacle, packed tightly enough to prevent jostling, covered with distilled water or rainwater, raised to the boiling point and boiled for five hours, and then cooled in water to a final temperature of 10 to $15^{\circ} \mathrm{C}$. (50 to $59^{\circ}$ F.)

21. The specimen shall be allowed to drain for one minute and, the superficial moisture having been removed by towel or blotting paper, placed upon the balance.

22. The test result shall be calculated as percentage of the initial dry weight.

23 . One specimen shall be tested of each pipe broken in the crushing test.

24 . The results shall be reported separately for each individual specimen, together with the mean for all the specimens from the same shipment of pipe.

25. Each specimen shall be marked so that it may be identified with the pipe used in the crushing test from which the specimen was taken. The marking shall be applied so that the pigment used shall not cover more than 1 per cent of the total superficial area of the specimen.

\section{PHYSICAL TEST REQUIREMENTS}

26. The test requirements of clay sewer pipe shall be as given in Table 2. The individual results of the various tests for each size of pipe and for each shipment, class, and mill shall be tabulated separately, so as to show the percentage which fails to comply with the requirements of each test.

TABLE 2.- Physical test requirements of clay sewer
\begin{tabular}{|c|c|c|}
\hline $\begin{array}{c}\text { Internal diam- } \\
\text { eter }\end{array}$ & $\begin{array}{c}\text { Minimum crush- } \\
\text { ing strength }\end{array}$ & $\begin{array}{c}\text { Maximum ab- } \\
\text { sorption }\end{array}$ \\
\hline & & \\
\hline Inches & Lbs. per lin.ft. & Per cent \\
4 & 1,430 & 8 \\
6 & 1,430 & 8 \\
8 & 1,430 & 8 \\
10 & 1,570 & 8 \\
12 & 1,710 & 8 \\
& & 8 \\
15 & 1,960 & 8 \\
21 & 2,200 & 8 \\
24 & 2,590 & 8 \\
27 & 3,070 & 8 \\
30 & 3,370 & 8 \\
33 & 3,690 & 8 \\
36 & 3,930 & 8 \\
39 & 4,400 & \\
42 & 4,710 & \\
& 5,030 & \\
\hline
\end{tabular}

1 See end of section 11 .

V. A. S. T. M. SIZES AND DIMENSIONS

27. Pipes shall be furnished of the sizes, internal diameter, and with the dimensions given in Tables 3 and 4 . Where several lengths are mentioned in the table the consumer or purchaser shall indicate, at the time of purchase, which lengths shall be furnished, and unless so indicated the manufacturer shall furnish such lengths as he may elect. 
TABLe 3.-Dimensions of clay sewer pipe

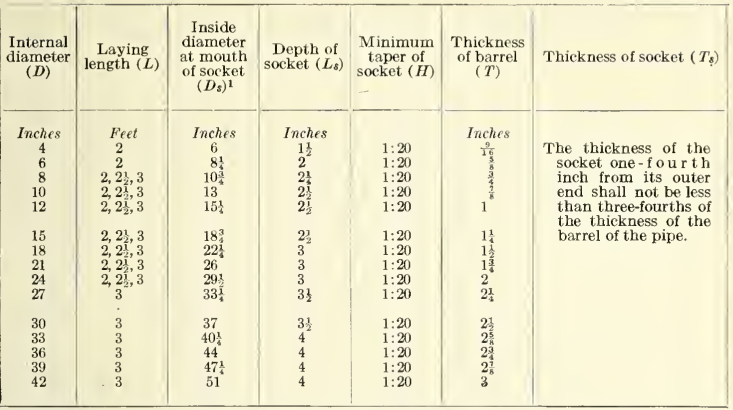

${ }^{1}$ When pipes are furnished having an increase in thickness over that given in last column, the diameter of socket shall be increased by an amount equal to twice the increase of thickness of barrel.
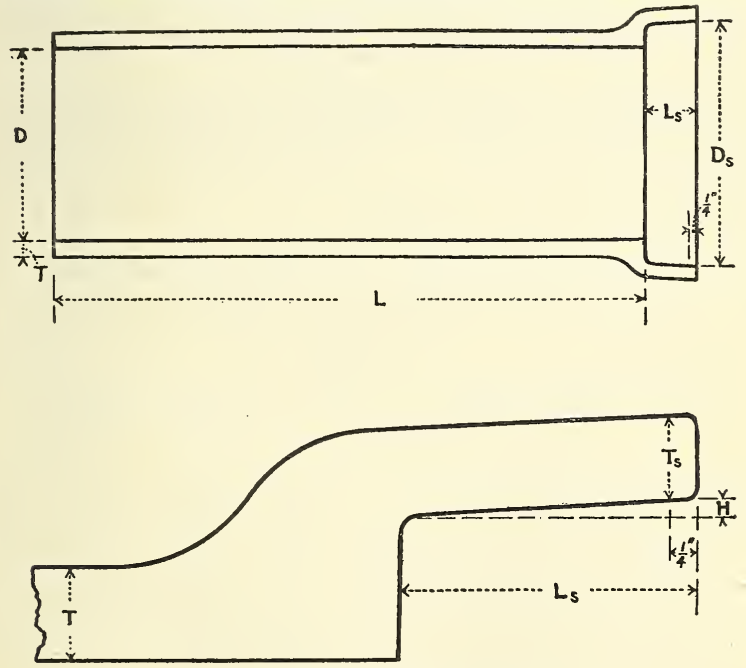

FIg. 4.-Application of dimensions given in Table 3

28. The permissible variation from the dimensions given in Table 3 shall not exceed those stated in Table 4 . Where the thickness of barrel is increased beyond that given in Table 4 in order to meet the specified requirements of strength, the diameter at inside $94877^{\circ}-24-17$ 
of socket shall be increased by double the increase in thickness of barrel. Pipes intended to be straight shall not have variation in alignment of more than one-eighth inch per foot of length.

\section{WORKMANSHIP AND FINISH}

29. Pipes shall be substantially free from fractures, large or deep cracks and blisters, laminations, and surface roughness.

30 . The inner surface of the socket and the outer surface of the spigot end shall be scored by triangular shaped or semicircular shaped rings about one-eighth inch deep.

The number of scorings shall be as follows:

For pipes 4 to 6 inches in internal diameter, inclusive ..... . None.

For pipes 8 to 10 inches in internal diameter, inclusive.... 2

For pipes 12 to 21 inches in internal diameter, inclusive...- 3

For pipes 24 to 30 inches in internal diameter, inclusive ... 4

For pipes 33 to 42 inches in internal diameter, inclusive

31. The glaze shall consist of a continuous layer of bright or semibright glass substantially free from coarse blisters and pimples. If present, none of these shall project more than one-eighth inch above the surrounding surface. Not more than 10 per cent of the inner surface of any pipe barrel shall be bare of glaze except the socket, where it may be entirely absent. Glazing will not be required on the outer surface of the barrel at the spigot end for a distance from the end equal to two-thirds the specified depth of socket for the corresponding size of pipe. Where glazing is required, there shall be absence of any well-defined net work of crazing lines or hair cracks. All glazing shall be equal to that produced by the best salt-glazing process.

32. The ends of the pipes shall be square with their longitudinal axis, except as provided in Table 4 .

TABLE 4.-Permissible variations in dimensions of clay sewer pipe

\begin{tabular}{|c|c|c|c|c|c|c|}
\hline \multirow{3}{*}{$\begin{array}{c}\text { Normal } \\
\text { size } \\
\text { (inches) }\end{array}$} & \multicolumn{6}{|c|}{ Limits of permissible variation in- } \\
\hline & \multirow{2}{*}{$\begin{array}{l}\text { Length, } \\
\text { inches per } \\
\text { foot }(-) \text {. }\end{array}$} & \multirow{2}{*}{$\begin{array}{l}\text { Lengths of } \\
\text { two oppo- } \\
\text { site sides }\end{array}$} & \multicolumn{2}{|c|}{$\begin{array}{l}\text { Internal diameter } \\
\text { (inches) }\end{array}$} & \multirow{2}{*}{$\begin{array}{c}\text { Depth of } \\
\text { socket }(-)\end{array}$} & \multirow{2}{*}{$\begin{array}{l}\text { Thickness of } \\
\text { barrel }(-)\end{array}$} \\
\hline & & & Spigot $( \pm)$ & Socket $( \pm)$ & & \\
\hline $\begin{array}{r}4 \\
6 \\
8 \\
10 \\
12\end{array}$ & $\begin{array}{l}\frac{1}{4} \\
\frac{1}{4} \\
i \\
\frac{1}{1} \\
\frac{1}{1} \\
\frac{1}{4}\end{array}$ & $\begin{array}{c}\text { Inches } \\
\frac{1}{8} \\
\frac{1}{8} \\
\frac{1}{3} \\
\frac{1}{6} \\
\frac{8}{8} \\
\frac{1}{8} \\
\frac{1}{8}\end{array}$ & $\begin{array}{c}\frac{1}{8} \\
\frac{1}{16} \\
\frac{1}{3} \\
\frac{1}{16} \\
\frac{3}{16}\end{array}$ & $\begin{array}{l}\frac{3}{16} \\
\frac{1}{6} \\
\frac{16}{16} \\
\frac{8}{16} \\
\frac{3}{8}\end{array}$ & $\begin{array}{c}\text { Inches } \\
\frac{1}{3} \\
\frac{1}{4} \\
\frac{1}{2} \\
\frac{1}{4} \\
\frac{1}{4} \\
\frac{1}{4}\end{array}$ & $\begin{array}{c}\text { Inches } \\
\frac{1}{10} \\
\frac{1}{16} \\
\frac{1}{16} \\
\frac{1}{18} \\
\frac{1}{18} \\
\frac{1}{16}\end{array}$ \\
\hline $\begin{array}{l}15 \\
18 \\
21 \\
24 \\
27\end{array}$ & $\begin{array}{l}\frac{1}{4} \\
\frac{1}{3} \\
\frac{1}{4} \\
\frac{3}{4} \\
\frac{3}{8}\end{array}$ & $\begin{array}{c}\frac{1}{8} \\
\frac{3}{16} \\
\frac{3}{16} \\
\frac{3}{3} \\
\frac{1}{4} \\
\frac{1}{4}\end{array}$ & $\begin{array}{l}\frac{5}{16} \\
\frac{3}{3} \\
\frac{7}{16} \\
\frac{1}{2} \\
\frac{5}{8}\end{array}$ & $\begin{array}{l}\frac{3}{8} \\
\frac{7}{16} \\
\frac{1}{2} \\
\frac{3}{16} \\
\frac{11}{16}\end{array}$ & $\begin{array}{l}\frac{1}{1} \\
\frac{1}{1} \\
\frac{1}{4} \\
\frac{1}{4} \\
\frac{1}{4}\end{array}$ & $\begin{array}{c}\frac{3}{3 / 3} \\
\frac{3}{32} \\
\frac{1}{6} \\
\frac{1}{8} \\
\frac{1}{8}\end{array}$ \\
\hline $\begin{array}{l}30 \\
33 \\
36 \\
39 \\
42\end{array}$ & $\begin{array}{l}\frac{3}{3} \\
\frac{1}{3} \\
\frac{3}{6} \\
\frac{3}{3} \\
\frac{3}{6}\end{array}$ & $\begin{array}{l}\frac{1}{4} \\
\frac{3}{3} \\
\frac{3}{4} \\
\frac{3}{4} \\
\frac{1}{3} \\
\frac{1}{3}\end{array}$ & $\begin{array}{l}\frac{5}{8} \\
\frac{3}{3} \\
\frac{3}{4} \\
\frac{3}{4} \\
4 \\
4\end{array}$ & $\begin{array}{l}11 \\
11 \\
11 \\
15 \\
13 \\
15 \\
15 \\
16 \\
15 \\
18\end{array}$ & $\begin{array}{l}\frac{1}{4} \\
\frac{1}{4} \\
\frac{1}{4} \\
\frac{1}{4} \\
\frac{1}{4} \\
\frac{1}{4}\end{array}$ & $\begin{array}{l}\frac{1}{8} \\
\frac{3}{16} \\
\frac{1}{16} \\
\frac{3}{16} \\
\frac{3}{16}\end{array}$ \\
\hline
\end{tabular}

Note, - The minus sign (-) alone indicates that the plus variation is not limited; the plus and minus sign $( \pm)$ indicates variation in both excess and deficiency in dimension. 
33. (a) Special shapes shall have a plain spigot end and a socket end corresponding in all respects with the dimensions specified for pipes of the corresponding internal diameter. Branch pipes shall be furnished to lay the same lengths as straight pipe. All specials shall conform in finish to the specifications for pipes given in sections $29,30,31$, and 32 .

(b) Slants shall have their spigot ends cut at an angle of approximately 45 degrees with the longitudinal axis.

(c) Curves shall be at angles of 90,45 , and $22 \frac{1}{2}$ degrees, as required. They shall conform substantially to the curvature specified.

(d) Branches shall be furnished with the connection or connections of the size or sizes specified, securely and completely fastened by fusion in the process of vitrification to the barrel of the pipe. T-branches and double T-branches shall have the axis perpendicular to the longitudinal axis of the pipe. Y-branches, double $Y$-branches, and V-branches shall have their axes approximately $45^{\circ}$ from the longitudinal axis of the pipe measured from the socket end. All branches shall terminate in sockets, and the barrel of the branch shall be of sufficient length to permit making a proper joint when the connecting pipe is inserted in the branch socket.

(e) Channel or split pipes, curves, and branches shall be accurate half sections of the corresponding size of straight pipe and specials.

\section{MARKINGS}

34. Pipes shall bear the initials or name of the person, company or corporation by whom they are manufactured, and the location of the mill. The markings shall be indented on the exterior of the barrel near the socket and shall be plainly legible for purpose of identification.

VIII. INSPECTION

35. All pipes shall be subject to inspection at the factory, trench, or other point of delivery by a competent inspector employed by the consumer or purchaser. The purposes of the inspection shall be to cull and reject pipes which, independent of the physical tests herein specified, fail to comply with the requirements of these specifications.

36. Pipes shall be subject to rejection on account of the following:

(a) Variations in any dimension exceeding the permissible variations given in Table 4.

(b) Fracture or cracks passing through the shell or socket, except that a single crack at either end of a pipe not exceeding 2 inches in length or a single fracture in the socket not exceeding 3 inches in width nor 2 inches in length will not be deemed cause for rejection unless these defects exist in more than 5 per cent of the entire shipment or delivery.

(c) Blisters where the glazing is broken or which exceed 3 inches in diameter, or which project more than one-eight inch above the surface.

(d) Laminations which indicate extended voids in the pipe material.

(e) Fire eracks or hair cracks sufficient to impair the strength, durability, or serviceability of the pipe.

(f) Variation of more than one-eighth inch per linear foot in alignment of a pipe intended to be straight. 
(g) Glaze which does not fully cover and protect all parts of the shell and ends except those exempted in section 31 ; also glaze which is not equal to best salt glaze.

(h) Failure to give a clear ringing sound when placed on end and dry-tapped with a light hammer.

(i) Insecure attachment of branches on spurs.

37. All rejected pipes shall be plainly marked by the inspector and shall be replaced by the manufacturer or seller with pipes which meet the requirements of these specifications without additional cost to the consumer or purchaser.

\section{CAST-IRON SOIL PIPE AND FITTINGS}

Serial Designation, A 74-18

JProposed as tentative, 1917; adopted 1918.]

\section{MANUFACTURE}

1. The cast iron from which the pipe and fittings are made shall be of such composition and the conditions of manufacture so maintained that the castings will be of uniform physical character, close grain, and not hard, brittle, nor difficult to cut with file or chisel.

2. (a) When pipe or fittings are to be coated, coal-tar pitch shall be used, which shall contain sufficient oil to make a smooth coating. The pitch shall be tough and tenacious when cold and not brittle nor having any tendency to scale.

(b) The varnish shall be heated to about ${ }^{\circ} 300^{\circ} \mathrm{F}$. and shall remain at this temperature during the time the casting is immersed.

(c) Each casting shall be heated to a uniform temperature of about $300^{\circ} \mathrm{F}$. immediately before it is dipped and shall possess this temperature at the time it is put in the bath.

(d) Each casting shall remain in the bath at least two minutes.

(e) Fresh pitch and oil shall be added when necessary to keep the mixture of the proper consistency, and the vat shall be emptied of its contents and refilled with fresh pitch whenever the accumulation of sand or carbonaceous matter renders this desirable, as can be seen by the solids adhering to the underside or lower ends of the castings.

$(f)$ After being coated the pipe and fittings shall be carefully drained of the surplus varnish.

\section{CHEMICAL PROPERTIES AND TESTS}

3. Drillings taken from the fractured end of the arbitration test bar shall not contain over 0.10 per cent of sulphur.

\section{PHYSICAL PROPERTIES AND TESTS}

4. The transverse test specimens (arbitration test bars) specified in section 7 , when placed horizontally upon supports 12 inches apart and tested under a centrally applied load, shall conform to the following minimum requirements:

Average load at center pounds_- 2,500

Average deflection at center. inches.. 0.10

5. All pipe shall be tested to a hydrostatic pressure of not less than 50 pounds per square inch before coating. Any casting showing defects under this hydrostatic test shall be promptly broken and returned to the cupola. 
6. The form and dimensions of the mold for the arbitration test bar shall be in accordance with Figure 1. The bottom of the bar shall be one-sixteenth inch smaller in diameter than the top to allow for draft and for the strain of pouring. The pattern shall not be rapped before withdrawing. The flask shall be rammed up with green molding sand, a little damper than usual, well mixed and put through a No. 8 sieve, with a mixture of 1 to 12 bituminous facing. The mold shall be rammed evenly and fairly hard, thoroughly dried, and not cast until it is cold. The test bar shall not be removed from

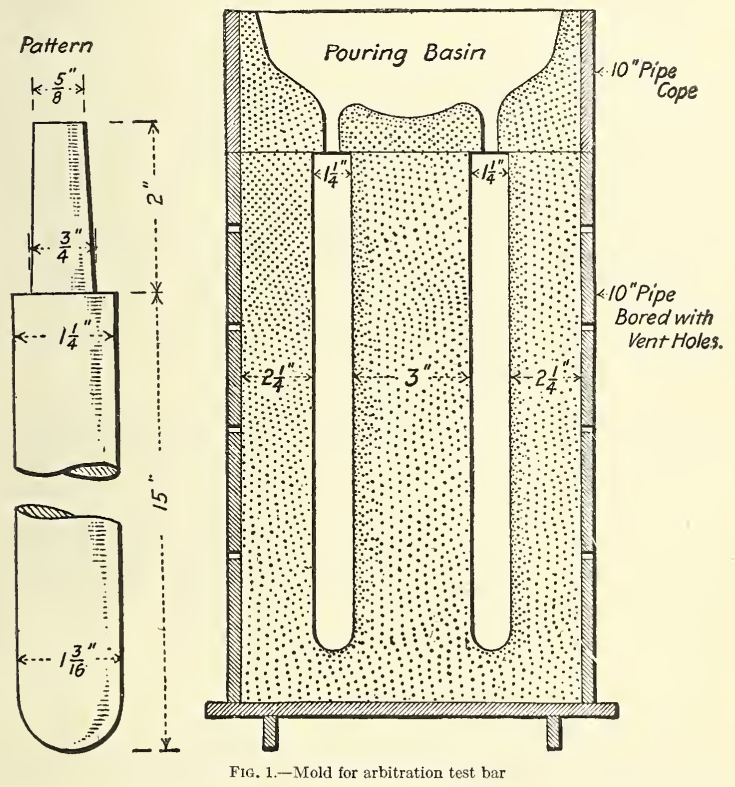

the mold until cold enough to be handled. It shall not be rumbled or otherwise treated, being simply brushed off before testing.

7. From each melt of metal not less than three test specimens (arbitration test bars) shall be poured, the first of which shall be poured within five minutes after the first ladle is tapped and the remainder at intervals not exceeding one hour throughout the melt.

\section{STANDARD SIZES AND WEIGHTS}

8. (a) The inside diameter of the barrel of any pipe or fittings or branch thereof shall not vary more than one-eighth inch under the nominal size of pipe. 
(b) The outside diameter of the barrel of pipe and fittings shall be one-half inch greater than its nominal inside diameter. A variation in the outside diameter of one-eighth inch over or under these figures will be permitted.

(c) All pipe and fittings shall be of uniform thickness of wall and present true circles at the hub and spigot ends. A variation of one-sixteenth of an inch under the following dimensions will be permitted, but only when the actual weight is not less than the variation of the marked or estimated weight as given in Tables 1 and 2:

Thickness of--

Barrel

Body of hub.

Bead of hub

Bead of spigot end

9 (a) Weights and measurements of pipe and fittings shall be taken as those of plain uncoated pipe. All weights shall be given in pounds.

(b) Individual lengths of pipe and fittings may weigh 5 per cent less than designated in Tables 1 and 2 , but only when the average weight of a given size and weight of pipe and fittings selected at random is not less than that shown in Tables 1 and 2 .

(c) The regular length of pipe shall be such as to lay 5 feet, including hub.

(d) The average weights of soil pipe and fittings shall not be less than those given in Tables 1 and 2 .

TABLE 1.-Weights of soil pipe

\begin{tabular}{|c|c|c|c|}
\hline \multirow{2}{*}{ Size (inches) } & \multicolumn{2}{|c|}{ Single hub } & \multirow{2}{*}{$\frac{\begin{array}{c}\text { Double } \\
\text { hub }\end{array}}{} \frac{\begin{array}{c}\text { Per 5-foot } \\
\text { length }\end{array}}{}$} \\
\hline & $\begin{array}{l}\text { Per } 5 \text {-foot } \\
\text { length }\end{array}$ & $\begin{array}{l}\text { Per foot in- } \\
\text { cluding hub }\end{array}$ & \\
\hline 5 6 & $\begin{array}{r}\text { Pounds } \\
27 \frac{1}{2} \\
47 \frac{1}{2} \\
65 \\
85 \\
100\end{array}$ & $\begin{array}{c}\text { Pounds } \\
5 \frac{1}{2} \\
9 \frac{1}{2} \\
13 \\
17 \\
20\end{array}$ & $\begin{array}{r}\text { Pounds } \\
27 \frac{1}{2} \\
47 \frac{1}{2} \\
65 \\
85 \\
100\end{array}$ \\
\hline
\end{tabular}

v. WORKMANSHIP AND FINISH

10. (a) All pipe and fittings shall be practically straight and cylindrical and fittings true to pattern. The specified sizes shall be for the inside diameter and shall conform, within the allowable variation, to the dimensions given in the tables.

(b) All pipe and fittings shall be carefully examined for defects and sounded with a hammer before shipment. No fillings with metal, cement, or other material, or so-called "burning on" of iron will be permitted. The castings shall be sound and free from cracks, sand holes, blowholes, and cold shots.

\section{MARKING}

11. All pipe and fittings shall be marked with the name of the manufacturer or appropriate initial. Each casting shall have cast upon it the minimum or estimated weight of same as shown in Tables 1 and 2 . 
TABLE 2.-Weights of soil pipe fittings

[On]y the staple fittings are shown. From the data berewith the weights of other fittings may be calculated. All values are in pounds]

\begin{tabular}{|c|c|c|c|c|c|c|c|c|c|c|c|c|c|c|c|}
\hline \multirow{2}{*}{1} & \multicolumn{15}{|c|}{ Size of fittings (inches) } \\
\hline & 2 & 3 & .4 & 5 & 6 & $\begin{array}{c}3 \\
\text { by } \\
2\end{array}$ & $\begin{array}{c}4 \\
\text { by } \\
2\end{array}$ & $\begin{array}{c}4 \\
\text { by } \\
3\end{array}$ & $\begin{array}{c}5 \\
\text { by } \\
2\end{array}$ & $\begin{array}{c}5 \\
\text { by } \\
3\end{array}$ & 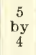 & $\begin{array}{c}6 \\
\text { by } \\
2\end{array}$ & $\begin{array}{c}6 \\
\text { by } \\
3\end{array}$ & $\begin{array}{c}6 \\
\text { by } \\
4\end{array}$ & $\begin{array}{c}6 \\
\text { by } \\
5\end{array}$ \\
\hline$\frac{1}{6}$ bends, regular............. & $6 \frac{3}{4}$ & $10 \frac{1}{3}$ & 15 & 19 & $23 \frac{1}{2}$ & & & & & & & & & & - \\
\hline bends, short sweep.... & 81 & $12 \frac{1}{2}$ & $17 \frac{3}{4}$ & $22 \frac{\pi}{2}$ & $27 \frac{1}{2}$ & & & & & & & & & & $\cdots$ \\
\hline$\frac{1}{4}$ bends, long sweep. & $10 \frac{1}{4}$ & $15_{4}^{3}$ & $22^{4}$ & $27 \frac{1}{2}$ & $33 \frac{1}{2}$ & & & & & & & & & & 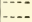 \\
\hline$\frac{1}{5}$ bends................. & $6 \frac{1}{4}$ & $9 \frac{3}{4}$ & $13_{4}^{3}$ & $17 \frac{1}{2}$ & $21 \frac{x}{2}$ & & & & & & & & & & $-\cdots$ \\
\hline bends & 6 & $9 \frac{1}{6}$ & 13 & $16_{2}^{2}$ & $20^{2}$ & & & & & & & 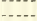 & $\ldots$ & & ..... \\
\hline$\frac{1}{8}$ bends... & $5 \frac{1}{2}$ & $8 \frac{1}{3}$ & $12 \frac{3}{8}$ & $15 \frac{2}{4}$ & $18 \frac{1}{4}$ & & & & & & & & & & - n \\
\hline$\frac{1}{16}$ bends $\ldots$ & 5 & $7 \frac{3}{8}$ & $10_{1}^{3}$ & $13 \frac{1}{4}$ & $15 \frac{3}{4}$ & & & & & & & & & 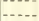 & -n \\
\hline Return bends............... & 83 & 14 & $20 \frac{1}{3}$ & $26 \frac{1}{2}$ & $33 \frac{1}{2}$ & & & & & & & & & & $-\infty$ \\
\hline Tees & $10^{\frac{1}{6}}$ & $15 \hat{3}$ & 21 & $26 \frac{1}{2}$ & $32 \frac{1}{2}$ & $13^{\pi}$ & $16 \frac{1}{2}$ & $18 \frac{3}{4}$ & $19_{4}^{1}$ & 22 & $24 \frac{1}{2}$ & $22 \frac{1}{2}$ & 25 & $27 \frac{1}{2}$ & 30 \\
\hline $\begin{array}{l}\text { Tapped tees (tapped up } \\
\text { to } 2 \text { inches) }\end{array}$ & 83 & & & & & $11 \frac{3}{1}$ & 15 & & $17 \frac{3}{4}$ & & & $20 \frac{2}{2}$ & & & \\
\hline Sanitary tees ............. & 11 & $16^{1}$ & $22 \frac{1}{2}$ & 28 & $34 \frac{1}{2}$ & 14 & $17 \frac{1}{4}$ & $19_{4}^{3}$ & $20^{\prime \prime}$ & 23 & $25 \frac{1}{2}$ & 23 & 26 & 29 & $31 \frac{1}{2}$ \\
\hline $\begin{array}{l}\text { Tapped sanitary tees } \\
\text { (tapped up to } 2 \text { incbes) }\end{array}$ & 9 & & & & & & $15 \frac{1}{4}$ & & & & & & & & \\
\hline$Y$ braneh & 11 & 17 & 24 & $31 \frac{1}{2}$ & $39 \frac{1}{2}$ & 14 & $17 \frac{1}{4}$ & $20 \frac{1}{2}$ & 20 & $23 \frac{1}{2}$ & $27 \frac{1}{2}$ & $23^{2}$ & 27 & 31 & 35 \\
\hline $\begin{array}{l}\frac{1}{2} \mathbf{Y} \text { branch } \\
\text { Tapped inverted }\end{array}$ & $10 \frac{1}{4}$ & $15_{2}^{1}$ & $21 \frac{1}{2}$ & $27 \frac{1}{2}$ & 34 & $13 \frac{1}{2}$ & $16 \frac{1}{2}$ & 19 & $19 \frac{1}{2}$ & 22 & 25 & $22 \frac{1}{2}$ & $25 \frac{1}{2}$ & $28 \frac{1}{2}$ & 31 \\
\hline $\begin{array}{l}\text { Tapped inverted } \\
\text { branch (tapped up to } \\
2 \text { inches) }\end{array}$ & $10_{4}^{x}$ & $13 \frac{3}{4}$ & $17 \frac{1}{2}$ & 21 & 24 & & & & & & & & & & \\
\hline Inverted Y brancb. & $11 \frac{1}{2}$ & 18 & $25 \frac{1}{2}$ & 33 & $41 \frac{1}{2}$ & 15 & $18_{4}^{3}$ & 22 & 22 & $25 \frac{1}{2}$ & $29 \overrightarrow{1}$ & $25 \frac{1}{2}$ & $29 \frac{\pi}{2}$ & 33 & 37 \\
\hline $\begin{array}{l}\text { Combination } Y \text { and } \frac{1}{4} \\
\text { bend }\end{array}$ & 12 & $18^{3}$ & 27 & 35 & 441 & 15 & $18^{x}$ & $22 \frac{1}{2}$ & 21 & 251 & 302 & 24 & 29 & 34 & 39 \\
\hline Upright $Y$ brancb & $12 \frac{1}{2}$ & $19 \frac{1}{2}$ & 28 & $36 \frac{1}{2}$ & $46^{2}$ & $15_{4}^{3}$ & $18 \frac{3}{4}$ & $23^{2}$ & $21 \frac{1}{2}$ & $26 \frac{1}{2}$ & $31_{2}^{1}$ & $24 \frac{1}{2}$ & $29 \frac{1}{2}$ & 35 & 40 \\
\hline
\end{tabular}

\section{INSPECTION AND REJECTION}

12. The manufacturer shall afford the inspector representing the purchaser, free of cost, all reasonable facilities to satisfy him that the castings are being furnished in accordance with these specifications. All tests and inspection shall be so conducted as not to interfere unnecessarily with the operation of the works and shall be made prior to shipment unless otherwise specified.

13. All pipe and fittings which fail to conform to the provisions of these specifications shall be subject to rejection.

\section{WELDED WROUGHT-IRON PIPE}

\section{Serial Designation, A 72-21}

[Proposed as tentative, 1917; adopted, 1918; revised, 1921]

1. These specifications cover "standard" and "extra strong" welded wrought-iron pipe, but not "double extra strong" pipe.

2. All pipes to be used on locomotives and cars shall be of coiling or bending quality.

\section{MANUFACTURE}

3. (a) The iron shall be made from muck bars, made from puddled pig iron, free from any admixture of iron scrap or steel.

(b) All pipe 3 inches or under in nominal diameter may be buttwelded, unless otherwise specified. All pipe over 3 inches in nominal diameter shall be lapwelded.

4. Iron scrap.-This term applies only to foreign or bought scrap and does not include local mill products, free from foreign or bought scrap. 


\section{PHYSICAL PROPERTIES AND TESTS}

5. (a) The material shall conform to the following minimum requirements as to tensile properties:

Tensile strength _._. per sq. in _- 40, 000

Yield point _...

Elongation in 8 inches............

(b) The yield point shall be determined by the drop of the beam of the testing machine. The speed of the crosshead of the machine shall not exceed three-fourths inch per minute.

6. All pipe shall be tested at the mill to the hydrostatic pressures specified in Table 1.

TABLE 1.-Hydrostatic pressures for welded wrought-iron pipe

[Pressures expressed in pounds per square inch]

BLACK AND GALVANIZED

\begin{tabular}{|c|c|c|c|c|c|c|}
\hline \multirow[b]{2}{*}{ Size (nominal inside diameter) (inches) } & \multicolumn{3}{|c|}{ "Standard" pipe } & \multicolumn{3}{|c|}{ "Extra strong" pipe } \\
\hline & $\begin{array}{l}\text { Weight } \\
\text { of pipe } \\
\text { per linear } \\
\text { foot, } \\
\text { threaded } \\
\text { and with } \\
\text { couplings }\end{array}$ & $\begin{array}{l}\text { Butt- } \\
\text { weld }\end{array}$ & $\begin{array}{l}\text { Lap- } \\
\text { weld. }\end{array}$ & $\begin{array}{l}\text { Weight } \\
\text { of pipe } \\
\text { per linear } \\
\text { foot, } \\
\text { plain } \\
\text { ends }\end{array}$ & $\begin{array}{l}\text { Butt- } \\
\text { weld }\end{array}$ & $\begin{array}{l}\text { Lap- } \\
\text { weld }\end{array}$ \\
\hline & Pounds & $\begin{array}{l}700 \\
700 \\
700 \\
700 \\
700 \\
700\end{array}$ & -. & Pounds & $\begin{array}{l}700 \\
700 \\
700 \\
700 \\
700 \\
700\end{array}$ & . \\
\hline $\begin{array}{l}1 \\
1 \\
1 \\
1 \\
2 \\
2 \\
21 \\
2 \\
3\end{array}$ & (2) & $\begin{array}{l}700 \\
700 \\
700 \\
800 \\
800\end{array}$ & $\begin{array}{l}1,000 \\
1,000 \\
1,000 \\
1,000 \\
1,000\end{array}$ & 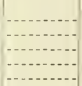 & $\begin{array}{l}1,500 \\
1,500 \\
1,500 \\
1,500 \\
1,500\end{array}$ & $\begin{array}{l}2,500 \\
2,500 \\
2,500 \\
2,000 \\
2,000\end{array}$ \\
\hline $\begin{array}{l}31 \\
4 \\
4 \\
4 \\
5 \\
5 \\
6\end{array}$ & & (n) & $\begin{array}{l}1,000 \\
1,000 \\
1,000 \\
1,000 \\
1,000\end{array}$ & - & 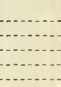 & $\begin{array}{l}2,000 \\
2,000 \\
1,800 \\
1,800 \\
1,800\end{array}$ \\
\hline $\begin{array}{l}7 \\
8 \\
8 \\
9 \\
9\end{array}$ & $\begin{array}{l}25.00 \\
28.81 \\
34.19 \\
32.00\end{array}$ & . & $\begin{array}{r}1,000 \\
800 \\
1,000 \\
900 \\
600\end{array}$ & $\begin{array}{r}43.39 \\
48.73\end{array}$ & - & $\begin{array}{l}1,500 \\
1,500 \\
1,200\end{array}$ \\
\hline 10 & $\begin{array}{l}35.00 \\
41.13 \\
46.25 \\
45.00 \\
50.71\end{array}$ & . & $\begin{array}{l}700 \\
900 \\
800 \\
600 \\
800\end{array}$ & $\begin{array}{l}54.74 \\
60.08 \\
65.42\end{array}$ & 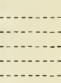 & $\begin{array}{r}1,000 \\
1,000 \\
1,000\end{array}$ \\
\hline
\end{tabular}

For pipes over 12 inches in inside diameter, the test pressures should he calculated hy the formula $P=\frac{2 S t}{D}$ in which $P=$ pressure in pounds per square inch; $S=$ fiher stress $=12,000$ pounds per square inch; $t=$ thickness of wall in inches; $D=$ inside diameter in inches.

7. A section of pipe 6 inches in length shall be flattened until broken by repeated light blows of a hammer or by pressure; the fracture developed shall have a fibrous appearance.

8. For pipe 2 inches or under in diameter a sufficient length of coiling or bending pipe shall withstand being bent cold through $90^{\circ}$. around a cylindrical mandrel, the diameter of which is 15 times 
the nominal diameter of the pipe, without developing eracks at any portion and without opening the weld.

9. (a) Test specimens shall consist of sections cut from a pipe. They shall be smooth on the ends and free from burrs.

(b) Tension test specimens shall be longitudinal.

(c) All specimens shall be tested cold.

10. One of each of the tests specified in sections 5, 7, and 8 may be made on a length in each lot of 500 or less of each size. Each length shall be subjected to the hydrostatic test.

11. If the results of the physical tests of any lot do not conform to the requirements specified in sections 5,7 , and 8 , retests of two additional pipes shall be made, each of which shall conform to the requirements specified.

\section{STANDARD WEIGHTS}

12. (a) The standard weights for pipe of various inside diameters are given in Table 2 .

(b) Nipples shall be cut from pipe of the same weight and quality as described in these specifications.

TABLE 2.-Standard weights of welded wrought-iron pipe

BLACK AND GALVANIZED

\begin{tabular}{|c|c|c|c|c|c|c|}
\hline \multirow[b]{2}{*}{ Size (nominal inside diameter) (inches) } & \multicolumn{4}{|c|}{ "Standard" pipe } & \multicolumn{2}{|c|}{ "Extra strong" pipe } \\
\hline & $\begin{array}{l}\text { Outside } \\
\text { diameter }\end{array}$ & $\begin{array}{l}\text { Number } \\
\text { of threads } \\
\text { per inch }\end{array}$ & $\begin{array}{l}\text { Thick- } \\
\text { ness }\end{array}$ & $\begin{array}{l}\text { Weight } \\
\text { of pipe } \\
\text { per } \\
\text { linear } \\
\text { foot, } \\
\text { threaded } \\
\text { and with } \\
\text { coup- } \\
\text { lings }\end{array}$ & $\begin{array}{c}\text { Thick- } \\
\text { ness }\end{array}$ & $\begin{array}{l}\text { Weight } \\
\text { of pipe } \\
\text { per } \\
\text { linear } \\
\text { foot, } \\
\text { plain } \\
\text { ends }\end{array}$ \\
\hline - & $\begin{array}{r}\text { Inches } \\
0.405 \\
.540 \\
.675 \\
.840 \\
1.050 \\
1.315\end{array}$ & $\begin{array}{l}27 \\
18 \\
18 \\
14 \\
14 \\
11 \frac{\pi}{2}\end{array}$ & $\begin{array}{l}\text { Inch } \\
0.068 \\
.088 \\
.091 \\
.109 \\
.113 \\
.133\end{array}$ & $\begin{array}{r}\text { Pounds } \\
0.25 \\
.43 \\
.57 \\
.85 \\
1.13 \\
1.68\end{array}$ & $\begin{array}{c}\text { Inch } \\
0.095 \\
.119 \\
.126 \\
.147 \\
.154 \\
.179\end{array}$ & $\begin{array}{r}\text { Pounds } \\
0.31 \\
.54 \\
.74 \\
1.09 \\
1.47 \\
2.17\end{array}$ \\
\hline 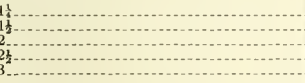 & $\begin{array}{l}1.660 \\
1.900 \\
2.375 \\
2.875 \\
3.500\end{array}$ & $\begin{array}{l}11 \frac{1}{2} \\
11 \frac{1}{2} \\
11 \frac{1}{2} \\
8 \\
8\end{array}$ & $\begin{array}{l}140 \\
145 \\
154 \\
.203 \\
216\end{array}$ & $\begin{array}{l}\text { 2. } 28 \\
\text { 2. } 73 \\
\text { 3. } 68 \\
\text { 5. } 82 \\
\text { 7. } 62\end{array}$ & $\begin{array}{l}191 \\
.200 \\
218 \\
276 \\
.300\end{array}$ & $\begin{array}{r}3.00 \\
3.63 \\
5.02 \\
7.66 \\
10.25\end{array}$ \\
\hline $\begin{array}{l}31 \\
4 \\
4\end{array}$ & $\begin{array}{l}\text { 4. } 000 \\
\text { 4. } 500 \\
5.000 \\
\text { 5. } 563 \\
6.625\end{array}$ & $\begin{array}{l}8 \\
8 \\
8 \\
8 \\
8\end{array}$ & $\begin{array}{l}226 \\
.237 \\
247 \\
258 \\
.280\end{array}$ & $\begin{array}{r}9.20 \\
10.89 \\
12.64 \\
14.81 \\
19.19\end{array}$ & $\begin{array}{l}.318 \\
.337 \\
.355 \\
.375 \\
.432\end{array}$ & $\begin{array}{l}12.51 \\
14.98 \\
17.61 \\
20.78 \\
28.57\end{array}$ \\
\hline $\begin{array}{l}81 \\
8 \\
8\end{array}$ & $\begin{array}{r}\text { 7. } 625 \\
8.625 \\
8.625 \\
9.625 \\
10.750\end{array}$ & $\begin{array}{l}8 \\
8 \\
8 \\
8 \\
8\end{array}$ & $\begin{array}{l}301 \\
.277 \\
.322 \\
.342 \\
.279\end{array}$ & $\begin{array}{l}23.77 \\
25.00 \\
28.81 \\
34.19 \\
32.00\end{array}$ & $\begin{array}{r}500 \\
.500 \\
.500 \\
-.+5\end{array}$ & $\begin{array}{r}38.05 \\
43.39 \\
48.73 \\
- \\
4\end{array}$ \\
\hline 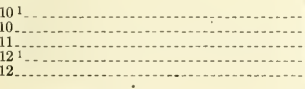 & $\begin{array}{l}\text { 10. } 750 \\
\text { 10. } 750 \\
\text { 11. } 750 \\
\text { 12. } 750 \\
12.750\end{array}$ & $\begin{array}{l}8 \\
8 \\
8 \\
8 \\
8\end{array}$ & $\begin{array}{l}.307 \\
.365 \\
.375 \\
.330 \\
.375\end{array}$ & $\begin{array}{l}35.00 \\
41.13 \\
46.25 \\
45.00 \\
50.71\end{array}$ & $\begin{array}{r}.500 \\
500 \\
.500\end{array}$ & $\begin{array}{r}54.74 \\
60.08 \\
65.42\end{array}$ \\
\hline
\end{tabular}

1 Unless specifically stated on the order the lighter weights will not be furnished. Weights given in the tables are for pipes up to and including 12 inches in nominal inside diameter, with threaded ends and couplings; sizes larger than shown in the table are measured by the outside diameter and will be furnished with plain ends; for such sizes it will be necessary to accept manufacturers' weights or calculate the weights on the basis of 1 cubic inch of iron weighing 0.2833 pound. 
13. The weight of the pipe shall not vary more than 5 per cent from that specified in Table 2.

14. Unless otherwise specified, pipe shall be furnished as to lengths in accordance with the following regular practice:

(a) Standard pipe shall be in random lengths from 16 to 22 feet, but not more than 5 per cent of the total number of lengths may be "jointers," which are two pieces coupled together. When ordered with plain ends, 5 per cent may be in lengths of 12 to 16 feet.

(b) Extra strong pipe shall be in random lengths of 12 to 22 feet, and 5 per cent may be in lengths of 6 to 12 feet.

\section{WORKMANSHIP AND FINISH}

15. For pipe $1 \frac{1}{2}$ inches or under in inside diameter the outside diameter at any point shall vary not more than one sixty-fourth inch over nor more than one thirty-second inch under the standard size. For pipe 2 inches or over in inside diameter, the outside diameter shall vary not more than 1 per cent over or under the standard size.

16. Unless otherwise specified, pipe shall conform to the following regular practices:

(a) Each end of standard pipe shall be threaded.

(b) Extra strong pipe shall be furnished with plain ends.

(c) All threads shall be in accordance with the American standard ${ }^{2}$ and cut so as to make a tight joint when the pipe is tested at the mill to the specified internal hydrostatic pressure. The variation from the standard, when tested with the standard working gauge, shall not exceed a maximum of one and one-half turns either way.

(d) Each length of threaded pipe shall be provided with one coupling, having clean-cut threads of such a pitch diameter as to make a tight joint. Couplings shall be of wrought iron.

17. The finished pipe shall be reasonably straight and free from injurious defects. All burrs at the ends of the pipe shall be removed.

\section{INSPECTION AND REJECTION}

18. The inspector representing the purchaser shall have free entry at all times while work on the contract of the purchaser is being performed to all parts of the manufacturer's works which concern the manufacture of the pipe ordered. The manufacturer shall afford the inspector, free of charge, all reasonable facilities to satisfy him that the pipe are being furnished in accordance with these specifications. All tests and inspection shall be made at the place of manufacture prior to shipment, unless otherwise specified, and shall be so conducted as not to interfere unnecessarily with the operation of the works.

19. Each length of pipe which develops injurious defects in shop working or application will be rejected, and the manufacturer shall be notified.

\footnotetext{
${ }^{2}$ A complete description of the American Standard Pipe Thread is contained in the Pipe Thread Standard prepared under the sponsorship of the American Gas Association and the American Society of Mechanical Engineers and approved as American standard by the Ameriean Engineering Standards Committee
} 


\section{WELDED AND SEAMLESS STEEL PIPE}

\section{Serial Designation, A 53-21}

[Adopted, 1915; revised, 1918, 1921]

1. These specifications cover "standard" and "extra strong" welded and seamless steel pipe, but not "double extra strong" pipe. Pipe ordered under these specifications are intended for bending, flanging, and other special purposes.

\section{MANUFACTURE}

2. (a) The steel for welded pipe shall be of soft weldable quality made by the Bessemer or by the open-hearth process. The steel for seamless pipe shall be made by the open-hearth process.

(b) Welded pipe 3 inches or under in nominal diameter may be butt welded, unless otherwise specified. Welded pipe over 3 inches in nominal diameter shall be lapwelded.

\section{CHEMICAL PROPERTIES AND TESTS}

3. Open-hearth steel shall conform to the following requirement as to chemical composition:

Phosphorus, not over 0.05 per cent.

\section{PHYSICAL PROPERTIES AND TESTS}

4. (a) The material shall conform to the following minimum requirements as to tensile properties:

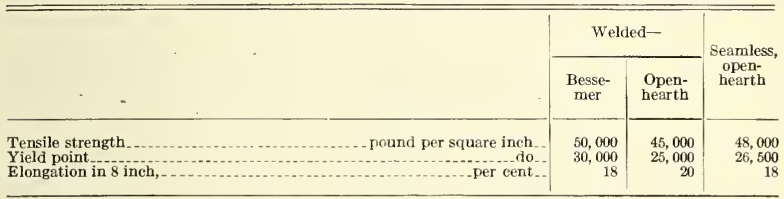

(b) The yield point shall be determined by the drop of the beam of the testing machine.

5. (a) Welded pipe shall be tested at the mill to the hydrostatic pressures specified in Table 1.

(b) Seamless pipe shall be tested at the mill to hydrostatic pressures not exceeding that required by the formula:

$$
P=\frac{2 S t}{D}
$$

in which $P=$ pressure in pounds per square inch; $S=$ allowable fiber stress $=16,000$ pounds per square inch; $t=$ thickness of wall in inches; and $D=$ inside diameter in inches.

6. (a) For lapwelded pipe over 2 inches in diameter a section of pipe 6 inches long shall be flattened between parallel plates until the distance between the plates is one-third the outside diameter of the pipe, with the weld located 45 degrees from the line of direction of the applied force, without developing cracks.

(b) For buttwelded pipe over 2 inches in diameter a section of pipe 6 inches long shall be flattened between parallel plates until the 
distance between the plates is 60 per cent of the outside diameter of the pipe, with the weld located 45 degrees from the line of direction of the applied force, without developing cracks.

TABLE 1.-Hydrostatic pressures for welded steel pipe

[Pressures expressed in pounds per square inch]

BLACK AND GALVANIZED

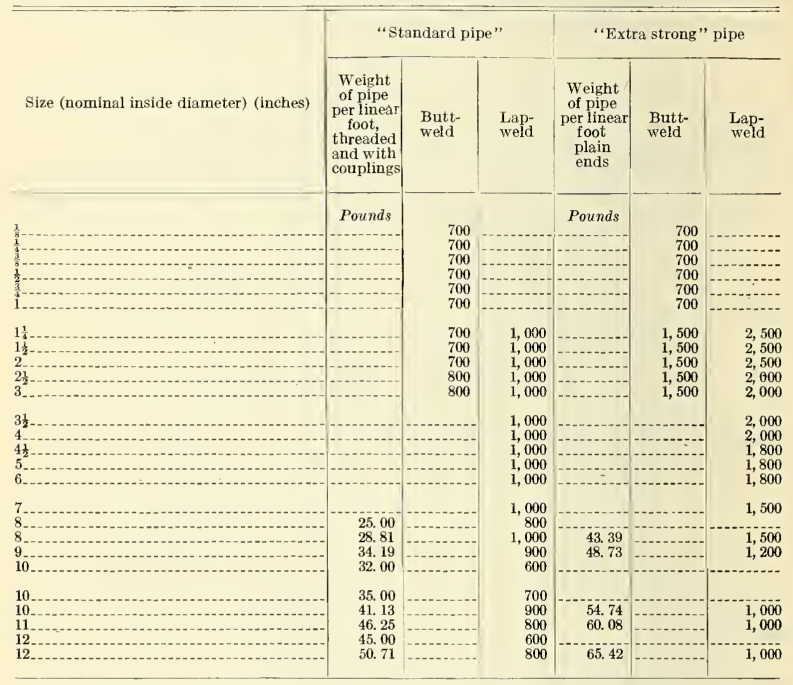

For pipes over 12 inches in inside diameter, the test pressures should be calculated by the formula $P=\frac{2 S t}{D}$ in which $P=$ pressure in pounds per square inch; $S=$ fiber stress $=12,000$ pounds per square inch; $t=$ thickness of wall in inches; $D=$ inside diameter in inches.

7. For pipe 2 inches or under in diameter, a sufficient length of pipe shall withstand being bent cold through 90 degrees around a cylindrical mandrel, the diameter of which is 12 times the nominal diameter of the pipe, without developing cracks at any portion and without opening the weld.

8. (a) Test specimens shall consist of sections cut from a pipe. They shall be smooth on the ends and free from burrs.

(b) Tension test specimens shall be longitudinal.

(c) All specimens shall be tested cold.

9. One of each of the tests specified in sections 4, 6, and 7 may be made on a length in each lot of 500 or less of each size. Each length shall be subjected to the hydrostatic test.

10. If the results of the physical tests of any lot do not conform to the requirements specified in sections 4,6 , and 7 retests of two additional pipes shall be made, each of which shall conform to the requirements specified. 


\section{STANDARD WEIGHTS}

11. (a) The standard weights for pipe of various inside diameters are given in Table 2.

(b) Nipples shall be cut from pipe of the same weight and quality as described in these specifications.

12. The weight of the pipe shall not vary more than 5 per cent from that specified in Table 2.

TABLE 2.-Standard weights and dimensions of welded and seamless steel pipe

BLACK AND GALVANIZED

\begin{tabular}{|c|c|c|c|c|c|c|}
\hline \multirow[b]{2}{*}{ Size (nominal inside diameter) (inches) } & \multicolumn{4}{|c|}{ "Standard" pipe } & \multicolumn{2}{|c|}{ "Extra strong" pipe } \\
\hline & $\begin{array}{l}\text { Outside } \\
\text { diameter }\end{array}$ & $\begin{array}{l}\text { Numher } \\
\text { of threads } \\
\text { per inch }\end{array}$ & $\begin{array}{c}\text { Thick- } \\
\text { ness }\end{array}$ & $\begin{array}{l}\text { Weight } \\
\text { of pipe } \\
\text { per linear } \\
\text { foot, } \\
\text { threaded } \\
\text { and with } \\
\text { couplings }\end{array}$ & $\begin{array}{l}\text { Thick- } \\
\text { ness }\end{array}$ & $\begin{array}{l}\text { Weight } \\
\text { of pipe } \\
\text { per linear } \\
\text { foot, } \\
\text { plain } \\
\text { ends }\end{array}$ \\
\hline 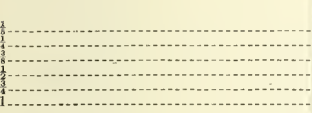 & $\begin{array}{r}\text { Inch } \\
0.405 \\
.540 \\
.675 \\
.840 \\
1.050 \\
1.315\end{array}$ & $\begin{array}{l}27 \\
18 \\
18 \\
14 \\
14 \\
11 \frac{1}{2}\end{array}$ & $\begin{array}{r}\text { Inch } \\
0.068 \\
.088 \\
.091 \\
.109 \\
.113 \\
.133\end{array}$ & $\begin{array}{r}\text { Pounds } \\
.0 .25 \\
.43 \\
.57 \\
.85 \\
1.13 \\
1.68\end{array}$ & $\begin{array}{r}\text { Inch } \\
0.095 \\
.119 \\
.126 \\
.147 \\
.154 \\
.179\end{array}$ & $\begin{array}{r}\text { Pounds } \\
0.31 \\
.54 \\
.74 \\
1.09 \\
1.47 \\
2.17\end{array}$ \\
\hline 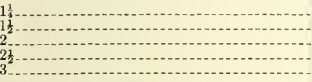 & $\begin{array}{l}\text { 1. } 660 \\
\text { 1. } 900 \\
2.375 \\
2.875 \\
3.500\end{array}$ & $\begin{array}{l}11 \frac{1}{2} \\
11 \frac{1}{2} \\
11 \frac{1}{2} \\
8 \\
8\end{array}$ & $\begin{array}{l}.140 \\
.145 \\
.154 \\
.203 \\
.216\end{array}$ & $\begin{array}{l}\text { 2. } 28 \\
\text { 2. } 73 \\
\text { 3. } 68 \\
\text { 5. } 82 \\
\text { 7. } 62\end{array}$ & $\begin{array}{l}.191 \\
.200 \\
.218 \\
.276 \\
.300\end{array}$ & $\begin{array}{r}3.00 \\
3.63 \\
5.02 \\
7.66 \\
10.25\end{array}$ \\
\hline $\begin{array}{l}3 \frac{1}{2} \\
4 \\
4\end{array}$ & $\begin{array}{l}\text { 4. } 000 \\
\text { 4. } 500 \\
\text { 5. } 000 \\
\text { 5. } 563 \\
6.625\end{array}$ & $\begin{array}{l}8 \\
8 \\
8 \\
8 \\
8\end{array}$ & $\begin{array}{l}.226 \\
.237 \\
.247 \\
.258 \\
.280\end{array}$ & $\begin{array}{r}9.20 \\
10.89 \\
12.64 \\
14.81 \\
19.19\end{array}$ & $\begin{array}{l}.318 \\
.337 \\
.355 \\
.375 \\
.432\end{array}$ & $\begin{array}{l}12.51 \\
14.98 \\
17.61 \\
20.78 \\
28.57\end{array}$ \\
\hline $\begin{array}{l}81 \\
8 \\
8\end{array}$ & $\begin{array}{r}\text { 7. } 625 \\
8.625 \\
8.625 \\
9.625 \\
10.750\end{array}$ & $\begin{array}{l}8 \\
8 \\
8 \\
8 \\
8\end{array}$ & $\begin{array}{l}.301 \\
.277 \\
.322 \\
.342 \\
.279\end{array}$ & $\begin{array}{l}23.77 \\
25.00 \\
28.81 \\
34.19 \\
32.00\end{array}$ & $\begin{array}{r}.500 \\
.500 \\
.500 \\
\end{array}$ & $\begin{array}{r}38.05 \\
43.39 \\
48.73\end{array}$ \\
\hline $10^{1} 10^{1}$ & $\begin{array}{l}\text { 10. } 750 \\
10.750 \\
\text { 11. } 750 \\
12.750 \\
12.750\end{array}$ & $\begin{array}{l}8 \\
8 \\
8 \\
8 \\
8\end{array}$ & $\begin{array}{l}.307 \\
.365 \\
.375 \\
.330 \\
.375\end{array}$ & $\begin{array}{l}35.00 \\
41.13 \\
46.25 \\
45.00 \\
50.71\end{array}$ & $\begin{array}{r}.500 \\
.500 \\
.500\end{array}$ & $\begin{array}{r}54.74 \\
60.08 \\
65.42\end{array}$ \\
\hline
\end{tabular}

1 Unless specifically stated on the order the lighter weights will not he furnished. Weights given in the tahle are for pipes up to and including 12 inches in nominal inside diameter, with threaded ends and couplings; sizes larger than those shown in the table are measured hy the outside diameter and will he furnished with plain ends unless otherwise specified; for such sizes it will be necessary to accept manufacturers' weights or calculate the weights on the hasis of 1 cuhic inch of steel weighing 0.2833 pound.

13. Unless otherwise specified, pipe shall be furnished as to lengths in accordance with the following regular practice:

(a) Standard pipe shall be in random lengths of 16 to 22 feet, but not more than 5 per cent of the total number of lengths may be "jointers," which are two pieces coupled together. When ordered with plain ends, 5 per cent may be in lengths of 12 to 16 feet.

(b) Extra strong pipe shall be in random lengths of 12 to 22 feet. Five per cent may be in lengths of 6 to 12 feet. 
v. WORKMANSHIP AND FINISH

14. For pipe $1 \frac{1}{2}$ inches or under in inside diameter the outside diameter at any point shall not vary more than one sixty-fourth inch over nor more than one thirty-second inch under the standard size. For pipe 2 inches or over in inside diameter the outside diameter shall not vary more than 1 per cent over or under the standard size.

15. Unless otherwise specified, pipe shall conform to the following regular practice:

(a) Each end of standard welded pipe shall be threaded.

(b) Extrastrong welded pipe and standard and extrastrong seamless pipe shall be furnished with plain ends.

(c) All threads shall be in accordance with the American standard and cut so as to make a tight joint when the pipe is tested at the mill to the specified internal hydrostatic pressure. The variation from the standard, when tested with the standard working gauge, shall not exceed a maximum of one and one-half turns either way.

(d) Each length of threaded pipe shall be provided with one coupling having clean-cut threads of such a pitch diameter as to make a tight joint. Couplings may be made of wrought iron or steel.

16. The finished pipe shall be reasonably straight and free from injurious defects. All burrs at the ends of the pipe shall be removed.

VI. INSPECTION AND REJECTION

17. The inspector representing the purchaser shall have free entry at all times while work on the contract of the purchaser is being performed to all parts of the manufacturer's works which concern the manufacture of the pipe ordered. The manufacturer shall afford the inspector, free of charge, all reasonable facilities to satisfy him that the pipe are being furnished in accordance with these specifications. All tests and inspection shall be made at the place of manufacture prior to shipment, unless otherwise specified, and shall be so conducted as not to interfere unnecessarily with the operation of the works.

18. Each length of pipe which develops injurious defects in shop working or application will be rejected, and the manufacturer shall be notified.

\section{BRASS PIPE, STANDARD SIZES}

\section{Serial Designation, B 43-23}

[Proposed as tentative, 1922; adopted, 1923]

1. These specifications cover seamless brass pipe suitable for use in plumbing, boiler feed lines, etc.

\section{MANUFACTURE}

2. The pipe shall be cold-drawn to size.

3. (a) The pipe shall be annealed sufficiently to enable it to pass the physical tests herein specified.

(b) All pipe shall be annealed sufficiently to prevent cracking. Semiannealed pipe, which is suitable for ordinary uses, shall be furnished unless otherwise specified.

(c) When pipe is required for bending, the purchaser shall so specify, in which case the pipe shall be furnished fully annealed. 
II. CHEMICAL PROPERTIES AND TESTS

4. The brass shall conform to the following requirements as to chemical composition.

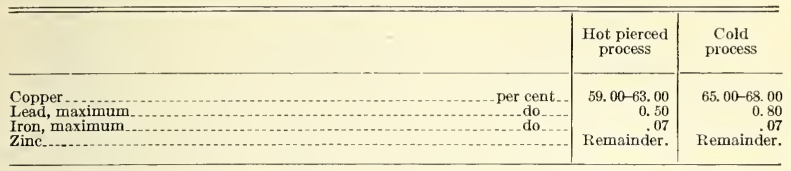

5. The sample for chemical analysis shall consist of drillings, millings, or clippings taken from the pipes selected for testing purposes, as specified in section 12, equal quantities being taken from each pipe and thoroughly mixed. Samples so prepared shall be divided into three equal parts, each of which shall be placed in a sealed package, one for the seller, one for the purchaser, and one for an umpire, if necessary.

\section{PHYSICAL PROPERTIES AND TESTS}

6. The pipe shall be capable of withstanding the following test without showing cracks or flaws: A piece cut from the ends of the pipe shall be hammered flat on different elements throughout its length so that a gauge set at 3 times the thickness of the metal shall pass over the pipe freely throughout the flattened part, except at such points where changes in the elements of flattening take place.

7. A test specimen 3 inches in length when split shall withstand opening out flat without showing cracks or flaws.

8. A test specimen 3 inches in length shall withstand an immersion in an aqueous mercurous nitrate solution containing $100 \mathrm{~g}$. of mercurous nitrate and $13 \mathrm{cc}$. of nitric acid (sp. gr. 1.42) per liter of solution for 15 minutes, without cracking.

9. The pipe shall withstand threading in a satisfactory manner.

10. In the case of pipe for bending, annealed full sections of the pipe shall withstand being bent cold through $180^{\circ}$ without cracking on the outside of the bent portion around a pin, the diameter of which is $1 \frac{1}{2}$ times the inside diameter of the pipe. This test shall be in addition to the tests specified in sections 6 to 9 , inclusive.

11. Each pipe shall withstand, without showing weakness or defects, an internal hydrostatic pressure sufficient to subject the material to a fiber stress of 7,000 pounds per square inch, determined by the formula for thin hollow cylinders under tension:

$$
P=2 \frac{t S}{D}
$$

in which $P$ equals the pressure in pounds per square inch, $t$ equals the thickness of wall in inches, $D$ equals the inside diameter of the pipe in inches, and $S$ equals the allowable unit stress of the material = 7,000 pounds per square inch. No pipe shall be tested beyond a pressure of 1,000 pounds per square inch unless so specified.

12. A sufficient number of pipe shall be taken at random to constitute 0.5 per cent of the shipment. One flattening, one strain, and one threading test shall be made on each pipe so selected. 
IV. DIMENSIONS AND PERMISSIBLE VARIATIONS

13. The standard weights and dimensions for pipe of various outside diameters are as follows:

\begin{tabular}{|c|c|c|c|c|}
\hline Size of pipe (inches) & $\begin{array}{l}\text { Outside } \\
\text { diameter }\end{array}$ & $\begin{array}{l}\text { lnside } \\
\text { diameter }\end{array}$ & Thickness & $\begin{array}{l}\text { Nominal } \\
\text { weight } \\
\text { (per foot of } \\
\text { length) }\end{array}$ \\
\hline 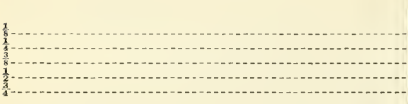 & $\begin{array}{r}\text { Inches } \\
0.405 \\
.540 \\
.675 \\
.840 \\
1.050\end{array}$ & $\begin{array}{r}\text { Inches } \\
0.281 \\
.375 \\
.494 \\
.625 \\
.822\end{array}$ & $\begin{array}{r}\text { Inches } \\
0.0620 \\
.0825 \\
.0905 \\
.1075 \\
.1140\end{array}$ & $\begin{array}{r}\text { Pounds } \\
0.246 \\
.437 \\
.612 \\
.911 \\
1.24\end{array}$ \\
\hline $1_{1}^{1} \frac{1}{2}{ }^{1}$ & $\begin{array}{l}1.315 \\
1.660 \\
1.900 \\
2.375 \\
2.875\end{array}$ & $\begin{array}{l}\text { 1. } 062 \\
\text { 1. } 368 \\
\text { 1. } 600 \\
\text { 2. } 062 \\
\text { 2. } 500\end{array}$ & $\begin{array}{l}.1265 \\
.1460 \\
.1500 \\
.1565 \\
.1875\end{array}$ & $\begin{array}{l}1.74 \\
2.56 \\
\text { 3. } 04 \\
\text { 4. } 02 \\
5.83\end{array}$ \\
\hline 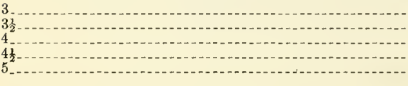 & $\begin{array}{l}3.500 \\
\text { 4. } 000 \\
\text { 4. } 500 \\
5.000 \\
5.563\end{array}$ & $\begin{array}{l}\text { 3. } 062 \\
\text { 3. } 500 \\
\text { 4. } 000 \\
\text { 4. } 500 \\
\text { 5. } 062\end{array}$ & $\begin{array}{l}.2190 \\
.2500 \\
.2500 \\
.2500 \\
.2505\end{array}$ & $\begin{array}{r}8.31 \\
10.85 \\
12.29 \\
13.74 \\
15.40\end{array}$ \\
\hline $9^{6}{ }^{6}$ & $\begin{array}{r}\text { 6. } 625 \\
7.625 \\
8.625 \\
9.625 \\
10.750\end{array}$ & $\begin{array}{r}6.125 \\
7.062 \\
8.000 \\
8.937 \\
10.019\end{array}$ & $\begin{array}{r}.2500 \\
.2815 \\
.3125 \\
.3440 \\
.3655\end{array}$ & $\begin{array}{l}18.44 \\
23.92 \\
30.05 \\
36.94 \\
43.91\end{array}$ \\
\hline
\end{tabular}

14. (a) No single piece of pipe that exceds the calculated weight by more than 5 per cent will be accepted. One cubic inch of the material is assumed to weigh 0.307 pound.

(b) The weight of the pipe shall vary not more than the following percentages from the weight specified in section 13: Pipe 6 inches or less in diameter, 5 per cent; pipe from 6 to 8 inches in diameter, 7 per cent; pipe over 8 inches in diameter, 8 per cent.

\section{WORKMANSHIP AND FINISH}

15. (a) The pipe shall be round and of uniform thickness throughout. They shall be free from cracks, seams, slivers, scale, and other surface defects.

(b) The thickness at any point shall not be less than that specified in section 13 by more than the following percentages: Pipe 6 inches or less in diameter, 5 per cent; pipe from 6 to 8 inches in diameter, 7 per cent; pipe over 8 inches in diameter, 8 per cent.

16. All pipes shall be acid cleaned after the final annealing.

\section{INSPECTION AND REJECTION}

17. (a) When the pipe is finished and ready for shipment, the inspector shall make the tests to govern the acceptance of the pipe. If any specimen fails to meet the requirements of sections 6 to 11 , inclusive, two additional specimens may be taken, each of which shall conform to the requirements specified.

(b) Pipes that show nonuniform annealing under handling shall be rejected from the lot.

18. The manufacturer shall afford the inspector, withoutizma rge, all reasonable facilities to satisfy him that the pipe is being furinshed 
in accordance with these specifications. All tests (except check analyses) and inspection shall be made at the place of manufacture prior to shipment, unless otherwise specified, and shall be so conducted as not to interfere unnecessarily with the operation of the works.

\section{COPPER PIPE, STANDARD SIZES}

\section{Serial Designation B 42-23}

[Proposed as tentative, 1922; adopted, 1923]

1. These specifications cover seamless copper tubes and seamless copper pipe suitable for use in plumbing, boller-feed lines, etc.

\section{MANUFACTURE}

2. (a) The pipe shall be cold drawn to size.

(b) When pipe is required for bending, the purchaser shall so specify, in which case the pipe shall be furnished with a proper bending temper.

\section{CHEMICAL PROPERTIES AND TESTS}

3. The copper shall have a purity of at least 99.880 per cent as determined by electrolytic assay, silver being counted as copper.

4. The sample for chemical analysis shall consist of drillings, millings, or clippings taken from the test specimens specified in section 9 , equal quantities being taken from each specimen and thoroughly mixed. Samples so prepared shall be divided into three equal parts, each of which shall be placed in a sealed package, one for the seller, one for the purchaser, and one for an umpire if necessary.

\section{PHYSICAL PROPERTIES AND TESTS}

5. The material shall conform to the following requirements as to tensile properties:

\begin{tabular}{|c|c|c|}
\hline . & $\begin{array}{l}\text { Tensile } \\
\text { strength }\end{array}$ & $\begin{array}{l}\text { Elongation } \\
\text { in } 4 \text { inches }\end{array}$ \\
\hline gg) & $\begin{array}{l}\text { Lbs. per } s q \text {. } \\
\text { inch. } \\
40,000 \\
30,000\end{array}$ & $\begin{array}{l}\text { Per cent } \\
\qquad \begin{array}{r}10 \\
25\end{array}\end{array}$ \\
\hline
\end{tabular}

6. (a) The test specimen, after being annealed, shall withstand being bent cold through 180 degrees without cracking on the outside of the bent portion, as follows: For material less than one-half inch in thickness, flat on itself; and for material one-half inch or over in thickness, around a pin, the diameter of which is twice the thickness of the specimen.

(b) In the case of pipe for bending, annealed full sections of the pipe shall withstand being bent cold through 180 degrees without cracking on the outside of the bent portion, around a pin the diameter of which is $1 \frac{1}{2}$ times the inside diameter of the pipe. This test shall be in addition to the test specified in paragraph $(a)$.

7. (a) An annealed test specimen not more than 4 inches in length shall have a flange turned over at right angles to the body of the pipe

$$
\checkmark 77^{\circ}-24-18
$$


without showing cracks or flaws. The width of this flange, as measured from the outside of the pipe, shall be one-fourth of the inside diameter of the pipe.

(b) In making the flange test it is recommended that the flaring tool and die block shown in Figure 1 be used.

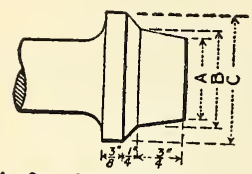

$A=$ Outs. Diam. of Flue less $\frac{5}{8}$.

$B=$ Outs. Diam. of Flue less $\frac{3}{8}$."

$C=$ Outs. Diam. of Flue plus $\frac{3}{16}$."

Flaring Tool.

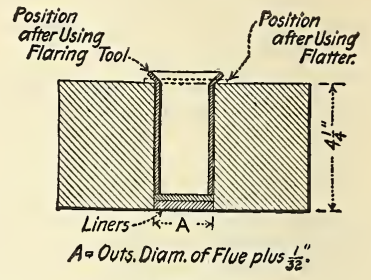

FIG. 1

8. Each pipe shall withstand, without showing weakness or defects, an internal hydrostatic pressure sufficient to subject the material to a fiber stress of 6,000 pounds per square inch, determined by the formula for thin hollow cylinders under tension:

$$
P=2 \frac{t S}{D}
$$

in which $P$ equals the pressure in pounds per square inch, $t$ equals the thickness of wall in inches, $D$ equals the inside diameter of the pipe in inches, and $S$ equals the allowable unit stress of the material= 6,000 pounds per square inch. No pipe shall be tested beyond a pressure of 1,000 pounds per square inch unless so specified.

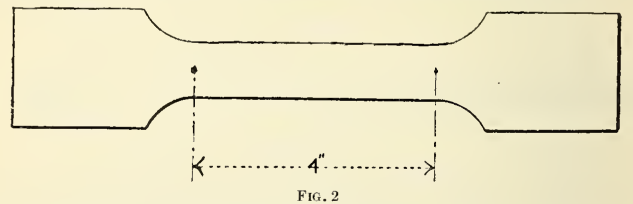

9. (a) Tension test specimens for pipe less than 2 inches in outside diameter shall consist of a full section of the unannealed pipe; the ends shall be plugged with metal plugs which shall not extend within the gauge marks.

(b) In the case of pipe 2 inches or over in outside diameter and not exceeding 6 inches in outside diameter the test specimen shall be cut longitudinally. In the case of pipe exceeding 6 inches in outside diameter the test specimen shall be cut circumferentially.

(c) The test specimen taken as specified in paragraph (b), shall be heated to a cherry red and straightened while hot. It shall then be machined to conform in shape to Figure 2. The width of the specimen shown in Figure 2 shall be governed by the thickness of the 
material. For material one-fourth inch or less in thickness, the width of the narrow portion of the test specimen shall be approximately 1 inch; for material over one-fourth inch in thickness, the width shall be such as to give a cross section of approximately onefourth square inch in area, but in no case shall the width be less than the thickness of the material. The drawn surfaces shall not be machined, but be left in their original condition.

(d) The bend test specimen shall consist of a strip not over $1 \frac{1}{2}$ inches in width cut longitudinally from the pipe.

10. One bend test shall be made for each 2,000 pounds or less of the finished product. For the remaining tests a sufficient number of pipe shall be taken at random to constitute 0.5 per cent of the shipment.

\section{DIMENSIONS AND PERMISSIBLE VARIATIONS}

11. The standard weights and dimensions for pipe of various outside diameters are as follows:

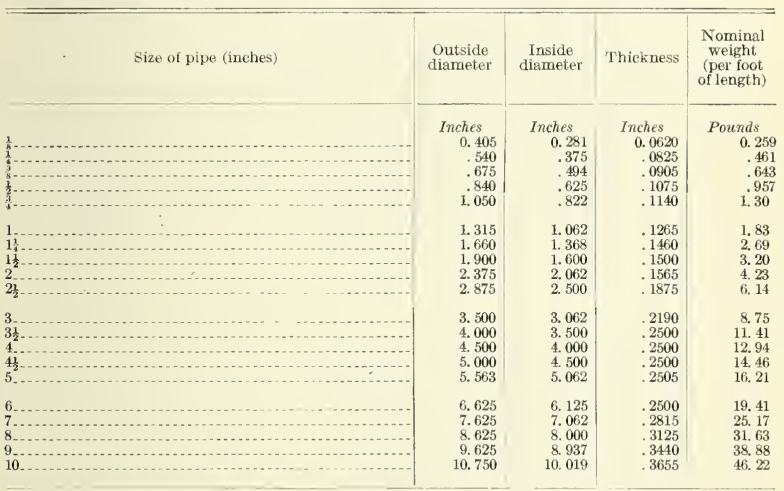

12. (a) No single piece of pipe that exceeds the calculated weight by more than 5 per cent will be accepted. One cubic inch of the material is assumed to weigh 0.323 pound.

(b) The weight of the pipe shall vary not more than the following percentages from the weight specified in section 11: Pipe 6 inches or less in diameter, 5 per cent; pipe from 6 to 8 inches in diameter, 7 per cent; pipe over 8 inches in diameter, 8 per cent.

\section{WORKMANSHIP AND FINISH}

13. (a) The pipe shall be round and of uniform thickness throughout. They shall be free from cracks, seams, slivers, scale, and other surface defects.

(b) The thickness at any point shall not be less than that specified in section 11 by more than the following percentages: Pipe 6 inches or less in diameter, 5 per cent; pipe from 6 to 8 inches in diameter, 7 per cent; pipe over 8 inches in diameter, 8 per cent. 
VI. INSPECTION AND REJECTION

14. When the pipe is finished and ready for shipment the inspector shall make the tests to govern the acceptance of the pipe. If any specimen fails to meet the requirements of sections 5 to 8 , inclusive, two additional specimens may be taken, each of which shall conform to the requirements specified.

15. The manufacturer shall afford the inspector, without charge, all reasonable facilities to satisfy him that the pipe is being furnished in accordance with these specifications. All tests (except check analyses) and inspection shall be made at the place of manufacture prior to shipment, unless otherwise specified, and shall be so conducted as not to interfere unnecessarily with the operation of the works. 
